\author{
UNIVERSIDADE DE SÃO PAULO \\ INSTITUTO DE FÍSICA DE SÃO CARLOS
}

Thalyta Tavares Martins

Aprisionamento óptico de micropartículas e desenvolvimento de potenciais ópticos dinâmicos

São Carlos 

Thalyta Tavares Martins

\section{Aprisionamento óptico de micropartículas e desenvolvimento de potenciais ópticos dinâmicos}

Dissertação apresentada ao Programa de PósGraduação em Física do Instituto de Física de São Carlos da Universidade de São Paulo, para obtenção do título de Mestre em Ciências.

Área de concentração: Física Aplicada

Orientador: Prof. Dr. Sérgio Ricardo Muniz

\section{Versão corrigida \\ (Versão original disponível na Unidade que aloja o Programa)}

\section{São Carlos}


AUTORIZO A REPRODUÇÃO E DIVULGAÇÃO TOTAL OU PARCIAL DESTE TRABALHO, POR QUALQÜER MEIO CONVENCIONAL OU ELETRÔNICO PARA FINS DE ESTUDO E PESQUISA, DESDE QUE CITADA A FONTE.

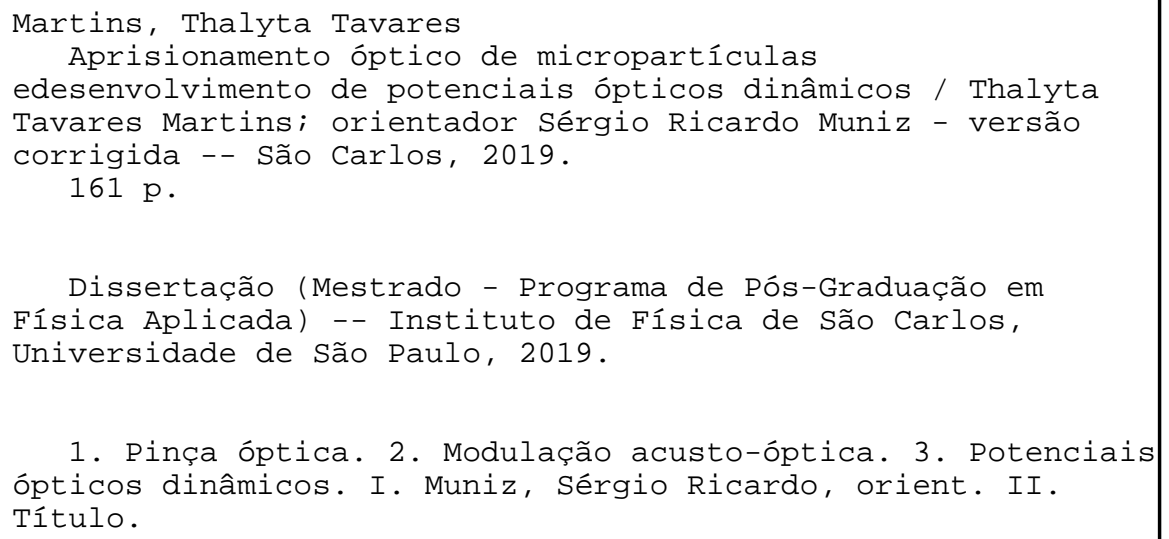

1. Pinça óptica. 2. Modulação acusto-óptica. 3. Potenciais ópticos dinâmicos. I. Muniz, Sérgio Ricardo, orient. II. Título. 


\section{AGRADECIMENTOS}

À minha família, que sempre esteve presente, mesmo nos momentos de distância. Agradeço aos meus pais Robson e Lucia, pelo cuidado, amor e, principalmente, pela amizade que temos, à minha irmã Maria Vallentina, aos meus avós João e Altair e à minha madrasta Adriana, pelo carinho e por terem contribuído de diversas formas na minha trajetória até aqui.

Aos amigos do laboratório e aos que acabaram se tornando parte dele, pela ajuda, pelas conversas e pelo café.

Ao meu orientador, Prof. Dr. Sérgio Muniz, pela oportunidade e confiança. Agradeço imensamente pelos ensinamentos, pela paciência e, principalmente, pelo apoio que recebi durante os anos de mestrado.

Aos colaboradores, Prof. Dr. René Nome, Prof. Dr. Sebastião Pratavieira, Prof. Dr. Renato Gonçalves e Prof. Dr. Fernando Lanças, pelo auxílio em diversos momentos e por fornecer materiais e amostras fundamentais para o desenvolvimento do trabalho.

Ao CNPq pelo auxílio financeiro. 



\section{RESUMO}

\section{MARTINS, T. T. Aprisionamento óptico de micropartículas e}

desenvolvimento de potenciais ópticos dinâmicos. 2019. 161p. Dissertação (Mestrado em Ciências) - Instituto de Física de São Carlos, Universidade de São Paulo, São Carlos, 2019.

Desde o desenvolvimento dos primeiros métodos de controle do movimento e posição de partículas usando lasers, ainda no início da década de 1970, até o reconhecimento com o prêmio Nobel de Física de 2018, uma das principais e mais versáteis ferramentas de manipulação óptica, as chamadas pinças ópticas, têm sido usadas majoritariamente para explorar objetos em dois regimes de tamanho: o limite das partículas sub-nanométricas (átomos e moléculas simples) e o limite das partículas micrométricas (com aplicações especialmente em sistemas biológicos). Nesse trabalho, foi desenvolvido e construído um aparato experimental para aprisionar micro e nanopartículas numa pinça óptica, que pode ser controlada de forma dinâmica usando modulação acusto-óptica do feixe de aprisionamento. A calibração da pinça óptica foi feita por diversos métodos, incluindo o método de equipartição de energia e análise do potencial óptico, resultando em forças de aprisionamento da ordem de piconewtons por micrometros. Ademais, simulações computacionais de modelos estocásticos foram realizadas com o intuito de comparar os resultados experimentais com àqueles previstos teoricamente e guiar estudos futuros.

Palavras-chave: Pinça óptica. Modulação acusto-óptica. Potenciais ópticos dinâmicos. 



\section{ABSTRACT}

\section{MARTINS, T. T. Optical trapping of microparticles and development of}

dynamic optical potentials. 2019. 161p. Dissertação (Mestrado em

Ciências) - Instituto de Física de São Carlos, Universidade de São Paulo, São Carlos, 2019.

Since the development of early methods for controlling the motion and position of particles using lasers, in the 1970s, to the recognition with the 2018 Nobel Prize for Physics, one of the most versatile optical manipulation tools, the so-called optical tweezers, have been used mostly to explore objects in two limits of sizes: the sub nanometric particles (atoms and simple molecules) and the micrometric particles (with applications especially in biological systems). In this work, an experimental apparatus was developed and built to trap micro and nanoparticles in an optical tweezer that can be dynamically controlled, using acoustic-optical modulation of the trapping beam. The calibration of the optical tweezer was done using several methods, including the energy equipartition method and optical potential analysis, resulting in trapping forces on the order of piconewtons per micrometers. In addition, computational simulations of stochastic models were performed with the purpose of comparing the experimental results with those predicted theoretically and guiding future studies.

Keywords: Optical tweezers. Acousto-optic modulation. Dynamic optical potentials. 



\section{LISTA DE FIGURAS}

Figura 1 - Representação de dois raios de luz que atravessam a esfera (esquerda) e a variação de momento linear na esfera (setas verdes, à direita) devido à cada raio. Ao focalizar um feixe gaussiano em uma esfera, a região central tem maior intensidade e resulta numa mudança maior do momento total (azul) na direção do foco, dando origem à força nessa direção. . . . . . 22

Figura 2 - Perfil de intensidade de um feixe gaussiano no plano $x y$ e feixe paraxial com simetria cilíndrica em torno do eixo z. . . . . . . . . . . . 2 25

Figura 3 - Esfera dielétrica de raio a imersa em um campo elétrico $\vec{E}$. . . . . . . 26

Figura 4 - Representação de um raio incidente em uma esfera com índice de refração maior que o meio. . . . . . . . . . . . . . . . . . . . . . 28

Figura 5 - Domínio de integração da Eq. 3.14. . . . . . . . . . . . . . 37

Figura 6 - Potencial teórico da posição para $T=300 \mathrm{~K}$ e diferentes constantes de força $\kappa_{x}=1 \mathrm{pN} / \mu \mathrm{m}, \kappa_{x}=2 \mathrm{pN} / \mu \mathrm{m}$ e $\kappa_{x}=3 \mathrm{pN} / \mu \mathrm{m} . \ldots . . . .$.

Figura 7 - Distribuição de probabilidade teórico da posição para $T=300 \mathrm{~K}$ e diferentes constantes de força $\kappa_{x}=1 \mathrm{pN} / \mu \mathrm{m}, \kappa_{x}=2 \mathrm{pN} / \mu \mathrm{m}$ e $\kappa_{x}=3 \mathrm{pN} / \mu \mathrm{m} . \ldots \ldots \ldots \ldots \ldots \ldots$

Figura 8 - Função de correlação teórica da posição de uma partícula de raio $r=1 \mu m$ imersa em água $(\eta=0.001 \mathrm{~Pa} \cdot \mathrm{s})$ a temperatura de $T=300 \mathrm{~K}$ para $\kappa_{x}=1 \mathrm{pN} / \mu \mathrm{m}, \kappa_{x}=2 \mathrm{pN} / \mu \mathrm{m}$ e $\kappa_{x}=3 \mathrm{pN} / \mu \mathrm{m} . \ldots . . .$.

Figura 9 - DQM teórico da posição de uma partícula de raio $r=1 \mu \mathrm{m}$ imersa em água $(\eta=0.001 \mathrm{~Pa} \cdot \mathrm{s})$ a temperatura de $T=300 \mathrm{~K}$ para $\kappa_{x}=1 \mathrm{pN} / \mu \mathrm{m}$, $\kappa_{x}=2 \mathrm{pN} / \mu \mathrm{m}$ e $\kappa_{x}=3 \mathrm{pN} / \mu \mathrm{m} . \ldots \ldots \ldots . \ldots . \ldots 4$

Figura 10 - Trajetórias para um intervalo de tempo próximo ao tempo característico da partícula. . . . . . . . . . . . . . . . .

Figura 11 - Trajetórias para um intervalo de tempo intervalo de tempo muito maior que o tempo característico da partícula. . . . . . . . . . . . . . . . . 4

Figura 12 - Simulação numérica da trajetória do CM da partícula aprisionada em um potencial óptico harmônico de constante de força $\vec{\kappa}=[3,3,0.6] \mathrm{pN} / \mu \mathrm{m}$ durante $10 \mathrm{~s}$ para um intervalo de tempo de $\Delta t=1 \mathrm{~ms}$ no espaço tridimensional (esquerda) e nos planos $x z$ (direita em cima) e $x y$ (direita embaixo). As barras de erro são menores que o tamanho do símbolo de cada ponto. . . . . . . . . . . . . . . . .

Figura 13 - Distribuição de probabilidade de uma partícula aprisionada em um potencial óptico harmônico de constante de força $\kappa_{x}=3 \mathrm{pN} / \mu \mathrm{m}$ durante $10 \mathrm{~s}$, com $\Delta t=0.1 \mathrm{~ms}$ e a curva calculada teoricamente. As barras de erro são menores que o tamanho do símbolo de cada ponto. . . . . . . . 
Figura 14 - Potencial de uma partícula aprisionada em um potencial óptico harmônico de constante de força $\kappa_{x}=3 \mathrm{pN} / \mu \mathrm{m}$ durante $10 \mathrm{~s}$, com $\Delta t=0.1 \mathrm{~ms}$ e a curva calculada teoricamente. As barras de erro são menores que o tamanho do símbolo de cada ponto. . . . . . . . . . . . . . . . . . . 51

Figura 15 - Função de correlação da posição de uma partícula aprisionada em um potencial óptico harmônico de constante de força $\kappa_{x}=3 \mathrm{pN} / \mu \mathrm{m}$ durante $10 \mathrm{~s}$, com $\Delta t=0.1 \mathrm{~ms}$ e a curva calculada teoricamente. As barras de erro são menores que o tamanho do símbolo de cada ponto. . . . . . . 52

Figura 16 - DQM da posição de uma partícula aprisionada em um potencial óptico harmônico de constante de força $\kappa_{x}=3 \mathrm{pN} / \mu \mathrm{m}$ durante $10 \mathrm{~s}$, com $\Delta t=0.1 \mathrm{~ms}$ e a curva calculada teoricamente. As barras de erro são menores que o tamanho do símbolo de cada ponto. . . . . . . . . . . 52

Figura 17 - Simulação da trajetória de uma partícula aprisionada em um potencial variável quadrado para $A=500 \mathrm{~nm}$ e $A=1000 \mathrm{~nm}$, frequência de $1 \mathrm{~Hz}$ e constante de força de $\kappa_{x}=2.5 \mathrm{pN} / \mu \mathrm{m}$. As barras de erro são menores que o tamanho do símbolo de cada ponto. . . . . . . . . . . . . . . 54

Figura 18 - Simulação da trajetória de uma partícula aprisionada em um potencial variável triangular para $A=500 \mathrm{~nm}$ e $A=1000 \mathrm{~nm}$, frequência de $1 \mathrm{~Hz}$ e constante de força de $\kappa_{x}=2.5 \mathrm{pN} / \mu \mathrm{m}$. As barras de erro são menores que o tamanho do símbolo de cada ponto. . . . . . . . . . . 55

Figura 19 - Simulação da trajetória de uma partícula aprisionada em um potencial variável senoidal para $A=500 \mathrm{~nm}$ e $A=1000 \mathrm{~nm}$, frequência de $1 \mathrm{~Hz}$ e constante de força de $\kappa_{x}=2.5 \mathrm{pN} / \mu \mathrm{m}$. As barras de erro são menores que o tamanho do símbolo de cada ponto. . . . . . . . . . . . . . . 55

Figura 20 - Representação da função $U(x, t)$ por linhas de contorno (esquerda) e por uma superfície em três dimensões (direita) para $A=100 \mathrm{~nm}$, $f=10 \mathrm{kHz}$ e $\kappa_{x}=10 \mathrm{pN} / \mu \mathrm{m} \ldots \ldots \ldots \ldots$. . . . . . . . . 56

Figura 21 - Curvas teóricas para o potencial de cada poço e para as aproximações com a função degrau e com a função polinomial. O valor utilizado para a amplitude foi de $A=100 \mathrm{~nm}$ e para a constante de força foi de $\kappa_{x}=1 \mathrm{pN} / \mu \mathrm{m} \ldots \ldots \ldots \ldots \ldots \ldots$. . . . . . . . . . . . . . . . . . .

Figura 22 - Trajetória simulada por $t_{T}=3 \mathrm{~s}$ para $\kappa_{x}=1 \mathrm{pN} / \mu \mathrm{m}$ e $A=100 \mathrm{~nm}$. As barras de erro são menores que o tamanho do símbolo de cada ponto. 58

Figura 23 - Curvas de potencial simuladas para $A=100 \mathrm{~nm}$ e $\kappa_{x}=2 \mathrm{pN} / \mu \mathrm{m}$ por

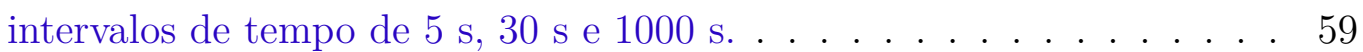

Figura 24 - Curvas de potencial simuladas para $A=100 \mathrm{~nm}$ e $t_{T}=100 \mathrm{~s}$ para as

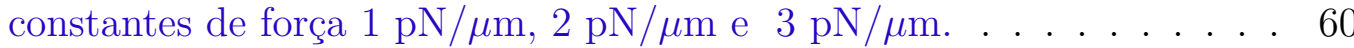

Figura 25 - Curvas de potencial simuladas para $t_{T}=100 \mathrm{~s}$ e $\kappa_{x}=2 \mathrm{pN} / \mu \mathrm{m}$ para as amplitudes $50 \mathrm{~nm}, 100 \mathrm{~nm}$ e $150 \mathrm{~nm}$. . . . . . . . . . . . 60 
Figura 26 - Diagrama do número de transições em função da constante de força do poço individual e da distância relativa entre poços, $N_{T}\left(\kappa_{x}, A\right)$, para uma temperatura fixa de $T=300 \mathrm{~K}$. Foram simuladas trajetórias para 20 diferentes valores de $\kappa_{x}$ e $A$, por um tempo total de 20 s cada, com $\Delta t=0.1 \mathrm{~ms}$.

Figura 27 - Esquema da montagem experimental completa com os lasers (infravermelho e verde), lentes (L1-3, LC), espelhos (E1-3), íris (I), divisores de feixe (DF), filtros para o infravermelho (F1) e para o verde (F2), espelhos dicroicos para o infravermelho (D1) e para o verde (D2), objetiva, condensadora, QPD, AOM, fotodetectores e amostra. . . . . . . . . . 63

Figura 28 - Fotografias da montagem experimental. . . . . . . . . . . . . . . . 64

Figura 29 - Potência do laser de infravermelho em função do tempo. A estabilidade de curto prazo é da ordem de $1 \%$ e as variações de longo termo são menores que $5 \%$.

Figura 30 - Fonte de tensão simétrica (em cima) para alimentar o QPD $( \pm 5 \mathrm{~V})$ e o amplificador operacional $( \pm 12 \mathrm{~V})$ e circuito de amplificação do sinal de saída (embaixo) . . . . . . . . . . . . . . .

Figura 31 - Interferômetro de Michelson com: um laser verde, um DF, um espelho móvel acoplado ao nanoposicionador, um espelho fixo, uma lente de distância focal de $5 \mathrm{~cm}$ e um fotodetector. . . . . . . . . . . . . . .

Figura 32 - Intensidade normalizada pela máxima para 10 rampas com 100 pontos cada rampa, $\Delta V=10 \mathrm{~V}$ e $\Delta t=10 \mathrm{~s}$ (média). As barras de erro são menores que o tamanho do símbolo de cada ponto. . . . . . . . . . . .

Figura 33 - Imagens de uma partícula de súlica, de diâmetro $d=2 \mu \mathrm{m}$, presa à lamínula antes do processamento (esquerda) e após processamento (direita). . . . . . . . . . . . . . . . .

Figura 34 - Sinal aplicado na direção vertical do nanoposicionador, composto por duas rampas de tensão com 100 pontos em cada rampa, (superior) e deslocamento vertical, em pixels, do CM de uma partícula de sílica, coletado com o auxílio da câmera (inferior). . . . . . . . . . . . . .

Figura 35 - Deslocamento do CM vertical (y) da partícula em função do deslocamento do piezoelétrico (média). As barras de erro são menores que o tamanho do símbolo de cada ponto. . . . . . . . . . . . . .

Figura 36 - Montagem experimental de parte do sistema, responsável por detectar a trajetória da partícula aprisionada com o auxílio de um QPD. O fotodetector de quadrante se divide em quatro áreas de detecção (superior em cima): para Q1, temos $x_{d}>0$ e $y_{d}>0$, para Q2 $x_{d}<0$ e $y_{d}>0$, para Q3 $x_{d}<0$ e $y_{d}<0$ e para Q4 $x_{d}>0$ e $y_{d}<0 \ldots \ldots \ldots$ 
Figura 37 - Sinal aplicado à direção horizontal do nanoposicionador composto por duas rampas de tensão com 100 pontos em cada rampa (superior) e tensão de resposta do QPD em $x_{Q P D}$ e $y_{Q P D}$ (inferior). . . . . . . 73

Figura 38 - Sinal de tensão de saída do QPD que representa deslocamento do CM da partícula no plano $x y$ ao aplicar uma rampa de tensão de $-10 \mathrm{~V}$ a $10 \mathrm{~V}$ no canal do nanoposicionador. As barras de erro são menores que o tamanho do símbolo de cada ponto. . . . . . . . . . . . . . .

Figura 39 - Calibração do QPD para partícula de sílica de $2 \mu \mathrm{m}$ utilizando um laser verde com potência de $1 \mathrm{~mW}$. As barras de erro são menores que o tamanho do símbolo de cada ponto. . . . . . . . . . . . . . . . . .

Figura 40 - Perfis normalizados de intensidade do feixe de aprisionamento observados no plano $x y$ : colimado antes da objetiva (esquerda) e divergindo após a objetiva (direita). A medida foi obtida com um perfilador de feixe comercial. $\mathrm{O}$ eixo vertical corresponde à direção de aprisionamento $x$ e o horizontal a direção $y$. As curvas em amarelo representam a intensidade do feixe e as curvas em vermelho o ajuste gaussiano.

Figura 41 - Posição do CM da partícula de sílica de diâmetro de $2 \mu \mathrm{m}$ aprisionada por uma potência de $(2.21 \pm 0.04) \mathrm{mW}$ no plano perpendicular ao laser. 76

Figura 42 - Posição do CM em função do tempo. Dados para a partícula de sílica com diâmetro de $2 \mu \mathrm{m}$ aprisionada com potência $(2.21 \pm 0.04) \mathrm{mW}$, sendo que o laser é momentaneamente desligado no intervalo de $2 \mathrm{~s}$ a $3.5 \mathrm{~s}$, aproximadamente. . . . . . . . . . . . . 76

Figura 43 - Histograma de posições $x$ da partícula de sílica de $2 \mu \mathrm{m}$ de diâmetro aprisionada em $(2.21 \pm 0.04) \mathrm{mW} \ldots \ldots \ldots$. . . . . . . . 77

Figura 44 - Potencial na direção $x$ da partícula de sílica de $2 \mu \mathrm{m}$ aprisionada em $(2.21 \pm 0.04) \mathrm{mW} \ldots \ldots \ldots \ldots 77$

Figura 45 - Constantes de força $\kappa_{x}$ e $\kappa_{y}$, determinadas pelo método de equipartição de energia e pelo método da análise do potencial, em função da potência do laser na amostra, calculadas para uma partícula de sílica de diâmetro

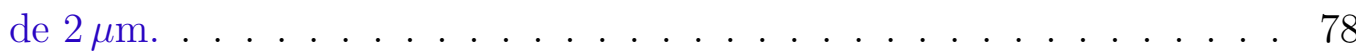

Figura 46 - Partes da montagem experimental, mostrando o laser infravermelho, o AOM e o sistema de detecção da potência do laser (esquerda), e representação de um AOM, constituído por um material acusto óptico e um transdutor piezoelétrico (direita). O sistema é alinhando para máxima eficiência de difração na primeira ordem $m=1$. . . . . . . . .

Figura 47 - Frequência da onda acústica no AOM em função da tensão aplicada. As barras de erro são menores que o tamanho do símbolo de cada ponto. 80 
Figura 48 - Potência normalizada do laser como função da tensão de controle no CMF do AOM (azul) e respectivo ajuste polinomial de grau 200 (laranja), função normalizadora da potência (vermelha) e potência mínima (verde). 81

Figura 49 - Potência do laser ao aplicar uma rampa de potencial de $-3 \mathrm{~V}$ a $-1 \mathrm{~V}$ no CMA do AOM. . . . . . . . . . . . . . . . . . . . 82

Figura 50 - Função da tensão aplicada no CMA em função da potência obtida e curva de ajuste polinomial de grau 200 . . . . . . . . . . . . . . . . 82

Figura 51 - Sinal de tensão aplicado no CMF (em cima) e sinal de tensão aplicado no CMA (embaixo) para normalizar a potência do feixe no intervalo escolhido. . . . . . . . . . . . . . . . . . . . .

Figura 52 - Potência detectada pelo fotodetector em 10 segundos de coleta e frequência de $1 \mathrm{~Hz}$ para vários intervalos de tensão $\Delta V_{f}$ aplicados no $\mathrm{CMF}$ com estabilização. . . . . . . . . . . . . . . . . . . . . . .

Figura 53 - Perfis de intensidade do feixe normalizados no plano $x y$ antes da objetiva (esquerda) e após a objetiva (direita) para uma frequência do AOM de aproximadamente $80 \mathrm{MHz}(0 \mathrm{~V})$. A medida foi obtida com o auxílio de um perfilador de feixe óptico de varredura de fenda, que inverte os eixos do sistema. Desse modo, o eixo vertical representa a direção de aprisionamento $x$ e o eixo horizontal a direção $y$. As curvas em amarelo representam a intensidade do feixe e as curvas em vermelho o ajuste gaussiano. . . . . . . . . . . . . . . .

Figura 54 - Perfis de intensidade do feixe normalizados no plano $x y$, após a objetiva, obtidos com o auxílio de um perfilador de feixe óptico de varredura de fenda, para várias frequências do AOM.

Figura 55 - Escala de cinza em uma fileira de pixels ao aplicar vários valores de tensão no CMF do AOM juntamente com a estabilização da potência pelo controle no CMA. . . . . . . . . . . . . . . . . . . . . .

Figura 56 - Posição média do feixe em função da tensão aplicada no CMF do AOM. As barras de erro são menores que o tamanho do símbolo de cada ponto. 86

Figura 57 - Sinais de tensão aplicados nos CMF (em cima) e CMA (meio) para um sinal triangular de $1 \mathrm{~Hz}$. Trajetória $(x)$ de uma partícula de sílica com $d=2 \mu \mathrm{m}$ aprisionada em um potencial variável triangular para $\Delta V_{f}=2 \mathrm{~V}$ e $\Delta V_{f}=4 \mathrm{~V}$ (embaixo) . . . . . . . . . .

Figura 58 - Sinais de tensão aplicados nos CMF (em cima) e CMA (meio) para um sinal quadrado de $1 \mathrm{~Hz}$. Trajetória $(x)$ de uma partícula de sílica com $d=2 \mu \mathrm{m}$ aprisionada em um potencial variável quadrado para

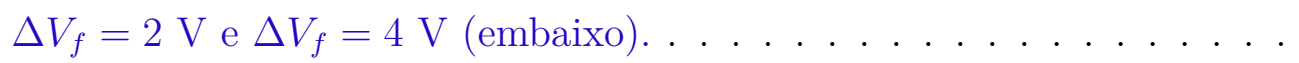


Figura 59 - Sinais de tensão aplicados nos CMF (em cima) e CMA (meio) para um sinal senoidal de $1 \mathrm{~Hz}$. Trajetória $(x)$ de uma partícula de sílica com $d=2 \mu \mathrm{m}$ aprisionada em um potencial variável senoidal para $\Delta V_{f}=2 \mathrm{~V}$ e $\Delta V_{f}=4 \mathrm{~V}$ (embaixo) . . . . . . . . . . . . 90

Figura 60 - Trajetória $(x)$ de uma partícula de sílica com $d=2 \mu \mathrm{m}$ aprisionada em um potencial variável quadrado para $\Delta V_{f}=2 \mathrm{~V}$ (em cima) e $\Delta V_{f}=4 \mathrm{~V}$ (embaixo) e uma potência inicial de $1.6 \mathrm{~mW}$. A linha tracejada representa o sinal aplicado no canal da frequência e a curva (laranja) o ajuste dos dados experimentais (verde). . . . . . . . . . 92

Figura 61 - Nanotubo de $\mathrm{TiO}_{2}$ aprisionado em um potencial variável quadrado com tensão de controle no CMF com amplitude de $\Delta V_{f}=1 \mathrm{~V}$ e frequência de $1 \mathrm{~Hz}$. As figuras têm uma diferença de tempo de $T / 2=0.5 \mathrm{~s}$ e mostram a partícula aprisionada em cada poço. . . . . . . . . . 93

Figura 62 - Trajetória do CM $(x)$ de um nanotubo de $\mathrm{TiO}_{2}$ aprisionado em um potencial variável quadrado, com tensão de controle no CMF com amplitude de $\Delta V_{f}=1 \mathrm{~V}$ e frequência de $1 \mathrm{~Hz}$. . . . . . . . . . . 94

Figura 63 - Sinais de tensão aplicados no CMF (em cima) e no CMA (embaixo) para a geração de um duplo-poço num intervalo de tempo de $0.4 \mathrm{~ms}$ com frequência de $10 \mathrm{kHz}$. . . . . . . . . . . . . . . . . . . . 9 95

Figura 64 - Duas partículas de poliestireno de diâmetro de $d=1 \mu \mathrm{m}$ aprisionadas em um potencial duplo de distância entre poços de $(2.24 \pm 0.02) \mu \mathrm{m}$ (direita) e $(1.12 \pm 0.02) \mu \mathrm{m}$ (esquerda) . . . . . . . . . . . 95

Figura 65 - Trajetória do CM $(x)$ da partícula aprisionada em um potencial duplo com $\Delta V=2 \mathrm{~V}$ e uma potência de aproximadamente $1.3 \mathrm{~mW}$. . . . . 97

Figura 66 - Distribuição de probabilidade de uma partícula aprisionada em um potencial duplo com $\Delta V=2 \mathrm{~V}$ e uma potência de aproximadamente

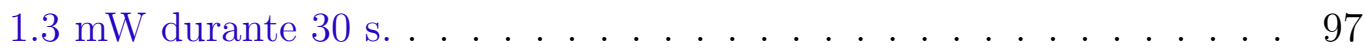

Figura 67 - Curva de potencial de uma partícula aprisionada em um potencial duplo com $\Delta V=2 \mathrm{~V}$ e uma potência de aproximadamente $1.3 \mathrm{~mW}$ durante 30 s. . . . . . . . . . . . . . . . . . . 98

Figura 68 - Trajetórias do CM $(x)$ de uma partícula de poliestireno aprisionada em um potencial duplo com distância entre poços de (562 \pm 5$)$ nm (em cima) e $(786 \pm 7) \mathrm{nm}$ (embaixo). São apresentadas as curvas da trajetória (azul), do sinal filtrado (laranja) e das transições obtidas (verde). . . . 99

Figura 69 - Distribuição de probabilidade de um nanotubo de $\mathrm{TiO}_{2}$ aprisionado em um potencial duplo com $\Delta V_{f}=1 \mathrm{~V}$ (azul) e $\Delta V_{f}=2 \mathrm{~V}$ (laranja) durante $30 \mathrm{~s} . \ldots \ldots \ldots 0 . \ldots \ldots$ 
Figura 70 - Curva de potencial de um nanotubo de $\mathrm{TiO}_{2}$ aprisionado em um potencial duplo com $\Delta V_{f}=1 \mathrm{~V}$ (azul) e $\Delta V_{f}=2 \mathrm{~V}$ (laranja) durante 30 s. . . . . . . . . . . . . . . . . . . . 101

Figura 71 - Distribuição de probabilidade (esquerda em cima), curva de potencial (direita em cima), função de correlação (esquerda embaixo) e desvio quadrático médio (direita embaixo) para uma partícula de poliestireno de diâmetro de $d=1 \mu \mathrm{m}$ aprisionada em uma potência de aproximadamente $2 \mathrm{~mW}$. A trajetória utilizada corresponde ao sinal de saída do QPD $x_{Q P D}$, em volts, que pode ser convertida para unidades de comprimento por um fator de calibração. . . . . . . . . . . . . . . 106

Figura 72 - Campos elétricos e magnéticos das ondas incidentes, refletidas e transmitidas com polarização P (esquerda) e polarização S (direita). . . . 116

Figura 73 - Deslocamento do centro de massa da partícula no plano xy ao aplicar uma rampa de tensão de $-10 \mathrm{~V}$ a $10 \mathrm{~V}$. . . . . . . . . . . . . . . . 119

Figura 74 - Curva de calibração da potência na amostra em função do sinal de tensão no fotodetector para o sistema sem o AOM. . . . . . . . . . . . 121

Figura 75 - Curva de calibração da potência na amostra em função do sinal de tensão no fotodetector para o sistema com o AOM. . . . . . . . . . . . 122 



\section{LISTA DE ABREVIATURAS E SIGLAS}

$\begin{array}{ll}\text { AOM } & \text { Modulador acusto-óptico } \\ \text { CM } & \text { Centro de massa } \\ \text { CMA } & \text { Canal de modulação da amplitude da onda acústica } \\ \text { CMF } & \text { Canal de modulação da frequência de oscilação do transdutor } \\ \text { DF } & \text { Divisor de feixe } \\ \text { QPD } & \text { Detector de quadrante } \\ \text { DQM } & \text { Desvio quadrático médio } \\ \text { UCNPs } & \text { Nanopartículas de conversão ascendente }\end{array}$



SUMÁRIO

INTRODUÇÃO $\ldots \ldots \ldots \ldots \ldots \ldots \ldots \ldots \ldots$

TEORIA DE PINÇAS ÓPTICAS . . . . . . . . . . . . . 23

2.1 Representação de um feixe gaussiano e focalização . . . . . . . . 23

2.2 Teoria de Rayleigh . . . . . . . . . . . . . . . . 25

$2.3 \quad$ Teoria de óptica geométrica $\ldots \ldots \ldots \ldots \ldots \ldots$

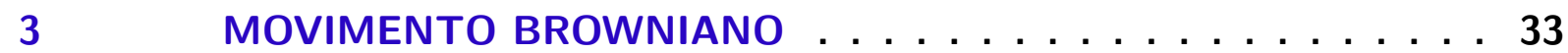

3.1 Equação de Langevin . . . . . . . . . . . . . . . 33

3.2 Relação entre as forças de flutuação e dissipação . . . . . . . . . 34

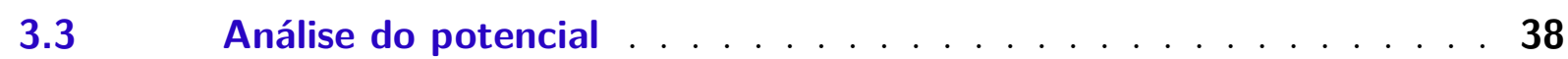

3.4 Teorema de equipartição de energia . . . . . . . . . . 40

$3.5 \quad$ Função de correlação $\ldots \ldots \ldots \ldots \ldots$

$3.6 \quad$ Desvio quadrático médio $\ldots \ldots \ldots 4$

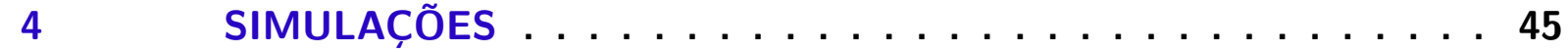

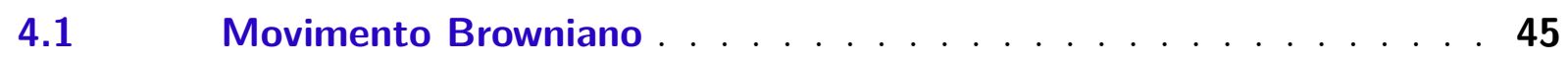

$4.2 \quad$ Potencial harmônico $\ldots \ldots \ldots \ldots \ldots \ldots$

$4.3 \quad$ Potencial dinâmico . . . . . . . . . . . . . . . . . 53

$4.4 \quad$ Potencial duplo $\ldots \ldots \ldots \ldots \ldots \ldots \ldots$

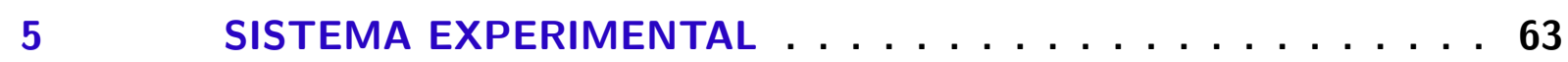

5.1 Calibração do nanoposicionador . . . . . . . . . . . 67

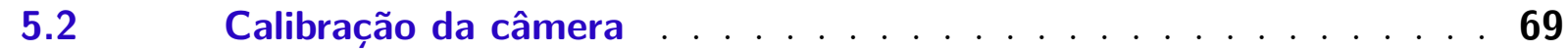

$5.3 \quad$ Calibração do QPD . . . . . . . . . . . . . . . 71

$6 \quad$ PINÇA ÓPTICA SIMPLES $\ldots \ldots \ldots \ldots \ldots$

7 CARACTERIZAÇÃO DA PINÇA ÓPTICA COM O AOM . . . . 79

7.1 Calibração do $A O M \ldots \ldots \ldots \ldots$

7.2 Controle de estabilização automático de potência do AOM . . . . 80

7.3 Calibração da pinça óptica com o AOM . . . . . . . . . . . . 84

8 SISTEMA DE MODULAÇÃO DINÂMICA . . . . . . . . 87

8.1 Modulação em baixas frequências . . . . . . . . . . . 87

8.2 Modulação em altas frequências: potencial por média temporal . . . 94

8.2.1 Microesferas de sílica . . . . . . . . . . . . . . . . . 96

8.2.2 Nanoesferas de poliestireno . . . . . . . . . . . . . 98 


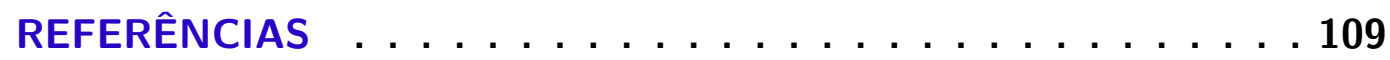

APÊNDICES

APÊNDICE A - EQUAÇÕES DE FRESNEL . . . . . . . . 115

APÊNDICE B - CÁLCULO DO ÂNGULO DE ROTAÇÃO DOS EIXOS DA CÂMERA EM RELAÇÃO AOS EIXOS DE REFERÊNCIA . . . . . . . . . 119

APÊNDICE C - CALIBRAÇÃO DO FOTODETECTOR . . . . 121

APÊNDICE D - SIMULAÇÃO DO MOVIMENTO BROWNIANO . 123

APÊNDICE E - SIMULAÇÃO DO POTENCIAL HARMÔNICO . . 125

APÊNDICE F - FUNÇÕES DE UM POTENCIAL HARMÔNICO . 133

APÊNDICE G - SIMULAÇÃO DE POTENCIAIS DINÂMICOS . . 135

APÊNDICE H-CONTAGEM DO NÚMERO DE TRANSIÇÕES DA PARTÍCULA NO POÇO DUPLO . . . . . . 139

APÊNDICE I - CÓDIGOS PARA CALIBRAÇÃO DO NANOPO-

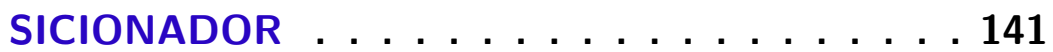

APÊNDICE J - CÓDIGOS PARA CALIBRAÇÃO DA CÂMERA .145

APÊNDICE K - CÓDIGOS PARA A CALIBRAÇÃO DA PINÇA

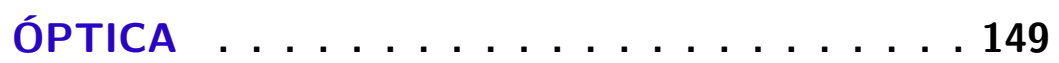

APÊNDICE L - CÓDIGOS PARA A CALIBRAÇÃO DO AOM . 151

APÊNDICE M-CÓDIGOS PARA A GERAÇÃO DE POTENCIAIS DINÂMICOS . . . . . . . . . . . 159 


\section{INTRODUÇÃO}

Em 1969, durante um estudo sobre o fenômeno de pressão de radiação, Arthur Ashkin observou que partículas de poliestireno se alinhavam na região de maior intensidade de luz ao serem incididas por um feixe de laser. (1) Logo após essa descoberta, uma série de estudos foram conduzidos por Ashkin e colaboradores, levando à construção da primeira armadilha óptica por pressão de radiação, com feixes contra propagantes (2) e, posteriormente, o desenvolvimento de um sistema de aprisionamento com único feixe (3), conhecido mais tarde como pinça óptica.

Técnicas de aprisionamento óptico possibilitaram, pela primeira vez, a manipulação de partículas abaixo da escala micrométrica. Por consequência, uma série de estudos dedicados às possíveis aplicações desse tipo de sistema surgiram, gerando contribuições em diversas áreas do conhecimento.

Devido às técnicas de aprisionamento a laser viabilizarem a manipulação de sistemas de forma não invasiva, uma série de pesquisas em microbiologia, como estudo de células, vírus, bactérias e DNA, foram desenvolvidas com o objetivo de explorar propriedades biomecânicas de sistemas microscópicos. (4-12)

A escala da força de aprisionamento - da ordem de piconewtons - aliada à possibilidade de detecção de movimentos com precisão nanométrica, viabilizou o estudo de sistemas termodinâmicos em micro e nano escalas, sendo possível estender noções clássicas, como trabalho, calor e entropia, para regimes fora do equilíbrio. (13-15)

Além de estudos termodinâmicos, o uso de pinças ópticas, associado à diversas técnicas, possibilitou o desenvolvimento de nanosensores aprisionados (16-18), caracterização de nanoestruturas com espectroscopia Raman (19), entre outras aplicações.

Em geral, a descrição teórica mais simples do fenômeno pode ser feita considerando dois casos limítrofes: o limite da óptica geométrica e o limite Rayleigh. (20-23) Quando o raio da partícula é muito maior que o comprimento de onda da luz incidente, podemos considerar o feixe de laser como um conjunto de raios de luz que passam por múltiplas reflexões e refrações, sendo possível derivar as forças de aprisionamento a partir de considerações de óptica geométrica. No entanto, quando as partículas são muito menores que o comprimento de onda do laser, estas podem ser tratadas como um dipolo induzido imerso em um campo elétrico aproximadamente uniforme, sendo esse o limite Rayleigh.

Para explicar qualitativamente o fenômeno de aprisionamento, vamos considerar uma partícula no limite da óptica geométrica. Como cada raio de luz carrega momento, a refração de um feixe na superfície da esfera promove uma variação de momento nos fótons do sistema, conforme a Fig. 1. Para que o momento se conserve, uma força em direção ao 


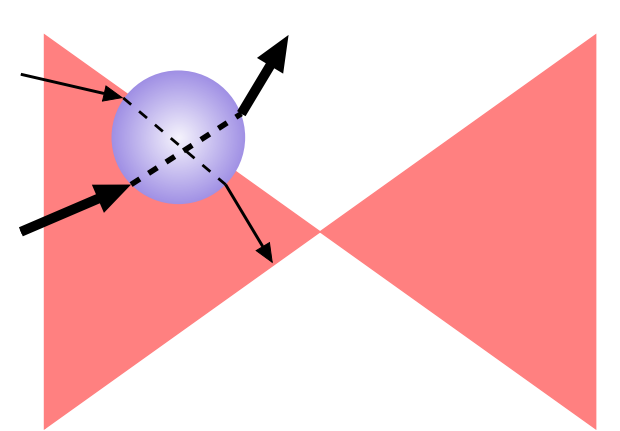

Trajetória do feixe

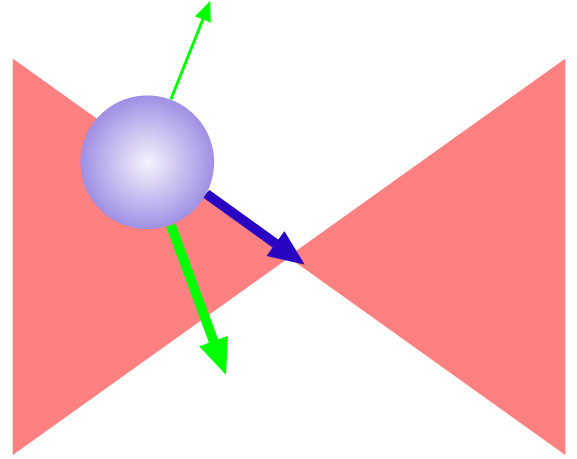

Momento agindo na esfera

Figura 1 - Representação de dois raios de luz que atravessam a esfera (esquerda) e a variação de momento linear na esfera (setas verdes, à direita) devido à cada raio. Ao focalizar um feixe gaussiano em uma esfera, a região central tem maior intensidade e resulta numa mudança maior do momento total (azul) na direção do foco, dando origem à força nessa direção.

Fonte: Elaborada pela autora.

foco do feixe, chamada força gradiente, deve agir na esfera. Essa força é responsável pelo aprisionamento de partículas com um único feixe.

No entanto, além da força gradiente, uma segunda força, causada pela reflexão dos raios na superfície, é responsável por empurrar a partícula na direção de propagação do feixe. Essa força, denominada pressão de radiação, é responsável pelo aprisionamento de partículas em sistemas de feixes contra-propagantes, além de sempre estar presente em sistemas de aprisionamento de feixe único, deslocando a posição de equilíbrio da pinça ligeiramente após o foco do feixe.

Primeiramente, foi desenvolvido no laboratório um sistema composto, basicamente, por uma objetiva de alta abertura numérica, responsável por focalizar o feixe de laser e criar uma região de maior intensidade de luz, e uma amostra de partículas dielétricas. O trabalho teve como objetivo inicial, além da construção do aparato experimental, calibrar a força da pinça óptica utilizando métodos de calibração conhecidos na literatura. (24-27)

Posteriormente, um sistema de modulação acusto-óptica foi implementado com o objetivo de modular o laser espacialmente (28) em baixas (1 Hz) e altas (10 kHz) frequências. No primeiro limite, a posição da pinça óptica é alterada mantendo a sua constante de força inalterada. Desse modo, a trajetória da partícula flutua em torno de uma posição média, que acompanha o sinal de modulação aplicado. No segundo, devido às forças viscosas, a partícula não acompanha o deslocamento da pinça óptica, mas sente um potencial efetivo, viabilizando a geração de diversos tipos de potenciais ópticos, como o duplo-poço. 


\section{TEORIA DE PINÇAS ÓPTICAS}

Neste capítulo será apresentada uma revisão das teorias básicas que descrevem o aprisionamento óptico de partículas nos limites já citados. Para ambos os regimes, o feixe de laser responsável pelo aprisionamento será aproximado a um feixe gaussiano focalizado por uma objetiva de alta abertura numérica.

\subsection{Representação de um feixe gaussiano e focalização}

Uma onda eletromagnética num meio homogêneo, com permissividade elétrica $\epsilon_{m}$ e permeabilidade magnética $\mu_{m}$, obedece a equação para o campo elétrico *

$$
\nabla^{2} \overrightarrow{\mathcal{E}}(\vec{r}, t)=\frac{n_{m}^{2}}{c^{2}} \frac{\partial^{2}}{\partial t^{2}} \overrightarrow{\mathcal{E}}(\vec{r}, t)
$$

onde $\nabla^{2}$ é o operador laplaciano, $n_{m}=\sqrt{\mu_{m} \epsilon_{m}}$ é o índice de refração do meio e $c$ é a velocidade de propagação da luz no vácuo.

Para campos eletromagnéticos monocromáticos, a dependência temporal pode ser separada e a solução para a Eq. 2.1 é uma onda plana monocromática

$$
\vec{E}(\vec{r})=E e^{i \vec{k}_{m} \cdot \vec{r}} \hat{e}
$$

sendo $\hat{e}$ o vetor de polarização e $\vec{k}_{m}=\omega n_{m} / c \hat{k}$ o vetor de onda, no qual a frequência angular é dada por $\omega$ e o vetor unitário da direção de propagação por $\hat{k}$.

Para um feixe de laser gaussiano ${ }^{\dagger}$, na cintura do feixe, que se encontra no plano $z=0$, o campo elétrico é dado por

$$
\vec{E}^{G}(x, y, 0)=\vec{E}_{0} \exp \left(-\frac{x^{2}+y^{2}}{\omega_{0}^{2}}\right)
$$

sendo $\omega_{0}$ o raio da cintura do feixe e $\vec{E}_{0}$ um vetor no plano perpendicular à $z$ contendo informações de amplitude, fase e polarização (Fig. 2).

Esta seção está baseada na referência (29).

$\dagger$ Um feixe de laser gaussiano possui uma intensidade aproximadamente gaussiana no plano perpendicular à direção de propagação e é um dos mais comuns para manipulação óptica. $(30)$ 
Considerando que um feixe de laser faz um pequeno ângulo com o eixo óptico do sistema, pode-se usar o limite paraxial, em coordenadas cilíndricas ${ }^{\ddagger}$

$$
\vec{E}^{G}(\rho, z)=\vec{E}_{0} \frac{\omega_{0}}{\omega(z)} \exp \left(-\frac{\rho^{2}}{\omega(z)^{2}}\right) \exp \left(+i k_{m} z-i \zeta(z)+i k_{m} \frac{\rho^{2}}{2 R(z)}\right)
$$

sendo a largura do feixe

$$
\omega(z)=\omega_{0} \sqrt{1+\frac{z^{2}}{z_{0}^{2}}}
$$

o raio de frente de onda

$$
R(z)=z\left(1+\frac{z_{0}^{2}}{z^{2}}\right)
$$

a correção de fase

$$
\zeta(z)=\operatorname{atan}\left(\frac{z}{z_{0}}\right)
$$

e o alcance de Rayleigh ${ }^{\S}$

$$
z_{0}=\frac{k_{m} \omega_{0}^{2}}{2}
$$

Quando um feixe, no limite paraxial, passa por uma objetiva de alta abertura numérica (NA), cuja íris tem raio $R$ e distância focal $f$, o mesmo sofre uma deflexão dada pela condição de Abbe (31):

$$
\theta=\arcsin \left(\frac{\rho}{f}\right)=\arcsin \left(\frac{\rho}{R} \frac{\mathrm{NA}}{n_{t}}\right)
$$

onde $\rho$ é a coordenada radial da onda incidente e $n_{t}$ o índice de refração do meio.

Uma primeira aproximação no cálculo da força de aprisionamento é que o feixe, ao ser focalizado, converge para um único ponto. No entanto, como a lamínula utilizada como porta-amostra e a água tem um índice de refração diferente, os raios se afastam

¥ A transformação de coordenadas cartesianas para coordenadas cilíndricas é dada por:

$$
\begin{aligned}
& \rho=\sqrt{x^{2}+y^{2}} \\
& \psi=\arctan \left(\frac{y}{x}\right) .
\end{aligned}
$$

§ O alcance de Rayleigh é a distância no eixo $z$ entre a posição da cintura do feixe a posição onde a largura do feixe aumenta por um fator de $\sqrt{2}$. 

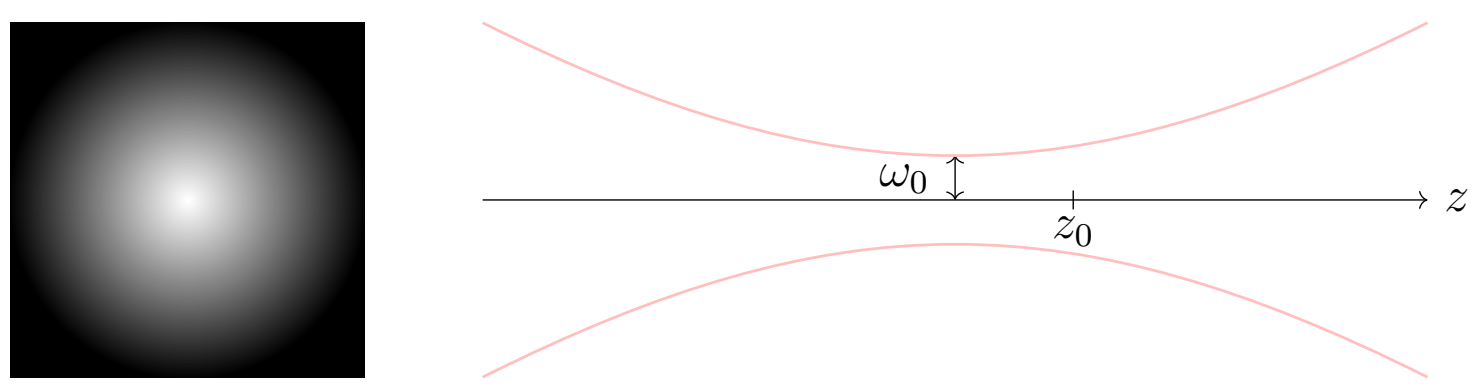

Figura 2 - Perfil de intensidade de um feixe gaussiano no plano $x y$ e feixe paraxial com simetria cilíndrica em torno do eixo $z$.

Fonte: Adaptada de JONES (29).

da normal e, consequentemente, não chegam na sua totalidade na esfera. Além disso, os raios têm diferentes ângulos de incidência e focalizam em diferentes pontos do eixo de propagação. Logo, a situação de convergência para um único ponto é apenas uma aproximação, sendo que, devido à aberração esférica da luz, os raios convergem para uma região de aprisionamento ${ }^{\Uparrow}$.

\subsection{Teoria de Rayleigh}

O limite de Rayleigh é válido para $2 k a(\mu-1)<<1$, sendo $k$ o vetor de onda da luz no meio onde estão as esferas, $a$ o raio da esfera e $\mu=n_{\text {esfera }} / n_{\text {meio }}$ o índice de refração relativoll.

Nesse regime, o comportamento da partícula é aproximado ao de uma esfera dielétrica de raio a imersa em um campo uniforme $\vec{E}$ (Fig. 3). Como o problema tem simetria axial, podemos tomar as soluções para dentro $\phi_{\text {dentro }}$ e fora $\phi_{\text {fora }}$ da esfera, respectivamente, como

$$
\begin{aligned}
& \phi_{\text {dentro }}=\sum_{l=0}^{\infty} A_{l} r^{l} P_{l} \cos \theta \\
& \phi_{\text {fora }}=\sum_{l=0}^{\infty}\left[B_{l} r^{l}+C_{l} r^{-(l+1)}\right] P_{l} \cos \theta .
\end{aligned}
$$

sendo $A_{l}, B_{l}$ e $C_{l}$ os parâmetros originados das condições de contorno, $r$ a posição, $\theta$ o ângulo entre o vetor posição e o eixo $z$ e $P_{l}$ os polinômios de Legendre de grau $l$.

Podemos obter os valores do parâmetro $B_{l}$ a partir da condição de contorno no infinito $-E z=-E r \cos \theta$, que resulta em $B_{1}=-E$, e $B_{l}=0$ para $l \neq 1$. Os demais

\footnotetext{
ף Mais informações sobre aberração esférica podem ser encontradas nas referências $(32,33)$.

\| Esta seção está baseada na referência (34).
} 


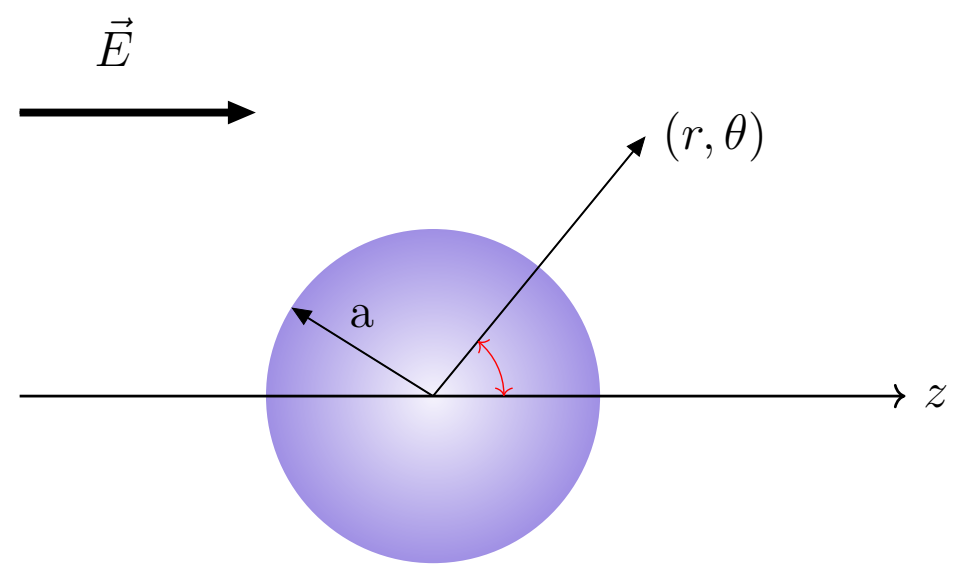

Figura 3 - Esfera dielétrica de raio a imersa em um campo elétrico $\vec{E}$.

Fonte: Elaborada pela autora.

parâmetros vêm das condições de contorno, para $r=a$, tangencial

$$
-\left.\frac{1}{a} \frac{\partial \phi_{\text {dentro }}}{\partial \theta}\right|_{r=a}=-\left.\frac{1}{a} \frac{\partial \phi_{\text {fora }}}{\partial \theta}\right|_{r=a},
$$

e normal

$$
-\left.\epsilon \frac{\partial \phi_{\text {dentro }}}{\partial \theta}\right|_{r=a}=-\left.\epsilon_{0} \frac{\partial \phi_{\text {fora }}}{\partial \theta}\right|_{r=a}
$$

Aplicando as condições de contorno nas séries (Eq. 2.11), temos

$$
\begin{aligned}
& A_{1}=-E+\frac{C_{1}}{a^{3}} \\
& A_{l}=\frac{C_{l}}{a^{2 l+1}}, \text { para } l \neq 1
\end{aligned}
$$

para a primeira condição e

$$
\begin{aligned}
& \left(\epsilon / \epsilon_{0}\right) A_{1}=-E-2 \frac{C_{1}}{a^{3}} \\
& \left(\epsilon / \epsilon_{0}\right) l A_{l}=-(l+1) \frac{C_{l}}{a^{2 l+1}}, \text { para } l \neq 1
\end{aligned}
$$

para a segunda condição. As Eqs. 2.14 e 2.15 são satisfeitas para $A_{l}=C_{l}=0$, para todo 
$l \neq 1$, e para

$$
\begin{aligned}
& A_{1}=-\left(\frac{3}{2+\epsilon / \epsilon_{0}}\right) E \\
& C_{1}=\left(\frac{\epsilon / \epsilon_{0}-1}{\epsilon / \epsilon_{0}+2}\right) a^{3} E .
\end{aligned}
$$

Na região externa à esfera, o potencial elétrico é dado por

$$
\phi(\theta, r)=-E r \cos \theta+\left(\frac{K-1}{K+2}\right) \frac{a^{3}}{r^{2}} E \cos \theta
$$

sendo $K=\epsilon / \epsilon_{0}$ a razão entre as permissividades elétrica do material e do meio e $E$ o campo elétrico uniforme.

Como o momento de dipolo elétrico induzido na esfera é dado por

$$
\vec{p}=\frac{K-1}{K+2} a^{3} \vec{E}
$$

podemos obter a força $\vec{F}$, sabendo que $\vec{F}=-\vec{\nabla} U$ e $U=-\vec{p} \cdot \vec{E}$. Logo,

$$
\vec{F}=\vec{\nabla}(\vec{p} \cdot \vec{E})=\frac{K-1}{K+2} a^{3} \vec{\nabla} E^{2}
$$

A força exercida na esfera é proporcional ao gradiente da intensidade do campo. Desse modo, essa força aponta para o ponto de maior intensidade que, no caso de um feixe focalizado, é a região onde se encontra o foco do laser, sendo esta a posição de equilíbrio do sistema.

A partícula aprisionada em uma pinça óptica, ao ser retirada da sua posição de equilíbrio $\vec{r}_{e q}$, pode ser aproximada a um sistema oscilatório simples, que sofre o efeito de uma força restauradora $\vec{F}=-\kappa_{x}\left(x-x_{e q}\right) \hat{i}-\kappa_{y}\left(y-y_{e q}\right) \hat{j}-\kappa_{z}\left(z-z_{e q}\right) \hat{k}$, sendo $\kappa_{x, y, z}$ a constante de força nas direções $x, y$ e $z$, respectivamente. Para a calibração da pinça óptica, comumente são determinados os valores de $\kappa_{x}$ e $\kappa_{y}$, dados por

$$
\kappa_{x, y}=-\left(\frac{\partial F_{x}}{\partial x}\right)_{\vec{r}_{e} q}=-\frac{K-1}{K+2} a^{3}\left(\frac{\partial^{2} E^{2}}{\partial x^{2}}\right)_{\vec{r}_{e q}},
$$

onde $\vec{r}_{e q}$ é a posição de equilíbro.

\subsection{Teoria de óptica geométrica}

Quando a partícula tem dimensões bem maiores que o comprimento de onda da luz incidente, o feixe de laser pode ser visto como um conjunto de raios de luz interagindo 
com uma superfície esférica que separa dois meios. Se o índice de refração da partícula for diferente do índice de refração do meio, uma fração de luz será refletida e a outra fração será refratada (Fig. 4). Portanto, a trajetória do feixe será alterada, mudando o momento associado aos fótons de luz do sistema. Devido à conservação de momento, uma força deve agir na partícula, sendo esta responsável pelo aprisionamento óptico.

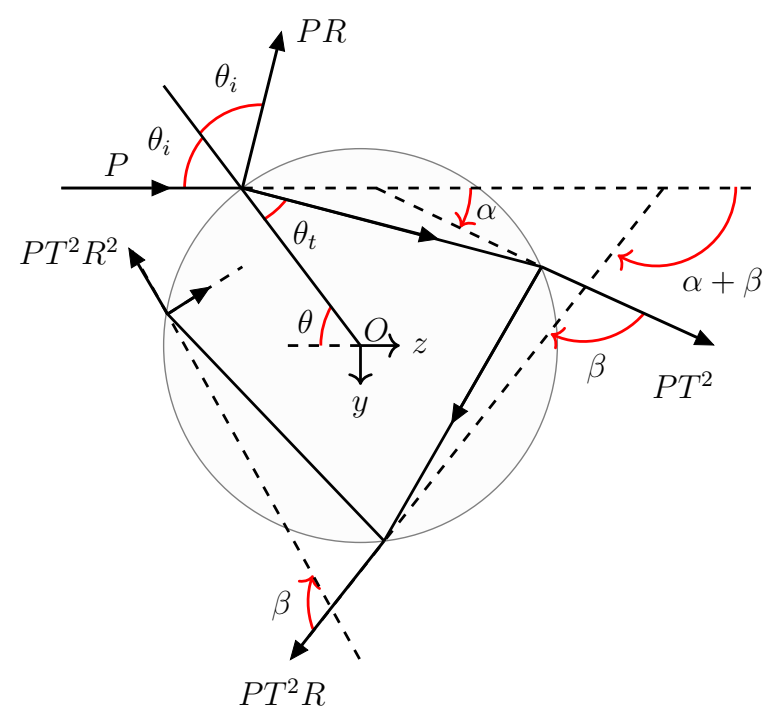

Figura 4 - Representação de um raio incidente em uma esfera com índice de refração maior que o meio.

Fonte: Adaptada de ASHKIN (21).

Considerando que um fóton possui uma energia $u=h c / \lambda_{0}$, sendo $h$ a constante de Planck, $c$ a velocidade da luz no vácuo e $\lambda_{0}$ o comprimento de onda no vácuo, o seu momento é dado por $\vec{p}=u / c \hat{u}=h / \lambda_{0} \hat{u}$, com o versor $\hat{u}$ paralelo ao vetor de onda $\vec{k}$.

Se um feixe de luz com potência $P$ é refletido por um espelho com incidência normal, o momento de cada fóton vai ser alterado em $\Delta \vec{p}=-2 \vec{p}$. Para um número de fótons $N=P / u$, a variação de momento será $\Delta \vec{P}=-2 P / c \hat{u}$. (27) Logo, o espelho sofrerá um recuo,

$$
\vec{F}_{r}=\frac{2 P}{c} \hat{u}
$$

Quando um raio de luz $\vec{r}_{i}$, com ângulo $\theta_{i}$ e potência $P_{i}$, interage com a superfície de uma esfera dielétrica, uma pequena parte de luz é refletida através do raio $\vec{r}_{r, 0}$, com o ângulo $\theta_{r}=\theta_{i}$ e potência $P_{r}$, e o restante é transmitido pela esfera através de $\vec{r}_{t, 0}$, com o ângulo $\theta_{t}$ e potência $P_{t}^{* *}$. No entanto, para o cálculo da força exercida no corpo, temos de considerar as $n$ reflexões do raio no interior da esfera e seus correspondentes $\vec{r}_{t, n}$. (29)

** Os ângulos estão apresentados em relação à normal. 
Desse modo, a força que age na esfera é dada por

$$
\vec{F}_{\text {raio }}=\frac{n_{i} P_{i}}{c} \hat{r}_{i}-\frac{n_{i} P_{r}}{c} \hat{r}_{r, 0}-\sum_{n=1}^{+\infty} \frac{n_{i} P_{t, n}}{c} \hat{r}_{t, n}
$$

sendo $\hat{r}$ o raio incidente e $\hat{r}_{r, n}$ e $\hat{r}_{t, n}$ os enésimos raios refletidos e transmitidos, respectivamente. E, para um conjunto de raios, a força que age no centro de massa (CM) da esfera é dada por

$$
\vec{F}_{O G}=\sum_{m} \vec{F}_{\text {raio }}^{(m)}=\sum_{m}\left[\frac{n_{i} P_{i}^{(m)}}{c} \hat{r}_{i}^{(m)}-\frac{n_{i} P_{r}^{(m)}}{c} \hat{r}_{r, 0}^{(m)}-\sum_{n=1}^{\infty} \frac{n_{i} P_{t, n}^{(m)}}{c} \hat{r}_{t, n}^{(m)}\right] .
$$

Com o objetivo de quantificar o momento efetivo transferido de cada raio para a partícula, a força (Eq. 2.22) pode ser dividida em duas componentes: pressão de radiação $\vec{F}_{\text {raio,pr }}$, responsável por empurrar a partícula na direção de incidência da luz, e força gradiente $\vec{F}_{\text {raio,fg }}$, responsável por puxar a partícula para uma região perpendicular ao feixe

$$
\vec{F}_{\text {raio }}=F_{\text {raio }, p r} \hat{r}_{i}+F_{\text {raio }, f g} \hat{r}_{\perp}
$$

Desta forma, é possível definir a eficiência de aprisionamento $Q_{\text {raio,pr }}$, devido à força de pressão de radiação,

$$
Q_{\text {raio }, p r}=\frac{c}{n_{i} P_{i}} F_{r a i o, p r}
$$

e a eficiência de aprisionamento $Q_{\text {raio,fg }}$, devido à força gradiente,

$$
Q_{\text {raio }, p r}=\frac{c}{n_{i} P_{i}} F_{r a i o, f g}
$$

sendo a eficiência de aprisionamento total $Q_{\text {raio }}$ dada por

$$
Q_{\text {raio }}=\sqrt{Q_{\text {raio,pr }}^{2}+Q_{\text {raio,fg }}^{2}}
$$

Para o cálculo dos valores $Q_{\text {raio,pr }}$ e $Q_{\text {raio,fg }}$, vamos considerar que um raio de potência $P_{i}$, ao interagir com uma esfera dielétrica, resulta em uma série raios espalhados $P_{i} R, P_{i} T^{2}, P_{i} T^{2} R, \ldots, P_{i} T^{2} R^{n} \ldots$, sendo $R$ e $T$ os coeficientes de Fresnel de intensidade ${ }^{\dagger \dagger}$. Conforme a Fig. 4, estes raios espalhados possuem ângulos relativos à direção de incidência $\pi+2 \theta_{i}, \alpha, \alpha+\beta, \ldots, \alpha+n \beta$, respectivamente, sendo $\alpha=2 \theta_{i}-2 \theta_{r}$ e $\beta=\pi-2 \theta_{r}$.

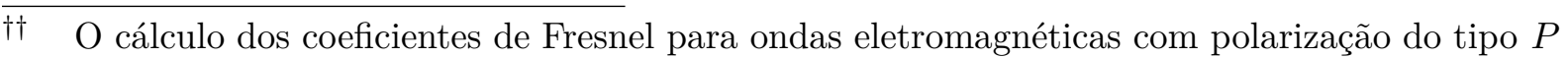
e tipo $S$ se encontram no Apêndice A. 
Desse modo, a eficiência de aprisionamento efetiva associada à pressão de radiação é dada por

$$
Q_{\text {raio,pr }}=1-\left[R \cos \left(\pi+2 \theta_{i}\right)+\sum_{n=0}^{\infty} T^{2} R^{n} \cos (\alpha+n \beta)\right]
$$

e, de modo análogo, a eficiência de aprisionamento efetiva associada à força gradiente é dada por

$$
Q_{\text {raio }, f g}=0-\left[R \sin \left(\pi+2 \theta_{i}\right)-\sum_{n=0}^{\infty} T^{2} R^{n} \sin (\alpha+\beta)\right]
$$

A eficiência total será representada, assim, no plano complexo $Q_{\text {raio }}=Q_{\text {raio,pr }}+$ $i Q_{\text {raio, } f g}$

$$
Q_{\text {raio }}=\left[1+R \cos \left(2 \theta_{i}\right)\right]+i R \sin \left(2 \theta_{i}\right)-T^{2} \sum_{n=0}^{\infty} R^{n} e^{i(\alpha+n \beta)}
$$

Sabendo que $\sum_{n=0}^{\infty} x^{n} e^{a n}=1 /\left(1-e^{a} x\right)$, temos

$$
Q_{\text {raio }}=\left[1+R \cos \left(2 \theta_{i}\right)\right]+i R \sin \left(2 \theta_{i}\right)-T^{2} e^{i \alpha}\left[\frac{1}{1-R e^{i \beta}}\right] .
$$

Para obter $Q_{\text {raio,pr }}$ e $Q_{\text {raio,fg }}$, devemos racionalizar o denominador e separar a parte real e imaginária. Utilizando as relações geométricas, apresentadas anteriormente, para $\alpha$ e $\beta$, temos

$$
Q_{\text {raio,pr }}=\left[1+R \cos \left(2 \theta_{i}\right)-\frac{T^{2}\left[\sin \left(2 \theta_{i}-2 \theta_{t}\right)+R \cos \left(2 \theta_{i}\right)\right]}{1+R^{2}+2 R \cos \left(2 \theta_{t}\right)}\right]
$$

$\mathrm{e}$

$$
Q_{\text {raio,fg }}=\left[R \sin \left(2 \theta_{i}\right)-\frac{T^{2}\left[\sin \left(2 \theta_{i}-2 \theta_{t}\right)+R \sin \left(2 \theta_{i}\right)\right]}{1+R^{2}+2 R \cos \left(2 \theta_{t}\right)}\right]
$$

Para polarizações circulares, as constantes $\kappa_{x}$ e $\kappa_{y}$ são iguais, enquanto $\kappa_{z}$ é tipicamente menor. Se o feixe não tiver polarização circular, as forças ópticas se tornam assimétricas e essa mudança é significativa para partículas menores ou da ordem do comprimento de onda do laser utilizado.

De modo análogo ao regime de Rayleigh, a partícula estará sob a ação de uma força responsável por aprisionar a mesma em uma posição de equilíbrio, pouco após o foco do feixe ${ }^{\ddagger \ddagger}$. Quando o CM da partícula é deslocado da posição de equilíbrio, novamente,

¥† A posição de equilíbrio será após o foco considerando a direção de propagação do feixe incidente. 
uma força restauradora atua no corpo, sendo possível o cálculo das constantes de força para a calibração da pinça óptica. 



\section{MOVIMENTO BROWNIANO}

Neste capítulo serão apresentadas, do ponto de vista estatístico, as considerações de Langevin para partículas brownianas submetidas à uma força externa e a derivação do teorema de flutuação dissipação. Além disso, cálculos analíticos, para uma partícula submetida a um potencial harmônico, de funções características desse tipo de movimento, como distribuição de probabilidade, função de correlação e desvio quadrático médio serão desenvolvidos*.

\subsection{Equação de Langevin}

Uma partícula de massa $m$ imersa em um líquido de temperatura absoluta $T$ apresenta um movimento randômico e perpétuo, devido às colisões entre a partícula e as moléculas do fluido. Esse movimento é chamado de movimento Browniano.

Para o estudo desse tipo de sistema, o líquido pode ser considerado como um reservatório térmico a uma temperatura $T$ e as interações entre a partícula e as moléculas do fluido são representadas pela força efetiva $F(t)$. Além disso, podemos considerar que a partícula interage com sistemas externos a partir de uma força $F_{\text {ext }}(t)$.

Por simplicidade, podemos tratar o problema unidimensionalmente, sendo $x(t)$ a trajetória do CM da partícula no tempo $t$ e $v=d x / d t$ a sua velocidade. Desse modo, a segunda lei de Newton pode ser escrita como

$$
m \frac{d v(t)}{d t}=F_{e x t}(t)+F(t)
$$

Tratando o problema estatisticamente, podemos considerar um ensemble de vários sistemas, constituídos por uma partícula e o meio que o cerca. A média de $F$ no instante de tempo $t$ para os $N$ sistemas é

$$
\bar{F}(t) \equiv \frac{1}{N} \sum_{k=1}^{N} F^{(k)}(t) .
$$

A força $F(t)$ depende das posições dos vários átomos que estão em constante movimento. Desse modo, $F(t)$ deve flutuar rapidamente e de forma irregular. A sua taxa de variação é caracterizada pelo tempo de correlação $\tau^{*}$ que mede, aproximadamente, o tempo entre dois máximos - ou mínimos - da função $F(t)^{\dagger}$.

* Essa seção está baseada na referência (35).

$\dagger$ O tempo de correlação é da ordem do período médio da força de flutuação $F(t)$, ou seja, depende do tempo entre colisões moleculares. 
A velocidade $v$ da partícula no fluido também deve flutuar no tempo e pode ser dividida em: uma variação lenta dada pela média do ensemble $\bar{v}$ e uma flutuação rápida $v^{\prime}$, cuja média vai à zero. Desse modo,

$$
v=\bar{v}+v^{\prime}
$$

sendo a componente lenta $\bar{v}$ crucial para determinar o comportamento da partícula em longos períodos de tempo.

De forma análoga à velocidade, a força efetiva $F$ também tem duas componentes

$$
F=\bar{F}+F^{\prime}
$$

sendo a componente lenta $\bar{F}$ responsável por restaurar o equilíbrio da partícula e a componente rápida $F^{\prime}$ uma flutuação puramente aleatória, cuja média sempre é zero, independente da velocidade ou posição da partícula.

A variação lenta da força deve depender da velocidade, sendo que, em equilíbrio, $\bar{v}=0, \bar{F}(\bar{v})=0$. Como $\bar{v}$ é pequeno, podemos expandir $\bar{F}$ em uma série de potências, cujo primeiro termo diferente de zero é dado por:

$$
\bar{F}=-\alpha \bar{v}
$$

sendo $\alpha$ o coeficiente de arrasto ${ }^{\ddagger}$ e o sinal negativo responsável por reduzir $\bar{v}$ à zero.

Se considerarmos que a contribuição de $\alpha v^{\prime}$ é pequena, podemos reescrever a Eq. 3.1 como

$$
m \frac{d v}{d t}=F_{e x t}+F=F_{e x t}-\alpha v+F^{\prime}(t)
$$

onde foi considerado que $\alpha \bar{v} \approx \alpha v$.

Essa equação, conhecida como equação de Langevin, descreve o comportamento da partícula em função do tempo, a partir de condições iniciais conhecidas.

\subsection{Relação entre as forças de flutuação e dissipação}

Novamente, considerando uma partícula browniana como um sistema em um banho térmico, cuja temperatura é dada por $T=\left(K_{B} \beta\right)^{-1}$, onde $K_{B}$ é a constante de Boltzmann, os possíveis estados do sistema são rotulados por $r$, sendo a força em um dado estado dada por $F_{r}$.

$\$$ O coeficiente de arrasto de uma partícula em um meio pode ser calculado pela Lei de Stokes, dada por $\alpha=6 \pi \eta a$, sendo $\eta$ a viscosidade do meio e $a$ o raio da partícula. 
Em um tempo arbitrário, a partícula possui velocidade $v(t)$ e pode ser considerada em situação de equilíbrio, com $\langle F\rangle=0$. A probabilidade da partícula estar no estado $r$ é dada por $W_{r}(t)$ e o número de estados acessíveis ao reservatório térmico com energia $E^{\prime}$ é dado por $\Omega\left(E^{\prime}\right)$.

Num instante posterior $t^{\prime}=t+\tau^{\prime}$, a partícula terá uma velocidade $v\left(t+\tau^{\prime}\right)$ e o meio será alterado pelo movimento da partícula. No entanto, se o intervalo de tempo $\tau^{\prime}$ for maior que o tempo de correlação, as interações moleculares vão re-estabilizar a situação de equilíbrio para a velocidade $v=v\left(t+\tau^{\prime}\right)$. O número de estados acessíveis do reservatório será $\Omega\left(E^{\prime}+\Delta E^{\prime}\right)$ e a probabilidade do sistema estar em um estado $r$ é dada por $W_{r}\left(t+\tau^{\prime}\right)$.

Para uma situação de equilíbrio, a probabilidade do sistema se encontrar num estado $r$ é proporcional ao número de estados acessíveis ao reservatório térmico. Desse modo:

$$
\frac{W_{r}\left(t+\tau^{\prime}\right)}{W_{r}(t)}=\frac{\Omega\left(E^{\prime}+\Delta E^{\prime}\right)}{\Omega\left(E^{\prime}\right)}=e^{\beta \Delta E^{\prime}}
$$

sendo $\beta \equiv \partial \log \Omega / \partial E^{\prime}$ o parâmetro de temperatura do reservatório térmico.

Considerando que a energia do reservatório térmico varia pouco, a probabilidade do sistema estar em um estado $r$ para um tempo $t^{\prime}=t+\tau^{\prime}$, usando a aproximação $e^{a x} \approx(1+a x)$, é dada por

$$
W_{r}\left(t+\tau^{\prime}\right)=W_{r}(t)\left(1+\beta \Delta E^{\prime}\right)
$$

Logo, o valor médio de $F$ será:

$$
\langle F\rangle=\sum_{r} W\left(t+\tau^{\prime}\right) F_{r}=\sum_{r} W_{r}(t)\left(1+\beta \Delta E^{\prime}\right) F_{r}=\left\langle\left(1+\beta \Delta E^{\prime}\right) F\right\rangle_{0}
$$

e, como $\langle F\rangle_{0}=0$, temos

$$
\langle F\rangle=\beta\left\langle F \Delta E^{\prime}\right\rangle_{0}
$$

Sabendo que a variação de energia do reservatório térmico no intervalo $\tau^{\prime}=t^{\prime}-t$ é o negativo do trabalho da força $F$ na partícula:

$$
\Delta E^{\prime}=\int_{t}^{t^{\prime}} v\left(t^{\prime \prime}\right) F\left(t^{\prime \prime}\right) d t^{\prime \prime} \approx-v(t) \int_{t}^{t^{\prime}} F\left(t^{\prime \prime}\right) d t^{\prime \prime}
$$


sendo feita a aproximação que v(t) é aproximadamente constante no intervalo de integração, podemos reescrever a Eq. 3.10:

$$
\left\langle F\left(t^{\prime}\right)\right\rangle=-\beta\left\langle F\left(t^{\prime}\right) v(t) \int_{t}^{t^{\prime}} F\left(t^{\prime \prime}\right) d t^{\prime \prime}\right\rangle_{0}=-\beta \bar{v}(t) \int_{t}^{t^{\prime}} d t^{\prime \prime}\left\langle F\left(t^{\prime}\right) F\left(t^{\prime \prime}\right)\right\rangle_{0}
$$

Desta forma, podemos voltar à Eq. 3.1 integrando a mesma sobre um intervalo de tempo $\tau=t^{\prime \prime}-t$ :

$$
m\langle v(t+\tau)-v(t)\rangle=F_{\text {ext }}(t) \tau+\int_{t}^{t+\tau}\left\langle F\left(t^{\prime}\right)\right\rangle d t^{\prime},
$$

onde assumimos que $F_{\text {ext }}$ varia lentamente e pode ser considerada aproximadamente constante no tempo $\tau$.

Substituindo o resultado obtido na Eq. 3.12 e definindo uma nova variável $s \equiv t^{\prime \prime}-t^{\prime}$, temos:

$$
m\langle v(t+\tau)-v(t)\rangle=F_{e x t}(t) \tau-\beta v(t) \int_{t}^{t+\tau} d t^{\prime} \int_{t-t^{\prime}}^{0} d s\left\langle F\left(t^{\prime}\right) F\left(t^{\prime}+s\right)\right\rangle_{0},
$$

sendo $\left\langle F\left(t^{\prime}\right) F\left(t^{\prime}+s\right)\right\rangle_{0}=K(s)$ a função de correlação ${ }^{\S}$.

A função de correlação tem uma série de propriedades, demonstradas na referência (35), dentre elas ${ }^{\top}$ :

1. $K(0)=\langle F(t) F(t)\rangle=\left\langle F^{2}(t)\right\rangle>0$, logo $K(0)$ é a média do quadrado da função da força de flutuação $F$.

2. Se o intervalo $s$ for suficientemente longo, $F(t)$ e $F(t+s)$ se tornam descorrelacionados, ou seja, $\lim _{s \rightarrow \infty} K(s)=\langle F(t)\rangle\langle F(t+s)\rangle$.

3. A maior correlação possível ocorre quando $s=0$, pois $|K(s)| \leq K(0)$.

4. A função é simétrica, logo $K(s)=K(-s)$.

Para resolver a integral da Eq. 3.14, basta trocar os intervalos de integração, de verticalmente simples para horizontalmente simples, conforme a Fig. 5,

$$
\int_{t}^{t+\tau} d t^{\prime} \int_{t-t^{\prime}}^{0} d s K(s)=\int_{-\tau}^{0} d s \int_{t-s}^{t+\tau} d t^{\prime} K(s)
$$

§ Quando o sistema está em equilíbrio, a média de ensemble é independente do tempo absoluto, dependendo só da diferença de tempo $s$.

ף Por facilidade de notação, foi escrito $t$ no lugar de $t^{\prime}$ e ignorado o subscrito dos brackets. 


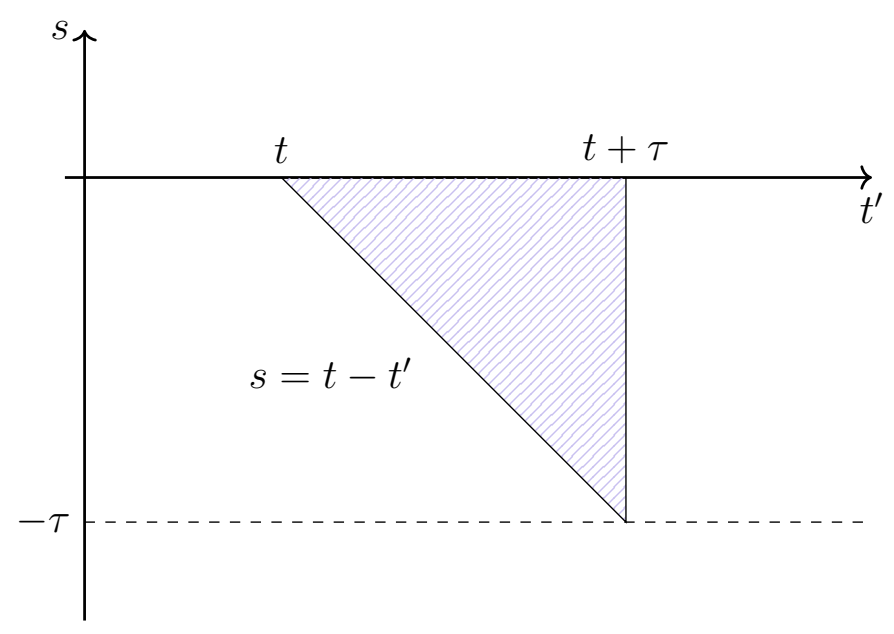

Figura 5 - Domínio de integração da Eq. 3.14.

Fonte: Adaptada de REIF (35).

Como $K(s)$ não depende do tempo absoluto $t^{\prime}$, a integral pode ser reescrita como

$$
\int_{-\tau}^{0} d s \int_{t-s}^{t+\tau} d t^{\prime} K(s)=\int_{-\tau}^{0} d s K(s)(\tau+s)
$$

Considerando que $\tau \gg \tau_{c}$, enquanto $K(s)$ tende à zero em intervalos $s$ grandes, podemos descartar a contribuição de $s$ e modificar o limite inferior da integral para $-\infty$. Usando a propriedade de simetria,

$$
\int_{-\tau}^{0} d s K(s)(\tau+s) \approx \tau \int_{-\infty}^{0} d s K(s)=\frac{1}{2} \tau \int_{-\infty}^{\infty} d s K(s)
$$

podemos reescrever a Eq. 3.14 em termos do coeficiente $\alpha$

$$
m\langle v(t+\tau)-v(t)\rangle=F_{e x t} \tau-\alpha \bar{v}(t) \tau
$$

sendo este dado por:

$$
\alpha \equiv \frac{1}{2 K_{B} T} \int_{-\infty}^{\infty}\langle F(0) F(s)\rangle_{0} d s
$$

Essa relação entre o coeficiente $\alpha$ e a correlação das forças de flutuação $F(t)$ na situação de equilíbrio é chamada de "teorema flutuação dissipação". 


\subsection{Análise do potencial}

Para uma partícula em equilíbrio térmico com as moléculas do fluido, sua distribuição de probabilidade segue a distribuição de Maxwell-Boltzmann, dada por

$$
\rho(x)=\rho_{0} \exp \left[-\frac{U(x)}{k_{B} T}\right]
$$

sendo $\rho_{0}$ um fator de normalização necessário para que $\int \rho(x) d x=1^{\|}$. Desse modo, o cálculo do potencial, para uma força externa qualquer é dado por

$$
U(x)=-k_{B} T \log [\rho(x)]+U_{0}
$$

com $U_{0}$ sendo uma constante.

Como uma pinça óptica simples exerce uma força restauradora do tipo $F_{\text {ext }}=$ $-\kappa_{x}\left(x-x_{e q}\right)$ na partícula browniana em torno da posição de equilíbrio $x_{e q}$, conforme apresentado na Seção 2, o potencial de energia será aproximadamente harmônico, ou seja, $U(x)=\kappa_{x}\left(x-x_{e q}\right)^{2} / 2$ (Fig. 6). Portanto, a distribuição de probabilidade, será gaussiana**:

$$
\rho(x)=\rho_{0} \exp \left[-\frac{\kappa_{x} x^{2}}{2 k_{B} T}\right]
$$

sendo a constante de força da pinça inversamente proporcional à largura da distribuição. Desse modo, conforme a constante aumenta, a partícula tem menos liberdade de movimento, permanecendo próxima à posição média, e a gaussiana fica mais estreita, conforme a Fig. 7 .

$\overline{\text { O }}$ O fator de normalização é $\rho=Z^{-1}$, sendo $Z$ a função de partição.

** Será considerado que $x_{e q}=0$. 


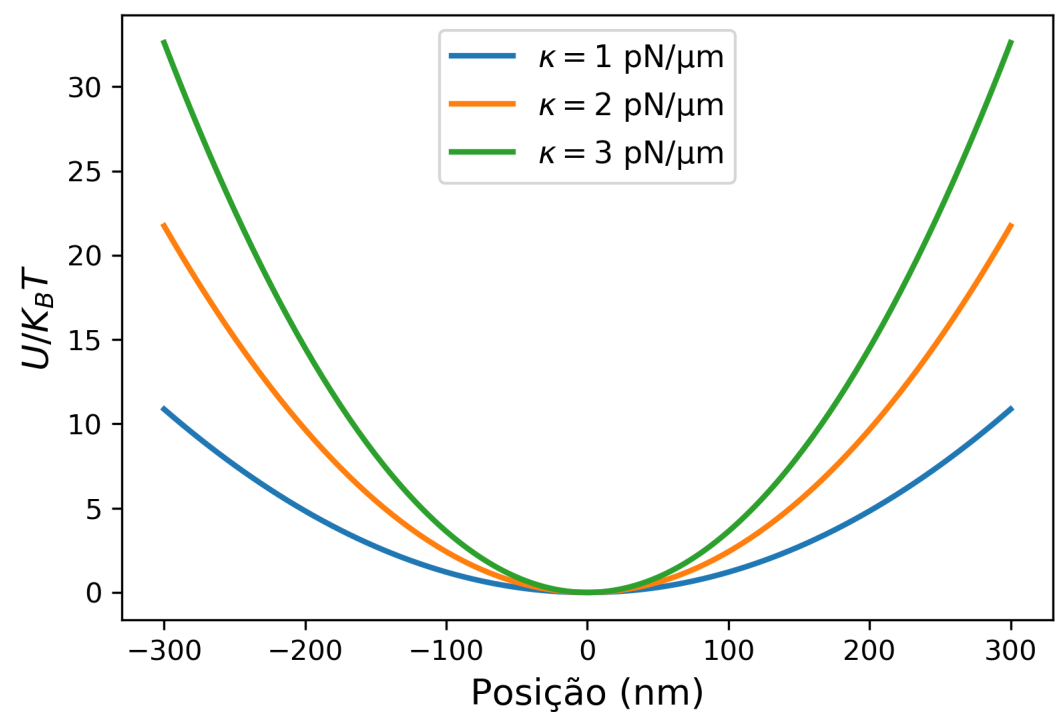

Figura 6 - Potencial teórico da posição para $T=300 \mathrm{~K}$ e diferentes constantes de força $\kappa_{x}=$ $1 \mathrm{pN} / \mu \mathrm{m}, \kappa_{x}=2 \mathrm{pN} / \mu \mathrm{m}$ e $\kappa_{x}=3 \mathrm{pN} / \mu \mathrm{m}$.

Fonte: Elaborada pela autora.

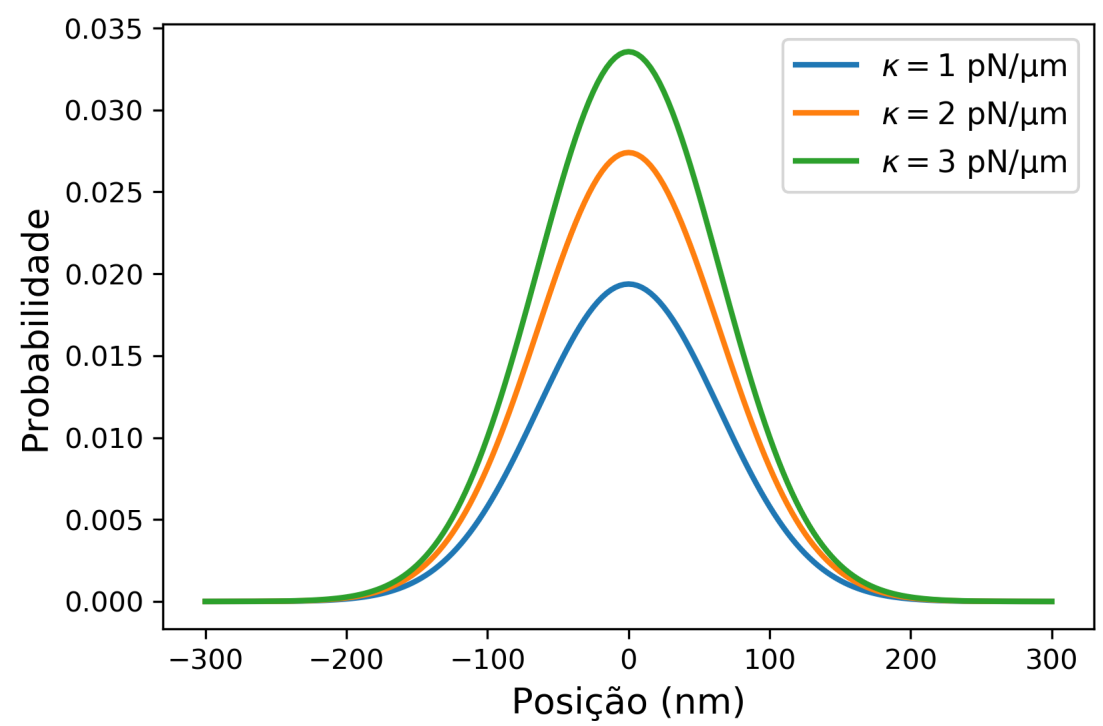

Figura 7 - Distribuição de probabilidade teórico da posição para $T=300 \mathrm{~K}$ e diferentes constantes de força $\kappa_{x}=1 \mathrm{pN} / \mu \mathrm{m}, \kappa_{x}=2 \mathrm{pN} / \mu \mathrm{m}$ e $\kappa_{x}=3 \mathrm{pN} / \mu \mathrm{m}$.

Fonte: Elaborada pela autora. 


\subsection{Teorema de equipartição de energia}

Ao contrário da análise do potencial, que pode ser aplicado para forças externas quaisquer, o estudo de equipartição de energia parte do pressuposto que uma armadilha óptica tem um potencial aproximadamente harmônico. Como a distribuição de probabilidade é gaussiana, a posição de equilíbrio de uma série temporal de posições $x_{l}$ é dada por

$$
x_{e q}=\frac{1}{L} \sum_{l=1}^{L} x_{l} .
$$

Como o teorema de equipartição é dado por (29),

$$
\langle U(x)\rangle=\frac{1}{2} \kappa_{x}\left\langle\left(x-x_{e q}\right)^{2}\right\rangle=\frac{1}{2} k_{B} T,
$$

a constante de força pode ser obtida, fazendo

$$
\kappa_{x}=\frac{k_{B} T}{\frac{1}{L} \sum_{l=1}^{L}\left(x_{l}-x_{e q}\right)^{2}} .
$$

sendo essa consideração comumente utilizada na calibração de pinças ópticas.

\subsection{Função de correlação}

Para um potencial harmônico, podemos reescrever a equação de Langevin como

$$
m \frac{d v}{d t}+\alpha v+\kappa x=F^{\prime}(t)
$$

Considerando que o tempo característico de uma partícula browniana aprisionada em um potencial harmônico é dado por $\tau_{c}=\alpha / \kappa^{\dagger \dagger}$, sendo $\alpha / \kappa \gg \tau^{*}$, nessa escala de tempo, a força viscosa domina a força inercial e podemos reescrever a Eq. 3.26 tomando $d v / d t=0^{\ddagger \ddagger}(26)$ :

$$
\frac{d x}{d t}+\frac{x}{\tau_{c}}=\frac{F^{\prime}(t)}{\alpha}
$$

\footnotetext{
$\dagger \dagger$ O tempo característico é o tempo no qual uma partícula demora para alcançar sua posição de equilíbrio.

$\sharp$ Na Seção 4 é feita uma análise numérica explorando a trajetória da partícula em duas escalas de tempo, em relação ao tempo característico $\tau^{*}$. Foi possível concluir que na escala de tempos maiores, que é a escala de interesse nesse tipo de problema, por $\tau_{c} \gg \tau^{*}$, desprezar o termo inercial é uma boa aproximação.
} 
O valor da posição da partícula em função do tempo pode ser obtido integrando a equação anterior:

$$
x(t)=x_{0} e^{-\frac{t-t_{0}}{\tau_{c}}}+\int_{t_{0}}^{t} \frac{F^{\prime}\left(t^{\prime}\right)}{\alpha} e^{-\frac{\left(t-t^{\prime}\right)}{\tau_{c}}} d t^{\prime}
$$

e, tomando o limite em que $t_{0} \rightarrow-\infty$

$$
x(t)=\int_{-\infty}^{t} \frac{F^{\prime}\left(t^{\prime}\right)}{\alpha} e^{-\frac{\left(t-t^{\prime}\right)}{\tau_{c}}} d t^{\prime}
$$

A partir da função $x(t)$ podemos calcular a função de correlação $C_{x}(s)$, que fornece o tempo para uma partícula esquecer sua posição inicial:

$$
C_{x}(s)=\langle x(0) x(s)\rangle=\frac{1}{\alpha^{2}} \int_{-\infty}^{0} d t^{\prime} \int_{-\infty}^{s}\left\langle F^{\prime}\left(t^{\prime}\right) F^{\prime}\left(t^{\prime \prime}\right)\right\rangle e^{-\frac{\left(s-t^{\prime}-t^{\prime \prime}\right)}{\tau_{c}}} d t^{\prime \prime}
$$

Quando o sistema está em equilíbrio, a média de ensemble é independente do tempo absoluto, dependendo só da diferença de tempo $s=t^{\prime \prime}-t^{\prime}$. A função de correlação estocástica $K(s)=\left\langle F^{\prime}\left(t^{\prime}\right) F^{\prime}\left(t^{\prime}+s\right)\right\rangle$ pode ser resolvida como

$$
K(s)=\langle F(0) F(s)\rangle
$$

que escrita na integral de Fourier $(26,35)$ é dada por

$$
K(s)=\int_{-\infty}^{+\infty} J(\omega) e^{i \omega s} d \omega
$$

sendo $J(\omega)$ a densidade espectral de $F$ :

$$
J(\omega)=\frac{1}{2 \pi} \int_{-\infty}^{+\infty} K(s) e^{-i \omega s} d s
$$

Desse modo, podemos reescrever o teorema de flutuação dissipação (Eq. 3.19) usando as relações acima:

$$
\begin{aligned}
2 K_{B} T \alpha & =\int_{-\infty}^{+\infty} d s\left[\int_{-\infty}^{+\infty} J(\omega) e^{i \omega s} d \omega\right] \\
& =\int_{-\infty}^{+\infty} J(\omega) d \omega\left[\int_{-\infty}^{+\infty} e^{i \omega s} d s\right] \\
& =2 \pi \int_{-\infty}^{+\infty} J(\omega) \delta(\omega) d \omega
\end{aligned}
$$

sendo a delta de Dirac definido como $\delta(x-a)=1 / 2 \pi \int_{-\infty}^{\infty} e^{i p(x-a)} d p$. 
Como o tempo de correlação $\tau_{c}$ é pequeno (35), a função $K(s)$ apresenta um pico estreito em torno de $s=0$. Logo, no domínio da frequência, $J(\omega)$ é aproximadamente constante e igual a

$$
J(\omega)=J(0)=\frac{K_{B} T \alpha}{\pi} .
$$

Substituindo o resultado obtido para $J(\omega)$ na Eq. 3.32, temos

$$
K(s)=\int_{-\infty}^{\infty} \frac{K_{B} T \alpha}{\pi} e^{i \omega s} d \omega=2 K_{B} T \alpha \delta(s)
$$

Desse modo, podemos escrever a seguinte relação:

$$
\left\langle F\left(t^{\prime}\right) F\left(t^{\prime \prime}\right)\right\rangle=2 K_{B} T \alpha \delta\left(t^{\prime \prime}-t^{\prime}\right)
$$

e, por fim, a solução analítica da função de correlação, obtida a partir da Eq. 3.30, é dada por (26):

$$
\begin{aligned}
C_{x}(s) & =\frac{2 K_{B} T}{\alpha} \int_{-\infty}^{0} d t^{\prime} \int_{-\infty}^{s} \delta\left(t^{\prime \prime}-t^{\prime}\right) e^{-\frac{\left(s-t^{\prime}-t^{\prime \prime}\right)}{\tau_{c}}} d t^{\prime \prime} \\
& =\frac{2 K_{B} T}{\alpha} \int_{-\infty}^{0} e^{-\frac{\left(s-2 t^{\prime}\right)}{\tau_{c}}} d t^{\prime} \\
& =\frac{K_{B} T}{\kappa} e^{-\frac{s}{\tau_{c}}} .
\end{aligned}
$$

A função de $C(s)$, para várias constantes de força, é apresentada na Fig. 8. 


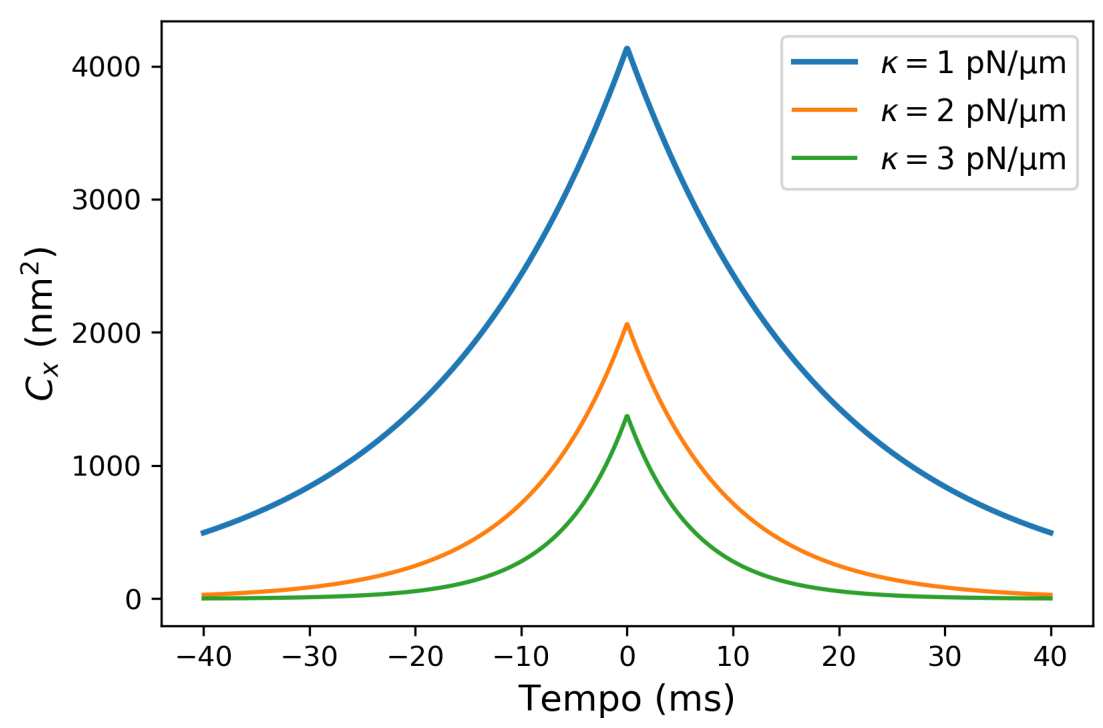

Figura 8 - Função de correlação teórica da posição de uma partícula de raio $r=1 \mu m$ imersa em água $(\eta=0.001 \mathrm{~Pa} \cdot \mathrm{s})$ a temperatura de $T=300 \mathrm{~K}$ para $\kappa_{x}=1 \mathrm{pN} / \mu \mathrm{m}$, $\kappa_{x}=2 \mathrm{pN} / \mu \mathrm{m}$ e $\kappa_{x}=3 \mathrm{pN} / \mu \mathrm{m}$.

Fonte: Elaborada pela autora.

\subsection{Desvio quadrático médio}

O desvio quadrático médio (DQM) quantifica como o corpo se move a partir de sua posição inicial e é dado por:

$$
\left\langle[x(t+s)-x(t)]^{2}\right\rangle=\left\langle x^{2}(t+s)\right\rangle-2\langle x(t) x(t+s)\rangle+\left\langle x^{2}(t)\right\rangle .
$$

O primeiro termo da Eq. 3.39 pode ser calculado de modo análogo à Eq. 3.30, modificando apenas o intervalo de integração:

$$
\left\langle x^{2}(t+s)\right\rangle=\frac{1}{\alpha^{2}} \int_{-\infty}^{t+s} d t^{\prime} \int_{-\infty}^{t+s}\left\langle F\left(t^{\prime}\right) F\left(t^{\prime \prime}\right)\right\rangle e^{-\frac{\left[2(t+s)-t^{\prime}-t^{\prime \prime}\right]}{\tau_{c}}} d t^{\prime \prime} .
$$

Usando a relação da Eq. 3.37, temos que

$$
\begin{aligned}
\left\langle x^{2}(t+s)\right\rangle & =\frac{2 K_{B} T}{\alpha} \int_{-\infty}^{t+s} e^{-\frac{2\left(t+s-t^{\prime}\right)}{\tau_{c}}} d t^{\prime} \\
& =\frac{K_{B} T}{\kappa}
\end{aligned}
$$

sendo os demais elementos calculados de forma análoga

$$
\left\langle x^{2}(t)\right\rangle=\frac{K_{B} T}{\kappa}
$$




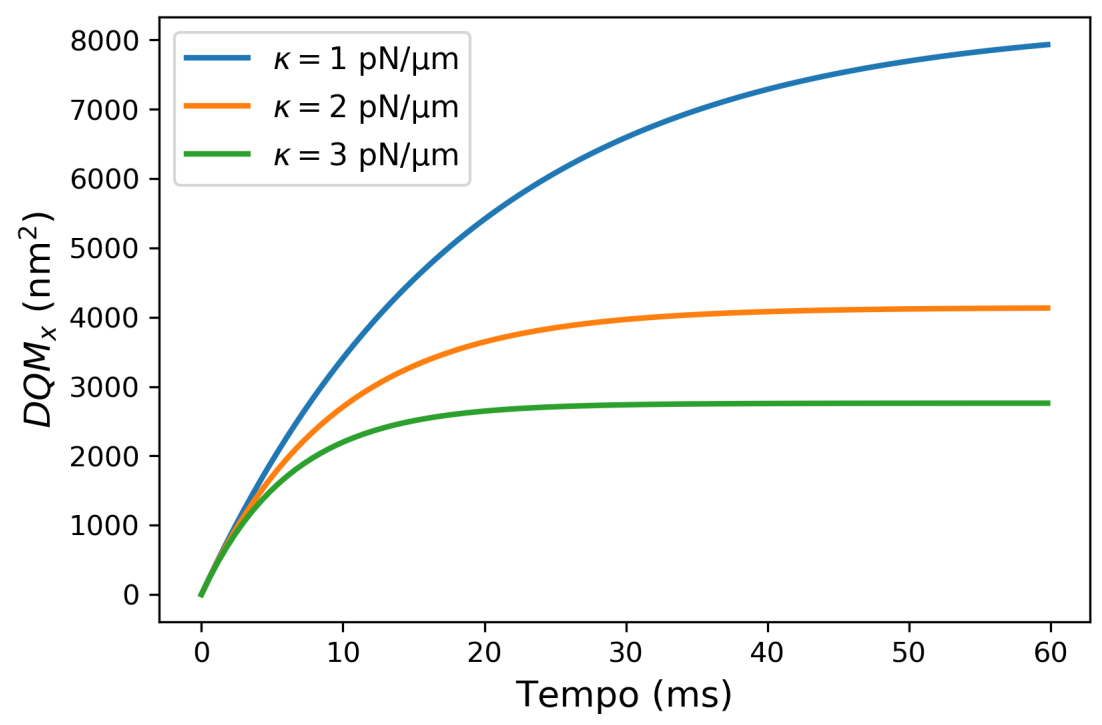

Figura 9 - DQM teórico da posição de uma partícula de raio $r=1 \mu m$ imersa em água $(\eta=$ $0.001 \mathrm{~Pa} \cdot \mathrm{s})$ a temperatura de $T=300 \mathrm{~K}$ para $\kappa_{x}=1 \mathrm{pN} / \mu \mathrm{m}, \kappa_{x}=2 \mathrm{pN} / \mu \mathrm{m} \mathrm{e}$ $\kappa_{x}=3 \mathrm{pN} / \mu \mathrm{m}$.

Fonte: Elaborada pela autora.

$$
2\langle x(t) x(t+s)\rangle=2 \frac{K_{B} T}{\kappa} e^{-\frac{s}{\tau_{c}}} .
$$

Logo, o desvio médio quadrático é dado por

$$
\left\langle[x(t+s)-x(t)]^{2}\right\rangle=\frac{2 K_{B} T}{\kappa}\left(1-e^{-\frac{s}{\tau_{c}}}\right) .
$$

A função de DQM, para várias constantes de força, é mostrada na Fig. 9. A escala de tempo $\tau_{c}$ caracteriza como a partícula cai na armadilha, pois conforme a constante de força aumenta, o tempo característico diminui. Nessa figura, podemos observar também uma transição de um crescimento linear, que corresponde ao comportamento difusivo livre em tempos menores que o tempo característico $\tau_{c}$, ao platô devido ao confinamento da partícula no potencial. (29) 


\section{SIMULAÇÕES}

Neste capítulo são apresentados os resultados das simulações numéricas, geradas com o auxílio de códigos em Python (Apêndices D, E e G), para uma partícula browniana em três tipos de situações: regime livre, aprisionada em um potencial harmônico e aprisionada em um potencial modulado dinamicamente (variável no tempo)*.

\subsection{Movimento Browniano}

Uma partícula em um fluido é descrita, como mencionado anteriormente, pela equação de Langevin. O termo da força estocástica, originado das colisões entre a partícula e as moléculas do fluido, pode ser escrito em termos do ruído branco $F^{\prime}(t)=\sqrt{2 K_{B} T \alpha} W(t)$. (36) Reescrevendo a Eq. 3.26, para o caso $F_{\text {ext }}=0$, temos

$$
m \frac{d^{2} x(t)}{d t^{2}}=-\alpha \frac{d x(t)}{d t}+\sqrt{2 K_{B} T \alpha} W(t) .
$$

Devido ao termo estocástico, a equação diferencial não tem uma solução analítica trivial, sendo pertinente um tratamento numérico do problema. Nesse tratamento, a posição $x(t)$ pode ser aproximada a uma série temporal discreta $x_{i} \approx x\left(t_{i}\right)$, para $t_{i}=i \Delta t$. Com $\Delta t$ suficientemente pequeno, temos a discretização da equação de movimento, dada por:

$$
\begin{aligned}
& x(t)=x_{i} \\
& \frac{d x(t)}{d t}=\frac{x_{i}-x_{i-1}}{\Delta t} \\
& \frac{d x^{2}(t)}{d t^{2}}=\frac{\left(x_{i}-x_{i-1}\right) / \Delta t-\left(x_{i-1}-x_{i-2}\right) / \Delta t}{\Delta t}=\frac{x_{i}-2 x_{i-1}+x_{i-2}}{(\Delta t)^{2}} .
\end{aligned}
$$

O ruído branco pode ser escrito como $W(t) \approx W_{i}=w_{i} / \sqrt{\Delta t}$, sendo $w_{i}$ uma sequência de números aleatórios de uma distribuição uniforme de $[0,1)$. Essa definição satisfaz as propriedades físicas do termo estocástico, sendo essas: $\langle W(t)\rangle=0$ para todo $t$, $\left\langle W(t)^{2}\right\rangle=1$ para cada tempo $t$ e $W\left(t_{1}\right)$ e $W\left(t_{2}\right)$ descorrelacionados para $t_{1} \neq t_{2}$.

Como a variância de $W_{i}$ é $1 / \sqrt{\Delta t}$, conforme $\Delta t$ diminui, $W_{i}$ necessariamente terá valores maiores na sua distribuição. Apesar dessa compensação, $\Delta t$ deve ser muito menor que o tempo característico da partícula para o processo ser simulado.

Desse modo, a Eq. 4.1 pode ser reescrita como

$$
m \frac{x_{i}-2 x_{i-1}+x_{i-2}}{(\Delta t)^{2}}=-\alpha \frac{x_{i}-x_{i-1}}{\Delta t}+\sqrt{2 K_{B} T \alpha} \frac{1}{\sqrt{\Delta t}} w_{i},
$$

* As Seções 4.1 e 4.2 estão baseadas na referência (36). 
sendo a solução, para $x_{i}$,

$$
x_{i}=\frac{2+\Delta t(\alpha / m)}{1+\Delta t(\alpha / m)} x_{i-1}-\frac{1}{1+\Delta t(\alpha / m)} x_{i-2}+\frac{\sqrt{2 K_{B} T \alpha}}{m[1+\Delta t](\alpha / m)}(\Delta t)^{3 / 2} w_{i}
$$

Como em condições experimentais típicas o tempo característico do movimento browniano é muito pequeno comparado ao tempo de interesse e de detecção do sistema experimental, podemos considerar que nessa escala de tempo a partícula alcança a velocidade de equilíbrio e é possível desprezar o termo inercial. Desse modo, a Eq. 4.1 pode ser reescrita considerando $m=0$ :

$$
0=-\alpha \frac{x_{i}-x_{i-1}}{\Delta t}+\sqrt{2 K_{B} T \alpha} \frac{1}{\sqrt{\Delta t}} w_{i}
$$

sendo a solução, para $x_{i}$,

$$
x_{i}=x_{i-1}+\sqrt{\frac{2 K_{B} T \Delta t}{\alpha}} w_{i} .
$$

Uma comparação na análise pode ser feita considerando o termo inercial e, posteriormente, desprezando o mesmo ${ }^{\dagger}$. Para $\Delta t \approx \tau_{m}$, o termo inercial suaviza a trajetória da partícula (Fig. 10). No entanto, para $\Delta t \gg \tau_{m}$, desprezar o termo inercial é uma boa aproximação, conforme a Fig. 11.

† Para a análise numérica é considerada uma micropartícula de raio $a=1 \mu \mathrm{m}$ e densidade $d=2.65 \mathrm{~g} / \mathrm{cm}^{3}$ imersa em solução aquosa de viscosidade $\eta=0.001 \mathrm{Ns} / \mathrm{m}^{2}$ e temperatura $T=300 \mathrm{~K}$. O coeficiente de arrasto será $\alpha=6 \pi \eta a$ e o tempo característico $\tau_{m}=m / \alpha \approx 0.6 \mu \mathrm{s}$. As trajetórias foram calculadas para $\Delta t=20 \mathrm{~ns}$. 


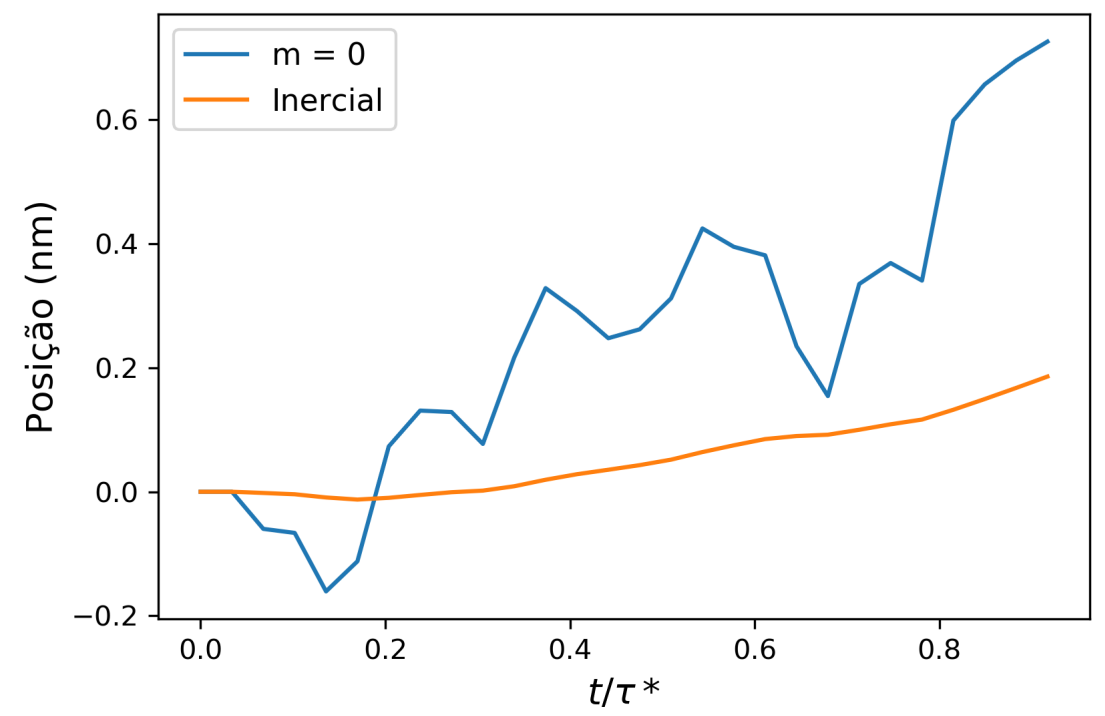

Figura 10 - Trajetórias para um intervalo de tempo próximo ao tempo característico da partícula.

Fonte: Elaborada pela autora.

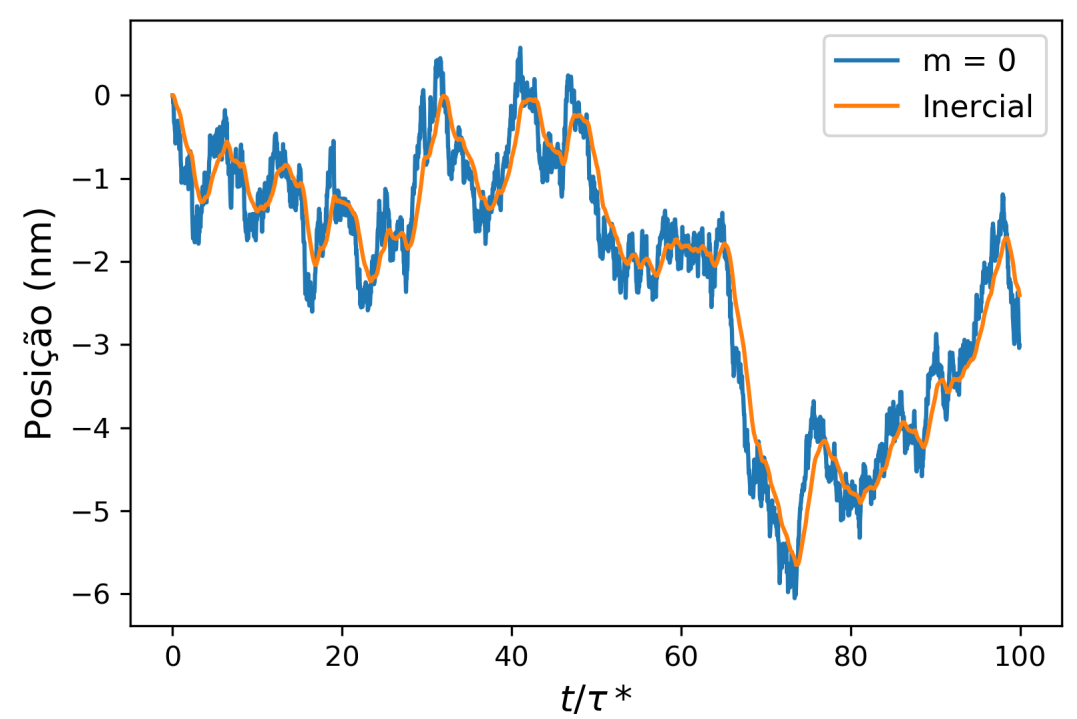

Figura 11 - Trajetórias para um intervalo de tempo intervalo de tempo muito maior que o tempo característico da partícula.

Fonte: Elaborada pela autora. 


\subsection{Potencial harmônico}

Para uma partícula em um potencial óptico harmônico de constante de força $\kappa$, o tempo característico será $\tau_{c}=\alpha / \kappa$. Esse tempo é maior que o tempo característico de uma partícula browniana livre, desse modo, é possível utilizar a aproximação em que o termo inercial é desprezado.

Considerando uma armadilha óptica tridimensional, a força pode ser expressa como:

$$
\left[\begin{array}{l}
F_{x} \\
F_{y} \\
F_{z}
\end{array}\right]=\left[\begin{array}{ccc}
\kappa_{x} & 0 & 0 \\
0 & \kappa_{y} & 0 \\
0 & 0 & \kappa_{z}
\end{array}\right]\left[\begin{array}{l}
x \\
y \\
z
\end{array}\right]=\boldsymbol{\kappa}(\vec{R}) .
$$

sendo $\boldsymbol{\kappa}$ o tensor da constante de força. A equação de Langevin (Eq. 3.27) pode ser reescrita como:

$$
\frac{d}{d t} \vec{R}(t)=-\frac{\kappa(\vec{R}(t))}{\alpha}+\sqrt{\frac{2 K_{B} T}{\alpha}} \vec{W}(t)
$$

Para a aproximação discreta, temos

$$
\vec{R}_{i}=\vec{R}_{i-1}-\frac{\kappa\left(\vec{R}_{i-1}\right) \Delta t}{\alpha}+\sqrt{\frac{2 K_{B} T \Delta t}{\alpha}} \vec{w}_{i}
$$

sendo $\vec{R}_{i}=\left[x_{i}, y_{i}, z_{i}\right]^{T}$ a posição do CM da partícula e $\vec{w}_{i}=\left[w_{x, i}, w_{y, i}, w_{z, i}\right]^{T}$.

A partir destas considerações, é possível simular a trajetória do CM de uma partícula aprisionada por uma constante de força de $\vec{\kappa}=[3,3,0.6] \mathrm{pN} / \mu \mathrm{m}$, conforme a Fig. $12^{\ddagger}$.

Para o estudo da dinâmica da partícula aprisionada, embora o movimento desta seja no espaço tridimensional, vamos considerar apenas a componente $x$ da posição. Para as demais dimensões, o tratamento é análogo.

Ao fazer um histograma da posição da partícula aprisionada, obtida na simulação, temos a distribuição de probabilidade $\rho(x)$ apresentada na Fig. 13, sendo utilizado para a criação do histograma 200 bins. A partir dos valores de distribuição de probabilidade normalizados, podemos calcular o potencial $U(x)$, apresentado na Fig. 14. Dos pontos simulados foi subtraída a constante $U_{0}$ para facilitar a comparação com a curva teórica que, para um potencial harmônico, é dada por:

$$
U(x)=\frac{\kappa_{x} x^{2}}{2} .
$$

¥ Para a análise numérica foi considerada uma micropartícula com as mesmas características apresentadas na Seção 4.1 e uma temperatura de $T=300 \mathrm{~K}$. 
As trajetórias simuladas também devem obedecer à função de correlação da posição da partícula, que, em tempos discretos $s_{k}=k \Delta t$, é dada por

$$
C_{k, x}=\frac{1}{N-k} \sum_{j=1}^{N-k} x_{j-k} x_{j},
$$

sendo estes valores apresentados na Fig. 15, juntamente com a curva teórica, calculada a partir da Eq. 3.38.

Além da função de correlação, é possível também calcular, para o conjunto de dados simulados, o DQM. Para defasagens de tempo $s_{k}=k \Delta t$, temos o DQM dado por

$$
D Q M_{x, k}=\frac{1}{N-k} \sum_{j=1}^{N-k}\left[x_{j+k}-x_{j}\right]^{2},
$$

conforme a Fig. 16. A curva teórica, calculada a partir da Eq. 3.44, para os mesmos parâmetros da simulação, também é apresentada. 

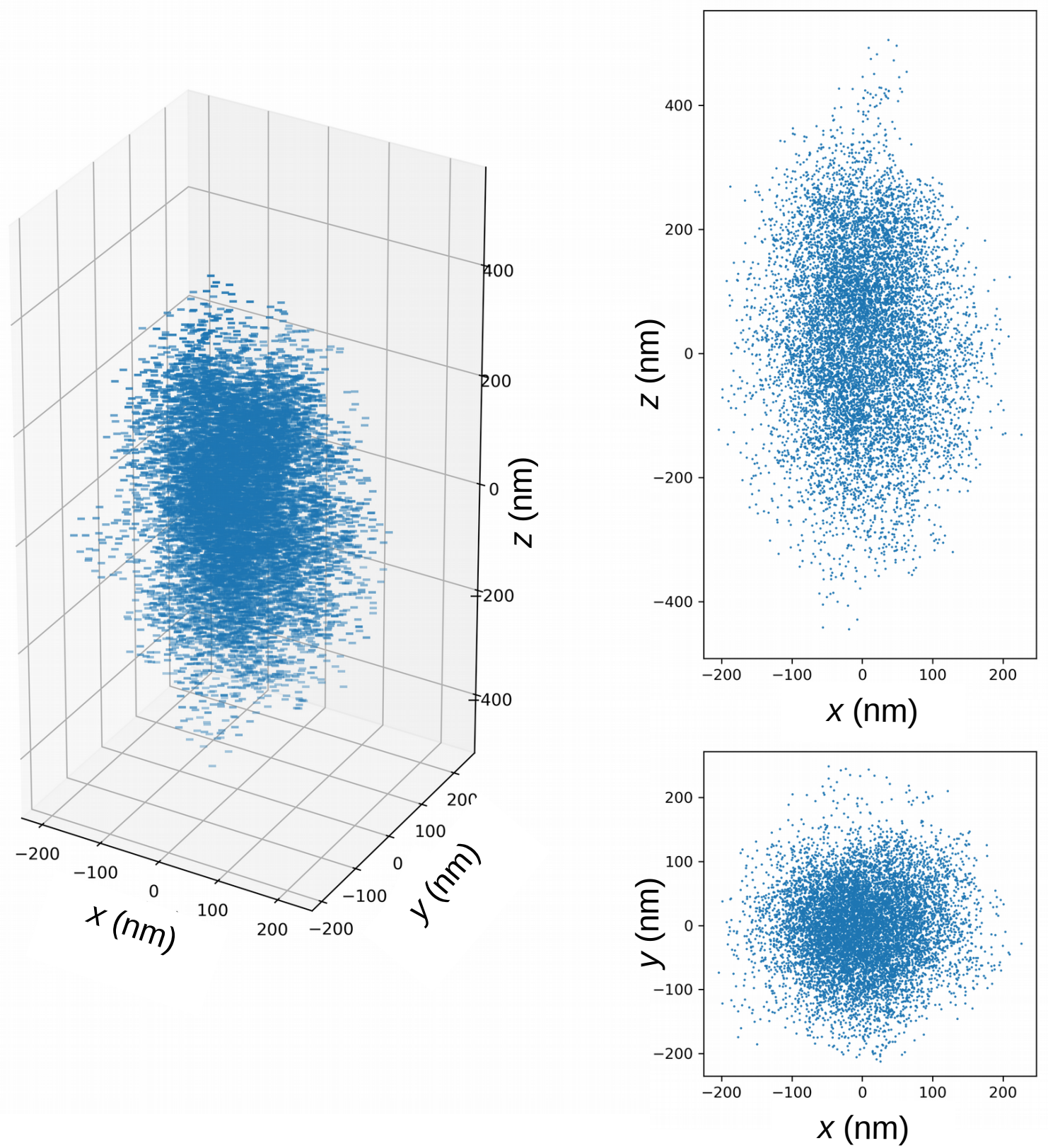

Figura 12 - Simulação numérica da trajetória do CM da partícula aprisionada em um potencial óptico harmônico de constante de força $\vec{\kappa}=[3,3,0.6] \mathrm{pN} / \mu \mathrm{m}$ durante $10 \mathrm{~s}$ para um intervalo de tempo de $\Delta t=1 \mathrm{~ms}$ no espaço tridimensional (esquerda) e nos planos $x z$ (direita em cima) e $x y$ (direita embaixo). As barras de erro são menores que o tamanho do símbolo de cada ponto.

Fonte: Elaborada pela autora. 


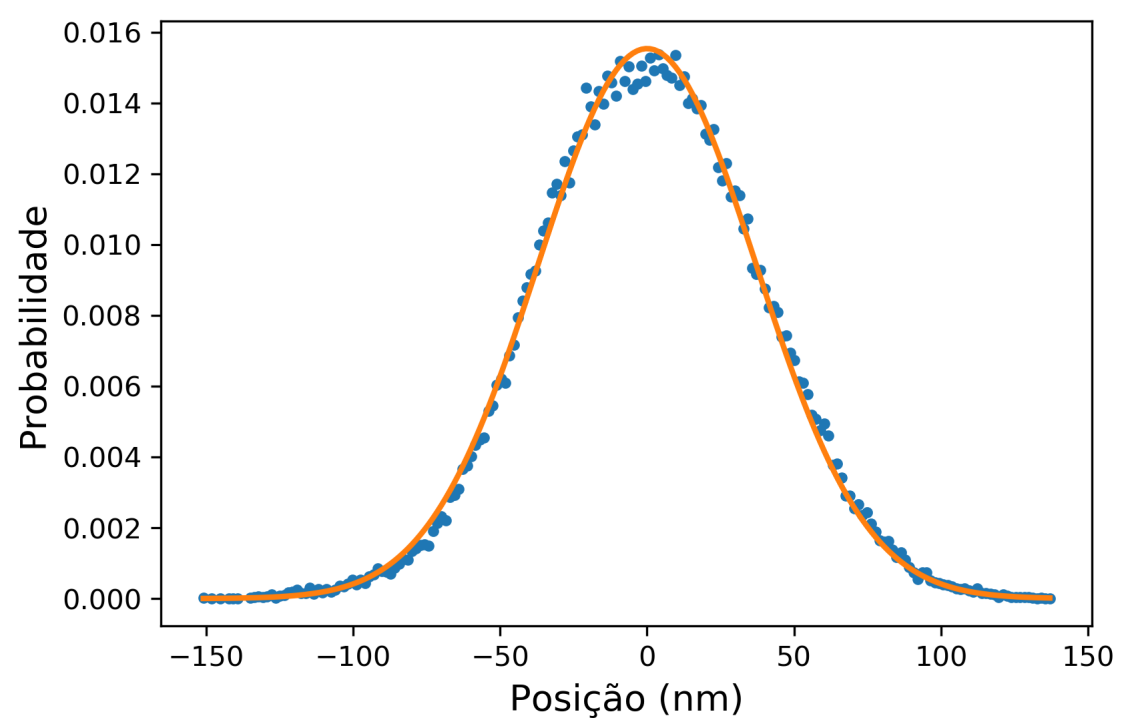

Figura 13 - Distribuição de probabilidade de uma partícula aprisionada em um potencial óptico harmônico de constante de força $\kappa_{x}=3 \mathrm{pN} / \mu \mathrm{m}$ durante $10 \mathrm{~s}$, com $\Delta t=0.1 \mathrm{~ms}$ e a curva calculada teoricamente. As barras de erro são menores que o tamanho do símbolo de cada ponto.

Fonte: Elaborada pela autora.

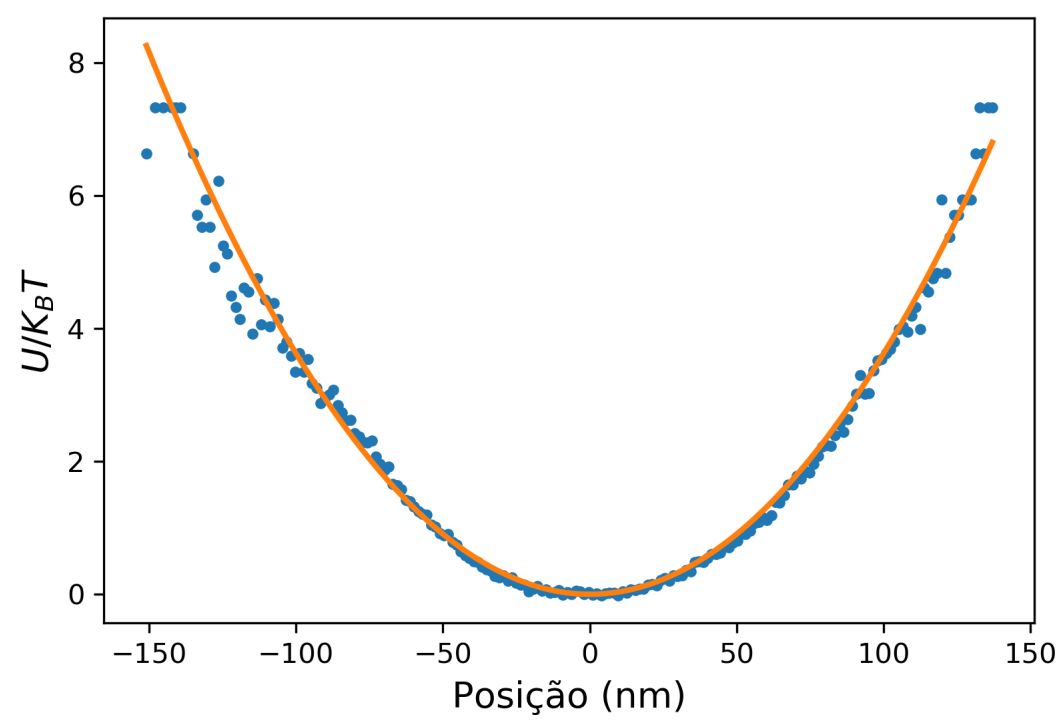

Figura 14 - Potencial de uma partícula aprisionada em um potencial óptico harmônico de constante de força $\kappa_{x}=3 \mathrm{pN} / \mu \mathrm{m}$ durante $10 \mathrm{~s}$, com $\Delta t=0.1 \mathrm{~ms}$ e a curva calculada teoricamente. As barras de erro são menores que o tamanho do símbolo de cada ponto.

Fonte: Elaborada pela autora. 


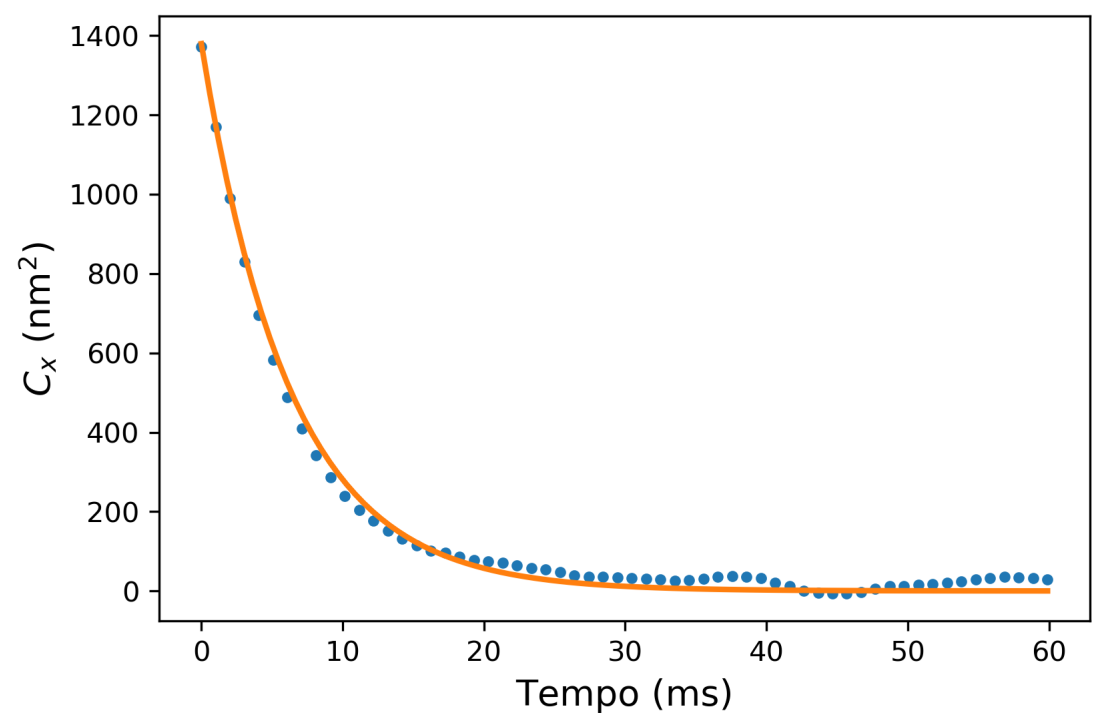

Figura 15 - Função de correlação da posição de uma partícula aprisionada em um potencial óptico harmônico de constante de força $\kappa_{x}=3 \mathrm{pN} / \mu \mathrm{m}$ durante $10 \mathrm{~s}$, com $\Delta t=0.1 \mathrm{~ms}$ e a curva calculada teoricamente. As barras de erro são menores que o tamanho do símbolo de cada ponto.

Fonte: Elaborada pela autora.

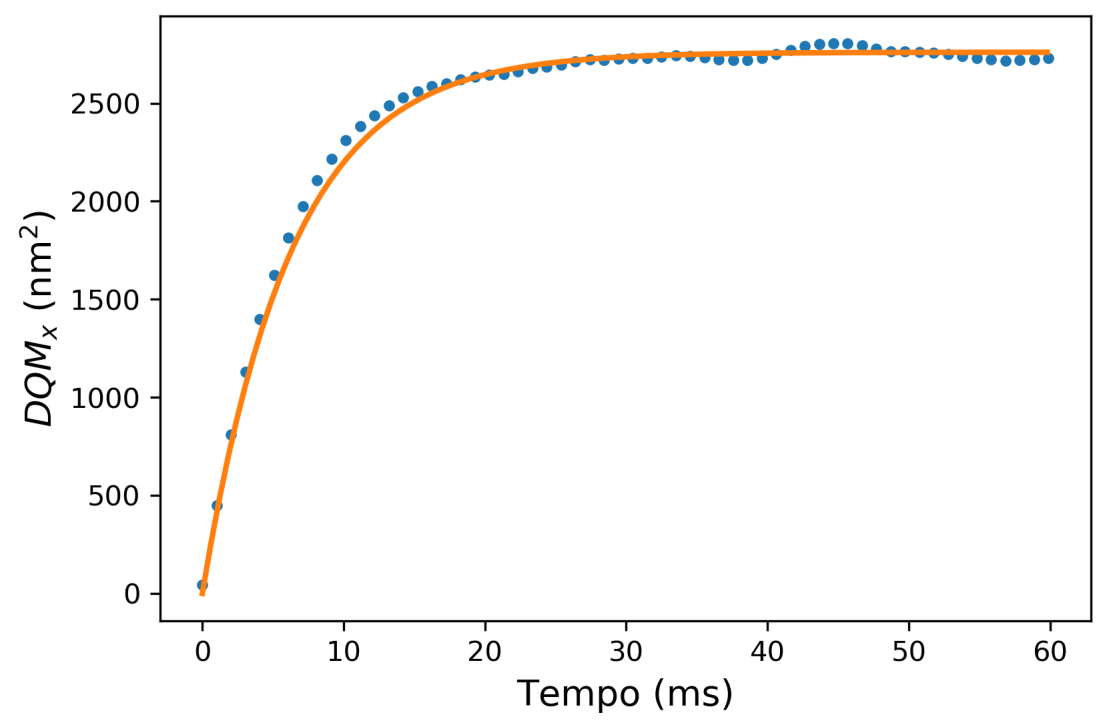

Figura 16 - DQM da posição de uma partícula aprisionada em um potencial óptico harmônico de constante de força $\kappa_{x}=3 \mathrm{pN} / \mu \mathrm{m}$ durante $10 \mathrm{~s}$, com $\Delta t=0.1 \mathrm{~ms}$ e a curva calculada teoricamente. As barras de erro são menores que o tamanho do símbolo de cada ponto.

Fonte: Elaborada pela autora. 


\subsection{Potencial dinâmico}

Na seção anterior, foi considerada que a posição de equilíbrio do potencial harmônico era constante e nula. No entanto, é possível, a partir da modulação espacial do laser, escrever uma função da posição de equilíbrio variável com o tempo $x_{0}(t)$. Nesta situação, a força óptica é descrita por

$$
F(x, t)=\kappa_{x}\left(x-x_{0}(t)\right)
$$

Reescrevendo a equação de Langevin para a força externa $F(x, t)$, temos:

$$
\frac{d}{d t} x(t)=-\frac{\kappa_{x}\left(x-x_{0}(t)\right)}{\alpha}+\sqrt{\frac{2 K_{B} T}{\alpha}} W(t)
$$

e, discretizando a equação de movimento,

$$
x_{i}=x_{i-1}-\frac{\kappa_{x}\left(x_{i-1}-x_{0, i}\right) \Delta t}{\alpha}+\sqrt{\frac{2 K_{B} T \Delta t}{\alpha}} w_{i} .
$$

Dado isso, é possível escrever qualquer tipo de função $x_{0}(t)$. No presente trabalho, vamos nos concentrar em três tipos de funções: quadradas, triangulares e senoidais, que serão posteriormente comparadas aos dados experimentais.

Um sinal quadrado de amplitude $A$ e frequência $f$ é dado por

$$
x_{0}(t)=A \operatorname{sgn}(\sin (2 \pi f t))
$$

sendo $\operatorname{sgn}($.$) uma função de sinal definida como$

$$
\operatorname{sgn}(a)=\left\{\begin{array}{cc}
-1, & \text { se } a<0 \\
1, & \text { se } a>0
\end{array}\right.
$$

O sinal triangular pode ser definido em termos da Eq. 4.17:

$$
x_{0}(t)=A \int_{0}^{t} \operatorname{sgn}(\sin (2 \pi f t)) d t
$$

e o sinal senoidal, como:

$$
x_{0}(t)=A \sin (2 \pi f t)
$$


Nas figuras abaixo, foram feitas simulações para sinais quadrados (Fig. 17), triangulares (Fig. 18) e senoidais (Fig. 19) com frequência de $1 \mathrm{~Hz}$ e amplitudes de $A=500 \mathrm{~nm}$ e $A=1000 \mathrm{~nm}^{\S}$.

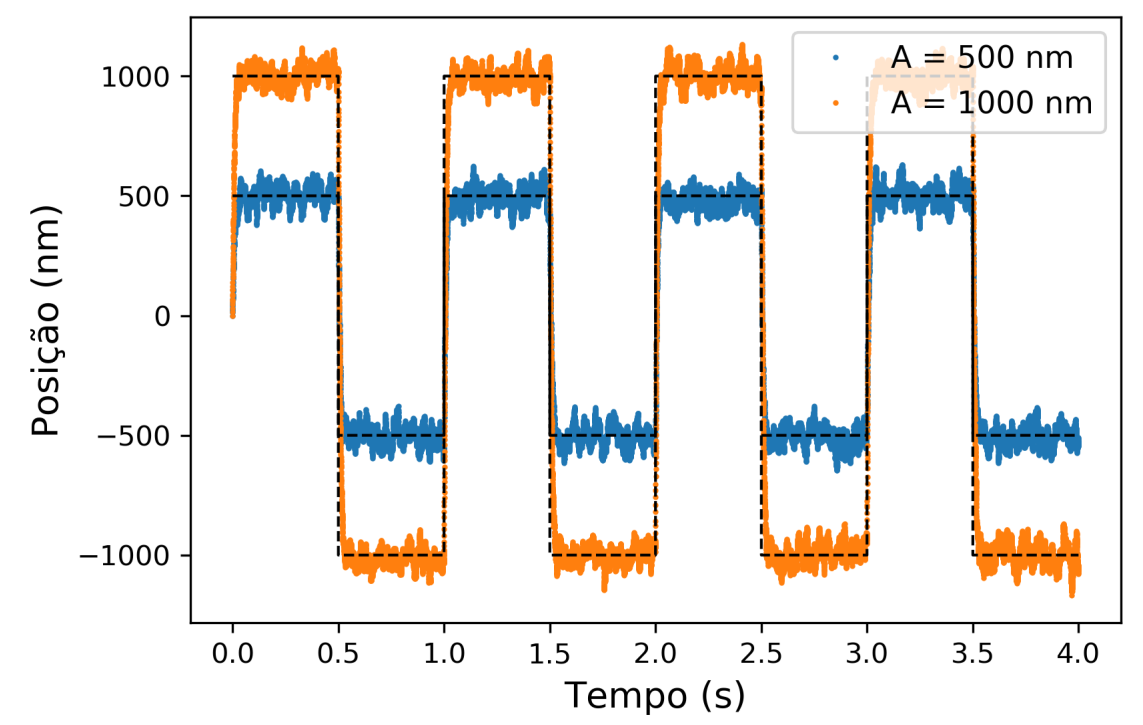

Figura 17 - Simulação da trajetória de uma partícula aprisionada em um potencial variável quadrado para $A=500 \mathrm{~nm}$ e $A=1000 \mathrm{~nm}$, frequência de $1 \mathrm{~Hz}$ e constante de força de $\kappa_{x}=2.5 \mathrm{pN} / \mu \mathrm{m}$. As barras de erro são menores que o tamanho do símbolo de cada ponto.

Fonte: Elaborada pela autora.

§ Para a análise numérica foi considerada uma micropartícula com as mesmas características apresentadas na Seção 4.1, $\Delta t=0.1 \mathrm{~ms}$ e uma temperatura de $T=300 \mathrm{~K}$. 


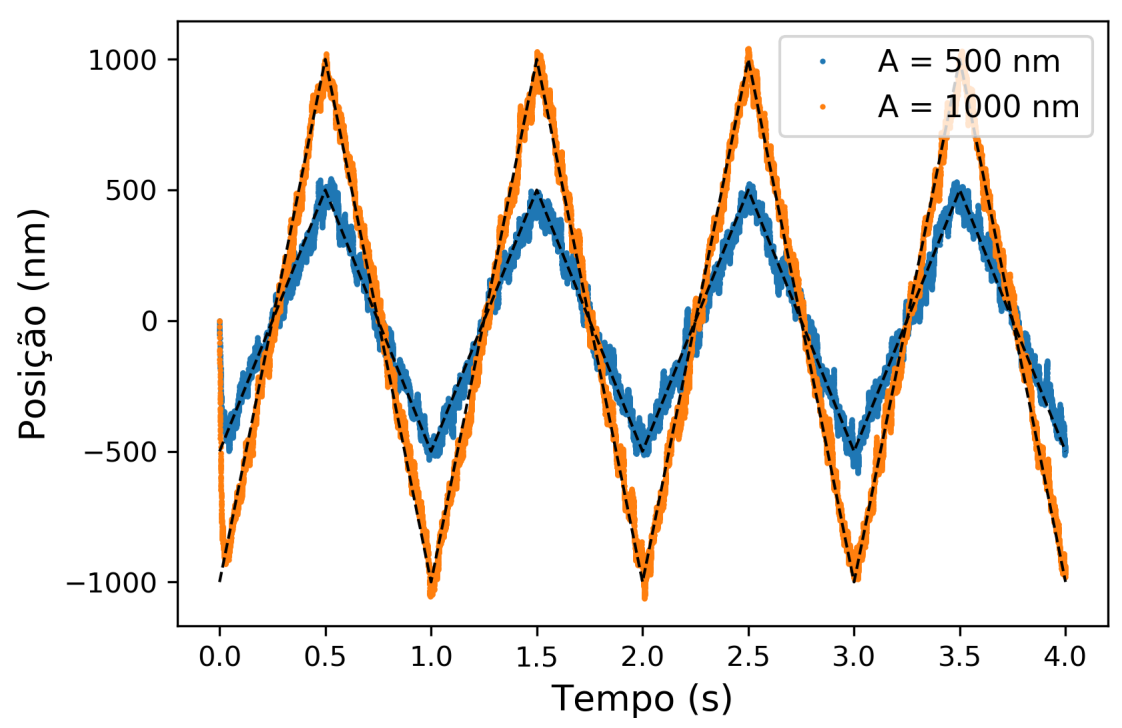

Figura 18 - Simulação da trajetória de uma partícula aprisionada em um potencial variável triangular para $A=500 \mathrm{~nm}$ e $A=1000 \mathrm{~nm}$, frequência de $1 \mathrm{~Hz}$ e constante de força de $\kappa_{x}=2.5 \mathrm{pN} / \mu \mathrm{m}$. As barras de erro são menores que o tamanho do símbolo de cada ponto.

Fonte: Elaborada pela autora.

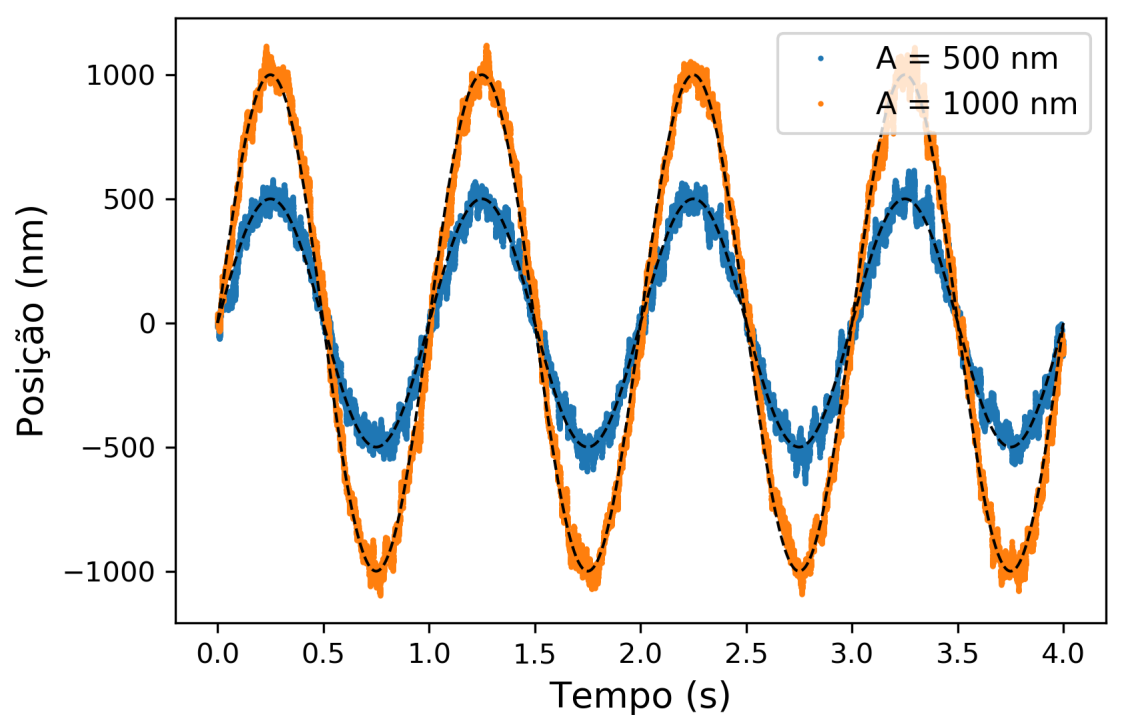

Figura 19 - Simulação da trajetória de uma partícula aprisionada em um potencial variável senoidal para $A=500 \mathrm{~nm}$ e $A=1000 \mathrm{~nm}$, frequência de $1 \mathrm{~Hz}$ e constante de força de $\kappa_{x}=2.5 \mathrm{pN} / \mu \mathrm{m}$. As barras de erro são menores que o tamanho do símbolo de cada ponto.

Fonte: Elaborada pela autora. 


\subsection{Potencial duplo}

Ao aplicar uma função quadrada em $x_{0}(t)$, para altas frequências, da ordem de $1 \mathrm{kHz}$ a $10 \mathrm{kHz}$, o potencial que age na partícula pode ser aproximado à uma média temporal de $U(x)=\kappa_{x}\left(x-x_{0}(t)\right)^{2} / 2$ num período de tempo $t_{T}$. Isso ocorre devido à viscosidade do meio e à inércia da partícula, que impede que sua trajetória média acompanhe a função $x_{0}(t)$, como anteriormente.
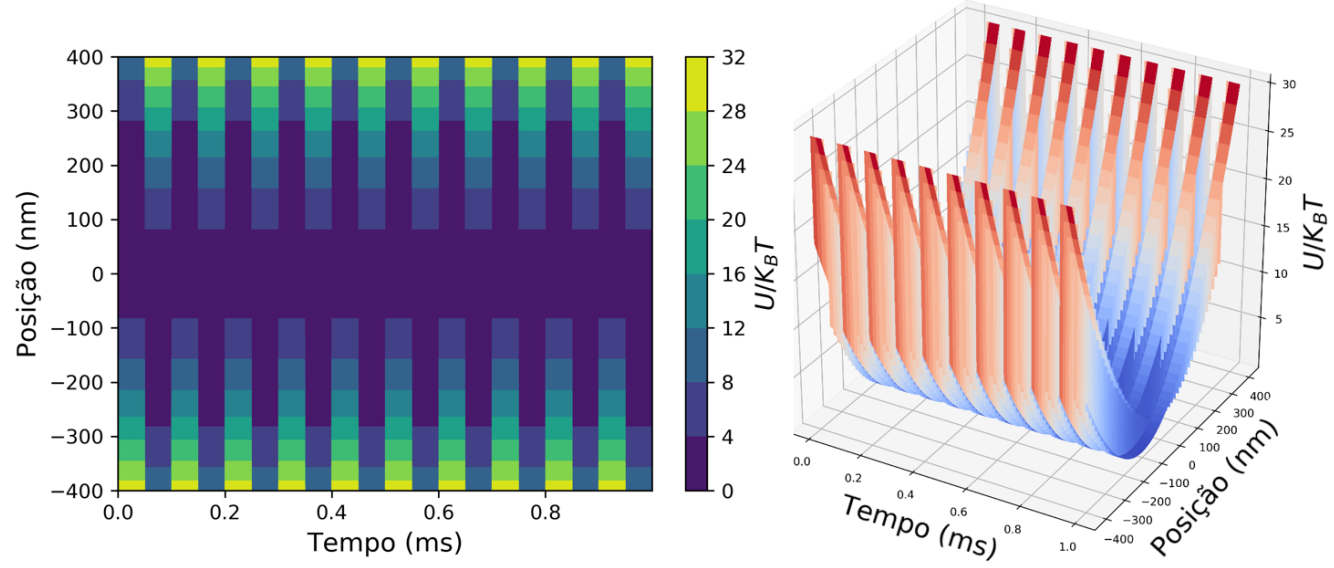

Figura 20 - Representação da função $U(x, t)$ por linhas de contorno (esquerda) e por uma superfície em três dimensões (direita) para $A=100 \mathrm{~nm}, f=10 \mathrm{kHz}$ e $\kappa_{x}=$ $10 \mathrm{pN} / \mu \mathrm{m}$.

Fonte: Elaborada pela autora.

Sendo a média de uma função $X(t)$ num intervalo de tempo $t_{T}$ definida por:

$$
\langle X(t)\rangle=\frac{1}{t_{T}} \int_{0}^{t_{T}} X\left(t^{\prime}\right) d t^{\prime}
$$

podemos escrever a média do potencial $U(x, t)$ modulado por um sinal quadrado como:

$$
\langle U(x, t)\rangle=\frac{1}{t_{T}} \int_{0}^{t_{T}} \frac{\kappa_{x}}{2}(x-A \operatorname{sgn}(\sin (2 \pi f t)))^{2} d t^{\prime} .
$$

Devido à dificuldade em se resolver essa função analiticamente, podemos aproximar o resultado a dois tipos de potenciais, um definido por uma função degrau, dada por

$$
\langle U(x, t)\rangle= \begin{cases}\frac{\kappa_{x}}{2}(x+A)^{2}, & \text { se } x<0 \\ \frac{\kappa_{x}}{2}(x-A)^{2}, & \text { se } x>0\end{cases}
$$




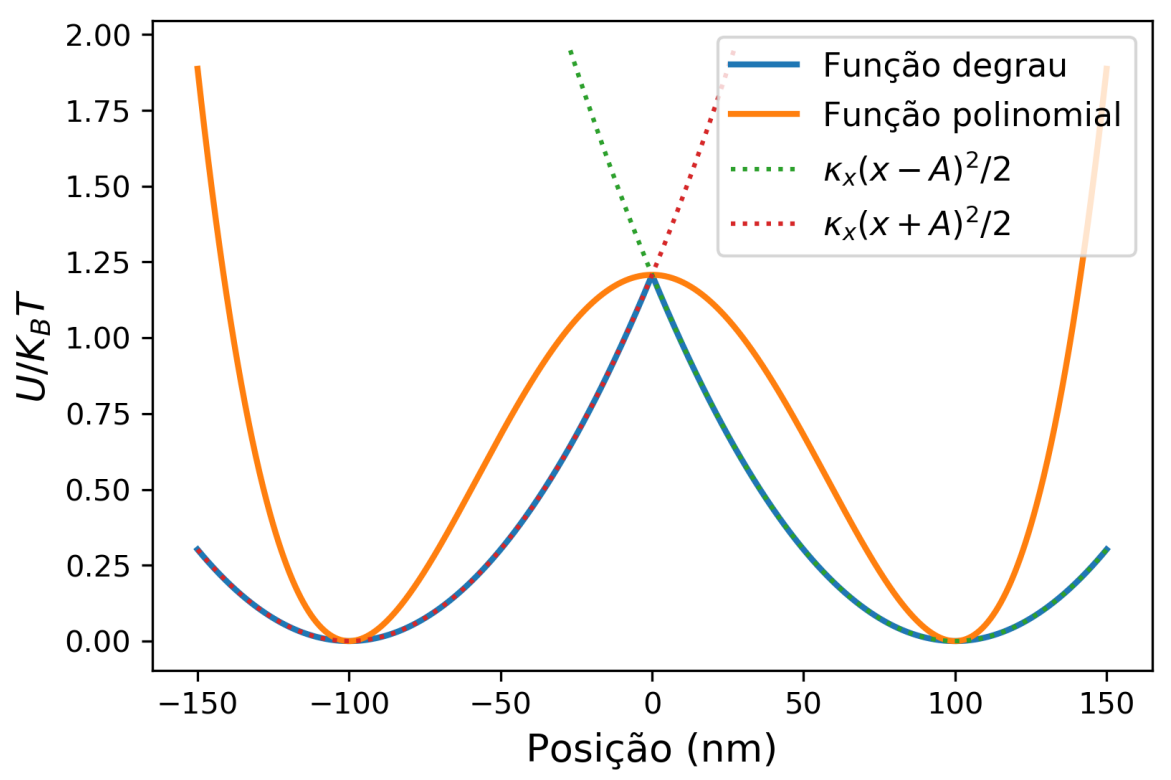

Figura 21 - Curvas teóricas para o potencial de cada poço e para as aproximações com a função degrau e com a função polinomial. O valor utilizado para a amplitude foi de $A=100 \mathrm{~nm}$ e para a constante de força foi de $\kappa_{x}=1 \mathrm{pN} / \mu \mathrm{m}$.

Fonte: Elaborada pela autora.

outro por um potencial suave, definido por um polinômio de ordem quatro, dado por:

$$
\langle U(x, t)\rangle=\frac{\kappa_{x}}{2 A^{2}}\left(x^{2}-A^{2}\right)^{2} .
$$

Ambas as aproximações, apresentadas na Fig. 21, contam com um máximo local dado por $U_{\max }=\kappa_{x} A^{2} / 2$. Logo, o potencial máximo é proporcional à constante de força e à distância entre os poços. Se a energia térmica da partícula for suficiente para ultrapassar a barreira, considerando que estamos no regime clássico, a partícula consegue saltar entre os poços.

Como a função polinomial é contínua em todo o espaço e mais simples de ser trabalhada, essa será considerada nas simulações seguintes. De maneira análoga à Seção 4.2, vamos escrever a equação do movimento para uma força dada por

$$
F(x)=-\frac{d U}{d x}=-\frac{2 \kappa_{x}}{A^{2}}\left(x^{3}-A^{2} x\right)
$$

$\log 0$

$$
x_{i}=x_{i-1}-\frac{2 \kappa_{x}\left(x_{i-1}^{3}-A^{2} x_{i-1}\right) \Delta t}{\alpha A^{2}}+\sqrt{\frac{2 K_{B} T \Delta t}{\alpha}} w_{i} .
$$

A trajetória simulada para uma constante de força $\kappa_{x}=1 \mathrm{pN} / \mu \mathrm{m}$ e um poço 
caracterizado por $A=100 \mathrm{~nm}$ é apresentada na Fig. 22 . A partir da trajetória da partícula é possível calcular a distribuição de probabilidade e, posteriormente, a curva do potencial, de modo análogo à seção anterior.

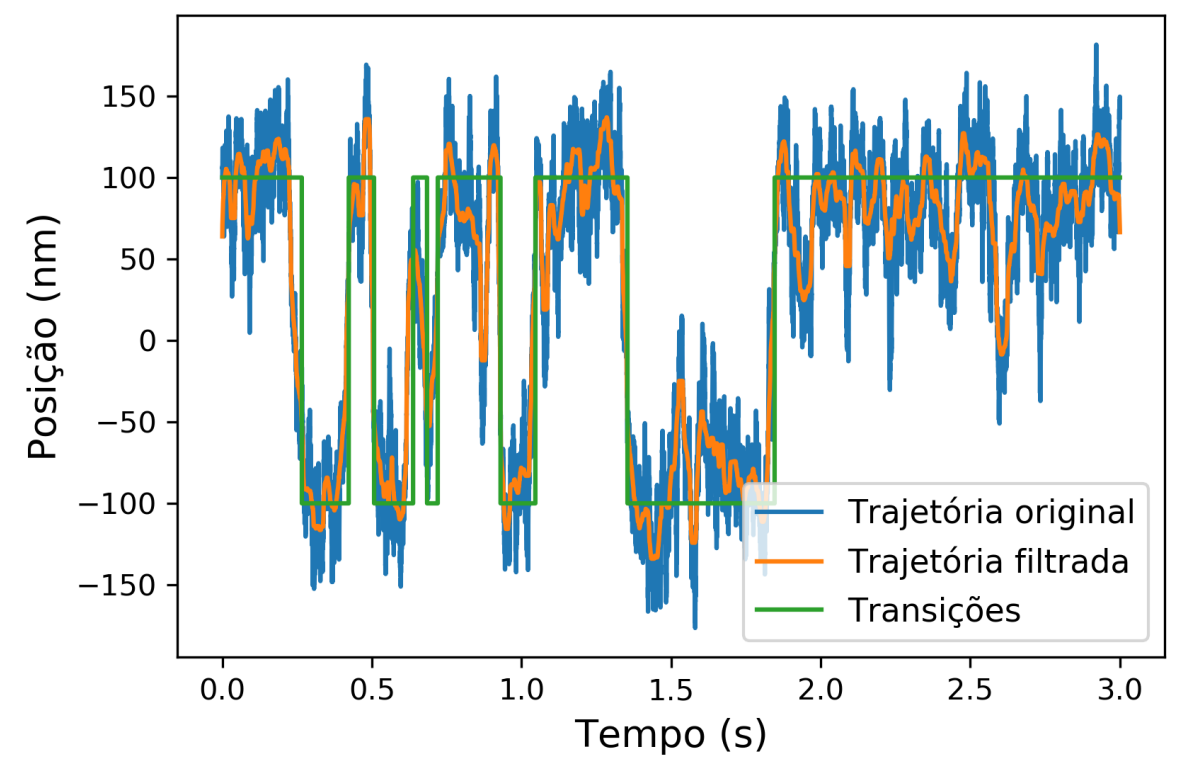

Figura 22 - Trajetória simulada por $t_{T}=3 \mathrm{~s}$ para $\kappa_{x}=1 \mathrm{pN} / \mu \mathrm{m}$ e $A=100 \mathrm{~nm}$. As barras de erro são menores que o tamanho do símbolo de cada ponto.

Fonte: Elaborada pela autora.

Além disso, também é possível calcular o número de transições entre os poços. Para isso, foi aplicado um filtro para suavizar a trajetória da partícula e definida uma condição para transição.

Sendo escolhido um valor inicial para a posição da partícula de $x_{0}=A$, enquanto a condição $x_{i}>-0.5 A$ for satisfeita para um instante posterior, podemos assumir que a partícula está aprisionada no poço positivo (posição de equilíbrio em $x=+A$ ). Quando a posição não obedecer à condição imposta, significa que a partícula transitou para o poço negativo (posição de equilíbrio em $x=-A$ ) e deve obedecer, agora, à condição $x_{i}<0.5 A$. Se a condição não for satisfeita, é assumido que a partícula voltou para o poço positivo e o processo continua.

Para cada instante, foi definido um elemento $d_{i}=A$, quando a trajetória satisfaz a primeira condição e $d_{i}=-A$, quanto a trajetória satisfaz a segunda condição. Um contador foi gerado para identificar as transições de um poço para outro, ou seja, quando $d_{i} \neq d_{i-1}$.

Para análises estatísticas, a escolha do intervalo de tempo $t_{T}$ deve ser suficientemente grande para que a distribuição de probabilidade das partículas em cada poço seja parecida,

๙ Para a análise numérica foi considerada uma micropartícula com as mesmas características apresentadas na Seção 4.1 e uma temperatura de $T=300 \mathrm{~K}$. 
já que a constante de força de cada poço é a mesma. Conforme a Fig. 23, num intervalo maior o potencial se torna mais próximo ao calculado teoricamente. No entanto, temos a curva simulada mais suave que a função definida.

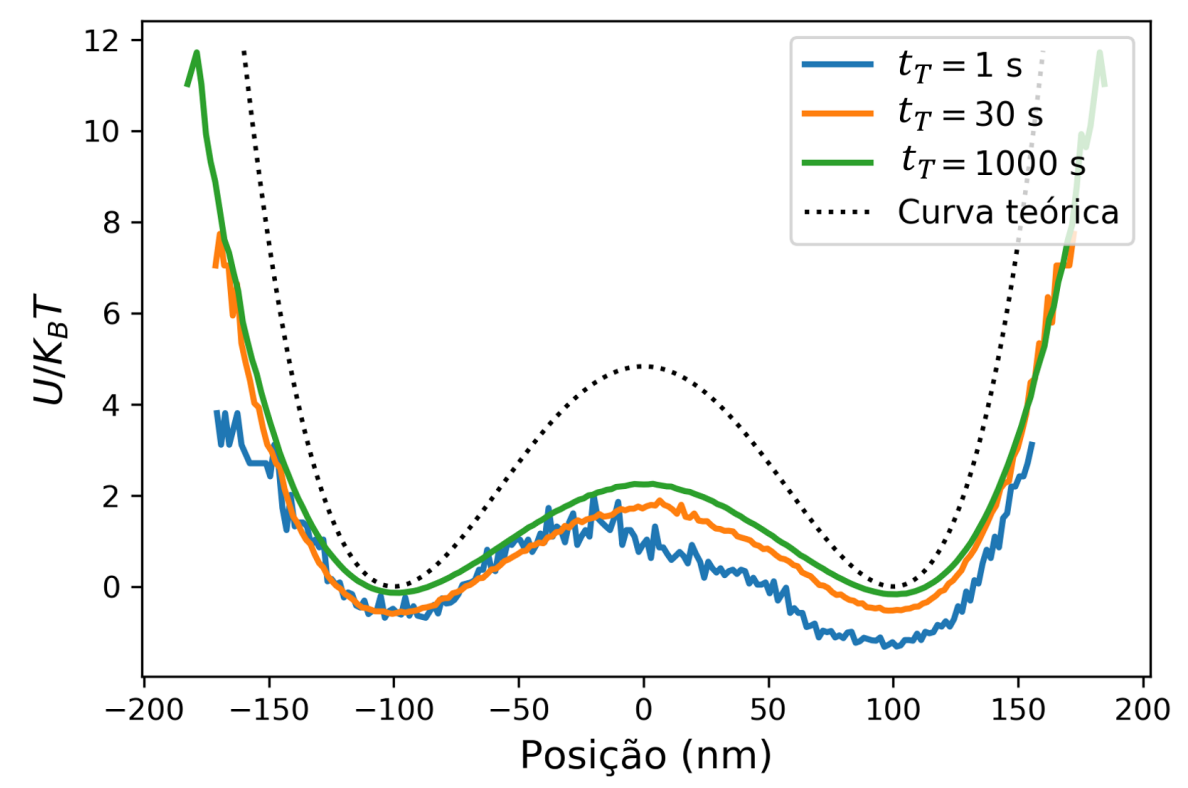

Figura 23 - Curvas de potencial simuladas para $A=100 \mathrm{~nm}$ e $\kappa_{x}=2 \mathrm{pN} / \mu \mathrm{m}$ por intervalos de tempo de $5 \mathrm{~s}, 30 \mathrm{~s}$ e $1000 \mathrm{~s}$.

Fonte: Elaborada pela autora.

Para analisar como o potencial se comporta ao aumentar o valor de $U_{\max }$, são apresentadas as simulações para várias constantes de força na Fig. 24 e para várias distâncias entre poços na Fig. 25.

Para estimar os parâmetros necessários para a existência de transições da partícula no duplo-poço, foi feito um diagrama da variação do número de transições $N_{T}\left(\kappa_{x}, A\right)$ em função da constante de força e da distância entre os poços $(2 A)$. Para isso, 400 trajetórias foram simuladas para um tempo de $t_{T}=20 \mathrm{~s}$. Conforme a Fig. 26, o maior número de transições é obtido para pequenas distâncias e pequenos valores da constante de força. Isso ocorre, pois a energia térmica da partícula é suficiente para vencer a barreira de potencial. Quando a barreira aumenta, o número de transições diminui e, a partir de certos valores $\left(\kappa_{x}, A\right)$, passa a ser zero, ou seja, a partícula fica aprisionada no potencial em que foi soltall.

\| O código utilizados para a geração do diagrama $N_{T}\left(\kappa_{x}, A\right)$ se encontra no Apêndice H. 


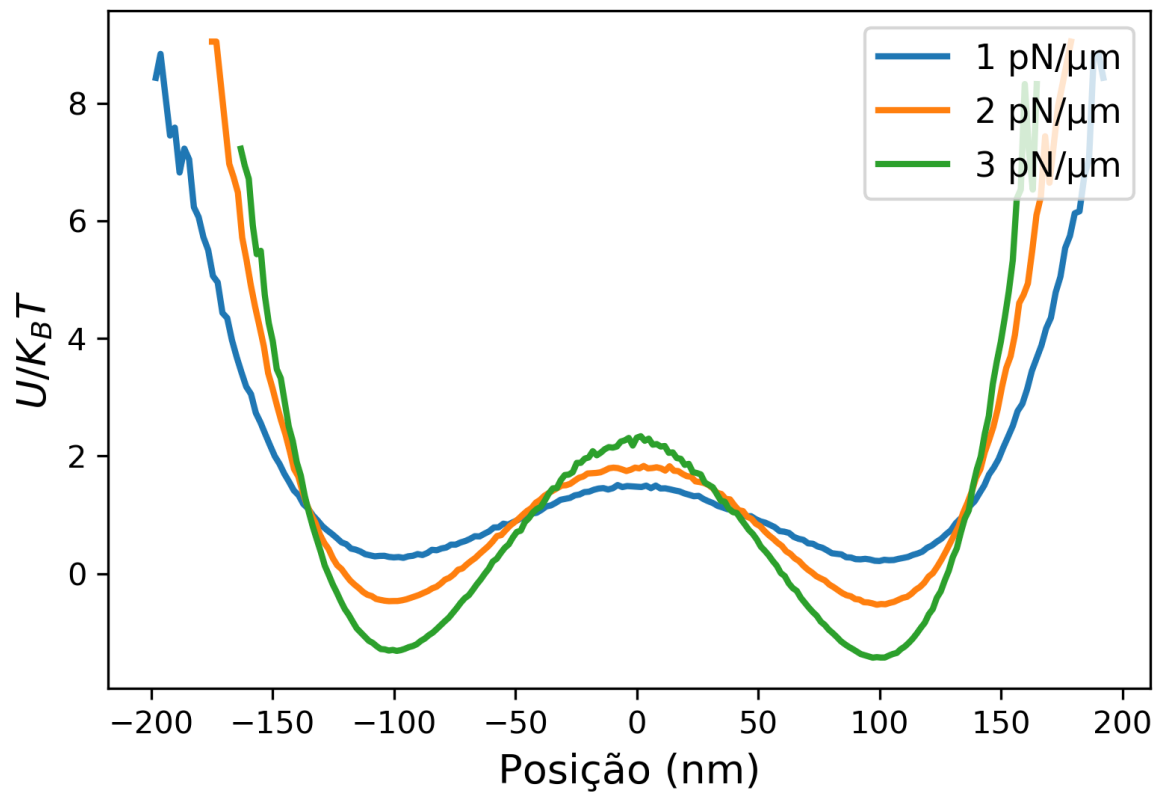

Figura 24 - Curvas de potencial simuladas para $A=100 \mathrm{~nm}$ e $t_{T}=100 \mathrm{~s}$ para as constantes de força $1 \mathrm{pN} / \mu \mathrm{m}, 2 \mathrm{pN} / \mu \mathrm{m}$ e $3 \mathrm{pN} / \mu \mathrm{m}$.

Fonte: Elaborada pela autora.

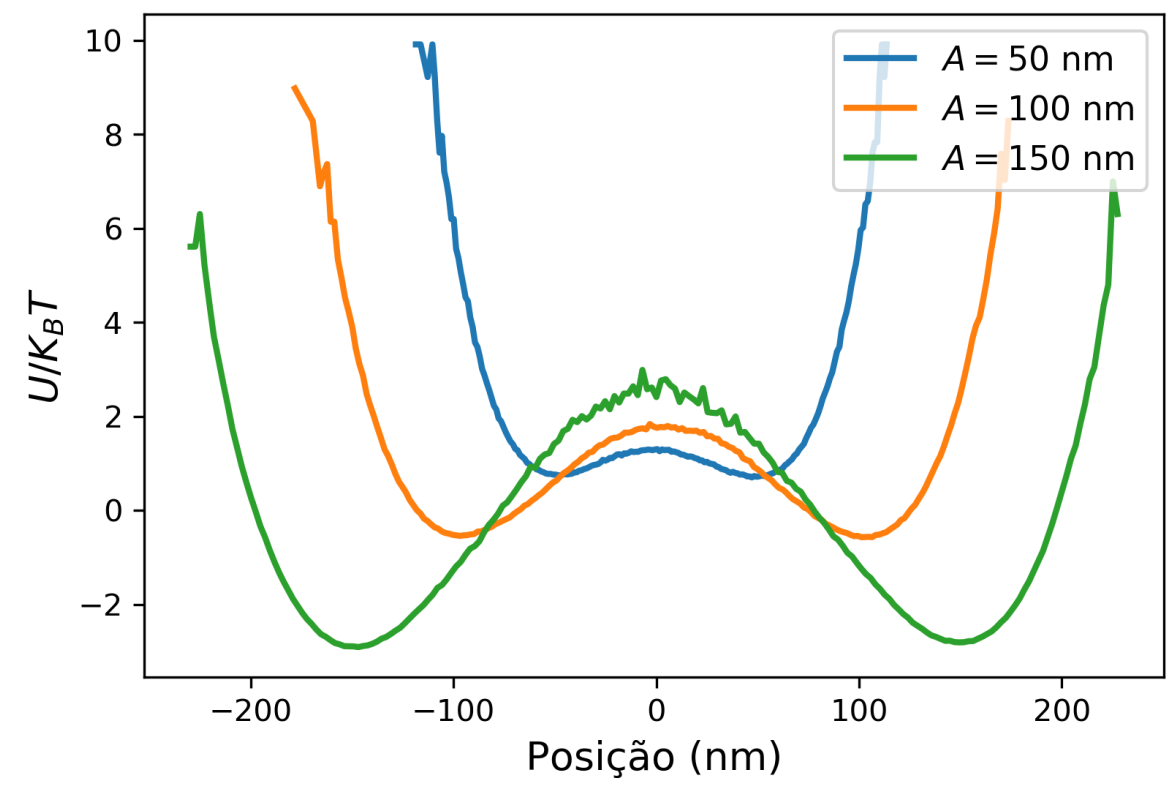

Figura 25 - Curvas de potencial simuladas para $t_{T}=100 \mathrm{~s}$ e $\kappa_{x}=2 \mathrm{pN} / \mu \mathrm{m}$ para as amplitudes $50 \mathrm{~nm}, 100 \mathrm{~nm}$ e $150 \mathrm{~nm}$.

Fonte: Elaborada pela autora. 


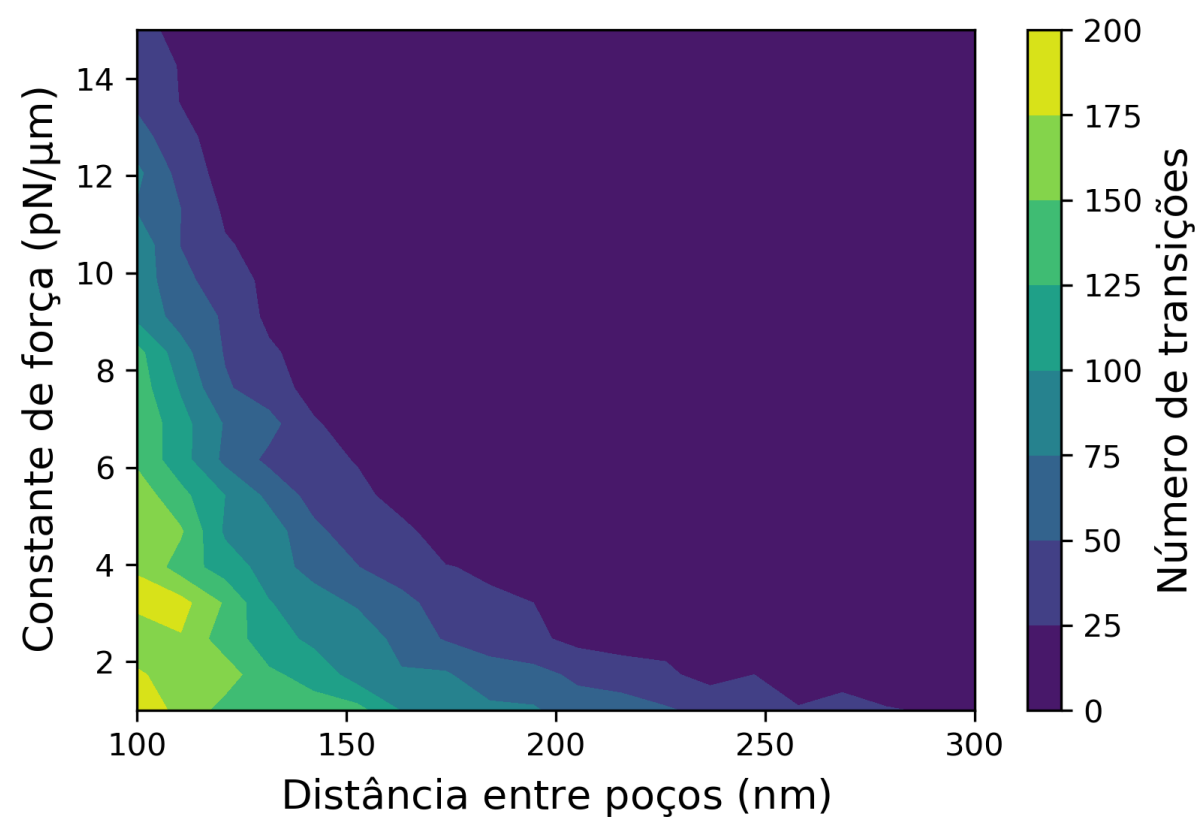

Figura 26 - Diagrama do número de transições em função da constante de força do poço individual e da distância relativa entre poços, $N_{T}\left(\kappa_{x}, A\right)$, para uma temperatura fixa de $T=$ $300 \mathrm{~K}$. Foram simuladas trajetórias para 20 diferentes valores de $\kappa_{x}$ e $A$, por um tempo total de $20 \mathrm{~s}$ cada, com $\Delta t=0.1 \mathrm{~ms}$.

Fonte: Elaborada pela autora. 



\section{SISTEMA EXPERIMENTAL}

Neste capítulo, são apresentados os elementos que compõem o sistema experimental construído durante o mestrado, bem como algumas das calibrações iniciais do sistema.

O esquema da montagem experimental e uma fotografia do aparato são apresentados nas Figs. 27 e 28, respectivamente. O sistema utiliza um laser de diodo na região do infravermelho, acoplado a uma fibra óptica, com comprimento de onda de $\lambda=976 \mathrm{~nm}$ e potência ajustável, para aprisionar as partículas. Um circuito de estabilização de corrente e temperatura foi construído e ajustado para manter a estabilidade de curto prazo da potência do laser numa faixa em torno de $1 \%$, e a estabilidade de longo prazo menor que $5 \%$. A potência total do laser, na saída da fibra, pode ser regulada entre $1 \mathrm{~mW}$ a $50 \mathrm{~mW}$ e a Fig. 29 apresenta a variação na potência deste ao longo de um período de aproximadamente duas horas.

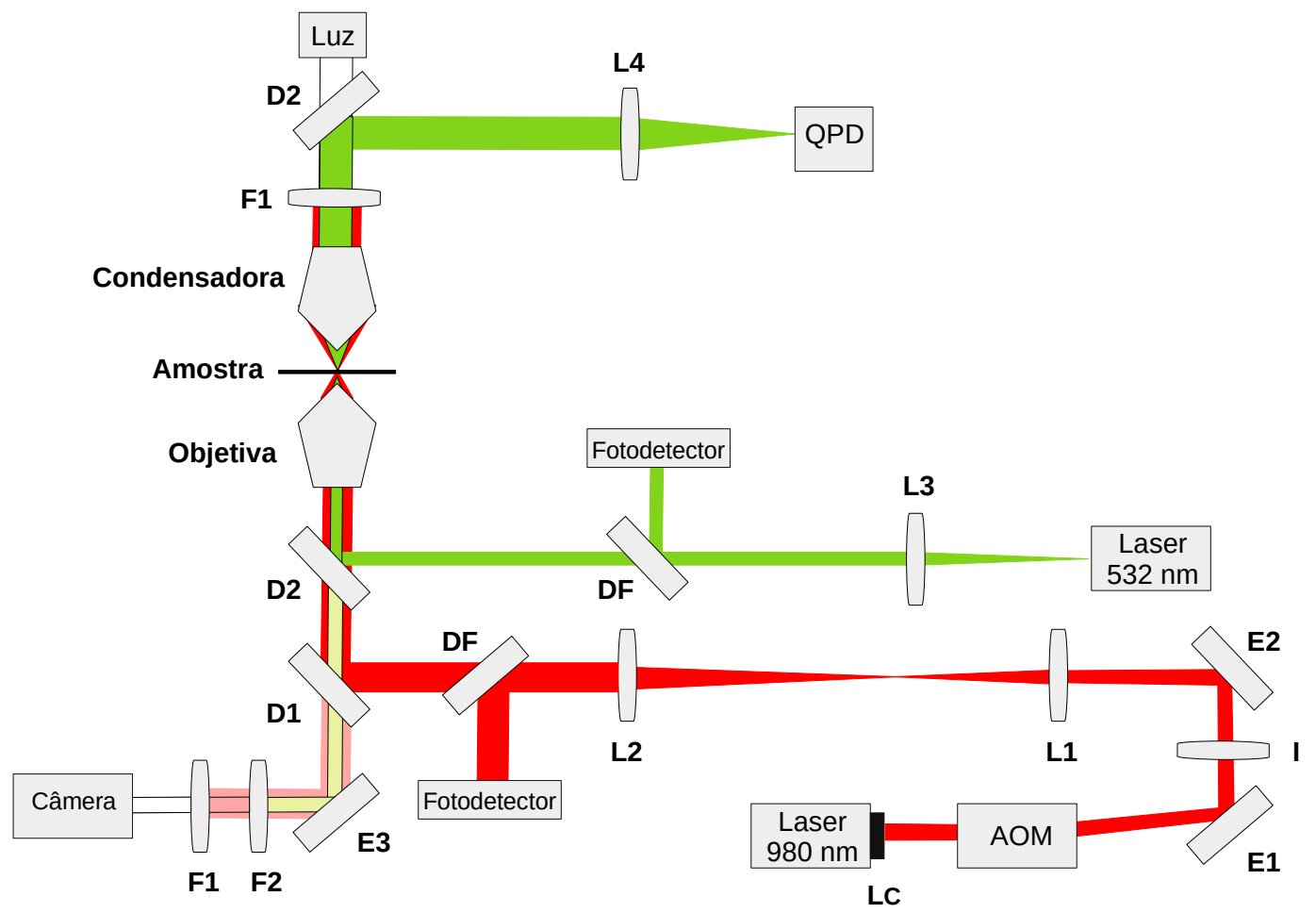

Figura 27 - Esquema da montagem experimental completa com os lasers (infravermelho e verde), lentes (L1-3, LC), espelhos (E1-3), íris (I), divisores de feixe (DF), filtros para o infravermelho (F1) e para o verde (F2), espelhos dicroicos para o infravermelho (D1) e para o verde (D2), objetiva, condensadora, QPD, AOM, fotodetectores e amostra.

Fonte: Elaborada pela autora. 


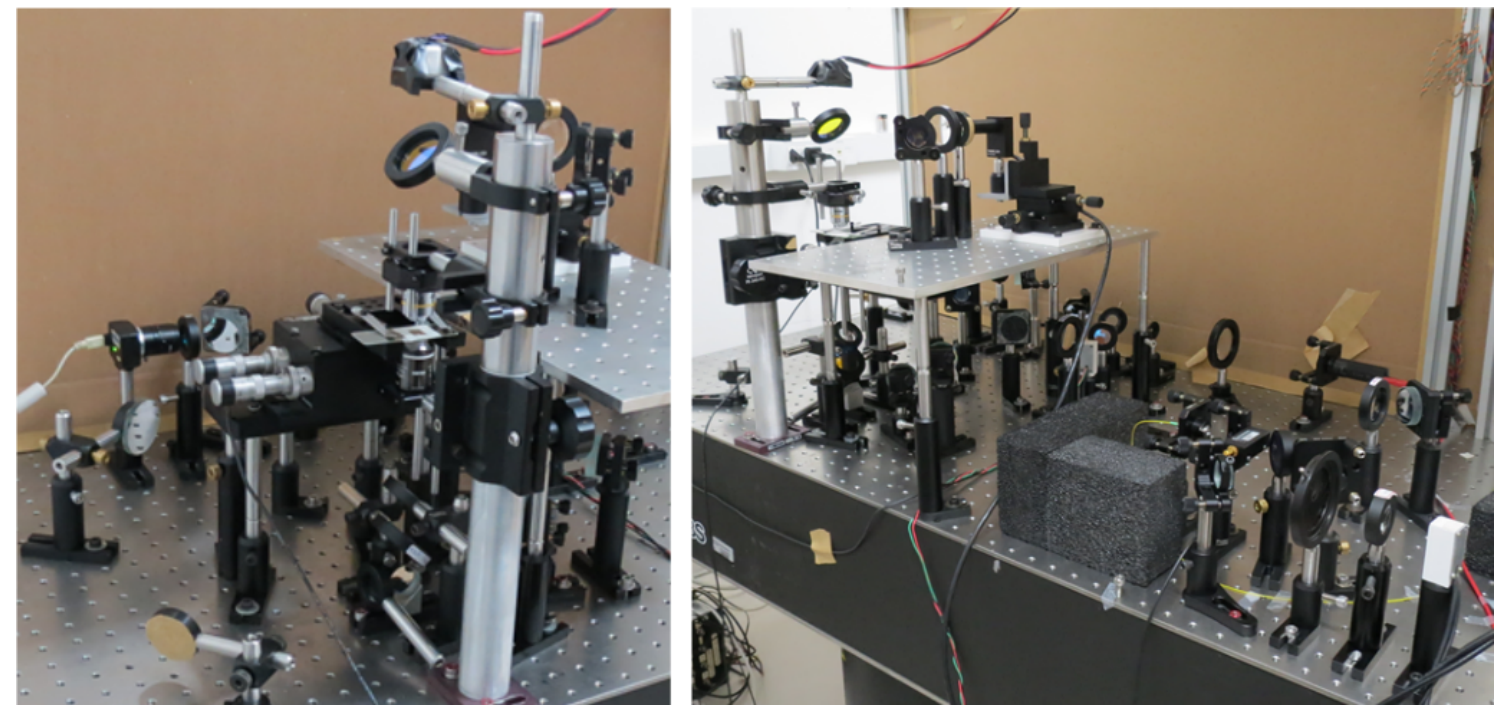

Figura 28 - Fotografias da montagem experimental.

Fonte: Elaborada pela autora.

Uma lente na saída da fibra óptica (LC) é responsável por deixar o feixe aproximadamente colimado e um conjunto de lentes (L1 e L2) é utilizado para ajustar a magnificação e a colimação do feixe.

Para direcionar os feixes do laser no caminho óptico desejado, são utilizados espelhos de alumínio e espelhos dicroicos. O primeiro espelho dicroico (D1) reflete luz infravermelha e transmite luz de comprimentos de onda menores e o segundo espelho dicroico (D2) reflete luz verde e transmite luz de comprimentos de onda maiores.

O feixe do laser que produz o aprisionamento óptico é focalizado com o auxílio de uma objetiva de imersão em óleo de $100 \times$ e com abertura numérica (NA) de 1.30. Inicialmente, para a iluminação da amostra, foi utilizado um LED branco alinhado a uma objetiva (condensadora) de $10 \times$ com abertura numérica de $0.25^{*}$.

Uma câmera CCD simples, modelo Firefly MV USB 2.0, ligada ao computador, foi utilizada para a aquisição de dados. As imagens analisadas são obtidas a partir da iluminação com luz branca, que incide na amostra e é coletada pela objetiva de maior abertura numérica. Filtros para ambos comprimentos de onda (verde e infravermelho) foram utilizados com o objetivo de bloquear a luz dos lasers de aprisionamento e diagnóstico, deixando passar apenas a luz do LED.

Após a calibração inicial do sistema, um modulador acusto-óptico (AOM, do inglês Acousto-Optic Modulator) foi posicionado na saída do laser, com o objetivo de modular a frequência e intensidade do laser. No caso do AOM, a modulação de frequência resulta

* Por simplicidade, a objetiva destinada à iluminação e detecção do movimento da partícula será referida como condensadora. 


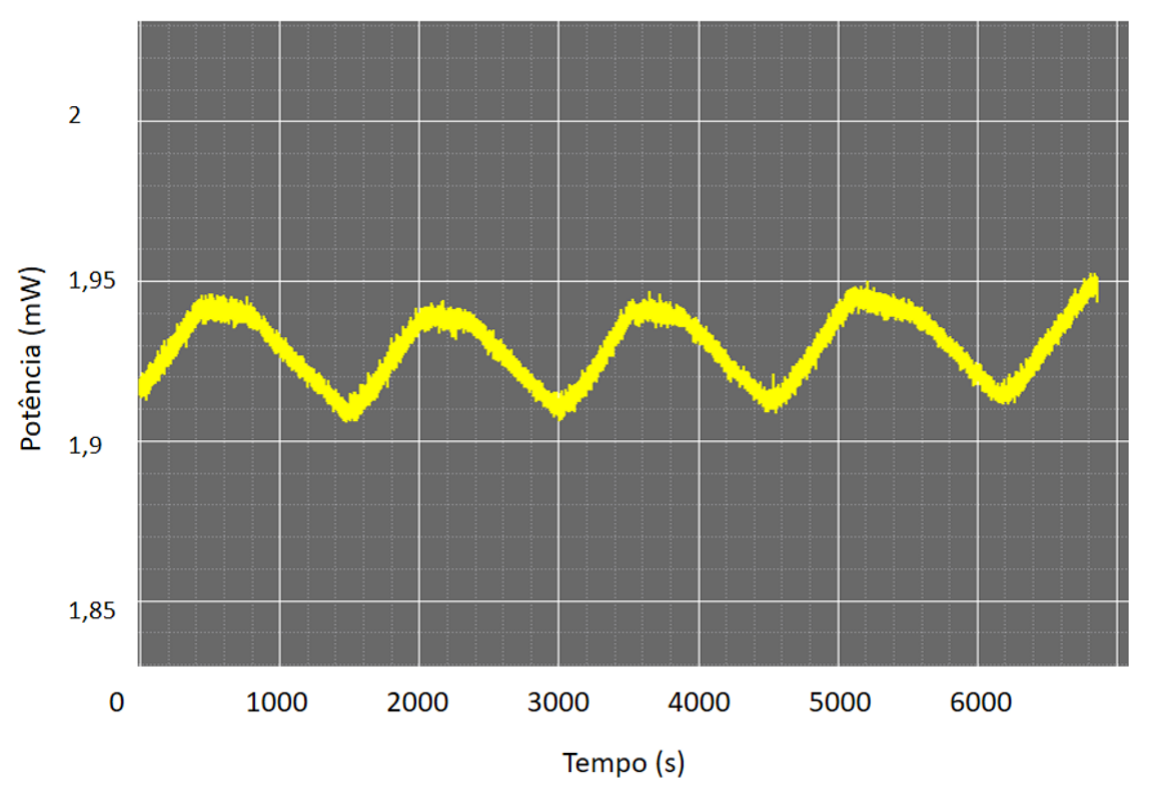

Figura 29 - Potência do laser de infravermelho em função do tempo. A estabilidade de curto prazo é da ordem de $1 \%$ e as variações de longo termo são menores que $5 \%$.

Fonte: Elaborada pela autora.

numa modulação de posição do feixe. O sistema foi alinhado para a primeira ordem de difração e um circuito de controle externo é utilizado para controlar a frequência e a amplitude das ondas acústicas geradas no AOM. O controle é feito com o auxílio de uma placa de aquisição da National Instruments PCI - 6259, manipulada com códigos em Python.

Para aumentar a resolução temporal e espacial do sistema de aquisição de dados, foi posicionado um detector de quadrante (QPD, do inglês quadrant photodetector), da empresa Thorlabs (PDQ80A), após a lente condensadora. Os dados obtidos com o QPD foram coletados com a placa de aquisição já mencionada. Um circuito foi construído para alimentar o QPD e amplificar o sinal de saída do mesmo, conforme a Fig. $30^{\dagger}$.

Um segundo laser, na faixa do visível, com comprimento de onda de $\lambda=532 \mathrm{~nm}$ foi utilizado como fonte de luz para a detecção do movimento das partículas e um circuito de estabilização de corrente foi utilizado para minimizar variações na potência do feixe, que é da ordem de miliwatts. A colimação do mesmo foi feita com o auxílio de uma lente de distância focal de $15 \mathrm{~cm}$.

A lente condensadora é utilizada para a coleta e colimação da luz verde espalhada na amostra e um espelho dicroico (D2) foi acrescentado no sistema, conforme mostra a Fig. 27. Uma lente (L4) de distância focal de $10 \mathrm{~cm}$ é responsável por focalizar a luz verde no

$\left\lceil\quad\right.$ O circuito é capaz de amplificar os sinais em $10,10^{2}, 10^{3}$ ou $10^{4}$ vezes. Capacitores também foram inseridos para filtrar o ruído do sinal. 

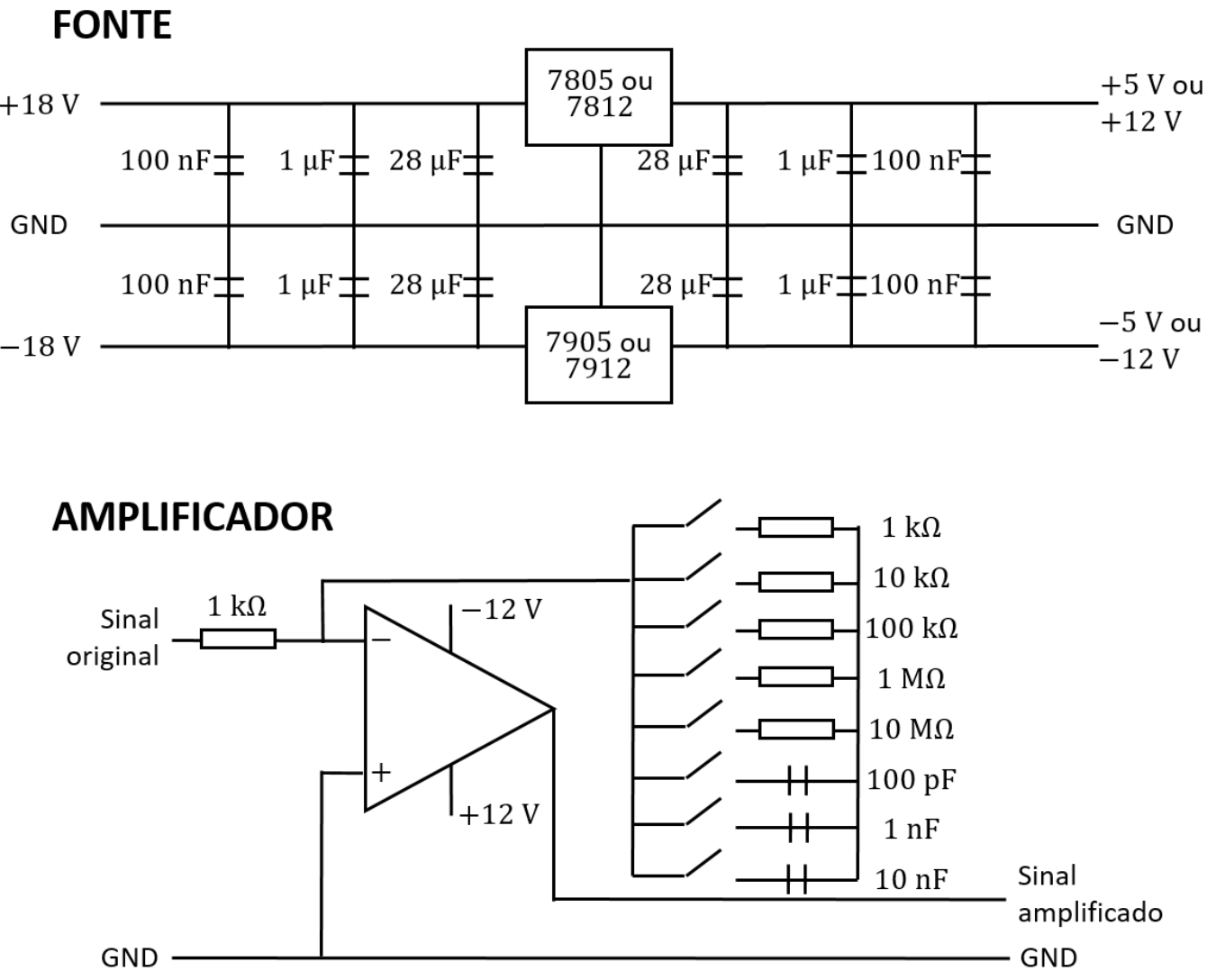

Figura 30 - Fonte de tensão simétrica (em cima) para alimentar o QPD $( \pm 5 \mathrm{~V})$ e o amplificador operacional $( \pm 12 \mathrm{~V})$ e circuito de amplificação do sinal de saída (embaixo).

Fonte: Elaborada pela autora.

centro do QPD e um filtro, similar à F1, foi posicionado para bloquear a luz infravermelha.

Divisores de feixe foram posicionados no caminho óptico para desviar parte da luz em direção dos fotodetectores. Estes foram calibrados, com o auxílio de um perfilador de feixe óptico de varredura de fenda (BP209-VIS), para se obter dados referentes à potência dos dois lasers ${ }^{\ddagger}$. Como a entrada dos fotodetectores é pequena, lentes foram utilizadas para diminuir o diâmetro do feixe de entrada.

Como o aparato foi desenvolvido durante o mestrado, não sendo um equipamento comercial, uma série de calibrações foram feitas a fim de caracterizar o sistema.

Para calibrar a pinça óptica foi utilizada uma amostra comercial da Thorlabs (OTKBTK) de esferas de sílica $\left(\mathrm{SiO}_{2}\right)$ de diâmetro de $2 \mu \mathrm{m}$ e concentração de $2 \mathrm{~g} / \mathrm{mL}$. Além disso, também foram feitas análises com partículas de poliestireno de diâmetro de $1 \mu \mathrm{m}$ e nanotubos de dióxido de titânio $\mathrm{TiO}_{2}$ de diâmetro de $120 \mathrm{~nm}$ e comprimento de

¥ A calibração do fotodetector utilizado para a aquisição de dados referentes à potência do laser infravermelho se encontra no Apêndice C. 
até $4 \mu \mathrm{m}^{\S}$.

\subsection{Calibração do nanoposicionador}

O nanoposicionador utilizado para posicionar a amostra pode ser controlado manualmente ou por meio de um dispositivo piezoelétrico. Para calibrar o deslocamento do controle piezoelétrico em função da tensão aplicada, foi construído um interferômetro de Michelson, conforme a Fig. 31.

Para a construção desse interferômetro foi utilizado o feixe de laser verde, com comprimento de onda $\lambda=532 \mathrm{~nm}$, e um divisor de feixe (DF) responsável por separar a luz em dois caminhos ópticos. O caminho fixo é dado por $r_{f}=2 d_{2}+d_{3}+d_{4}$, sendo $d_{2}$ a distância entre o DF e o espelho fixo, $d_{3}$ a distância entre o DF e o fotodetector e $d_{4}$ entre a fonte de luz e o DF. O caminho variável é dado por: $r_{m}=2 d_{1}+d_{3}+d_{4}$, sendo $d_{1}$ a distância entre o DF e o espelho móvel.

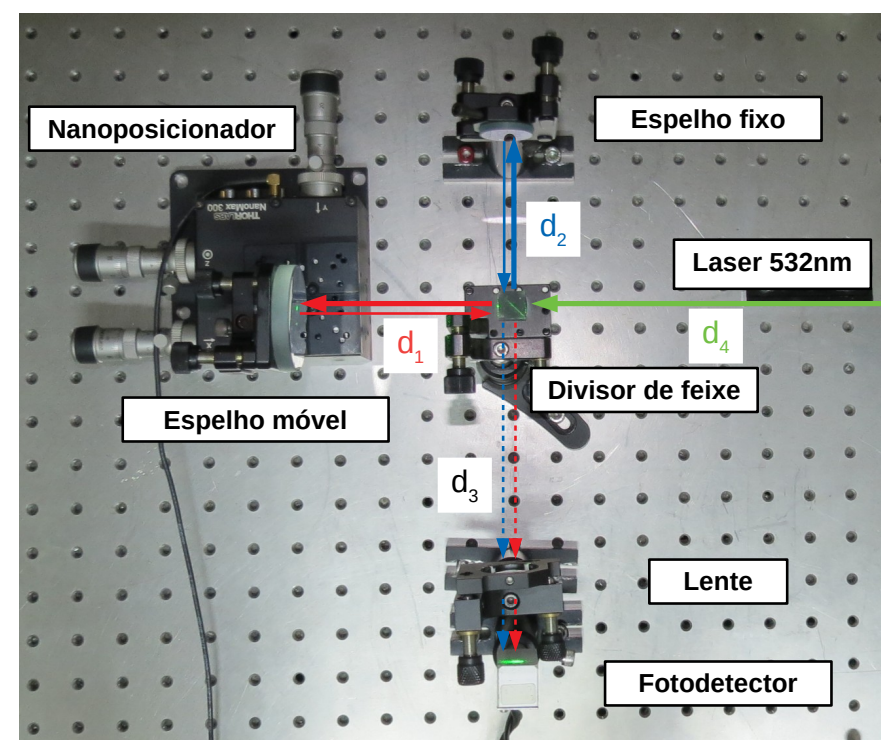

Figura 31 - Interferômetro de Michelson com: um laser verde, um DF, um espelho móvel acoplado ao nanoposicionador, um espelho fixo, uma lente de distância focal de $5 \mathrm{~cm}$ e um fotodetector.

Fonte: Elaborada pela autora.

Conforme apresentado na Fig. 31, o feixe móvel e o feixe fixo serão sobrepostos na entrada do fotodetector. O campo elétrico de cada feixe pode ser obtido a partir da Eq. 2.1

$$
\vec{E}_{f, m}\left(\vec{r}_{f, m}, t\right)=\vec{E}_{f, m, 0} e^{i\left(\vec{k}_{\vec{r}} \vec{r}_{f, m}-w t+\phi_{f, m}\right)},
$$

sendo $k$ o vetor de onda, $\vec{r}$ o caminho óptico, $\phi$ a fase inicial e $\omega$ a frequência angular. Como os dois feixes possuem o vetor de onda paralelo ao caminho óptico e as mesmas

$\S \quad$ Todas as amostras se encontram em meio aquoso. 
fases iniciais, a diferença entre caminhos ópticos gera uma diferença de fase entre as ondas dada por

$$
\delta=k\left(r_{m}-r_{f}\right)=k\left(d_{1}-d_{2}\right)
$$

Considerando que as amplitudes de ambos os campos são iguais a $E_{0}$, podemos calcular a irradiância da sobreposição ${ }^{\llbracket}$ das ondas a partir de $I=\epsilon_{0} c\left|\vec{E}^{2}\right|$ :

$$
\frac{I}{\epsilon_{0} c}=\left|\vec{E}^{2}\right|=2 E_{0}^{2}+2 E_{o} \operatorname{Re}\left[e^{i \delta}\right]=2 E_{0}^{2}(1+\cos \delta)=4 E_{0} \cos ^{2} \frac{\delta}{2}
$$

Para a irradiância ser máxima,

$$
\delta=2 \pi m \Leftrightarrow 2 \Delta d_{\max }=\lambda m
$$

e para a irradiância ser mínima,

$$
\delta=\pi(2 m+1) \Leftrightarrow 2 \Delta d_{\min }=\lambda(m+1 / 2) .
$$

Logo, a diferença entre uma irradiância máxima e uma irradiância mínima adjacente é obtida subtraindo as Eqs. 5.4 e 5.5:

$$
2 \Delta d_{a d j}=\frac{\lambda}{2}
$$

sendo um ponto de máximo uma franja clara e um ponto de mínimo uma franja escura. Desse modo, ao deslocar o espelho móvel uma distância $\lambda / 4$, a irradiância varia entre o valor máximo e o mínimo, permitindo contar o número de franjas no fotodetector. $\mathrm{O}$ deslocamento do espelho em função do número de mudanças entre uma franja clara e uma escura $N$ é dado por (37):

$$
d=N \frac{\lambda}{4}
$$

Para a calibração do deslocamento do piezoelétrico, foi aplicado uma tensão no canal que controla a posição Y do nano-posicionador, com o auxílio da placa de controle analógico". O sinal de controle consiste em uma rampa linear de tensão. Devido à presença de ruído, foram aplicadas 10 rampas de varredura num tempo de $10 \mathrm{~s}$. Simultaneamente à aplicação das rampas, foi coletado o sinal de tensão do fotodetector e o resultado da média feita dessas 10 leituras do sistema é mostrado na Fig. 32.

ף O campo elétrico final $\vec{E}$, composto pela sobreposição de dois campos elétricos, é dado pela soma dos campos $\overrightarrow{E_{f}}$ e $\overrightarrow{E_{m}}$.

॥ O código para a criação do sinal de tensão, coleta do sinal do fotodetector e análise de dados se encontra no Apêndice I. 


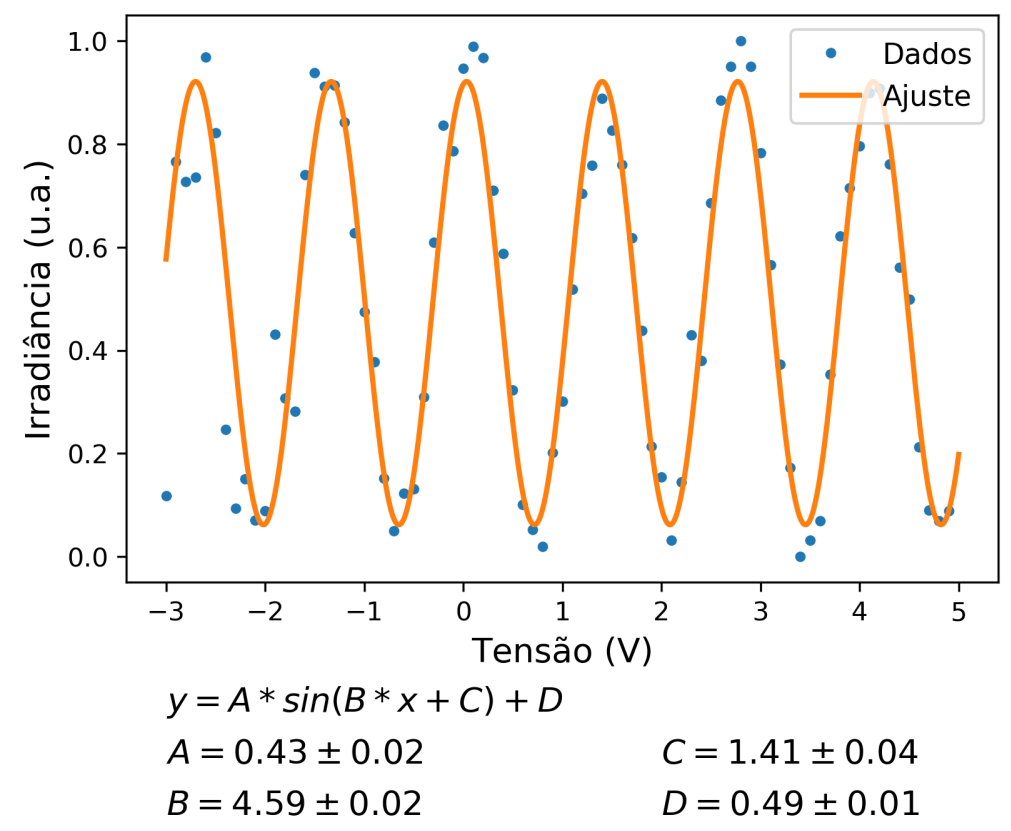

Figura 32 - Intensidade normalizada pela máxima para 10 rampas com 100 pontos cada rampa, $\Delta V=10 \mathrm{~V}$ e $\Delta t=10 \mathrm{~s}$ (média). As barras de erro são menores que o tamanho do símbolo de cada ponto.

Fonte: Elaborada pela autora.

A tensão aplicada no controle do piezoelétrico equivalente à detecção de pontos de máximo, ou mínimo, consecutivos na irradiância, ou seja, um deslocamento de $d=266 \mathrm{~nm}$, é dada por $2 \pi / B$, sendo $B$ um parâmetro de ajuste. Desta forma, a análise dos dados resulta na calibração do controle piezoelétrico na direção Y dada por $(194.4 \pm 0.8) \mathrm{nm} / \mathrm{V}$. É esperado que a calibração no eixo X seja equivalente.

\subsection{Calibração da câmera}

A calibração da câmera mostra a relação entre o deslocamento em pixels e deslocamento em nanômetros. Para isso foi utilizada uma amostra de sílica de diâmetro de $d=2 \mu \mathrm{m}$ presa à lamínula. Com o auxílio do software FlyCap2, um vídeo de $15.21 \mathrm{fps}$ (frames por segundo) foi feito ao aplicar 10 rampas de potencial, com $\Delta V=20 \mathrm{~V}$, de forma análoga à seção anterior**.

Com o auxílio do software ImajeJ, o vídeo foi processado, para minimizar ruídos, e binarizado. A imagem original e aquela obtida após o processamento são mostradas na Fig. 33. Com o auxílio do código em Python (Apêndice J), o CM (centroide) da partícula, destacado na figura, foi calculado para cada frame do vídeo. Uma rotação equivalente a

** O eixo do nano-posicionador no qual foi aplicado o sinal corresponde à direção vertical da câmera. 

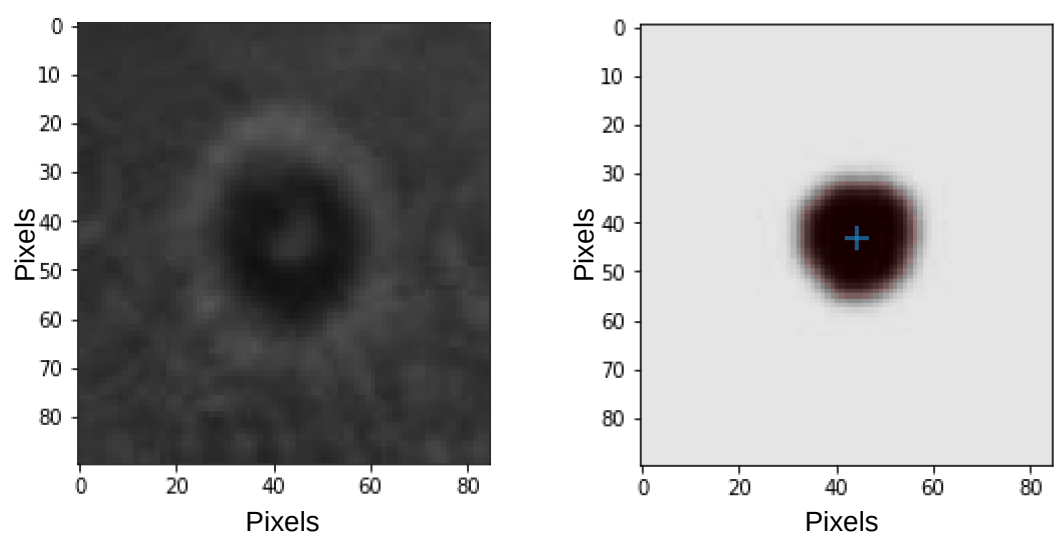

Figura 33 - Imagens de uma partícula de sílica, de diâmetro $d=2 \mu \mathrm{m}$, presa à lamínula antes do processamento (esquerda) e após processamento (direita).

Fonte: Elaborada pela autora.

$\theta_{r}=14.73^{\circ}$ foi feita nas coordenadas de posição do CM de cada frame, pois os eixos da imagem não são coincidentes com os eixos de referência do nanoposicionador ${ }^{\dagger \dagger}$.
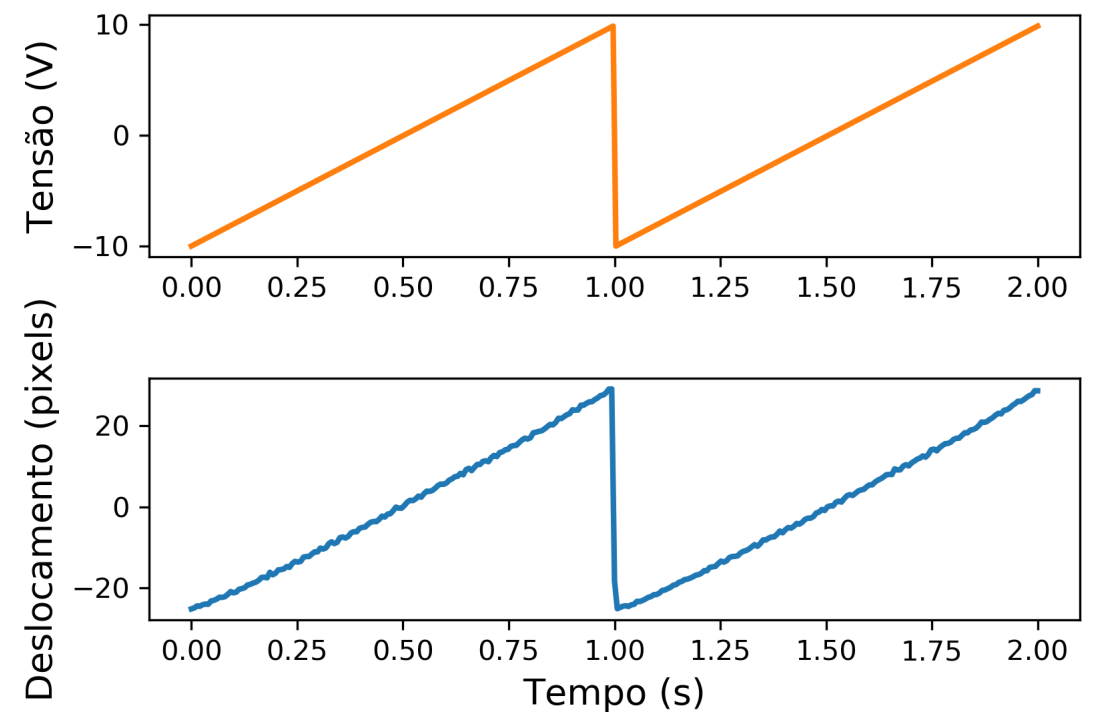

Figura 34 - Sinal aplicado na direção vertical do nanoposicionador, composto por duas rampas de tensão com 100 pontos em cada rampa, (superior) e deslocamento vertical, em pixels, do CM de uma partícula de sílica, coletado com o auxílio da câmera (inferior).

Fonte: Elaborada pela autora.

O deslocamento, em pixels, do CM da partícula, para cada frame, em função do deslocamento aplicado no piezoelétrico do nanoposicionador se encontra na Fig. 35.

$\overline{\dagger \dagger}$ Todo o processo para a obtenção do ângulo de rotação se encontra no Apêndice B. 


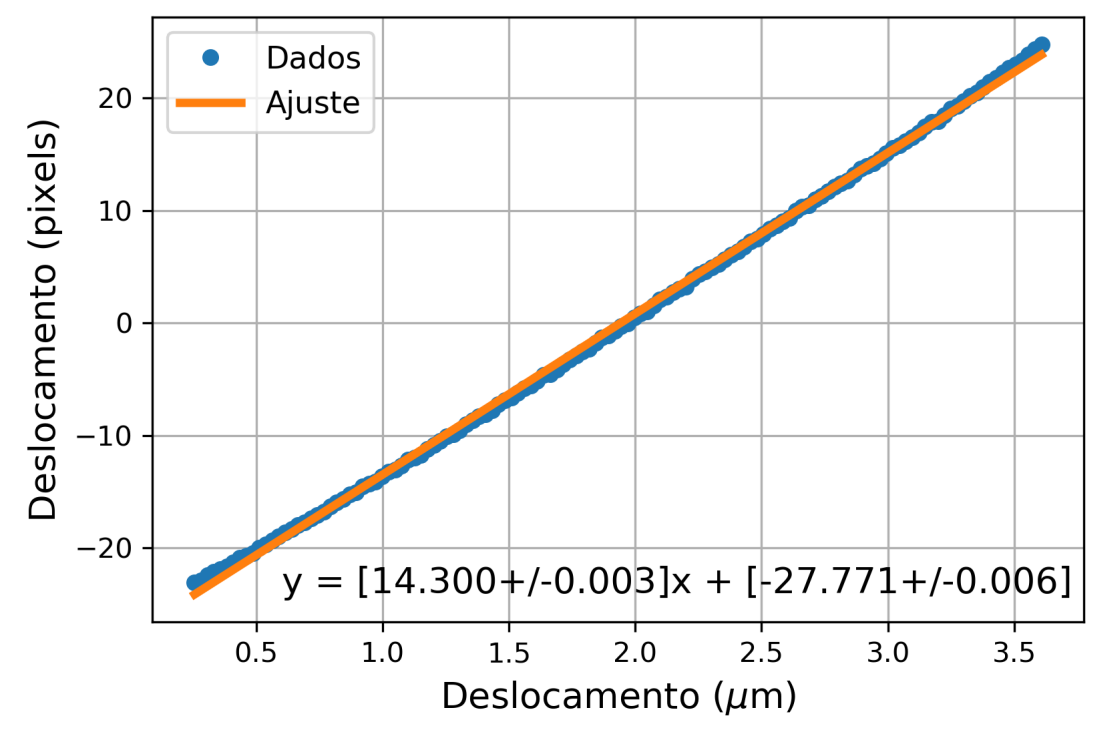

Figura 35 - Deslocamento do CM vertical (y) da partícula em função do deslocamento do piezoelétrico (média). As barras de erro são menores que o tamanho do símbolo de cada ponto.

Fonte: Elaborada pela autora.

A resolução da câmera, dada pelo coeficiente angular $14.300 \pm 0.003$ pixels $/ \mu \mathrm{m}$, é da ordem de um pixel, ou seja $0.070 \mu \mathrm{m} /$ pixel. No entanto, a resolução da posição do CM é consideravelmente maior, sendo possível analisar o movimento da partícula com precisão de nanômetros.

\subsection{Calibração do QPD}

O fotodiodo de quadrantes (QPD) é um conjunto de quatro fotodetectores, montados conforme o esquema apresentado na Fig. 36, que permite detectar, com boa resolução temporal e espacial, pequenos deslocamentos de um feixe laser. Esse equipamento tem um diâmetro de $7.8 \mathrm{~mm}$ e mede com eficiência feixes de diâmetros entre $1 \mathrm{~mm}$ e $3.9 \mathrm{~mm}$. No nosso sistema, a resolução é de 12 bits, logo a tensão de saída é dada por passos $V_{s}=V_{r} / 2^{12}$, sendo $V_{r}$ o intervalo da tensão de entrada. (38)

Para quantificar os sinais associados à posição da partícula, vamos assumir $x_{d}$ e $y_{d}$ como as coordenadas no plano imagem e $I$ a intensidade do campo incidente. A resposta de cada canal de tensão do QPD é dada por (29):

$$
\begin{aligned}
x_{q p d} & =\iint_{x_{d}>0} I\left(x_{d}, y_{d}\right) d x_{d} d y_{d}-\iint_{x_{d}<0} I\left(x_{d}, y_{d}\right) d x_{d} d y_{d} \\
y_{q p d} & =\iint_{y_{d}>0} I\left(x_{d}, y_{d}\right) d x_{d} d y_{d}-\iint_{y_{d}<0} I\left(x_{d}, y_{d}\right) d x_{d} d y_{d} \\
z_{q p d} & =\iint I\left(x_{d}, y_{d}\right) d x_{d} d y_{d}
\end{aligned}
$$




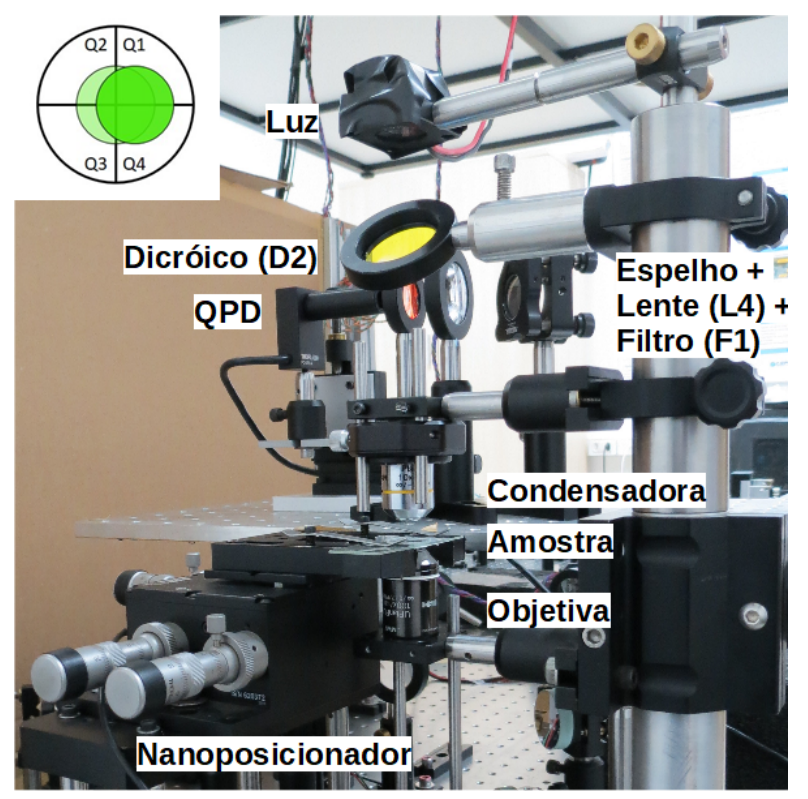

Figura 36 - Montagem experimental de parte do sistema, responsável por detectar a trajetória da partícula aprisionada com o auxílio de um QPD. O fotodetector de quadrante se divide em quatro áreas de detecção (superior em cima): para Q1, temos $x_{d}>0$ e $y_{d}>0$, para Q2 $x_{d}<0$ e $y_{d}>0$, para Q3 $x_{d}<0$ e $y_{d}<0$ e para Q4 $x_{d}>0$ e $y_{d}<0$.

Fonte: Elaborada pela autora.

Como o sinal do QPD é dado em unidades de tensão (V), foi feita uma calibração do mesmo, com o auxílio do nanoposicionador e de uma partícula de sílica de diâmetro $d=2 \mu \mathrm{m}$ presa à lamínula, sendo que a mesma estava em solução aquosa.

Novamente, foi aplicado uma rampa de potencial de $-10 \mathrm{~V}$ a $10 \mathrm{~V}$, similar à usada nas demais calibrações. Devido à presença de ruído, foram aplicadas 10 rampas de potencial num tempo de $10 \mathrm{~s}$. Simultaneamente à aplicação das rampas, foi coletado o sinal de tensão para os eixos $x_{Q P D}$ e $y_{Q P D}$ do QPD. Na Fig. 37 são apresentadas duas, das dez rampas de tensão aplicadas, juntamente com o sinal original de tensão para $x_{Q P D}$ e $y_{Q P D}$.

De modo análogo à imagem obtida com a câmera, os eixos do QPD também apresentaram um ângulo em direção à vertical do sistema de referência diferente de zero. Esse ângulo foi calculado para a zona de linearidade do QPD, de forma análoga ao apresentado no Apêndice B, conforme a Fig. 38. O valor obtido foi de $\theta=180 / \pi \arctan (m)=66.1^{\circ} \pm 0.3^{\circ}$. Desse modo, em todo o conjunto de dados, foi aplicado uma rotação $\theta$ para os valores de $x_{Q P D}$ e $y_{Q P D}$ (Apêndice B).

Após aplicar a rotação, o deslocamento médio do conjunto de dez rampas obtidas foi calculado. Conforme a Fig. 39, para deslocamentos da ordem do raio da partícula, o sinal de resposta do QPD tem comportamento linear. Desse modo, a calibração do QPD é 

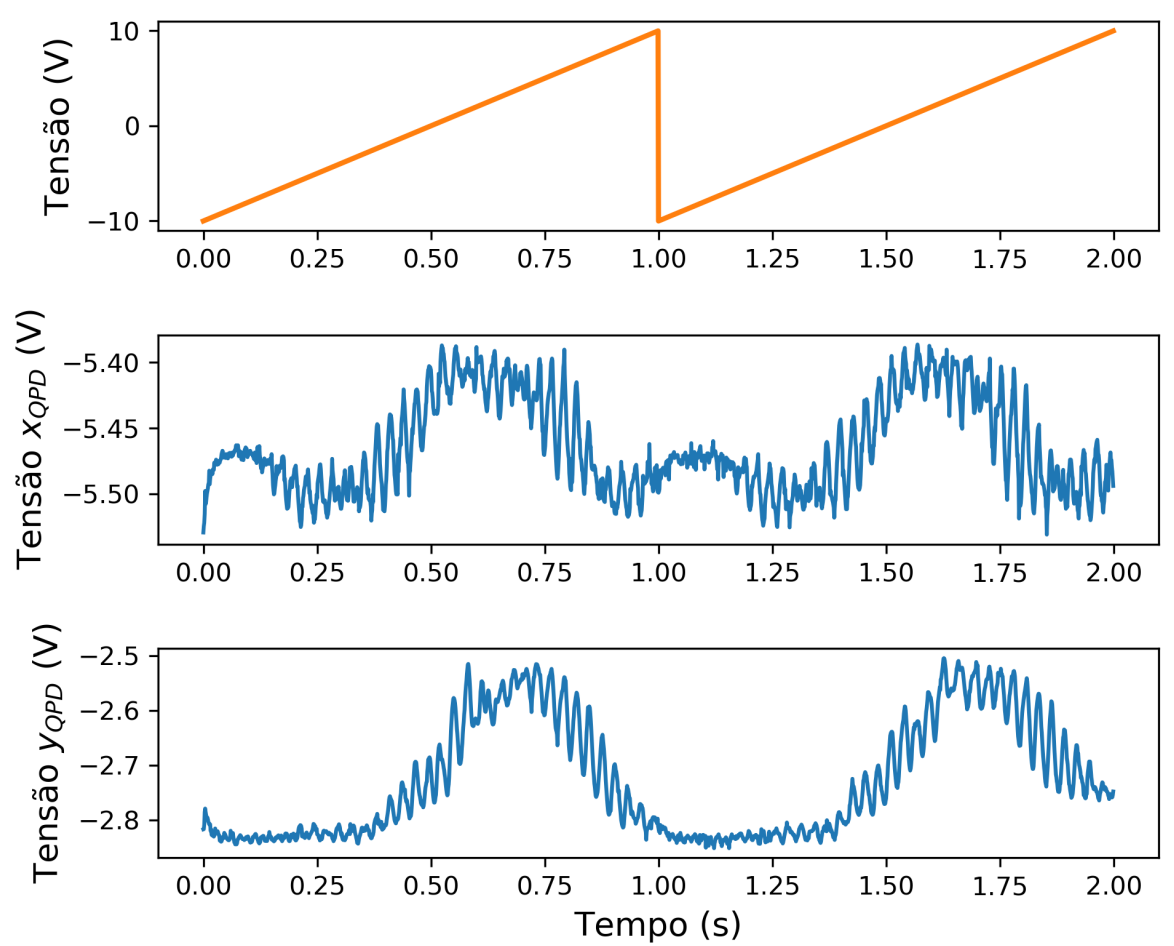

Figura 37 - Sinal aplicado à direção horizontal do nanoposicionador composto por duas rampas de tensão com 100 pontos em cada rampa (superior) e tensão de resposta do QPD em $x_{Q P D}$ e $y_{Q P D}$ (inferior).

Fonte: Elaborada pela autora.

dada pelo coeficiente angular $(0.280 \pm 0.002) \mathrm{V} / \mu \mathrm{m}$.

Para o estudo da dinâmica da partícula aprisionada com o QPD são coletados dados contendo os sinais de resposta do QPD em $x_{Q P D}$ e $y_{Q P D}$, além da variação da potência do laser infravermelho e da potência do laser verde no tempo de coleta, com o auxílio dos fotodetectores ${ }^{\ddagger \ddagger}$. O QPD possibilita o estudo da dinâmica de partículas em um tempo muito pequeno, pois a taxa de aquisição pode chegar a $150 \mathrm{kHz}$. No entanto, foi fixada uma taxa de $15 \mathrm{kHz}$, pelo intervalo de tempo $d t=66.7 \mu$ s ser suficientemente pequeno para os estudos propostos neste trabalho.

¥¥ Foi utilizado um código em Python, similar ao apresentado no Apêndice I, para a coleta de dados do QPD (parte destinada ao controle e detecção de sinal). No entanto, foi feita uma pequena modificação na linha 41 , acrescentando mais canais de leitura. 


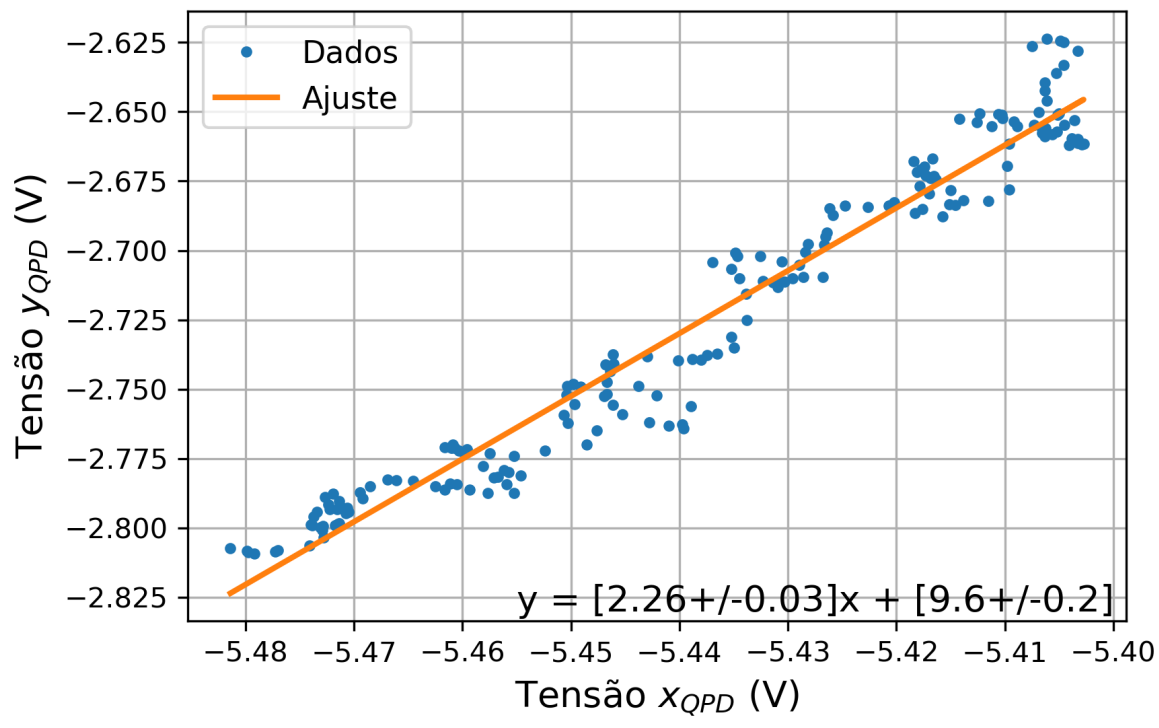

Figura 38 - Sinal de tensão de saída do QPD que representa deslocamento do CM da partícula no plano $x y$ ao aplicar uma rampa de tensão de $-10 \mathrm{~V}$ a $10 \mathrm{~V}$ no canal do nanoposicionador. As barras de erro são menores que o tamanho do símbolo de cada ponto.

Fonte: Elaborada pela autora.

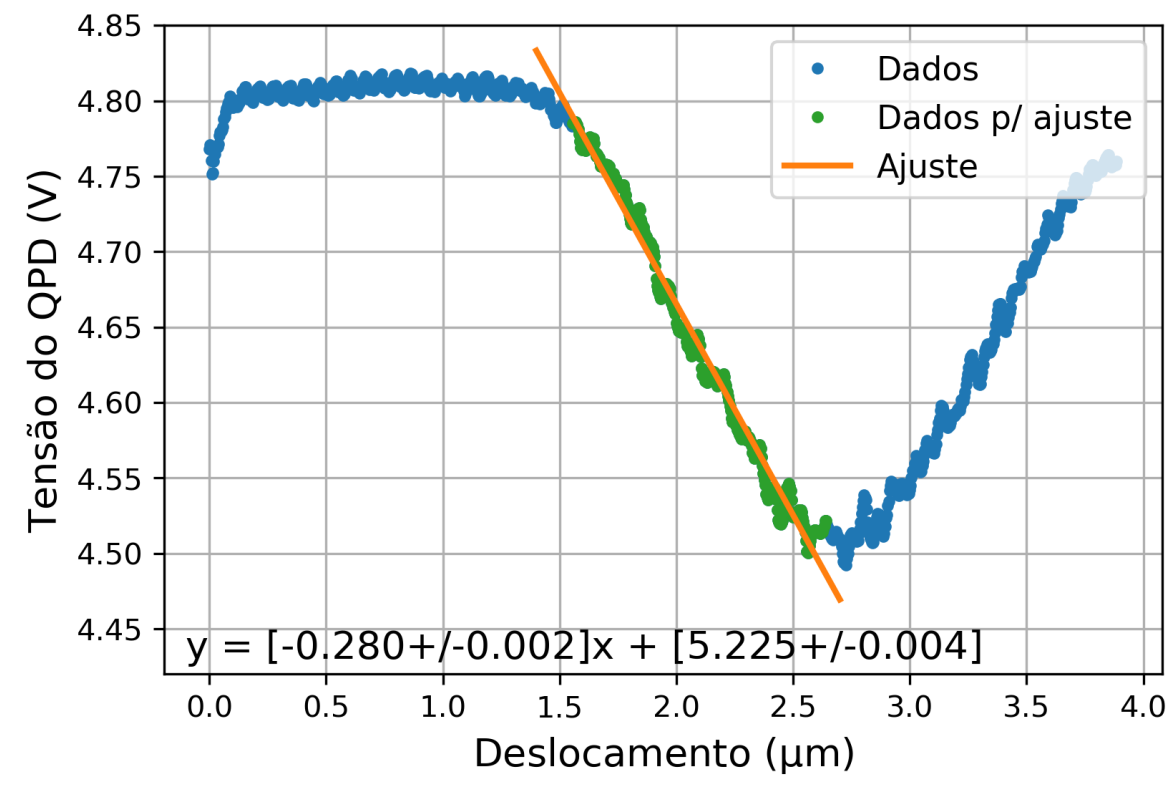

Figura 39 - Calibração do QPD para partícula de sílica de $2 \mu \mathrm{m}$ utilizando um laser verde com potência de $1 \mathrm{~mW}$. As barras de erro são menores que o tamanho do símbolo de cada ponto.

Fonte: Elaborada pela autora. 


\section{PINÇA ÓPTICA SIMPLES}

Neste capítulo, é calculada a constante de força da pinça óptica simples, ou seja, sem o AOM, pelos métodos de equipartição de energia e análise do potencial.

O perfil de intensidade do feixe infravermelho medido antes da objetiva e pouco acima do foco da objetiva são mostrados na Fig. 40. Como esperado, o feixe é aproximadamente gaussiano e simétrico no plano $x y$, com um diâmetro* de $5.40 \pm 0.03 \mathrm{~mm}$, na entrada da objetiva do microscópio.
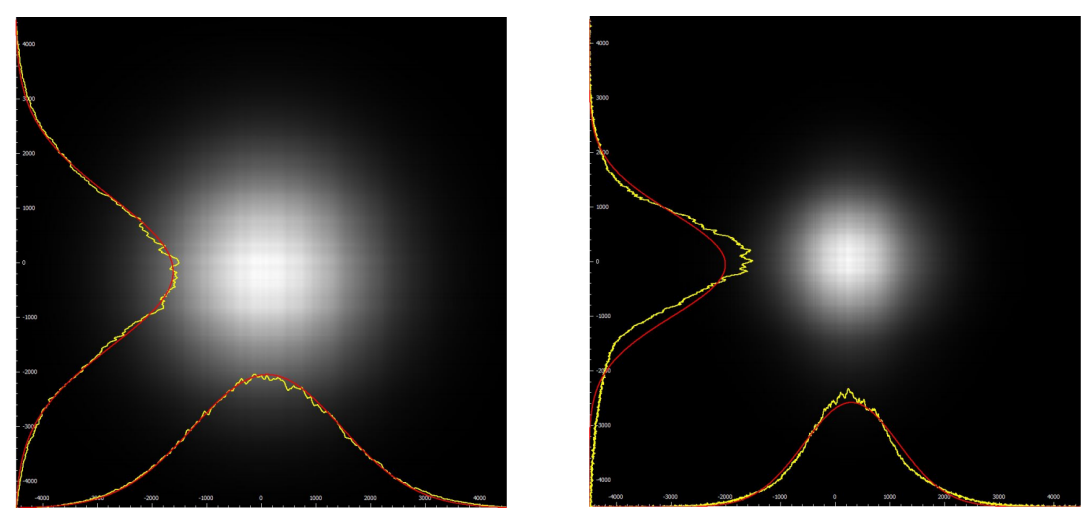

Figura 40 - Perfis normalizados de intensidade do feixe de aprisionamento observados no plano $x y$ : colimado antes da objetiva (esquerda) e divergindo após a objetiva (direita). A medida foi obtida com um perfilador de feixe comercial. O eixo vertical corresponde à direção de aprisionamento $x$ e o horizontal a direção $y$. As curvas em amarelo representam a intensidade do feixe e as curvas em vermelho o ajuste gaussiano.

Fonte: Elaborada pela autora.

Com o auxílio da câmera, foram gravados vídeos de partículas aprisionadas individualmente com 180 fps durante $30 \mathrm{~s}^{\dagger}$. De modo análogo à simulação, foi analisada a posição do CM da partícula $x_{l}$, para cada frame $l$. Embora a força da pinça óptica tenha componentes nas três dimensões, vamos considerar apenas o plano perpendicular ao feixe, composto pelos eixos $x$ e $y$.

A posição do CM de uma partícula de sílica, aprisionada por uma potência de $(2.21 \pm 0.04) \mathrm{mW}^{\ddagger}$, em todos os frames, se encontra na Fig. 41. Podemos perceber que o desvio padrão no eixo $y$ é claramente maior que no eixo $x$. No entanto, isso se deve às vibrações mecânicas do sistema e não à força de aprisionamento óptico, que, para o feixe de laser em questão, deveria ser simétrica no plano.

O diâmetro foi calculado com o auxílio do perfilador de feixe óptico de varredura de fenda.

$\dagger$ O processamento de imagem é similar ao utilizado na calibração da câmera, na Seção 5.2. O código em Python utilizado para analisar os dados se encontra no Apêndice K.

¥ Em todo o trabalho, a potência apresentada se refere à potência que chega na amostra. 


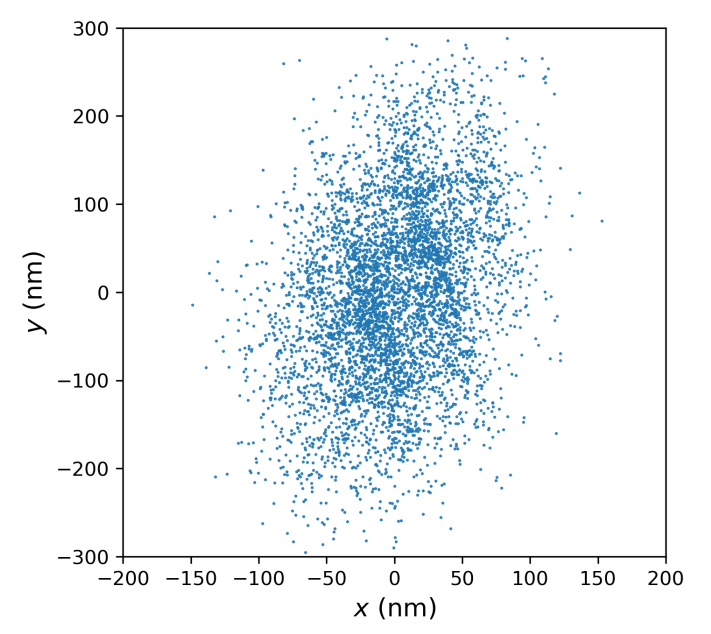

Figura 41 - Posição do CM da partícula de sílica de diâmetro de $2 \mu \mathrm{m}$ aprisionada por uma potência de $(2.21 \pm 0.04) \mathrm{mW}$ no plano perpendicular ao laser.

Fonte: Elaborada pela autora.

Com o laser ligado, a força de aprisionamento restringe o movimento da partícula em torno da posição de equilíbrio. Ao desligar o laser, a partícula deixa de estar confinada e apresenta comportamento similar ao simulado na Seção 4.1 (Fig. 11). Se o laser for novamente ligado, a partícula é atraída para a posição de equilíbrio e volta a ser aprisionada, conforme a Fig. 42. É possível notar que a trajetória média da partícula, desconsiderando as flutuações, no pequeno intervalo de tempo após ligar o laser, tem comportamento exponencial. Essa aproximação será discutida em detalhes na Seção 8.1.

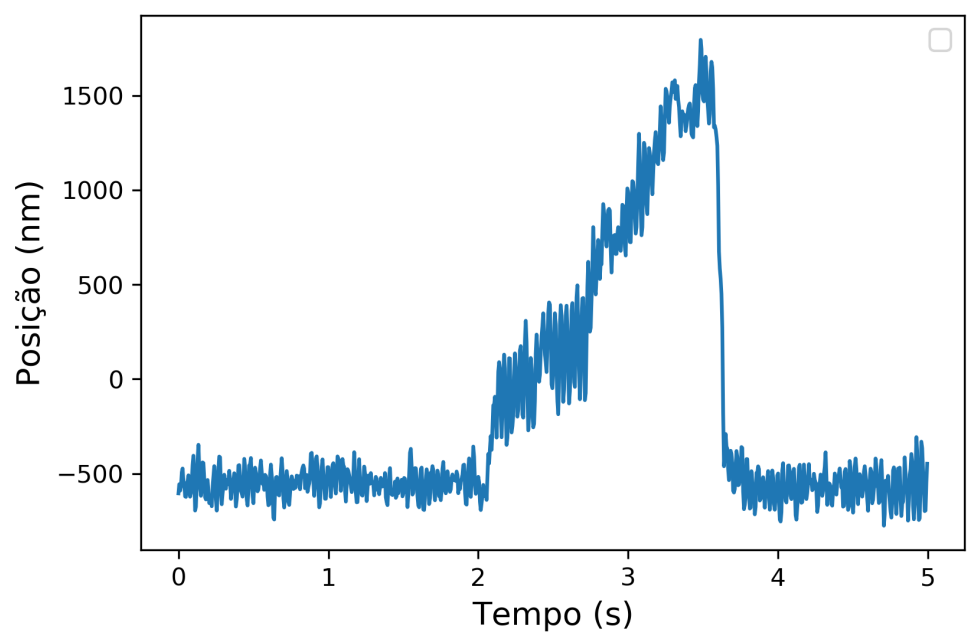

Figura 42 - Posição do CM em função do tempo. Dados para a partícula de sílica com diâmetro de $2 \mu \mathrm{m}$ aprisionada com potência $(2.21 \pm 0.04) \mathrm{mW}$, sendo que o laser é momentaneamente desligado no intervalo de $2 \mathrm{~s}$ a $3.5 \mathrm{~s}$, aproximadamente.

Fonte: Elaborada pela autora. 


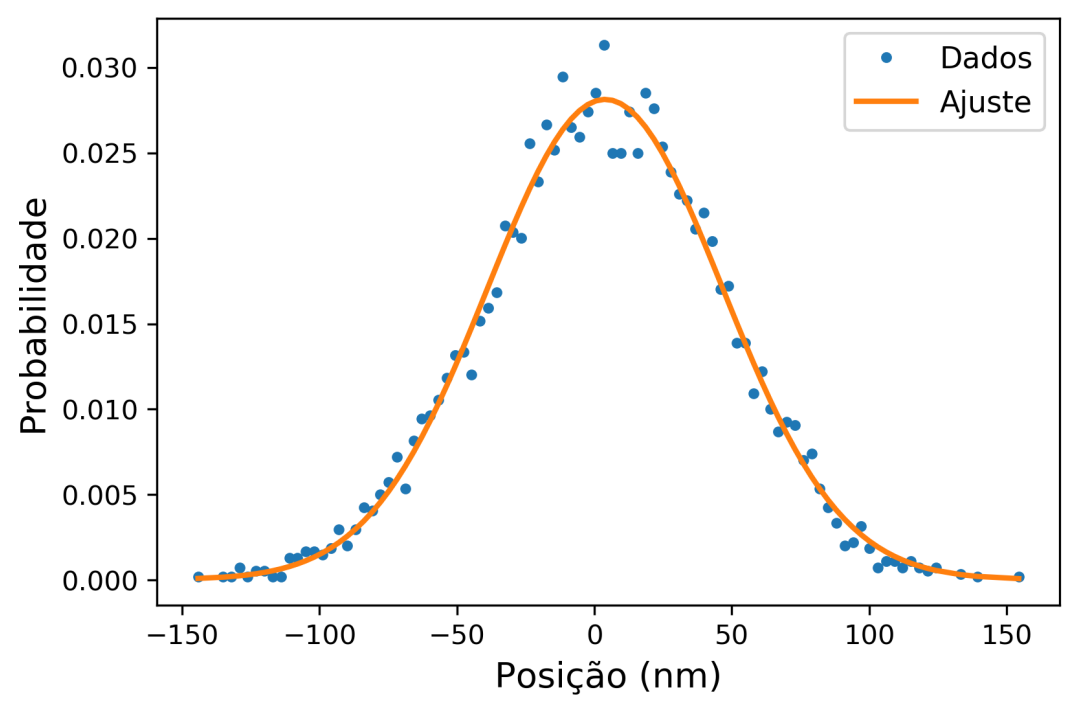

Figura 43 - Histograma de posições $x$ da partícula de sílica de $2 \mu \mathrm{m}$ de diâmetro aprisionada em $(2.21 \pm 0.04) \mathrm{mW}$.

Fonte: Elaborada pela autora.

Ao fazer um histograma normalizado das posições $x_{l}$ da partícula aprisionada, temos a distribuição de probabilidade $\rho(x)$, conforme a Fig. 43. A contagem de posições para cada posição $m$, obedece $(m-1 / 2) \Delta x<x_{l}<(m+1 / 2) \Delta x$, sendo que $\Delta x$ está em torno de nanômetros. Na construção da Fig. 43 foram utilizados 100 bins (divisões do intervalo). A partir da distribuição de probabilidade, pode-se calcular o potencial $U(x)$, que é aproximadamente harmônico em torno do ponto de equilíbrio. Um ajuste polinomial de segundo grau foi feito para calcular a constante de força $\kappa_{x}$.

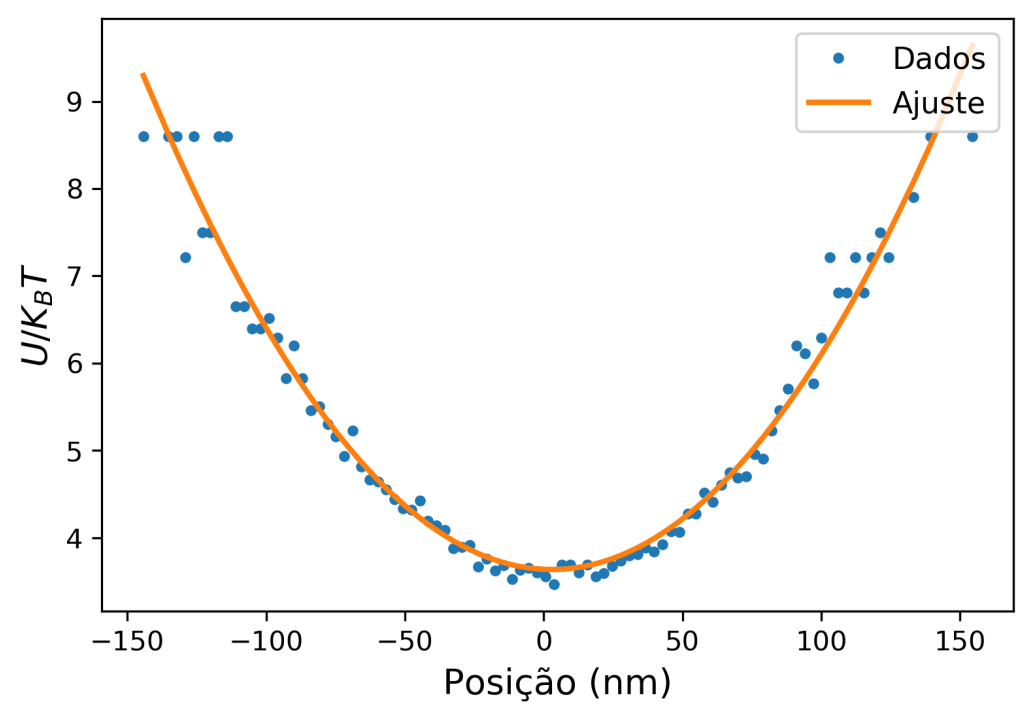

Figura 44 - Potencial na direção $x$ da partícula de sílica de $2 \mu \mathrm{m}$ aprisionada em (2.21 \pm 0.04$) \mathrm{mW}$.

Fonte: Elaborada pela autora. 
O mesmo processo foi repetido para 9 vídeos, obtendo as constantes $\kappa_{x}$ e $\kappa_{y}$. A média dos valores obtidos, juntamente com a incerteza ${ }^{\S}$, foi calculada e o procedimento repetido para várias potências do laser. Os resultados estão resumidos na Fig. 45, onde se pode notar um crescimento linear da constante de força em função da potência do laser. As contantes de força também foram calculadas pelo estudo de equipartição de energia, obtendo valores similares aos obtidos com a análise do potencial. Os dados mostram que a constante $\kappa_{y}$ é consideravelmente menor que $\kappa_{x}$. Esse resultado parece ser influenciado por vibrações mecânicas do sistema experimental (incluindo a mesa óptica) e, em particular, o suporte da amostra no microscópio, que parece ser mais susceptível nessa direção.
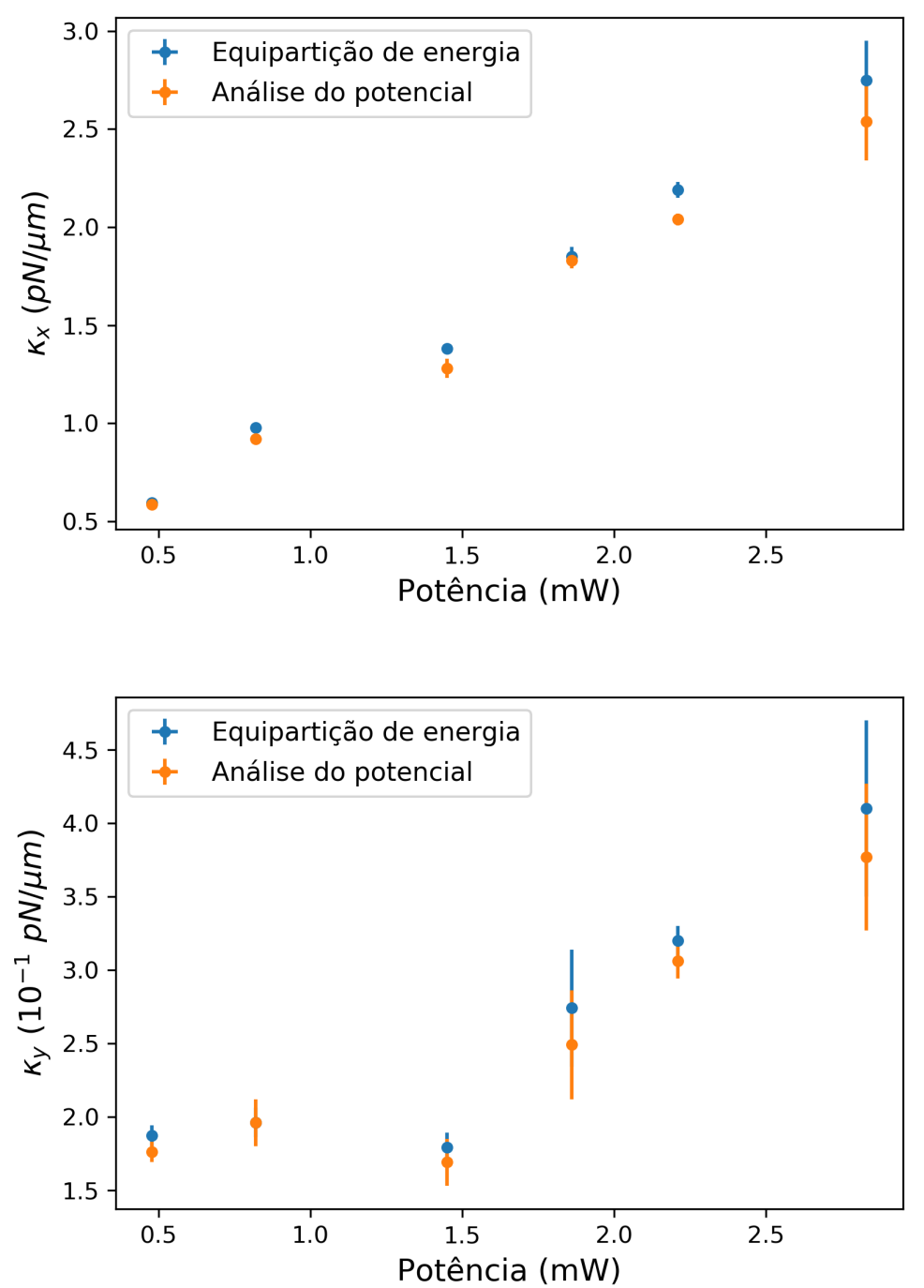

Figura 45 - Constantes de força $\kappa_{x}$ e $\kappa_{y}$, determinadas pelo método de equipartição de energia e pelo método da análise do potencial, em função da potência do laser na amostra, calculadas para uma partícula de sílica de diâmetro de $2 \mu \mathrm{m}$.

Fonte: Elaborada pela autora.

$\S \quad$ A incerteza é dada por $S_{x}=s / \sqrt{n}$, sendo $s$ o desvio padrão e $n$ o número de medidas. 


\section{CARACTERIZAÇÃO DA PINÇA ÓPTICA COM O AOM}

Neste capítulo, são apresentadas as calibrações feitas após inserir o AOM, bem como o procedimento desenvolvido para estabilizar a potência do laser difratado durante a varredura do feixe*.

\subsection{Calibração do AOM}

Um AOM modelo ATM-901A2, da empresa IntraAction, foi adicionado antes da objetiva, com o objetivo de modular o feixe ao longo do eixo $x$ do sistema de referência, conforme ilustra a Fig. 46. Ao aplicar um sinal de radiofrequência ${ }^{\dagger}$ num transdutor piezoelétrico fixado ao cristal do AOM, o mesmo gera ondas acústicas que propagam no material. A onda acústica, por sua vez, produz uma modulação no índice de refração que dá origem à difração da luz que atravessa o cristal do AOM.

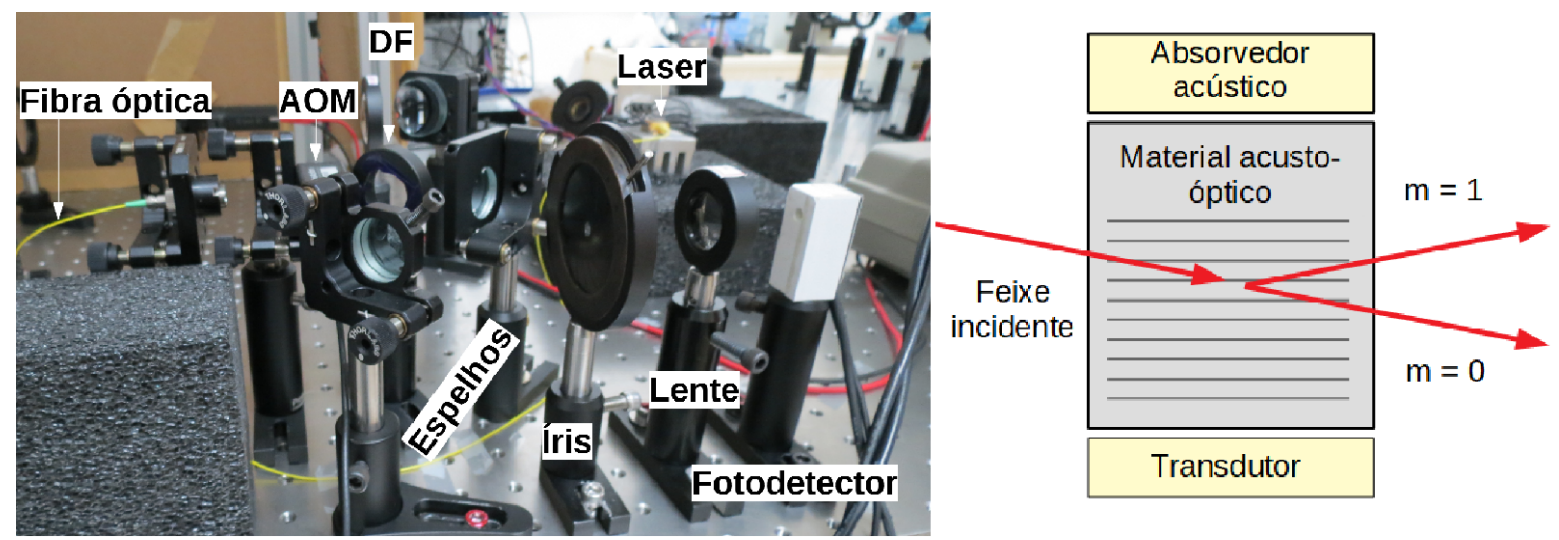

Figura 46 - Partes da montagem experimental, mostrando o laser infravermelho, o AOM e o sistema de detecção da potência do laser (esquerda), e representação de um AOM, constituído por um material acusto óptico e um transdutor piezoelétrico (direita). O sistema é alinhando para máxima eficiência de difração na primeira ordem $m=1$.

Fonte: Elaborada pela autora.

O feixe difratado tem um ângulo $\theta$ relativo ao incidente dado pela relação de Bragg:

$$
2 \Lambda \sin \theta=m \lambda
$$

sendo $\lambda$ o comprimento de luz incidente, $\Lambda$ o comprimento de onda acústica e $m=$ $0, \pm 1, \pm 2, \cdots$ a ordem de difração. Desse modo, ao mudar a frequência do AOM, é possível

* Os códigos utilizados nesta seção se encontram no Apêndice M.

$\dagger$ Um circuito (driver) externo é utilizado para controlar o AOM, gerando e amplificando o sinal de radiofrequência a partir de um uma tensão de controle produzida num dos canais de modulação do computador. 
alterar a posição angular do feixe difratado $(m \neq 0)$ e, consequentemente, a sua posição no plano focal do microscópio.

A relação entre a tensão de controle no canal de modulação da frequência de oscilação do transdutor (CMF) e a frequência correspondente é obtida a partir da curva de calibração apresentada na Fig. 47. O alinhamento foi otimizado para a primeira ordem de difração com uma frequência de $80 \mathrm{MHz}$.

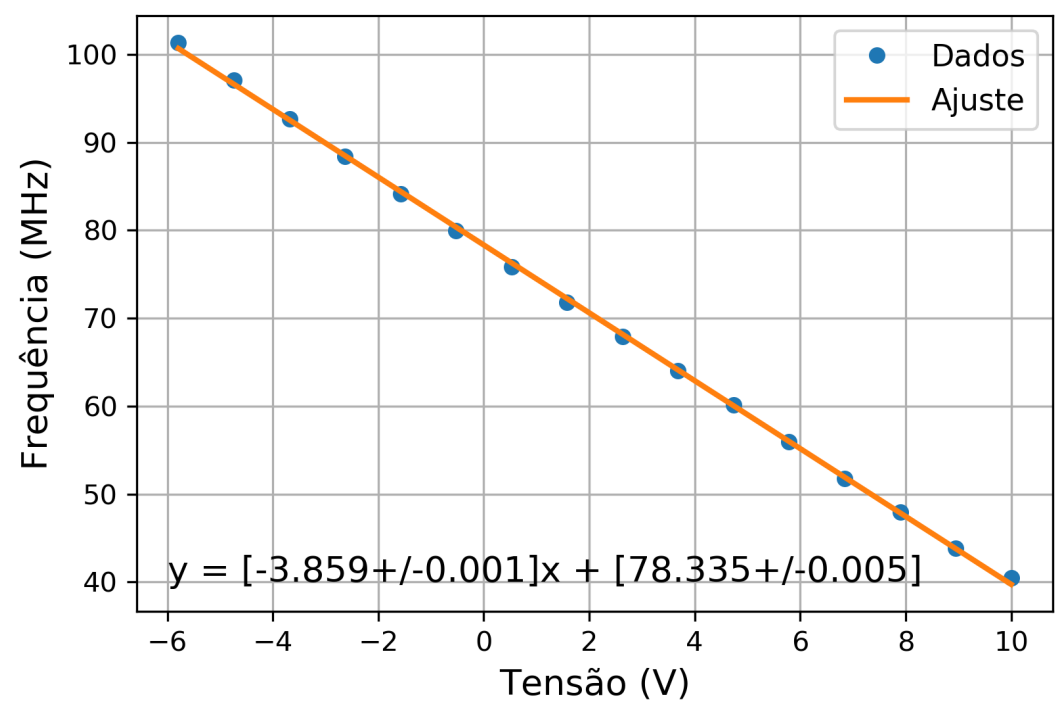

Figura 47 - Frequência da onda acústica no AOM em função da tensão aplicada. As barras de erro são menores que o tamanho do símbolo de cada ponto.

Fonte: Elaborada pela autora.

Uma consequência da modulação da frequência do AOM é a queda da potência de saída do feixe difratado, devido à mudança do alinhamento ótimo dado pela condição de Bragg. Como a constante de força da pinça óptica é proporcional à potência do laser, conforme os resultados da Seção 6, é desejável minimizar esse efeito com o auxílio de um mecanismo automatizado de correção da potência, usando uma função normalizadora, para manter a intensidade do feixe constante durante toda a varredura. Desse modo, foi desenvolvido um sistema de controle com o objetivo de manter a potência constante ao aplicar uma tensão variável no CMF.

\subsection{Controle de estabilização automático de potência do AOM}

Com o auxílio de um fotodetector, foi medida a potência do laser ao aplicar uma rampa de tensão de $-5 \mathrm{~V}$ a $5 \mathrm{~V}$ no CMF, conforme a Fig. 48. Pode-se observar que a potência máxima ocorre para aproximadamente $80 \mathrm{MHz}$, frequência na qual o sistema foi otimizado e, em nenhum intervalo de tensão, a potência permanece a mesma. 


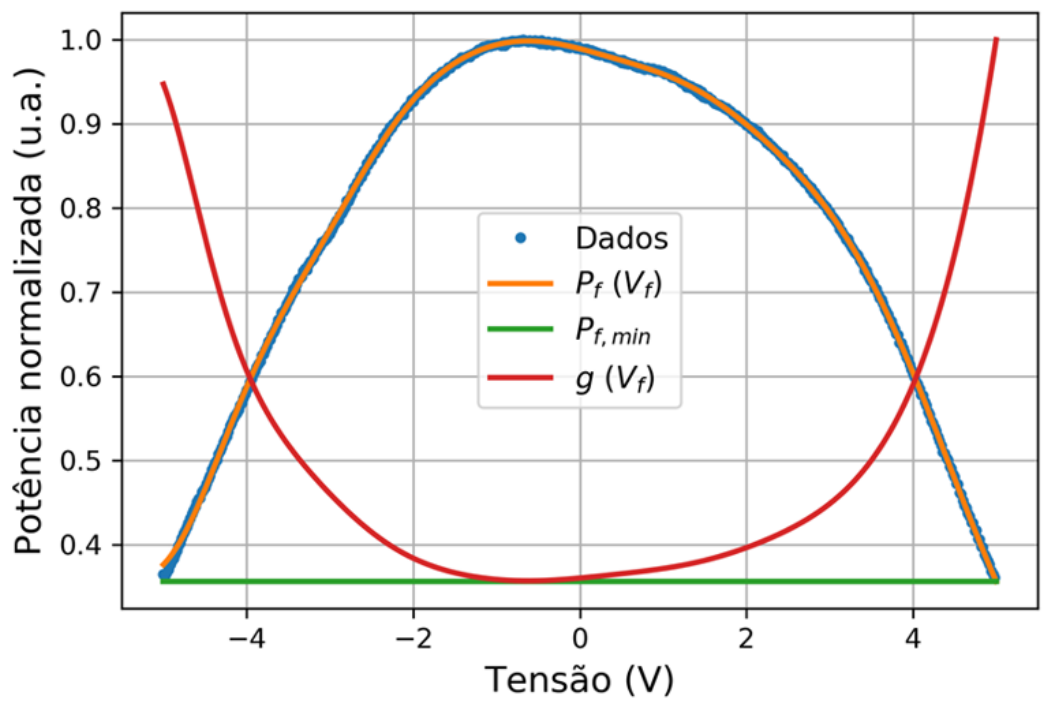

Figura 48 - Potência normalizada do laser como função da tensão de controle no CMF do AOM (azul) e respectivo ajuste polinomial de grau 200 (laranja), função normalizadora da potência (vermelha) e potência mínima (verde).

Fonte: Elaborada pela autora.

A partir da curva da potência $P_{f}$ em função da tensão $V_{f}$, um ajuste polinomial foi feito. Assim, a função normalizadora $g\left(V_{f}\right)$ em termos de $P_{f}\left(V_{f}\right)$ é dada por:

$$
P_{f}\left(V_{f}\right) g\left(V_{f}\right)=P_{f, \min }
$$

sendo $P_{f, \min }$ a potência mínima, para um dado intervalo de tensão.

A função normalizadora $g\left(V_{f}\right)$ é, nesse sistema, a potência resultante $P_{a}$ obtida ao aplicar uma tensão de controle $V_{a}$ no canal de modulação da amplitude da onda acústica (CMA). Para caracterizar a curva de potência $P_{a}\left(V_{a}\right)$, foi aplicada uma rampa de tensão de $-10 \mathrm{~V}$ a $10 \mathrm{~V}$ no CMA. Observou-se uma alteração na potência no intervalo de $-3 \mathrm{~V}$ a $-1 \mathrm{~V}$, conforme a Fig. 49. Desse modo, ao aplicar uma tensão de $-2 \mathrm{~V}$ a $-1.2 \mathrm{~V}$ é possível controlar a potência do feixe no intervalo $P_{a, \min }$ a $P_{a, \max }$.

Como a potência $P_{a}$ é controlada pelo sinal de tensão aplicado ao CMA, a função de estabilização deve ser escrita em termos de $V_{a}\left(P_{f, \min } / P_{f}\left(V_{f}\right)\right)$, sendo necessário calcular a função inversa $V_{a}\left(P_{a}\right)$. Para isso, os eixos foram invertidos e um ajuste polinomial foi feito, conforme a Fig. 50. A partir do ajuste, foram calculados os valores de tensão $V_{a}\left(V_{f}\right)$ a serem aplicados no canal da amplitude, simultaneamente com $V_{f}$, para modular o feixe espacialmente mantendo sua potência estável. Ao aplicar uma rampa de $-5 \mathrm{~V}$ a $5 \mathrm{~V}$ no CMF, por exemplo, é necessário aplicar um sinal de tensão no CMA conforme apresentado na Fig. 51. 


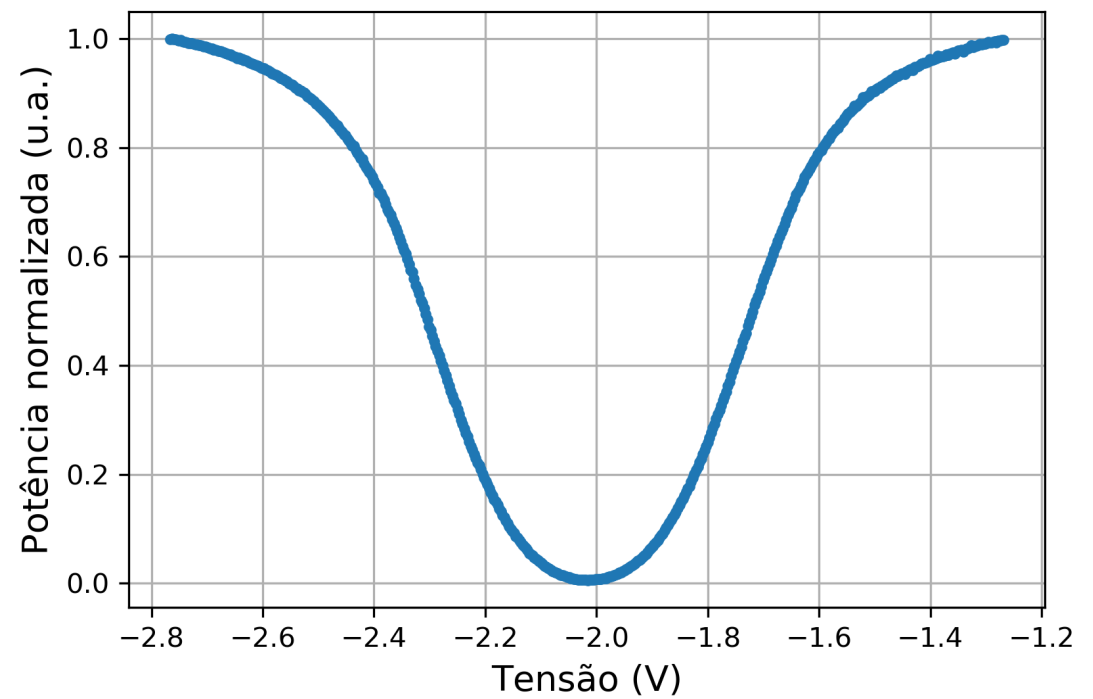

Figura 49 - Potência do laser ao aplicar uma rampa de potencial de $-3 \mathrm{~V}$ a $-1 \mathrm{~V}$ no CMA do AOM.

Fonte: Elaborada pela autora.

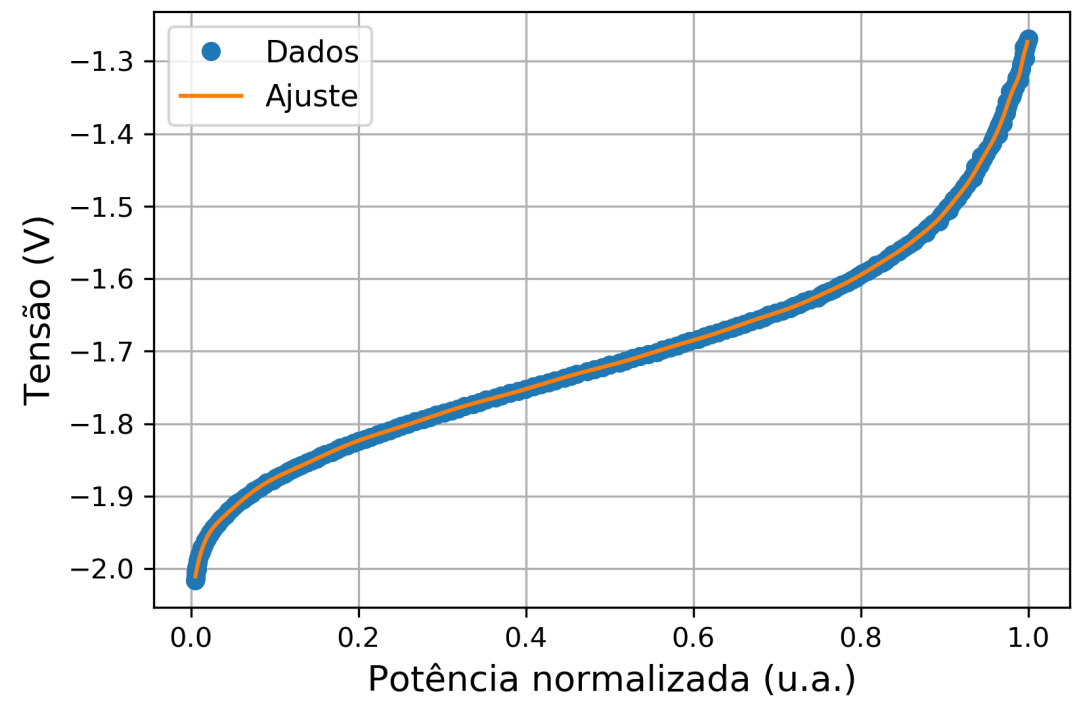

Figura 50 - Função da tensão aplicada no CMA em função da potência obtida e curva de ajuste polinomial de grau 200.

Fonte: Elaborada pela autora. 


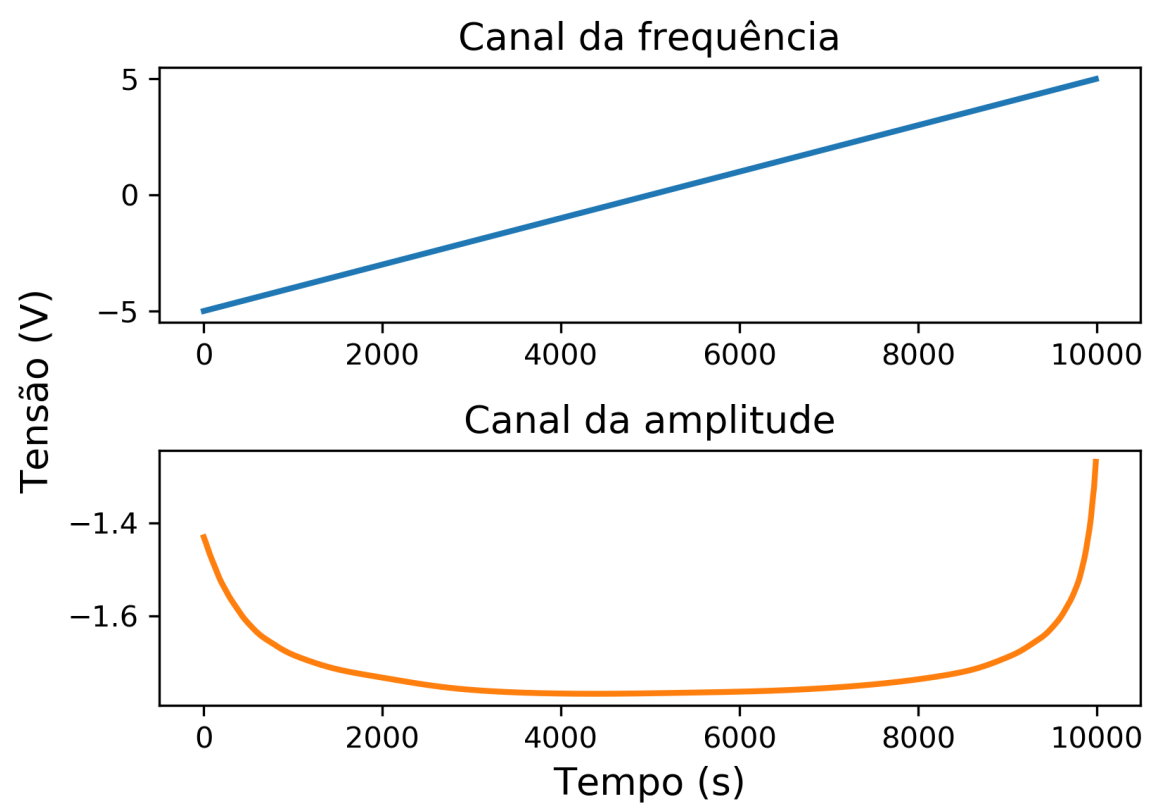

Figura 51 - Sinal de tensão aplicado no CMF (em cima) e sinal de tensão aplicado no CMA (embaixo) para normalizar a potência do feixe no intervalo escolhido.

Fonte: Elaborada pela autora.

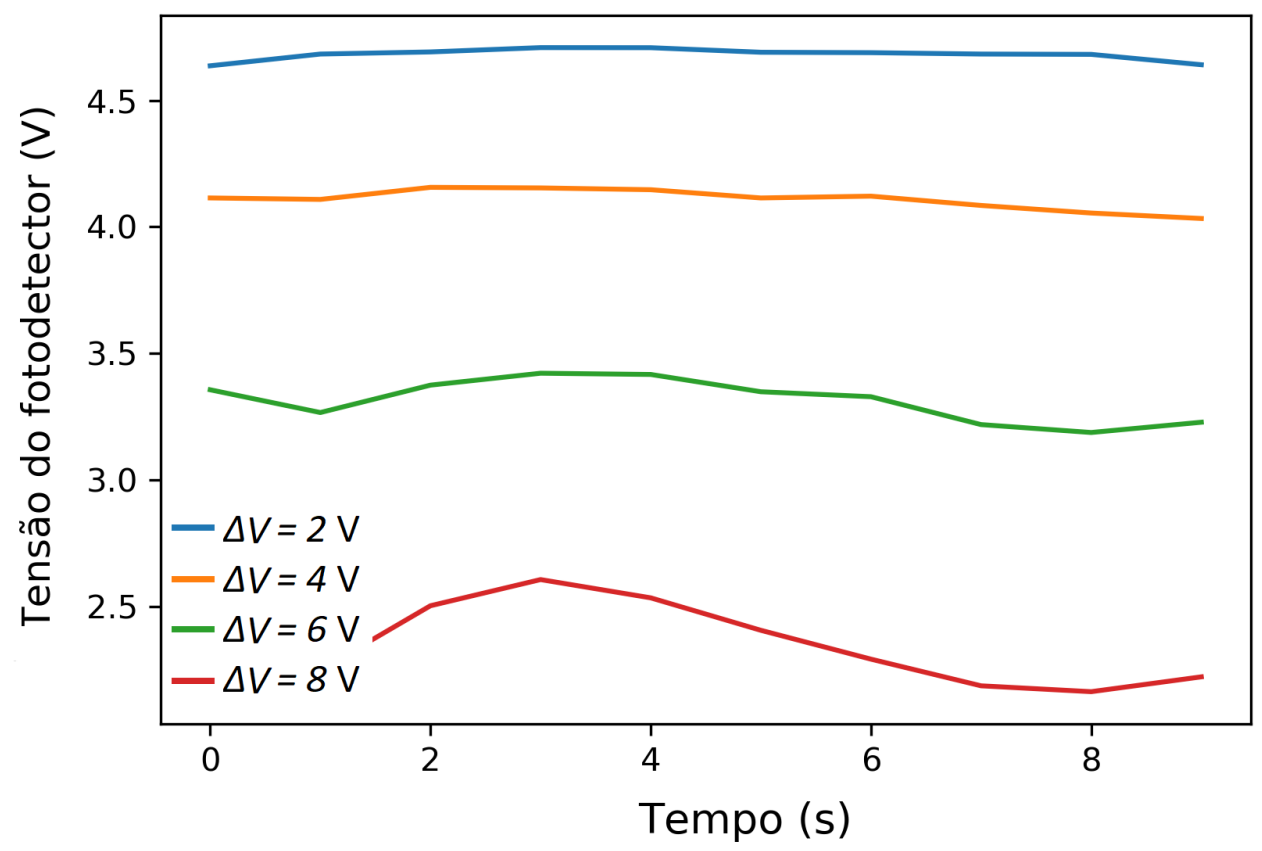

Figura 52 - Potência detectada pelo fotodetector em 10 segundos de coleta e frequência de $1 \mathrm{~Hz}$ para vários intervalos de tensão $\Delta V_{f}$ aplicados no CMF com estabilização.

Fonte: Elaborada pela autora. 
A tensão de resposta do fotodetector, ao aplicar diferentes intervalos de tensão ${ }^{\ddagger}$, se encontra na Fig. 52. O sinal enviado corresponde a 10 rampas, com 10 pontos cada, e um tempo de coleta de $10 \mathrm{~s}$. Conforme o intervalo de tensão aumenta, a potência mínima, na qual o feixe é estabilizado, diminui. Desse modo, maiores intervalos de frequência (maior $\left.\Delta V_{f}\right)$ causam uma maior perda de potência do feixe difratado.

\subsection{Calibração da pinça óptica com o AOM}

Os perfis de intensidade do feixe de aprisionamento, antes da objetiva (colimado) e pouco acima do foco (divergindo) da objetiva, são apresentados na Fig. 53. Apesar de ser aproximadamente gaussiano, pela presença do modulador, o feixe não é mais simétrico no plano $x y$, apresentando na entrada da objetiva um diâmetro de $5.61 \pm 0.04 \mathrm{~mm}$ no eixo $x$ e de $3.29 \pm 0.01 \mathrm{~mm}$ no eixo $y$.

Mesmo com a estabilização da potência do feixe difratado pelo AOM, o deslocamento angular do feixe na direção $x$, gera uma variação na potência que chega à amostra ao modular o laser espacialmente, além de mudar a forma do feixe focalizado, conforme a Fig. 54. Esses são desafios a serem vencidos em futuras implementações desse sistema, se o objetivo for obter extremo controle do potencial óptico de aprisionamento.
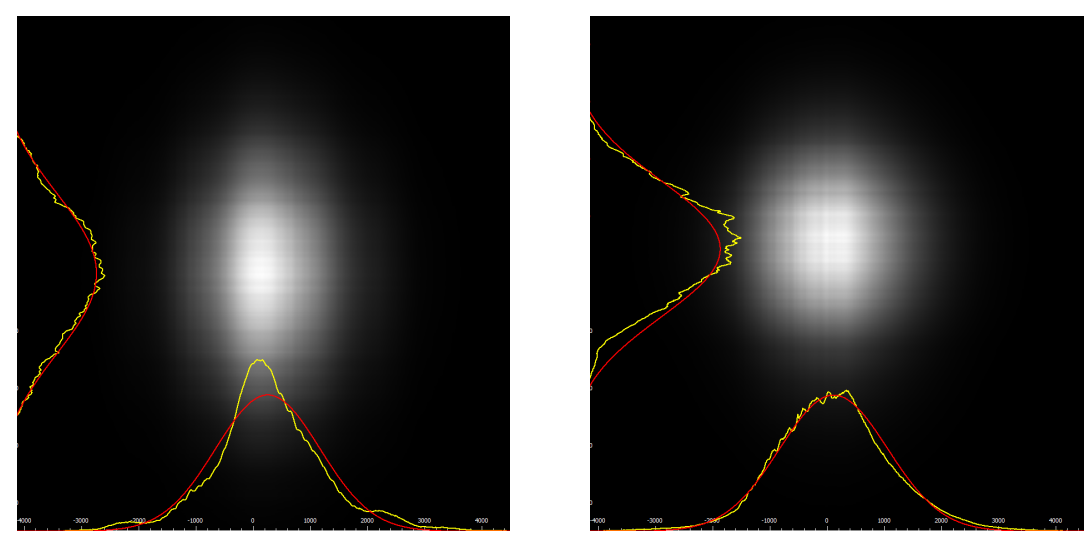

Figura 53 - Perfis de intensidade do feixe normalizados no plano $x y$ antes da objetiva (esquerda) e após a objetiva (direita) para uma frequência do AOM de aproximadamente $80 \mathrm{MHz}$ $(0 \mathrm{~V})$. A medida foi obtida com o auxílio de um perfilador de feixe óptico de varredura de fenda, que inverte os eixos do sistema. Desse modo, o eixo vertical representa a direção de aprisionamento $x$ e o eixo horizontal a direção $y$. As curvas em amarelo representam a intensidade do feixe e as curvas em vermelho o ajuste gaussiano.

Fonte: Elaborada pela autora.

Com o auxílio da câmera ${ }^{\S}$, foi analisado o perfil de luz do feixe de laser espalhado na superfície da lâmina, para várias tensões aplicadas no CMF, conforme a Fig. 55. A escala do

$¥$ Os intervalos de tensão são rampas de $-\Delta V_{f} / 2$ a $\Delta V_{f} / 2$.

$\S$ A posição da câmera no sistema para a aquisição desses dados é a mesma usada na coleta dos vídeos. No entanto, foi retirado o filtro para o infravermelho e foram alteradas as configurações da câmera para não saturar a imagem. 

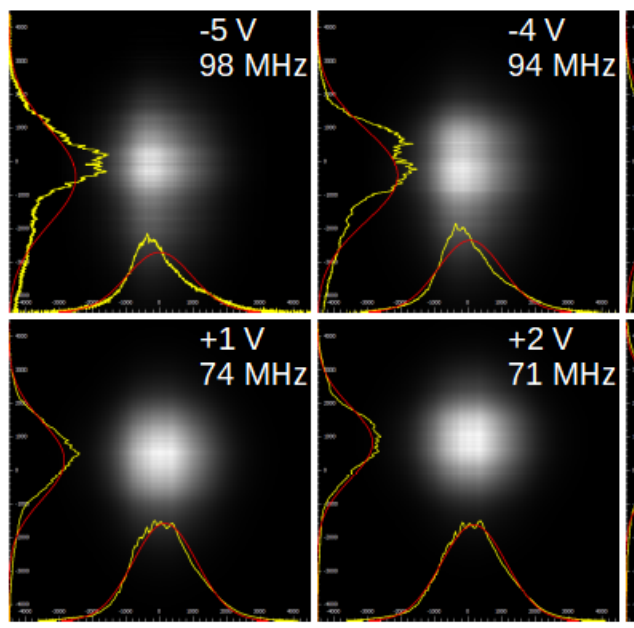
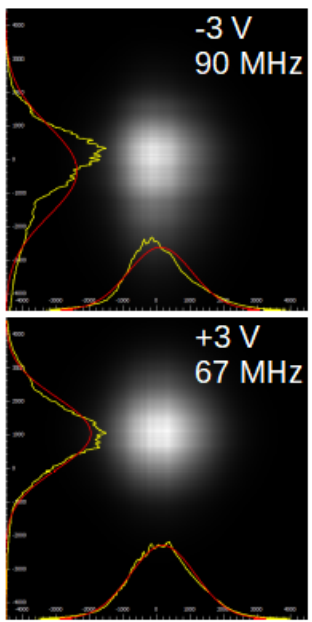
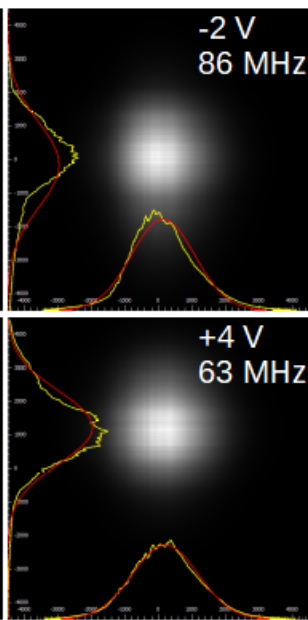

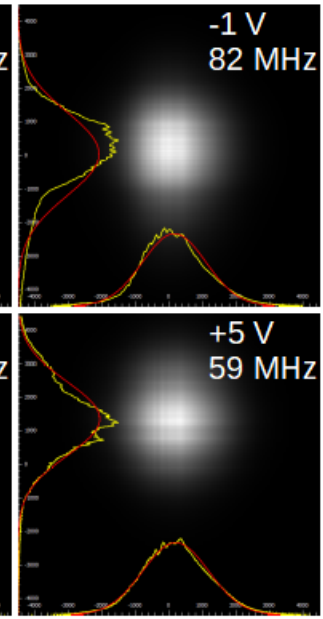

$-1 \mathrm{~V}$ Z

Figura 54 - Perfis de intensidade do feixe normalizados no plano $x y$, após a objetiva, obtidos com o auxílio de um perfilador de feixe óptico de varredura de fenda, para várias frequências do AOM.

Fonte: Elaborada pela autora.

gráfico representa a escala de cinza da imagem na câmera, sendo 0 o valor correspondente à menor intensidade de luz e 255 o valor correspondente à maior intensidade de luz. Os dados foram coletados para uma fileira horizontal de pixels em um conjunto de imagens gravadas ao aplicar sinais de tensão CMF de $-5 \mathrm{~V}$ a $5 \mathrm{~V}$, juntamente com a tensão de estabilização aplicada no CMA, e ilustram uma medida relativa da intensidade da pinça óptica, como função da tensão de controle no AOM. Além disso, o deslocamento relativo dos picos também pode ser usado para calibrar o deslocamento (in situ) do feixe no plano focal do microscópio.

Conforme o esperado, o máximo de intensidade do feixe se desloca linearmente com a variação de tensão aplicada no CMF. Além disso, podemos perceber que as distribuições de maior amplitude ocorrem ao aplicar uma tensão de $2 \mathrm{~V}$ a $4 \mathrm{~V}$ e, para tensões abaixo de $-3 \mathrm{~V}$, a intensidade é muito baixa para haver detecção, com as dadas configurações da câmera. Apesar do feixe ser alinhado para uma frequência de $80 \mathrm{MHz}(V=0 \mathrm{~V})$, sua eficiência é máxima para uma leve variação angular e esse resultado é consequência de um pequeno desalinhamento do feixe ao entrar na objetiva.

A partir dos perfis de intensidade, é possível calcular o deslocamento espacial do laser ao aplicar uma dada tensão de controle $V_{f}$ no CMF. Para cada perfil de intensidades foi feito um ajuste gaussiano e o valor da posição média, correspondente ao pico de intensidade, foi obtido. A posição média do feixe em função da tensão aplicada se encontra na Fig. 56. A partir de um ajuste linear é obtida a calibração do deslocamento do laser modulado, que corresponde a $562 \pm 5 \mathrm{~nm} / \mathrm{V}$. 


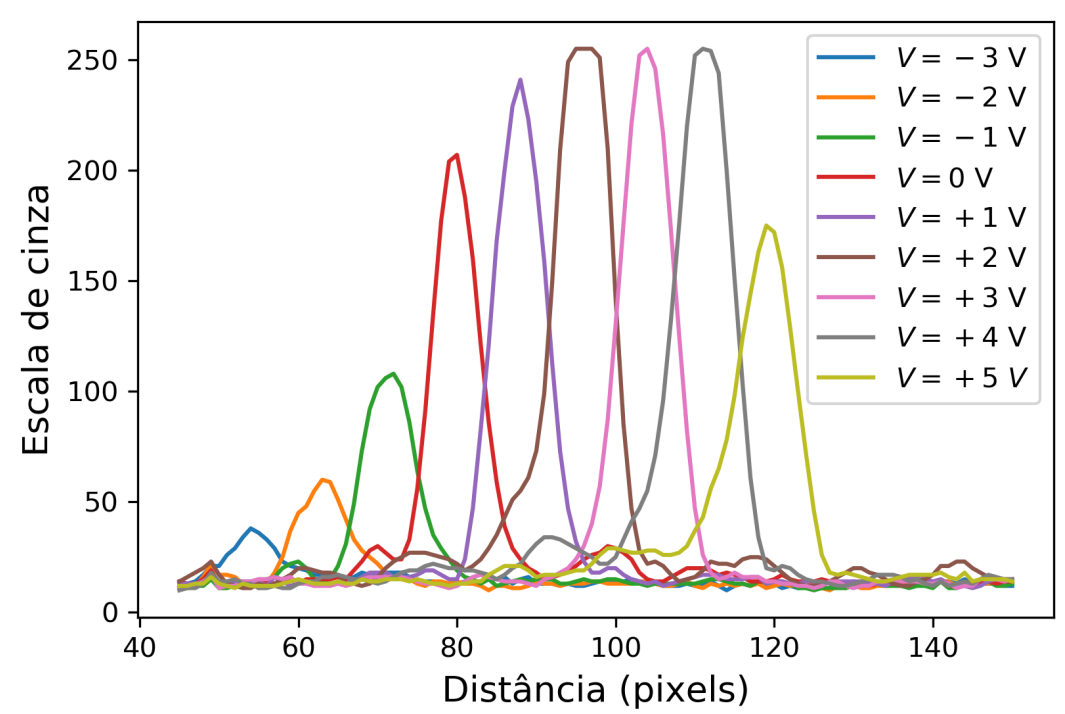

Figura 55 - Escala de cinza em uma fileira de pixels ao aplicar vários valores de tensão no CMF do AOM juntamente com a estabilização da potência pelo controle no CMA.

Fonte: Elaborada pela autora.

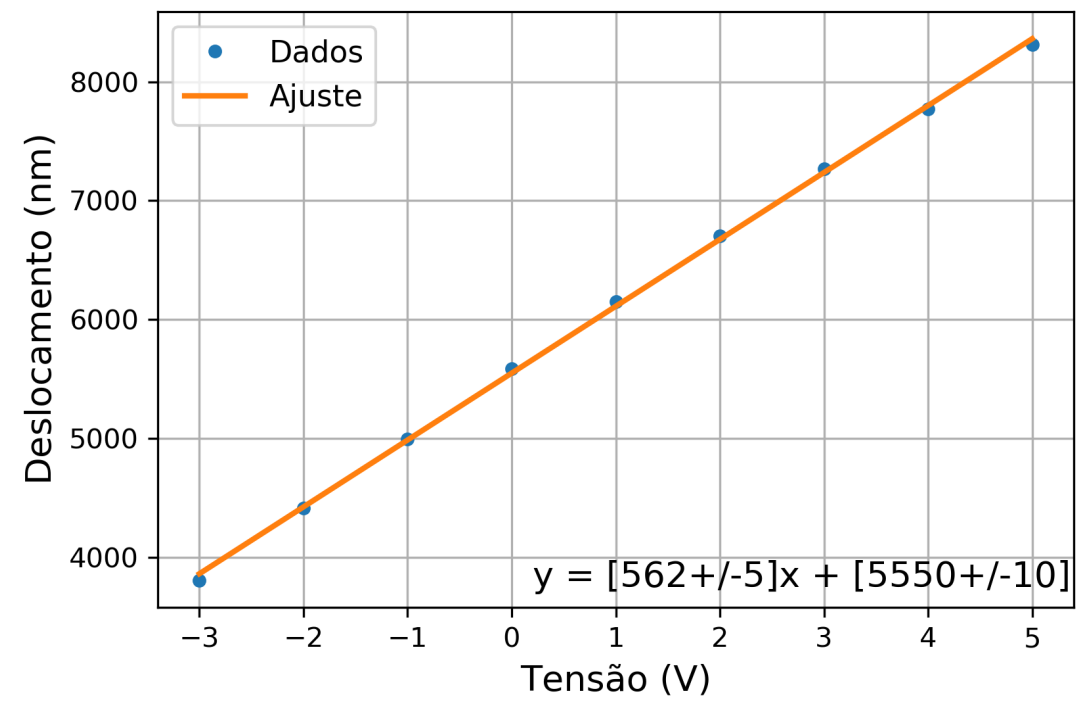

Figura 56 - Posição média do feixe em função da tensão aplicada no CMF do AOM. As barras de erro são menores que o tamanho do símbolo de cada ponto.

Fonte: Elaborada pela autora. 


\section{SISTEMA DE MODULAÇÃO DINÂMICA}

Este capítulo apresenta um estudo de trajetórias de partículas aprisionadas num potencial óptico dinâmico, gerado com o auxílio de um AOM. Sinais de tensão variáveis no tempo foram aplicados no CMF do AOM, nos limites de baixa $(1 \mathrm{~Hz})$ e alta $(10 \mathrm{kHz})$ frequências. No primeiro caso, a trajetória média da partícula acompanha o deslocamento espacial do laser, já no segundo, devido à viscosidade do meio, a partícula não acompanha a rápida variação espacial da pinça, mas sente um potencial efetivo de aprisionamento*.

\subsection{Modulação em baixas frequências}

Para um sinal de tensão $V_{f}(t)$ variável no tempo, de forma similar ao apresentado na Seção 7.2, a função de estabilização da potência é dada por:

$$
g\left(V_{f}(t)\right)=\frac{P_{f, \min }}{P_{f}\left(V_{f}(t)\right)}
$$

A partir dos coeficientes do ajuste polinomial, calculados anteriormente para as curvas de calibração, são obtidos os valores para $P_{f}\left(V_{f}(t)\right)$ e para a função de estabilização $g\left(V_{f}\right)$. Desse modo, os valores de tensão $V_{a}(t)$ a serem aplicados no CMA dependem do tipo de sinal $V_{f}(t)$ aplicado. No presente trabalho, foram testados três diferentes tipos de sinais: triangular, quadrado e senoidal.

A partir das definições de cada tipo de sinal, discutidos na Seção 4.3, podemos calcular os valores de tensão, a serem aplicados nos CMF e CMA, necessários para a geração de funções triangulares (Fig. 57), quadradas (Fig. 58) e senoidais (Fig. 59) de frequência $1 \mathrm{~Hz}$. As trajetórias obtidas para uma partícula de sílica de $2 \mu \mathrm{m}$ de diâmetro aprisionada por uma potência inicial de $1.6 \mathrm{~mW}$, com $\Delta V_{f}=2 \mathrm{~V}$ e $\Delta V_{f}=4 \mathrm{~V}$ também são apresentadas nestas figuras ${ }^{\dagger}$.

O sinal quadrado gera, basicamente, um potencial harmônico cuja posição de equilíbrio se move de modo descontínuo (abrupto), no espaço. Ao mudar a posição de equilíbrio da armadilha no tempo, de $x_{0,1}$ para $x_{0,2}$, a partícula, que inicialmente estava aprisionada em torno da primeira posição, é solta repentinamente da pinça, apresentando movimento browniano livre por alguns instantes, até se aproximar suficientemente da posição da segunda pinça e sentir sua força de aprisionamento. À medida que a partícula sai de uma pinça e é puxada por outra pode-se analisar o deslocamento médio $\langle x\rangle$ no tempo e estudar essa dinâmica.

* Os códigos de controle utilizados nesta seção se encontram no Apêndice M.

$\dagger$ Embora a representação do sinal aplicado aos canais tenha duração de $4 \mathrm{~s}$, o sinal real foi aplicado por um longo período de tempo e vários vídeos foram coletados nesse intervalo. 

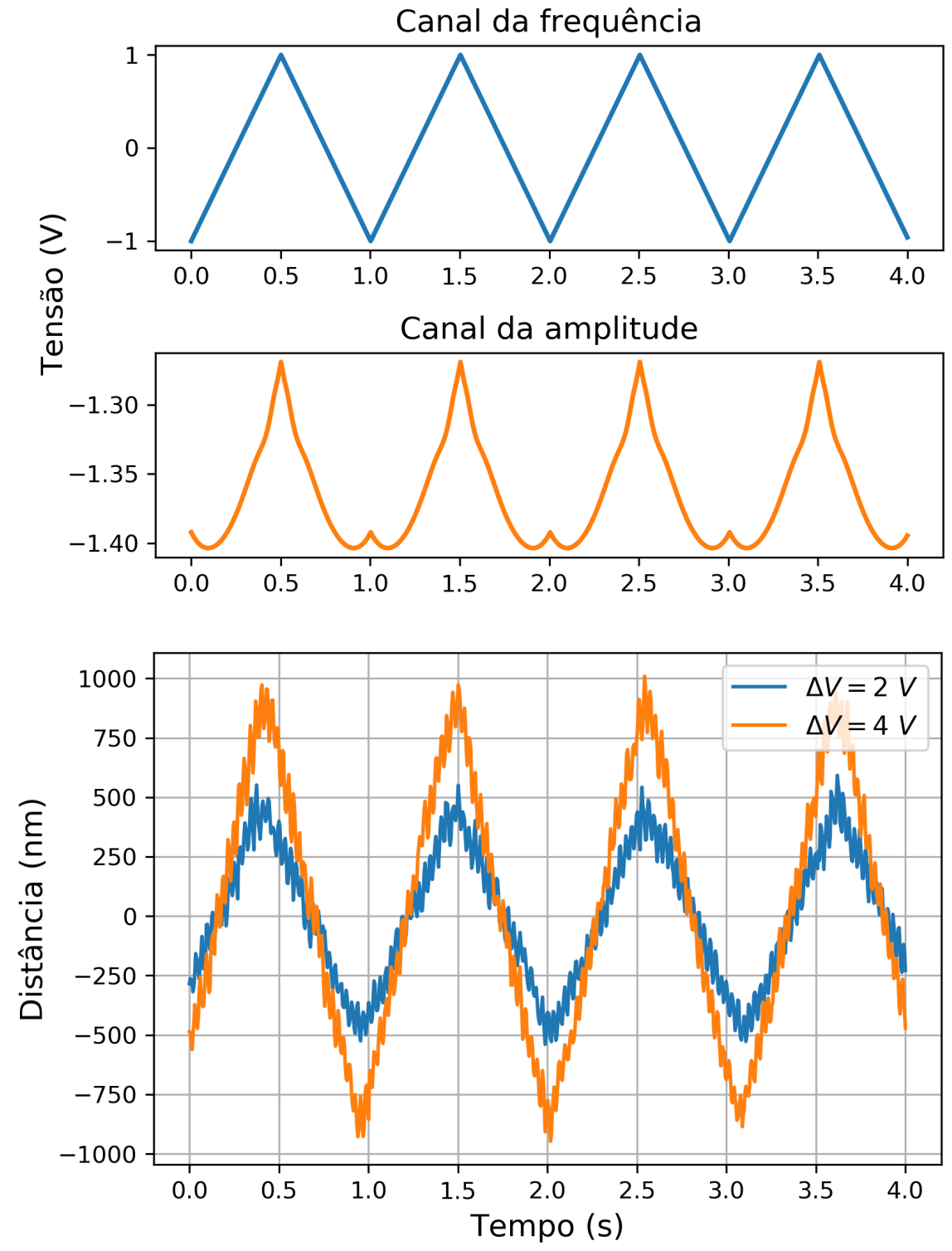

Figura 57 - Sinais de tensão aplicados nos CMF (em cima) e CMA (meio) para um sinal triangular de $1 \mathrm{~Hz}$. Trajetória $(x)$ de uma partícula de sílica com $d=2 \mu \mathrm{m}$ aprisionada em um potencial variável triangular para $\Delta V_{f}=2 \mathrm{~V}$ e $\Delta V_{f}=4 \mathrm{~V}$ (embaixo).

Fonte: Elaborada pela autora. 

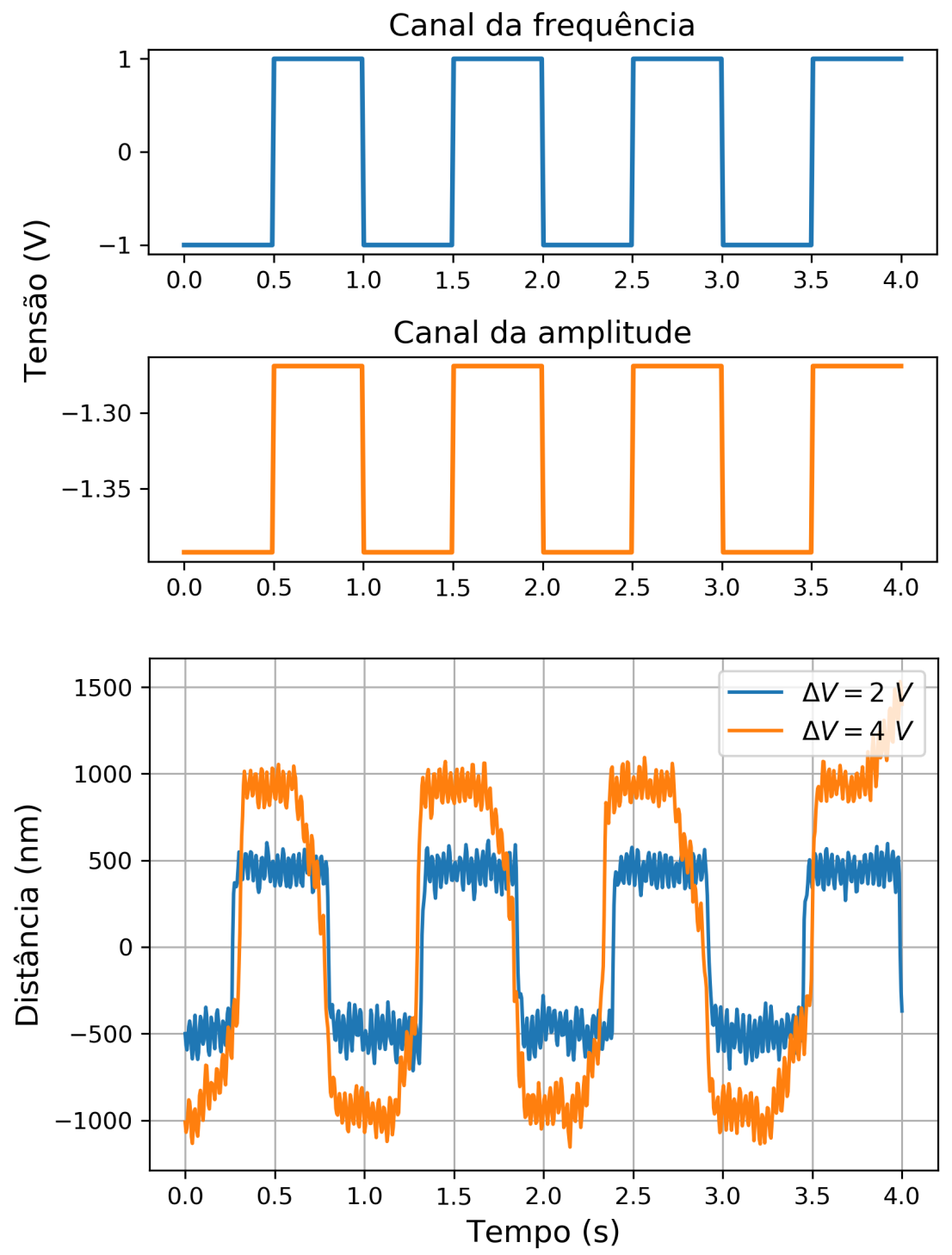

Figura 58 - Sinais de tensão aplicados nos CMF (em cima) e CMA (meio) para um sinal quadrado de $1 \mathrm{~Hz}$. Trajetória $(x)$ de uma partícula de sílica com $d=2 \mu \mathrm{m}$ aprisionada em um potencial variável quadrado para $\Delta V_{f}=2 \mathrm{~V}$ e $\Delta V_{f}=4 \mathrm{~V}$ (embaixo).

Fonte: Elaborada pela autora. 

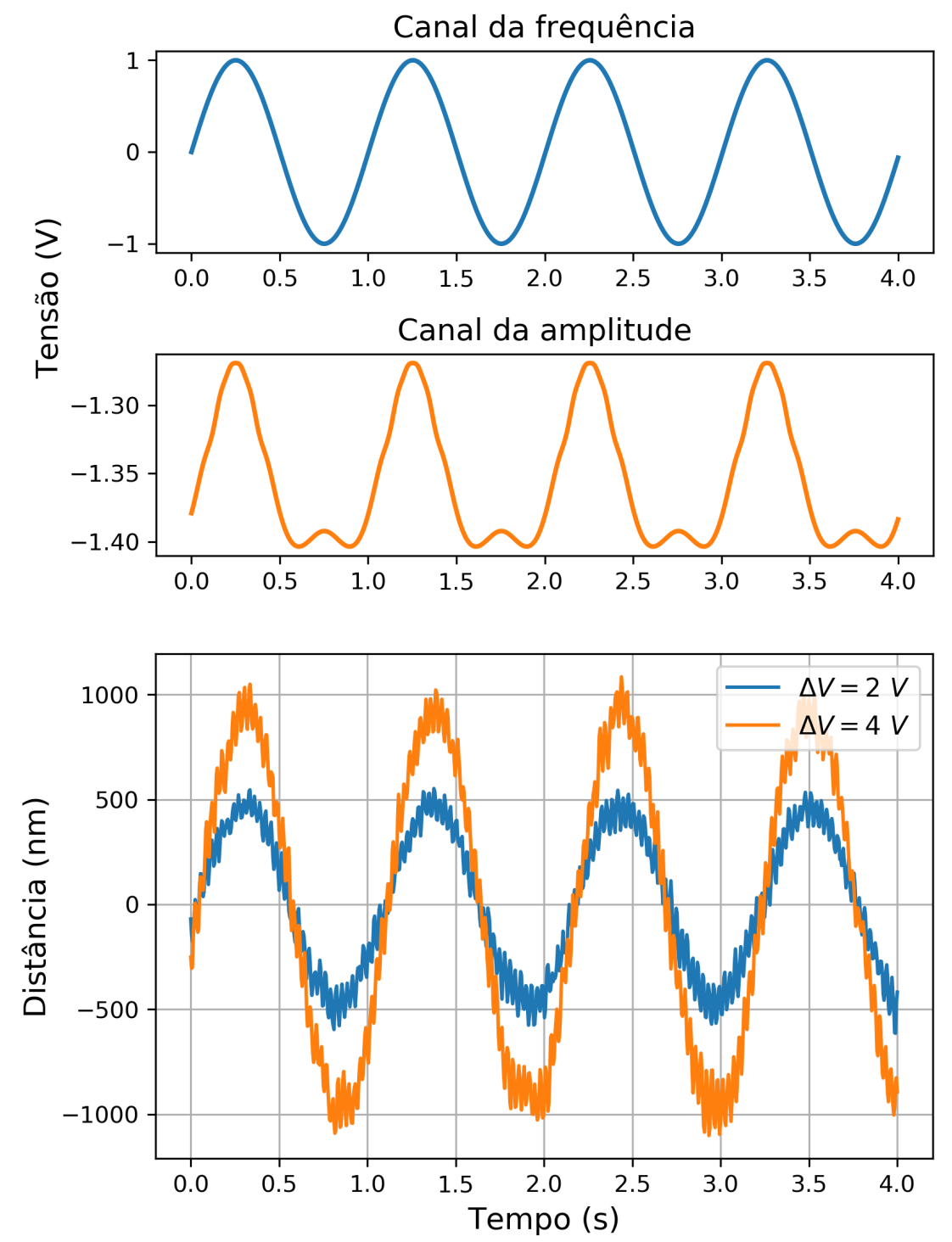

Figura 59 - Sinais de tensão aplicados nos CMF (em cima) e CMA (meio) para um sinal senoidal de $1 \mathrm{~Hz}$. Trajetória $(x)$ de uma partícula de sílica com $d=2 \mu \mathrm{m}$ aprisionada em um potencial variável senoidal para $\Delta V_{f}=2 \mathrm{~V}$ e $\Delta V_{f}=4 \mathrm{~V}$ (embaixo).

Fonte: Elaborada pela autora. 
Tabela 1 - Constante de força da pinça para cada valor de $V_{f}$ aplicado no CMF do AOM.

\begin{tabular}{rc}
\hline Tensão de controle $V_{f}$ aplicada $(\mathrm{V})$ & Constante de força $(\mathrm{pN} / \mu \mathrm{m})$ \\
\hline \hline-2.00 & $0.46 \pm 0.03$ \\
\hline-1.00 & $1.3 \pm 0.2$ \\
\hline 1.00 & $1.3 \pm 0.1$ \\
\hline 2.00 & $1.05 \pm 0.06$ \\
\hline
\end{tabular}

Fonte: Elaborada pela autora.

Essa trajetória nos mostra como a partícula cai na armadilha óptica numa escala de distâncias muito maior que a utilizada comumente nos métodos de calibração usuais. Considerando o limite sobreamortecido, descartando o termo de flutuação rápidas, por nos interessar apenas as componentes lentas da função de Langevin (Eq. 3.10), e desprezando também o termo inercial ${ }^{\ddagger}$, podemos reescrever a Eq. 3.10 como:

$$
\kappa_{x}\langle x\rangle=-\alpha \frac{d}{d t}\langle x\rangle
$$

Logo, a trajetória média da partícula é dada por:

$$
\langle x\rangle=A e^{-t / \tau_{c}},
$$

sendo $\tau_{c}=\alpha / \kappa_{x}$ o tempo característico e $A$ uma constante que depende das condições de contorno. Desse modo, analisando as trajetórias obtidas ao modular o CMF do AOM por um sinal quadrado, é possível estimar a constante de força ao aplicar sinais de tensão no CMF de $V_{f}=-2 \mathrm{~V},-1 \mathrm{~V}, 1 \mathrm{~V}$ e $2 \mathrm{~V}$.

A Fig. 60 apresenta as mesmas curvas de trajetória que a Fig. 58, no entanto, destacando os pontos num intervalo de tempo menor e próximo à transição entre as duas posições. A linha tracejada indica o momento em que a pinça muda sua posição de equilíbrio. Como a pinça tem um alcance limite, que depende dos parâmetros experimentais, foi escolhido um conjunto de pontos, suficientemente próximos à armadilha, para calcular a função de ajuste. O processo foi repetido para as demais tensões e as constantes de força calculadas se encontram na tabela $1^{\S}$.

¥ Para a escala de tempo de interesse, podemos considerar que a partícula já alcançou eu estado de equilíbrio, portanto, podemos reescrever a equação de Langevin desprezando o termo inercial.

$\S$ O valor teórico do coeficiente de arrasto foi utilizado nos cálculos da constante de força, sendo este dado por $\alpha=6 \pi \eta a$, sendo $\eta=0.001 \mathrm{~Pa} \cdot \mathrm{s}$ a viscosidade da água e $a=1 \mu \mathrm{m}$ o raio da partícula. 

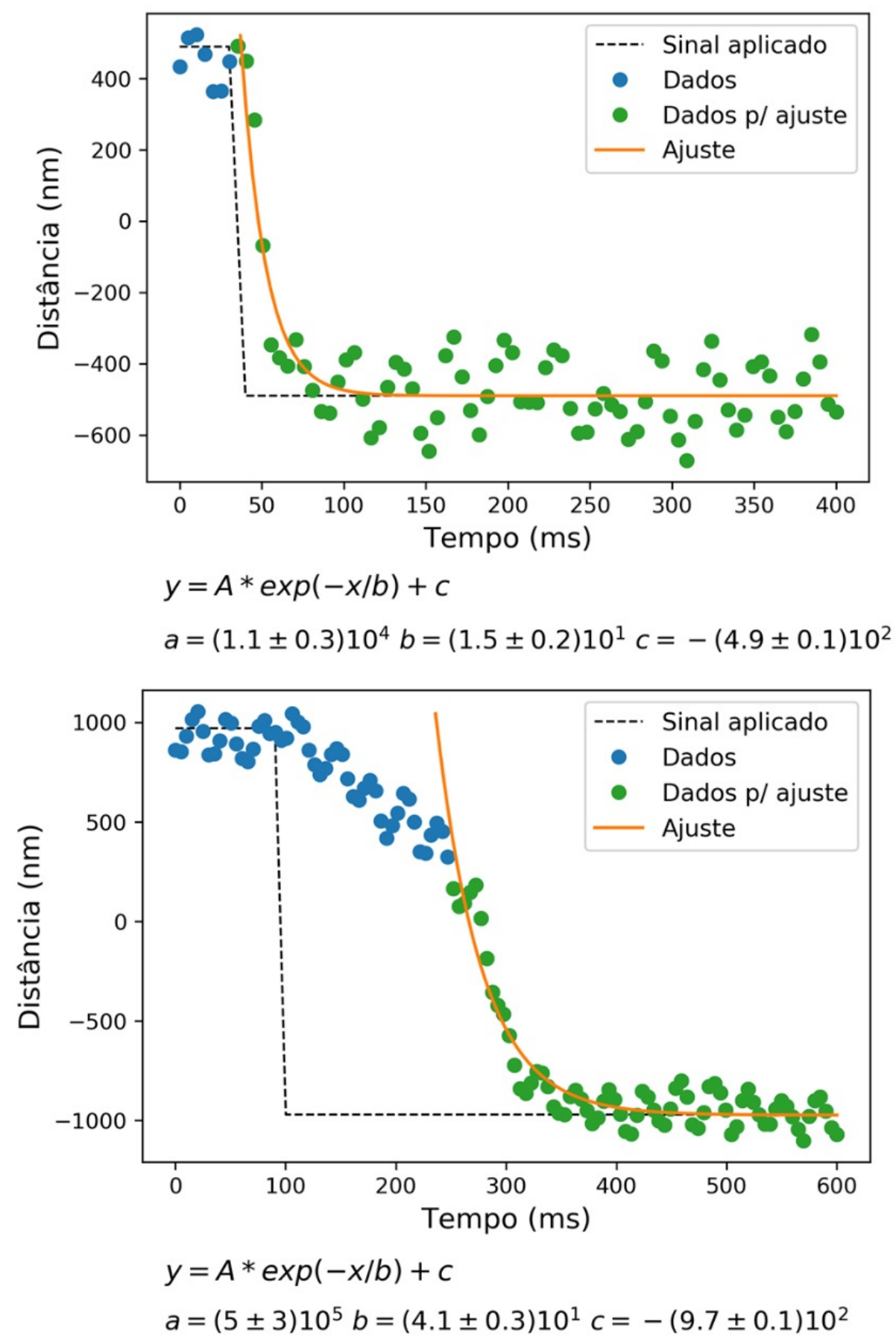

Figura 60 - Trajetória $(x)$ de uma partícula de sílica com $d=2 \mu \mathrm{m}$ aprisionada em um potencial variável quadrado para $\Delta V_{f}=2 \mathrm{~V}$ (em cima) e $\Delta V_{f}=4 \mathrm{~V}$ (embaixo) e uma potência inicial de $1.6 \mathrm{~mW}$. A linha tracejada representa o sinal aplicado no canal da frequência e a curva (laranja) o ajuste dos dados experimentais (verde).

Fonte: Elaborada pela autora.

Esse método de calibração pode ser utilizado para sistemas com baixa taxa de aquisição de dados (preferencialmente acima de $180 \mathrm{~Hz}$ ), e apresenta resultados consistentes com os parâmetros utilizados (Fig. 55). 

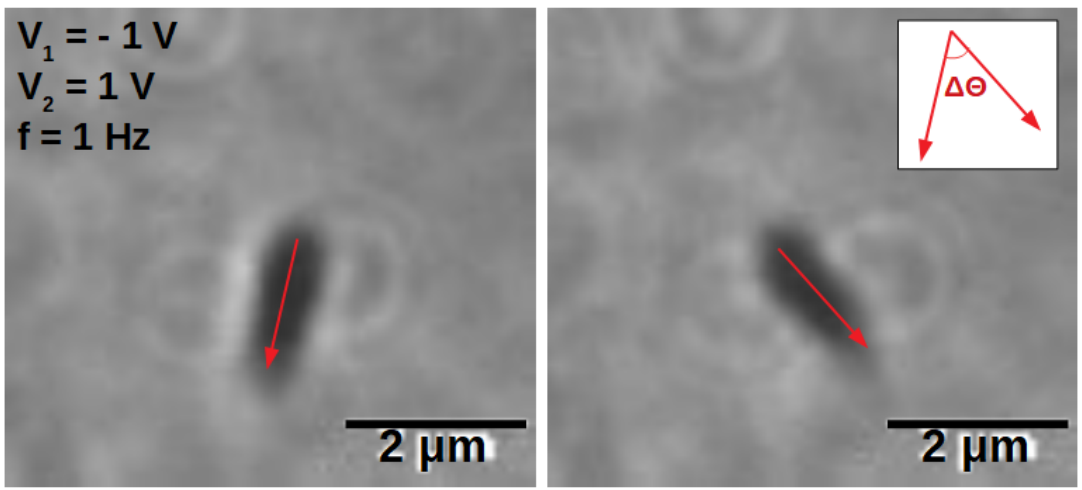

Figura 61 - Nanotubo de $\mathrm{TiO}_{2}$ aprisionado em um potencial variável quadrado com tensão de controle no CMF com amplitude de $\Delta V_{f}=1 \mathrm{~V}$ e frequência de $1 \mathrm{~Hz}$. As figuras têm uma diferença de tempo de $T / 2=0.5$ s e mostram a partícula aprisionada em cada poço.

Fonte: Elaborada pela autora.

Além da amostra de sílica, também foram aprisionados nanotubos de $\mathrm{TiO}_{2}$. Ainda aplicando um sinal quadrado no canal de modulação de frequência do AOM, com amplitude $\Delta V_{f}=1 \mathrm{~V}$ e frequência de $1 \mathrm{~Hz}$, observou-se que o nanotubo apresentou um movimento oscilatório angular no decorrer do tempo, apresentado na Fig. 61.

A hipótese aqui é que, como a força óptica tem um alcance finito e efeito distribuído sobre uma estrutura alongada, a pinça óptica parece ter sido mais efetiva em aprisionar uma região (não central) do nanotubo, gerando um torque no mesmo, ao mudar de posição. Por consequência, as mudanças de posição da pinça causaram uma rotação na partícula, ao invés do simples deslocamento do CM.

Podemos estimar a frequência do movimento, em uma primeira aproximação, ao analisar a trajetória do CM do nanotubo na direção $x$. Devido à inércia do movimento, a posição do CM é similar à uma função senoidal. A partir da Fig. 62, podemos notar que a frequência do movimento é da ordem de $1 \mathrm{~Hz}$, conforme o esperado. 


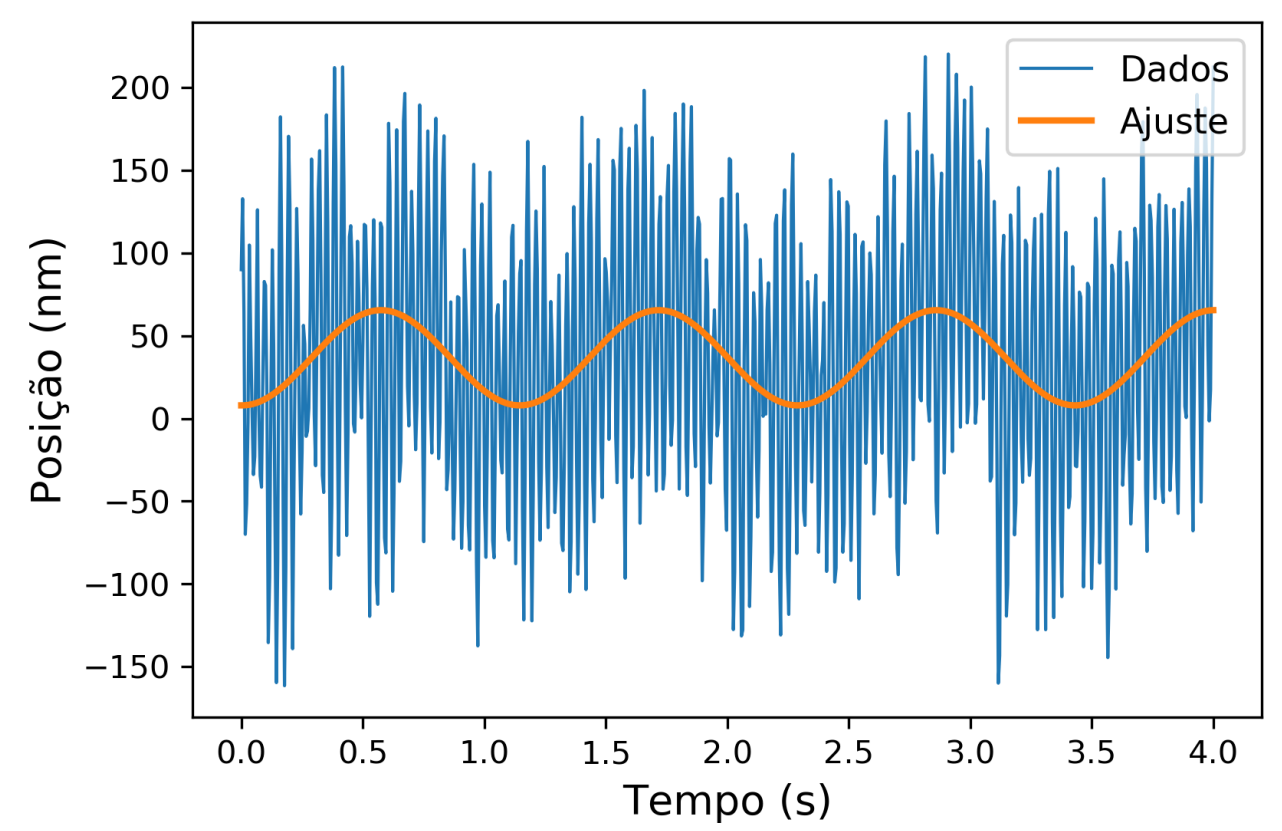

Figura 62 - Trajetória do $\mathrm{CM}(x)$ de um nanotubo de $\mathrm{TiO}_{2}$ aprisionado em um potencial variável quadrado, com tensão de controle no CMF com amplitude de $\Delta V_{f}=1 \mathrm{~V}$ e frequência de $1 \mathrm{~Hz}$.

Fonte: Elaborada pela autora.

\subsection{Modulação em altas frequências: potencial por média temporal}

Para gerar o duplo-poço foi utilizado um sinal de controle quadrado para deslocar o feixe no espaço e, como anteriormente, a potência foi estabilizada por uma função $g\left(V_{f}\right)$. No entanto, a função aplicada ao CMA levou em consideração uma segunda função $g_{L D}$, responsável por desligar completamente o laser no momento em que ele passa de um degrau para outro. O tempo que o laser permanece desligado foi escolhido tal que $t_{d}=0.1 T$, sendo $T$ o período do sinal. Desse modo, a função de estabilização final utilizada é dada por (Fig. 63):

$$
g_{\text {final }}\left(V_{f}\right)=g\left(V_{f}\right) * g_{L D}
$$

Para testar a armadilha dupla, foi utilizada uma amostra de poliestireno de diâmetro de $d=1 \mu \mathrm{m}$ aprisionada próxima à lâmina superior. As características dessa partícula fazem com que a força de espalhamento seja relativamente grande, impossibilitando o confinamento pela força gradiente, com o sistema experimental atual. Desse modo, a esfera de poliestireno, ao passar próxima à região da pinça, é empurrada pela força de espalhamento até se aproximar da lâmina superior. Como a força de contato com a lâmina impede que a partícula avance mais, esta pode ser aprisionada - pelo conjunto de forças ópticas e de contato

๙ A força de contato, aqui definida, impede que a partícula avance mais ao ser empurrada pelo feixe, no entanto, esta não gruda na superfície, apresentando movimento browniano. 


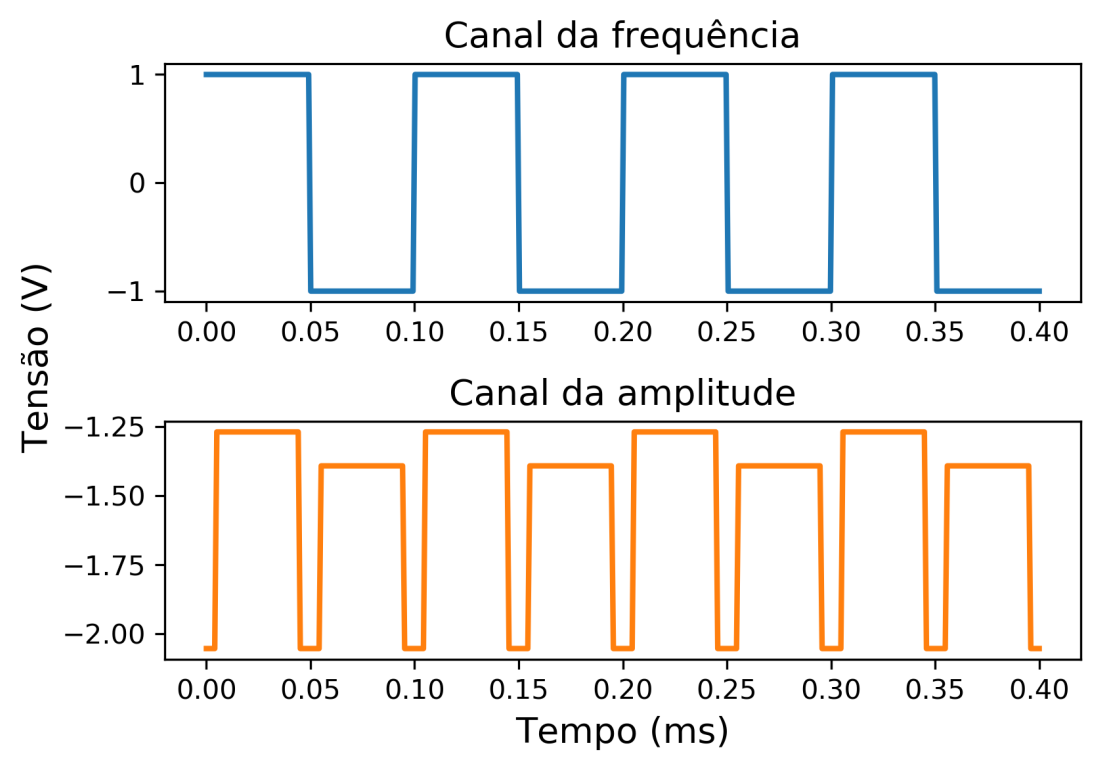

Figura 63 - Sinais de tensão aplicados no CMF (em cima) e no CMA (embaixo) para a geração de um duplo-poço num intervalo de tempo de $0.4 \mathrm{~ms}$ com frequência de $10 \mathrm{kHz}$.

Fonte: Elaborada pela autora.
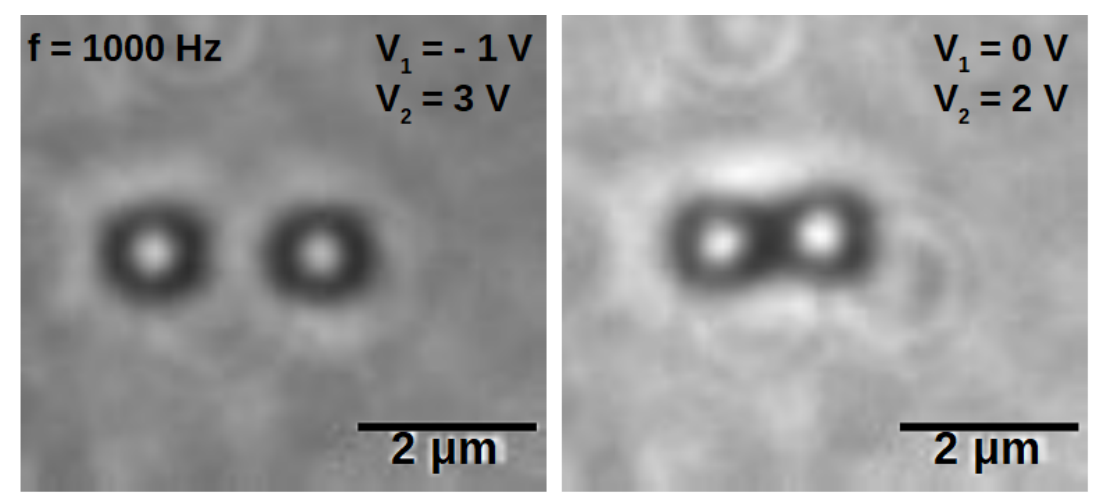

Figura 64 - Duas partículas de poliestireno de diâmetro de $d=1 \mu \mathrm{m}$ aprisionadas em um potencial duplo de distância entre poços de $(2.24 \pm 0.02) \mu \mathrm{m}$ (direita) e (1.12 \pm 0.02) $\mu \mathrm{m}$ (esquerda).

Fonte: Elaborada pela autora. 
Primeiramente, foi gerado um duplo-poço com distância de $(2.24 \pm 0.02) \mu \mathrm{m}$, correspondendo a $\Delta V_{f}=4 \mathrm{~V}$, ao varrer o sinal de tensão aplicado no CMF de $-1 \mathrm{~V}$ a $3 \mathrm{~V}^{\|}$, com uma potência inicial de $1.8 \mathrm{~mW}$. Uma imagem obtida para duas partículas aprisionadas simultaneamente, cada uma em um poço, é apresentada na Fig. 64.

O processo foi repetido para uma variação de sinal de $\Delta V_{f}=2 \mathrm{~V}$, entre $0 \mathrm{~V}$ a $2 \mathrm{~V}$, ou seja, reduzindo a distância entre os poços pela metade. Conforme apresentado, as distâncias entre os poços são coerentes com as calibrações já feitas e a pinça dupla, apesar da baixa potência, é suficientemente estável para estudar a dinâmica das partículas em múltiplas armadilhas.

Embora esse teste inicial tenha sido feito para distâncias relativamente grandes entre poços, pela facilidade de visualização e para impedir que as partículas se unam em um único poço, no caso de uma partícula isolada pode ser interessante diminuir esse parâmetro para distâncias bem menores, por exemplo, para estudar taxas de Kramers. (39-42) Pois assim, conforme o diagrama apresentado na Fig. 26, a chance de se obter transições aumenta. A partir disso, um estudo exploratório foi feito, utilizando diversos tipos de amostra, com o intuito de observar transições de uma partícula única entre poços.

\subsubsection{Microesferas de sílica}

Vários testes foram feitos na tentativa de se observar transições das esferas de sílica entre diferentes poços duplos. No entanto, para pequenas distâncias, nenhuma transição foi observada. Ao aplicar o sinal para a criação do duplo-poço, sendo o intervalo de tensão escolhido de $-1 \mathrm{~V}$ a $1 \mathrm{~V}$, com uma potência de aproximadamente $1.3 \mathrm{~mW}$, observou-se uma transição, apresentada na Fig. 65. A partir do vídeo completo, com 30 s de duração, foi gerado o histograma de posições normalizado (Fig. 66) e a curva de potencial (Fig. 67), de maneira análoga à análise da Seção 6.

Embora uma transição seja visível próximo ao instante $t=2 \mathrm{~s}$, não é possível afirmar que se trata de uma transição entre poços devido à energia térmica da partícula, pois os dados não foram reprodutíveis em outras coletas utilizando os mesmos parâmetros. As demais trajetórias apresentaram comportamento semelhante ao de uma partícula aprisionada em um potencial harmônico. Além disso, para essa distância entre poços, não é esperada a existência de transições, de acordo com as simulações feitas, pois a partícula, teoricamente, não tem energia térmica suficiente para mudar de poço. Portanto, a transição

I Nesta seção, a variação de tensão aplicado no CMF não tem como ponto médio $V=0 \mathrm{~V}$ (aproximadamente $80 \mathrm{MHz}$ ). A partir dos resultados obtidos na Seção 7.3, a intensidade do feixe que chega na amostra não é máxima para $V=0 \mathrm{~V}$, mas sim, para tensões a partir de $V=1 \mathrm{~V}$. Como espera-se obter um maior número de transições para uma pinça dupla simétrica, cujos poços têm aproximadamente a mesma constante de força, os sinais gerados para a modulação espacial do feixe foram escolhidos para valores de tensão que possibilitam tal situação. 


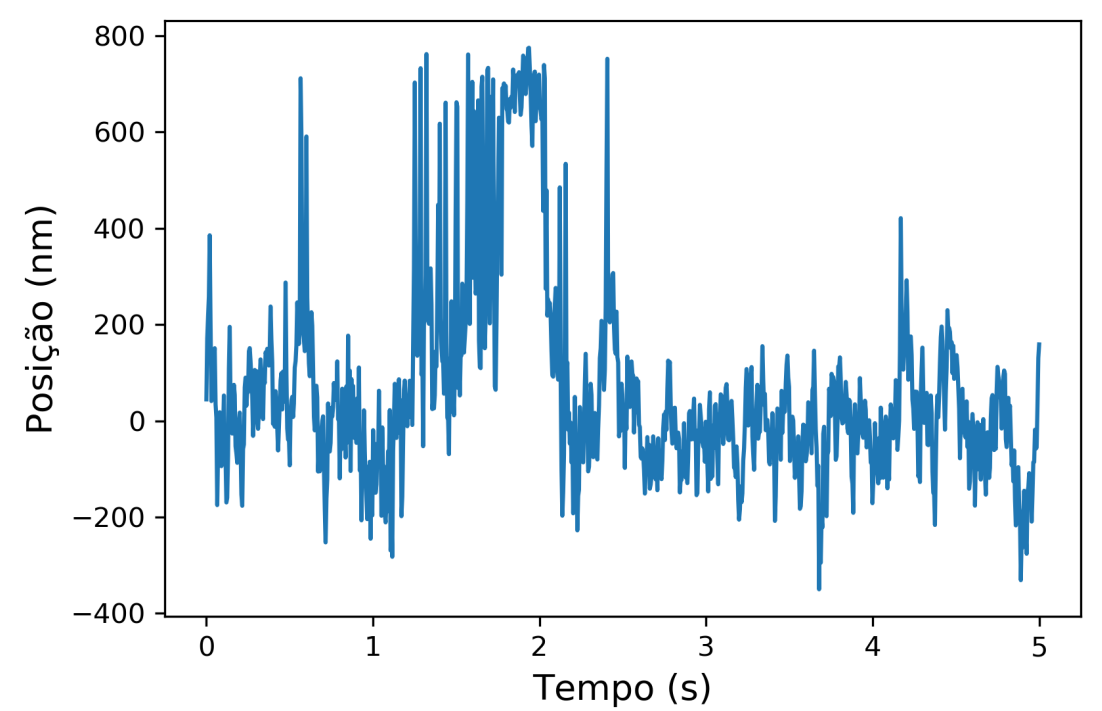

Figura 65 - Trajetória do CM $(x)$ da partícula aprisionada em um potencial duplo com $\Delta V=2 \mathrm{~V}$ e uma potência de aproximadamente $1.3 \mathrm{~mW}$.

Fonte: Elaborada pela autora.

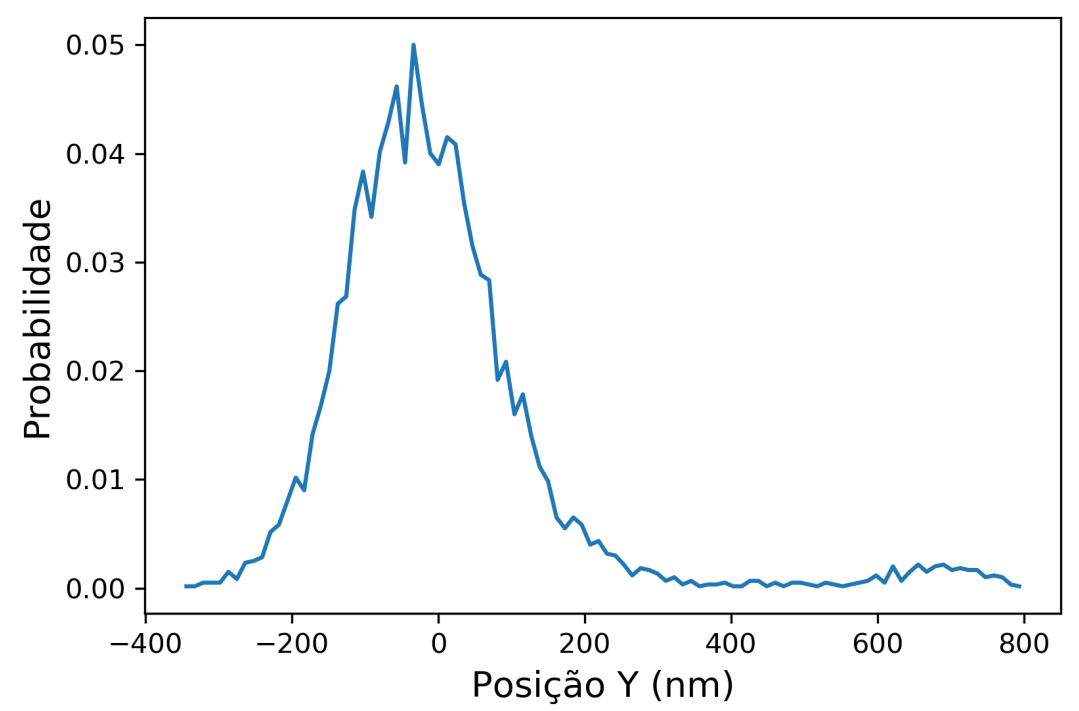

Figura 66 - Distribuição de probabilidade de uma partícula aprisionada em um potencial duplo com $\Delta V=2 \mathrm{~V}$ e uma potência de aproximadamente $1.3 \mathrm{~mW}$ durante $30 \mathrm{~s}$.

Fonte: Elaborada pela autora. 


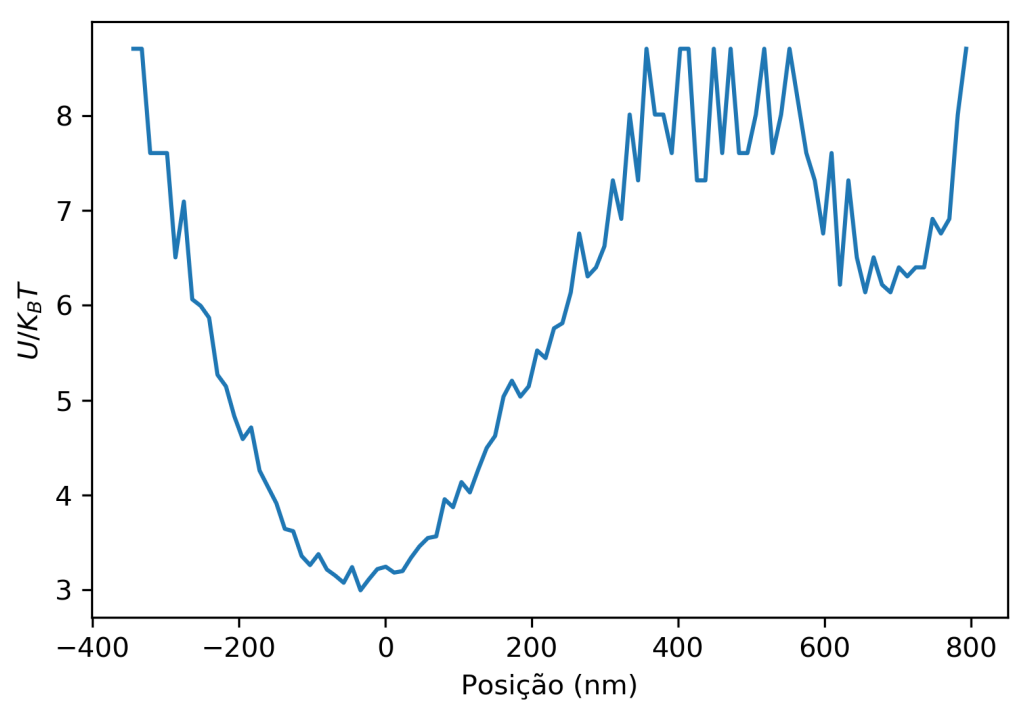

Figura 67 - Curva de potencial de uma partícula aprisionada em um potencial duplo com $\Delta V=2 \mathrm{~V}$ e uma potência de aproximadamente $1.3 \mathrm{~mW}$ durante $30 \mathrm{~s}$.

Fonte: Elaborada pela autora.

observada pode ter sido causada devido a vibrações mecânicas da mesa. Ainda assim, esse resultado mostra que o método de análise é sensível para detectar detalhes do potencial.

A distância aproximada entre os poços, a partir da análise da trajetória da partícula no tempo, é de aproximadamente $350 \mathrm{~nm}$. No entanto, como um dos poços apresenta uma constante de força significativamente menor que o outro, conforme análises prévias, não é possível prever o tamanho da barreira de potencial, pelo menos nas condições atuais.

\subsubsection{Nanoesferas de poliestireno}

Uma partícula de poliestireno, com raio de $500 \mathrm{~nm}$, foi aprisionada num potencial duplo, primeiramente com distância entre poços de $(562 \pm 5) \mathrm{nm}\left(\right.$ para $\left.V_{f}=\{0.5 \mathrm{~V}, 1.5 \mathrm{~V}\}\right)$ e, posteriormente, com distância entre poços de $(786 \pm 7) \mathrm{nm}\left(V_{f}=\{0.3 \mathrm{~V}, 1.7 \mathrm{~V}\}\right)$, para uma mesma potência inicial do laser. Os dados obtidos são mostrados na Fig. 68. Foram verificadas transições entre os poços em ambas as situações e o número de transições $N_{T}$, calculadas de forma análoga à Seção 4.4, diminuiu ao distanciar os poços, conforme o esperado.

\subsubsection{Nanotubos de $\mathrm{TiO}_{2}$}

Foi também utilizada uma amostra de nanotubo** de $\mathrm{TiO}_{2}$, com diâmetro externo médio de $60 \mathrm{~nm}$ e comprimentos entre centenas de nanometros até alguns micrometros (43),

** A amostra de nanotubos é mesma descrita na ref. (43). Detalhes das dimensões físicas dos nanotubos podem ser observadas na Fig. 6 dessa referência. 

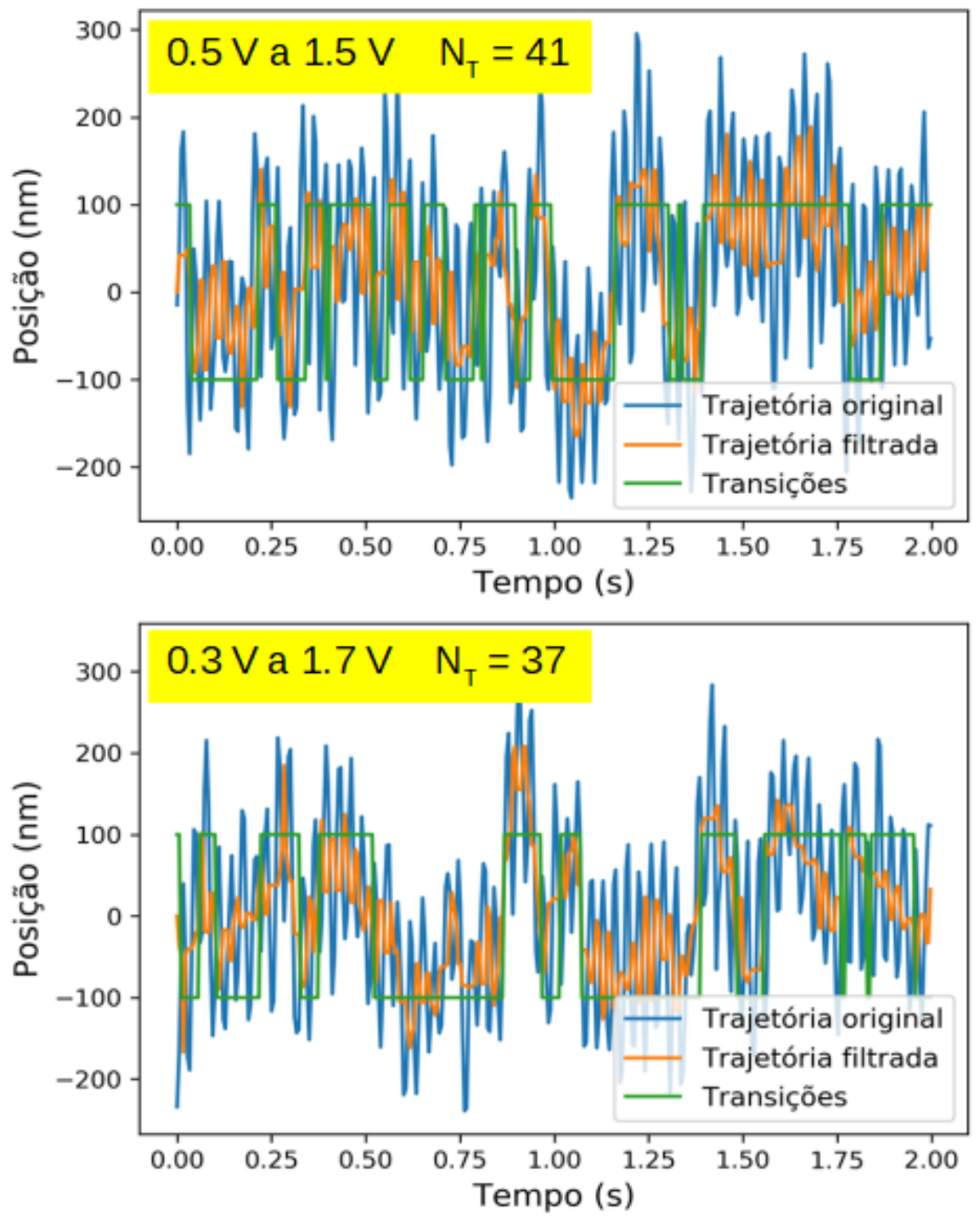

Figura 68 - Trajetórias do CM $(x)$ de uma partícula de poliestireno aprisionada em um potencial duplo com distância entre poços de $(562 \pm 5) \mathrm{nm}$ (em cima) e (786 \pm 7$) \mathrm{nm}$ (embaixo). São apresentadas as curvas da trajetória (azul), do sinal filtrado (laranja) e das transições obtidas (verde).

Fonte: Elaborada pela autora. 


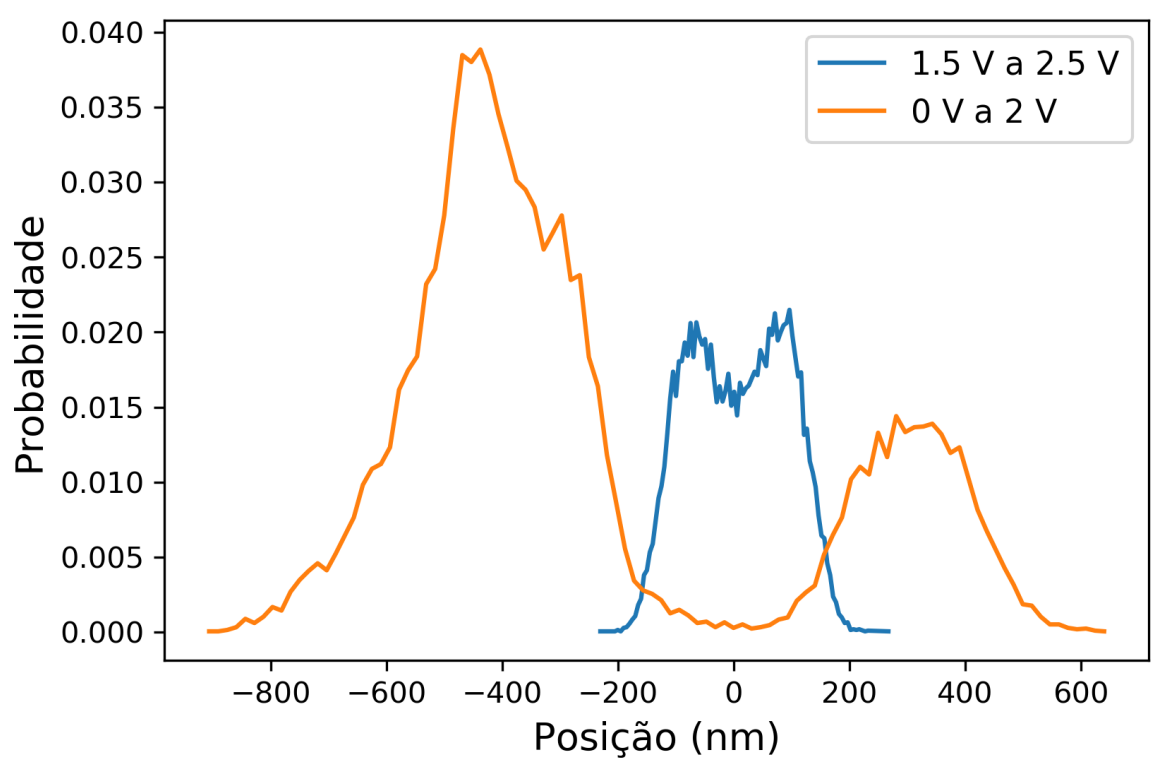

Figura 69 - Distribuição de probabilidade de um nanotubo de $\mathrm{TiO}_{2}$ aprisionado em um potencial duplo com $\Delta V_{f}=1 \mathrm{~V}$ (azul) e $\Delta V_{f}=2 \mathrm{~V}$ (laranja) durante $30 \mathrm{~s}$.

Fonte: Elaborada pela autora.

como uma das partículas aprisionada numa potência inicial de $1.8 \mathrm{~mW}$. Um duplo-poço foi gerado ao varrer o sinal de tensão no CMF de $1.5 \mathrm{~V}$ a $2.5 \mathrm{~V}$. De modo análogo ao resultado apresentado na Fig. 62, no qual foi gerado um sinal quadrado de modulação, a partícula transita entre os poços por meio de rotações e um resultado similar de transição entre poços foi obtido para a trajetória da posição do CM no eixo $x$.

A distribuição de probabilidade do CM da partícula no eixo $x$ se encontra na Fig. 69 e a curva de potencial desse conjunto de dados se encontra na Fig. 70. Conforme o esperado, é possível observar a existência de dois picos na distribuição de probabilidade e, consequentemente, uma curva de potencial duplo.

Como a estrutura do nanotubo de $\mathrm{TiO}_{2}$ aprisionado é suficientemente longa para transitar entre poços relativamente distantes, também foi aplicado um sinal de tensão no CMF de $0 \mathrm{~V}$ a $2 \mathrm{~V}$. Conforme o esperado, a distância entre os poços do potencial calculado (Fig. 70) aumentou para o sinal com $\Delta V_{f}=2 \mathrm{~V}$, em comparação ao obtido com $\Delta V_{f}=1 \mathrm{~V}$, no entanto o aumento não foi proporcional à variação de tensão aplicada. 


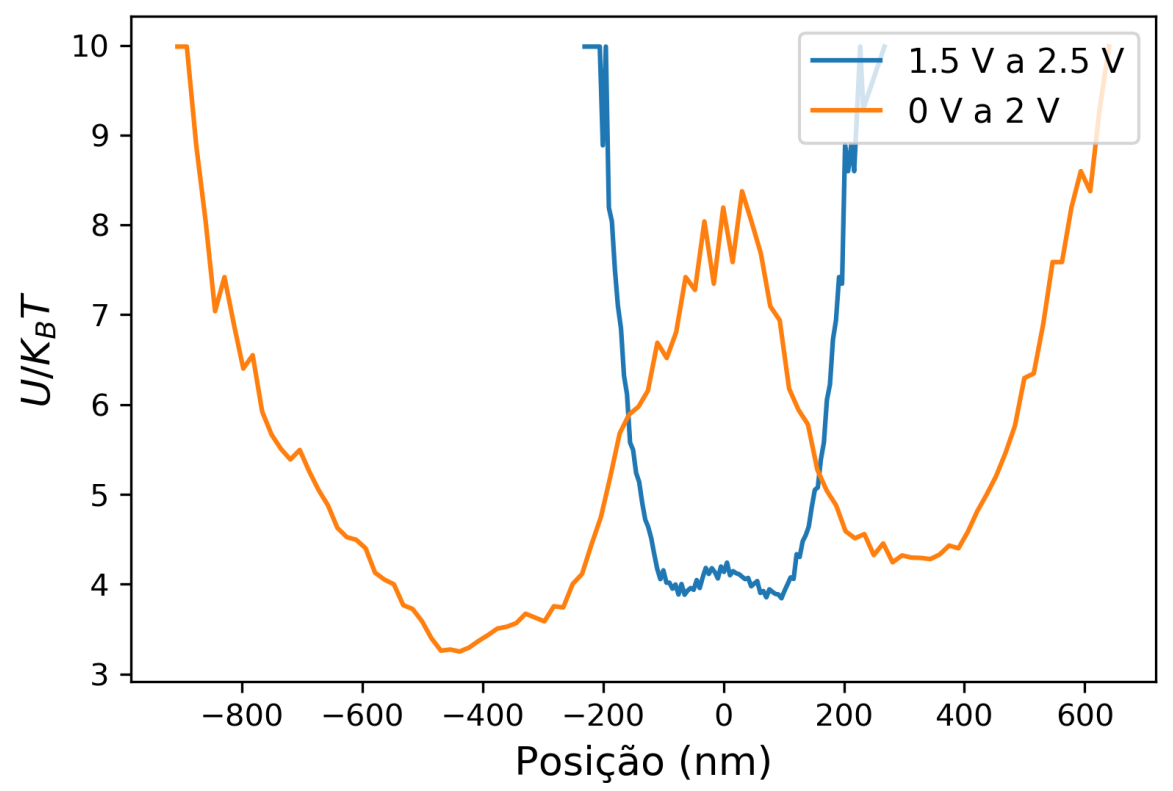

Figura 70 - Curva de potencial de um nanotubo de $\mathrm{TiO}_{2}$ aprisionado em um potencial duplo com $\Delta V_{f}=1 \mathrm{~V}$ (azul) e $\Delta V_{f}=2 \mathrm{~V}$ (laranja) durante $30 \mathrm{~s}$.

Fonte: Elaborada pela autora. 



\section{CONCLUSÕES}

O objetivo principal deste trabalho foi a construção e caracterização de uma pinça óptica para aprisionamento e controle dinâmico de micro e nanopartículas, no laboratório de tecnologias quânticas do Instituto de Física de São Carlos. Esse sistema foi construído praticamente partindo do zero e envolveu uma quantidade significativa de desenvolvimentos técnicos em instrumentação óptica e eletrônica. O trabalho também envolveu o estudo de diversas teorias relevantes e analises teóricas e computacionais, incluindo desenvolvimento de códigos para simulações numéricas e análise dos dados experimentais, coletados por diferentes tipos de sensores.

A partir de uma primeira montagem básica, equivalente à uma pinça óptica simples, foram feitas as primeiras calibrações do sistema e desenvolvidos os procedimentos de análise e caracterização do sistema experimental. O passo seguinte foi incluir um dispositivo de controle óptico (AOM) que permite controlar dinamicamente o potencial óptico produzido na pinça. O uso de um AOM possibilitou a modulação espacial do feixe e, por consequência, da pinça, com precisão de nanometros em uma escala de frequências de $1 \mathrm{~Hz}$ a $10 \mathrm{kHz}$. O sistema construído foi caracterizado e ainda está em contínuo estágio de desenvolvimento, mas já viabiliza alguns estudos interessantes com micro e nanopartículas, conforme mostrado nesta dissertação e em estudos com nanotubos que deram origem ao trabalho publicado na referência (43). No futuro, como um próximo passo de desenvolvimento deste trabalho, esse sistema será estendido e ampliado para explorar outros sistemas físicos de interesse do laboratório.

De modo cronológico, o sistema inicial foi constituído, basicamente, por um laser de infravermelho, responsável pelo aprisionamento óptico, um conjunto de lentes de magnificação e uma objetiva, responsável pela focalização do feixe, e espelhos adequados, como o espelho dicroico, importante para o aprisionamento e observação das amostras. Todos os dados foram coletados com uma câmera digital (CCD) de baixo custo e taxa de aquisição de imagens máxima de 200 fps. Esse sistema possibilitou a geração de uma força de aprisionamento da ordem de piconewtons e foi importante para a o desenvolvimento do primeiros estudos de dinâmica das micropartículas.

No período em que esta configuração da pinça esteve no laboratório, foram desenvolvidos códigos em Python para a calibração do sistema. Os métodos utilizados deveriam ser robustos mesmo com a baixa resolução temporal, limitada pelo taxa de aquisição de imagens da câmera. Posteriormente, como o objetivo aprimorar o sistema experimental, foi incluído o QPD - que chega a uma taxa de aquisição de $150 \mathrm{kHz}$. Foram desenvolvidos também códigos para calibração mais sofisticados, que permitem o estudo da dinâmica da partícula para tempos muito menores. Como naquele momento ainda não existiam 
dados experimentais com maior resolução temporal, foram geradas simulações de dinâmica estocástica para a trajetória de uma partícula browniana aprisionada em um potencial harmônico e essas foram utilizadas para testar a funcionalidade dos códigos de calibração desenvolvidos.

Após esses estudos iniciais de caracterização da pinça óptica simples, foi adicionado um AOM na saída do feixe e todo o sistema foi realinhado para a primeira ordem de difração desse modulador. Isso possibilitou o controle preciso da potência, além da viabilidade de se modular o laser espacialmente, ao longo de uma direção. No entanto, ao modular a frequência do AOM, dependendo da amplitude de modulação em frequência, pode haver uma variação significativa da potência do feixe difratado. Na tentativa de minimizar esse efeito, foi desenvolvido um sistema de controle que compensa a alteração na potência a partir do controle da amplitude da onda acústica no AOM. Apesar de resultados preliminares satisfatórios, pretende-se desenvolver, futuramente, um sistema mais sofisticado de feedback para controlar a intensidade do feixe de aprisionamento em situações de modulação mais complexas.

Após isso, novas calibrações foram feitas para melhor caracterizar o novo sistema e, mesmo com as deformações do feixe e a perda de potência efetiva do laser, ainda foi possível aprisionar diversas partículas de interesse, em potenciais modulados dinamicamente. E, como essas partículas se encontram num meio viscoso, o seu comportamento pôde ser distinguido em dois limites, um para modulação em baixas frequências (onde as partículas seguem o potencial) e outro para modulação em altas frequências (onde as partículas observam um potencial efetivo).

Em baixas frequências $(1 \mathrm{~Hz})$, a trajetória média da partícula acompanha o deslocamento espacial do laser, possibilitando a manipulação espacial com precisão de poucos nanometros. Três tipos de sinais foram testados, sendo estes ondas quadradas, triangulares e senoidais. Devido ao tamanho do caminho óptico utilizado e ao diâmetro da abertura da objetiva, a manipulação era efetiva num deslocamento da ordem de $3 \mu \mathrm{m}$. Para distâncias maiores, a constante de força da pinça reduzia-se significativamente.

O uso de um sinal de modulação quadrado* possibilitou o estudo da viabilidade de um método de calibração simples, que se baseia na análise da trajetória média da partícula no tempo. Os resultados obtidos foram consistentes com os parâmetros utilizados e viabilizam um método de calibração, não muito usual, que pode ser feito mesmo para um sistema de aquisição com baixa resolução temporal. Além disso, simulações foram feitas e o comportamento nesse limite de modulação foi similar ao observado experimentalmente.

No limite de altas frequências $(10 \mathrm{kHz})$, devido à viscosidade do meio, a partícula não acompanha a rápida variação espacial da pinça, mas sente um potencial efetivo de

* Foi utilizado um sinal quadrado para o estudo desse método de calibração, no entanto, bastaria um controle on-off do laser para reproduzir essas análises. 
aprisionamento. Com isso, foi possível explorar condições experimentais equivalentes a de um potencial do tipo duplo-poço, no qual é possível controlar a constante de força de cada poço individual, como também a distância e a altura relativa entre poços. Dados experimentais mostram o aprisionamento simultâneo de duas partículas de $1 \mu \mathrm{m}$ de diâmetro, mostrando a funcionalidade do potencial construído. Também foram realizados experimentos aprisionando uma única partícula na condição de duplo-poço, visando medir experimentalmente as taxas de transições entre os poços, no entanto os primeiros testes com uma única partícula (sílica) não apresentaram transição efetiva entre os poços. Essa também será uma das direções a ser mais explorada em futuros experimentos.

Na tentativa de melhor escolher os parâmetros utilizados na geração do duplopoço, para aumentar o efeito de transição da partícula, foi desenvolvido um modelo computacional, baseado em equações diferenciais estocásticas, e verificou-se que a pinça construída (dentro dos parâmetros experimentais disponíveis) possibilita a transição entre poços $^{\dagger}$. No entanto, a resolução temporal da câmera, aliada às vibrações mecânicas no aparato atual, dificultam a visualização e quantificação precisa desse efeito. Na tentativa de contornar isso, duas medidas experimentais foram exploradas: a primeira foi aprisionar partículas com diferentes tamanhos e formatos, para tentar verificar a transição entre poços, e a outra foi a montagem de um fotodiodo de quadrantes (QPD), para medir a posição das partículas com maior resolução espacial e temporal. Resultados positivos foram obtidos ao aprisionar nanotubos de $\mathrm{TiO}_{2}$ e esferas de poliestireno, onde neste último sistema observou-se os primeiros indicativos de transições entre os poços de aprisionamento óptico.

Embora a calibração do QPD tenha se mostrado consistente com os parâmetros utilizados, ao coletar dados referentes às trajetórias das partículas aprisionadas, um problema técnico (eletrônico) resultou num ruído excessivo no sinal coletado e que impossibilitou o uso desses resultados no período disponível para conclusão deste trabalho, por isso foi utilizado dados de calibração obtidos com a câmera, na maioria das situações descritas nesta dissertação. No entanto, dados iniciais obtidos com o QPD, anteriores ao problema técnico no circuito, apresentaram um comportamento próximo ao esperado.

Os resultados obtidos para a distribuição de probabilidade, curva de potencial, função de correlação e desvio quadrático médio, para uma partícula de poliestireno de diâmetro de $d=1 \mu \mathrm{m}$ aprisionada em uma potência de aproximadamente $2 \mathrm{~mW}$, se encontram na Fig. 71. Embora a trajetória utilizada esteja em unidades arbitrárias, visto que no período da coleta desses dados não tínhamos ainda uma calibração final. O comportamento das curvas é similar ao apresentado na Seção 4.2.

† É importante destacar que o duplo-poço simétrico, ou seja, com as mesmas constantes de força para o potencial de cada poço, são ideais para o estudo de transições, inicialmente. No entanto, devido às características do sistema experimental, ainda não foi possível gerar esse tipo de potencial com boa precisão. 
Desse modo, espera-se solucionar esses problemas, em breve, visto que o aumento de resolução temporal e espacial são importantes para o prosseguimento dos estudos com a pinça óptica no laboratório.
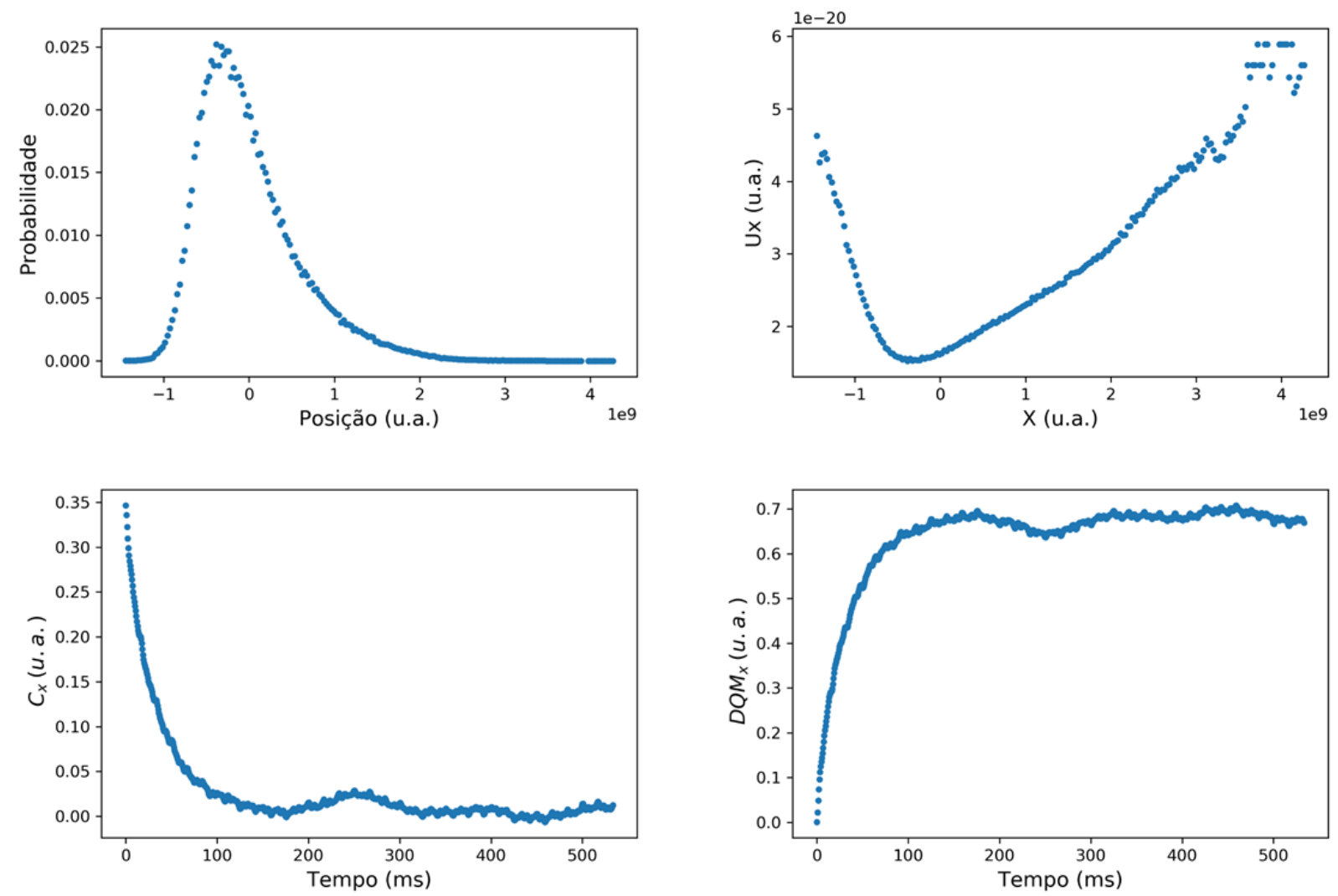

Figura 71 - Distribuição de probabilidade (esquerda em cima), curva de potencial (direita em cima), função de correlação (esquerda embaixo) e desvio quadrático médio (direita embaixo) para uma partícula de poliestireno de diâmetro de $d=1 \mu \mathrm{m}$ aprisionada em uma potência de aproximadamente $2 \mathrm{~mW}$. A trajetória utilizada corresponde ao sinal de saída do QPD $x_{Q P D}$, em volts, que pode ser convertida para unidades de comprimento por um fator de calibração.

Fonte: Elaborada pela autora.

O sistema atual, embora construído sobre uma mesa óptica, não conta atualmente com um sistema pneumático de estabilização e desacoplamento de vibrações, que poderia reduzir bastante algumas vibrações mecânicas observadas. Acreditamos que essas vibrações sejam responsáveis por algumas das maiores incertezas na calibração atual do sistema, especialmente na direção $y$. Algumas melhorias desse aparato já estão previstas e deverão permitir a continuidade desses estudos, num futuro próximo.

Embora não sejam discutidas nesta dissertação, vale mencionar que além das partículas apresentadas no presente trabalho, foram também aprisionadas na pinça óptica 
micro e nanodiamantes com centros de nitrogênio-vacância ${ }^{\ddagger}$ e nanopartículas de conversão ascendente $^{\S}$ (UCNPs, do inglês upconversion nanoparticles). Essas partículas ainda estão sendo estudadas e são objetos de grande interesse para futuras pesquisas no laboratório.

Desta forma, além de contribuir com o contínuo avanço da fronteira na área de aprisionamento óptico, esta pesquisa deu início a nova linha de estudos em nosso laboratório e deverá viabilizar uma série de trabalhos futuros, entre eles, a possibilidade de explorar propriedades termodinâmicas de nano-sistemas fora do equilíbrio, bem como a capacidade de controlar nano-sensores quânticos (45), baseados em centros de nitrogênio-vacância em nanodiamantes. Esse tipo de estudo é importante no contexto de futuras tecnologias quânticas, tema de grande interesse e investimento internacional, por seu potencial de inovação técnico-científica e também econômico.

$¥$ O centro de nitrogênio-vacância consiste em um átomo de nitrogênio substitucional ao lado de uma vacância na rede cristalina do diamante. Quando excitada opticamente por um laser verde, a amostra fluoresce na região do vermelho $(44,45)$, tornando possível sua detecção.

$\S$ As UCNPs são observadas através da fluorescência, como os nanodiamantes com centros de nitrogênio-vacância. No entanto, a absorção ocorre no infravermelho e a emissão na regiões visível ou ultravioleta, por conversão ascendente de fótons. 



\section{REFERÊNCIAS}

1 ASHKIN, A. Acceleration and trapping of particles by radiation pressure. Physical Review Letters, v. 24, n. 4, p. 156, 1970.

2 ASHKIN, A.; DZIEDZIC, J. Optical levitation by radiation pressure. Applied Physics Letters, v. 19, n. 8, p. 283-285, 1971.

3 ASHKIN, A. et al. Observation of a single-beam gradient force optical trap for dielectric particles. Optics Letters, v. 11, n. 5, p. 288-290, 1986.

4 ASHKIN, A.; DZIEDZIC, J. M.; YAMANE, T. Optical trapping and manipulation of single cells using infrared laser beams. Nature, v. 330, n. 6150, p. 769, 1987.

5 HELLER, I. et al. Optical tweezers analysis of dna-protein complexes. Chemical Reviews, v. 114, n. 6, p. 3087-3119, 2014.

6 STEPHENSON, W. et al. Nanomanipulation of single rna molecules by optical tweezers. Journal of Visualized Experiments, n. 90, p. e51542, 2014.

7 BOCKELMANN, U. et al. Unzipping dna with optical tweezers: high sequence sensitivity and force flips. Biophysical Journal, v. 82, n. 3, p. 1537-1553, 2002.

8 WEN, J.-D. et al. Force unfolding kinetics of rna using optical tweezers. i. effects of experimental variables on measured results. Biophysical Journal, v. 92, n. 9, p. 2996-3009, 2007.

9 SVOBODA, K.; BLOCK, S. M. Biological applications of optical forces. Annual Review of Biophysics and Biomolecular Structure, v. 23, n. 1, p. 247-285, 1994.

10 MEHTA, A. D. et al. Single-molecule biomechanics with optical methods. Science, v. 283, n. 5408, p. 1689-1695, 1999.

11 ISHII, Y.; ISHIJIMA, A.; YANAGIDA, T. Single molecule nanomanipulation of biomolecules. TRENDS in Biotechnology, v. 19, n. 6, p. 211-216, 2001.

12 KUO, S. C. Using optics to measure biological forces and mechanics. Traffic, v. 2, n. 11, p. $757-763,2001$.

13 JARZYNSKI, C. Stochastic and macroscopic thermodynamics of strongly coupled systems. Physical Review X, v. 7, n. 1, p. 011008, 2017.

14 BUSTAMANTE, C.; LIPHARDT, J.; RITORT, F. The nonequilibrium thermodynamics of small systems. 2005. Disponível em: <arXiv preprint cond-mat/0511629>. Acesso em: 24.06.2019.

15 SEIFERT, U. Stochastic thermodynamics, fluctuation theorems and molecular machines. Reports on Progress in Physics, v. 75, n. 12, p. 126001, 2012.

16 HOROWITZ, V. R. et al. Electron spin resonance of nitrogen-vacancy centers in optically trapped nanodiamonds. Proceedings of the National Academy of Sciences, v. 109, n. 34, p. 13493-13497, 2012. 
17 ACOSTA, V. et al. Broadband magnetometry by infrared-absorption detection of nitrogen-vacancy ensembles in diamond. Applied Physics Letters, v. 97, n. 17, p. 174104, 2010.

18 TAYLOR, J. et al. High-sensitivity diamond magnetometer with nanoscale resolution. Nature Physics, v. 4, n. 10, p. 810, 2008.

19 WU, M.-y. et al. Stable optical trapping and sensitive characterization of nanostructures using standing-wave raman tweezers. Scientific Reports, v. 7, p. 42930, 2017.

20 CHANG, Y.-R.; HSU, L.; CHI, S. Optical trapping of a spherically symmetric sphere in the ray-optics regime: a model for optical tweezers upon cells. Applied Optics, v. 45, n. 16, p. 3885-3892, 2006.

21 ASHKIN, A. Forces of a single-beam gradient laser trap on a dielectric sphere in the ray optics regime. Biophysical Journal, v. 61, n. 2, p. 569-582, 1992.

22 BRADAC, C. Nanoscale optical trapping: A review. Advanced Optical Materials, v. 6, n. 12 , p. $1800005,2018$.

23 BOHREN, C. F.; HUFFMAN, D. R. Absorption and scattering of light by small particles. New York: John Wiley \& Sons, 2008.

24 SARSHAR, M.; WONG, W.; ANVARI, B. Comparative study of methods to calibrate the stiffness of a single-beam gradient-force optical tweezers over various laser trapping powers. Journal of Biomedical Optics, v. 19, n. 11, p. 115001, 2014.

25 TOLIĆ-NØRRELYKKE, S. F. et al. Calibration of optical tweezers with positional detection in the back focal plane. Review of Scientific Instruments, v. 77, n. 10, p. 103101, 2006.

26 ALVES, P. S. Teoria e calibração de pinças ópticas. 2012.75 p. Dissertação (Mestrado) — Universidade Federal de Viçosa, Viçosa, 2012.

27 ROCHA, M. S. Pinças ópticas: experimento, teoria e aplicação no estudo da interação DNA-fármacos. 2008. Tese (Doutorado) — Universidade Federal de Minas Gerais, Belo Horizonte, 2008.

28 ORTAS, J. F. Dynamic optical tweezers using acousto-optic Modulators. 2015. Disponivel em: <https://pdfs.semanticscholar.org/ce15/22eb57914917b03a2fca512b16494641963f.pdf.>. Acesso em: 24.06.2019.

29 JONES, P. H.; MARAGÒ, O. M.; VOLPE, G. Optical tweezers: principles and applications. Cambridge: Cambridge University Press, 2015.

30 BANDRES, M. A.; GUTIÉRREZ-VEGA, J. C. Ince-gaussian beams. Optics Letters, v. 29, n. 2, p. 144-146, 2004.

31 LEUTENEGGER, M. et al. Fast focus field calculations. Optics Express, v. 14, n. 23, p. 11277-11291, 2006. 
32 LOCK, J. A. Calculation of the radiation trapping force for laser tweezers by use of generalized lorenz-mie theory. i. localized model description of an on-axis tightly focused laser beam with spherical aberration. Applied Optics, v. 43, n. 12, p. 2532-2544, 2004.

33 XIN-CHENG, Y. et al. Effects of spherical aberration on optical trapping forces for rayleigh particles. Chinese Physics Letters, v. 18, n. 3, p. 432, 2001.

34 JACKSON, J. D. Classical electrodynamics. New York: John Wiley Sons, Inc., 1962.

35 REIF, F. Fundamentals of statistical and thermal physics. New York: McGraw-Hill, 1965.

36 VOLPE, G.; VOLPE, G. Simulation of a brownian particle in an optical trap. American Journal of Physics, v. 81, n. 3, 2013.

37 FELEKIS, D.; PAPADOPOULOS, E. Design and development of a low-cost interferometric device for nanoscale position and velocity feedback. In: INTERNATIONAL CONFERENCE ON ADVANCED INTELLIGENT MECHATRONICS,IEEE/ASME, 2010, Montreal, Canada. Proceedings.. Montreal, 2010. p. 611-616.

38 THORLABS. Position-Sensing Detector. Disponivel em: $<$ https://www.thorlabs.com>. Acesso em: 24.06.2019.

39 KRAMERS, H. Brownian motion in a field of force and the diffusion model of chemical reactions. Physica, v. 7, n. 4, p. $284-304,1940$.

40 MCCANN, L. I.; DYKMAN, M.; GOLDING, B. Thermally activated transitions in a bistable three-dimensional optical trap. Nature, v. 402, n. 6763, p. 785-787, 1999.

41 ZORNIO, B. F. Estudo teórico e experimental da teoria de Kramers utilizando pinças ópticas e dinâmica de Langevin. 2014. Dissertação (Mestrado) Universidade Estadual de Campinas, Campinas, 2014.

42 BAI, Z.-W. Simple generalization of kramers theory to finite barrier height in spatial diffusion regime. Physics Letters A, v. 382, n. 32, p. 2103-2107, 2018.

43 OLIVEIRA, G. H. et al. Real time single TiO2 nanoparticle monitoring of the photodegradation of methylene blue. Solar Energy, v. 190, n. 32, p. 239-245, 2019.

44 RUDNICKI, D. et al. Diamond nanocrystals with nitrogen-vacancy centers as new type temperature sensors. Mechanik, v. 89, n. 5-6, p. 526-527, 2016.

45 SEGURA, C. O. O. Diamond studies for applications in quantum technologies. 2019. 115 p. Tese (Doutorado em Ciências) — Instituto de Física de São Carlos, Universidade de São Paulo, São Carlos, 2019.

46 LVOVSKY, A. I. Fresnel equations. In: HOFFMAN, C. (Ed.). Encyclopedia of Optical Engineering. 2.ed. Boca Raton: CRC Press, 2015. 6p. 

Apêndices 



\section{APÊNDICE A - EQUAÇÕES DE FRESNEL}

Quando uma onda eletromagnética de vetor de onda $\vec{k}_{i}$, orientada por um ângulo $\theta_{i}{ }^{*}$ e amplitude $E_{i}$, incide em uma interface entre dois meios dielétricos, o ângulo de reflexão $\theta_{r}$ é dado pela lei da reflexão

$$
\theta_{r}=\theta_{i}
$$

e o ângulo de transmissão é dado pela lei de Snell

$$
n_{t} \sin \left(\theta_{t}\right)=n_{i} \sin \left(\theta_{i}\right)
$$

sendo $n_{i}$ o índice de refração no meio da luz incidente e $n_{t}$ o índice de refração no meio da luz transmitida e $E_{r}$ e $E_{t}$ as amplitudes das ondas refletida e transmitida, respectivamente. $(34)$

Como a onda eletromagnética é transversa, podemos decompor o campo nas componentes de polarização P e S. Na primeira, o campo elétrico está contido no plano de incidência e na segunda, o campo elétrico é ortogonal ao plano, conforme a Fig. $72^{\dagger}$.

Para uma onda de polarização $\mathrm{P}$, as condições de contorno para o campo elétrico $E$ e magnético $H$ são dadas por:

$$
\begin{gathered}
E_{i} \cos \left(\theta_{i}\right)+E_{r} \cos \left(\theta_{i}\right)=E_{t} \cos \left(\theta_{t}\right) \\
H_{i}-H_{r}=H_{t} .
\end{gathered}
$$

As amplitudes do campo elétrico e magnético obedecem a relação $H=\sqrt{\epsilon / \mu} E$, sendo $\epsilon$ e $\mu$ a permissividade elétrica e permeabilidade magnética, respectivamente. Como o índice de refração é dado por $n=\sqrt{\epsilon \mu}$, temos

$$
\begin{aligned}
& H_{i, r}=n_{i} E_{i} / \mu_{i} c \\
& H_{t}=n_{2} E_{t} / \mu_{2} c .
\end{aligned}
$$

* O ângulo de incidência $\theta_{i}$ é definido como o ângulo entre a onda eletromagnética incidente e a direção $n$ normal a superfície.

† Este apêndice está baseado na referência (46). 


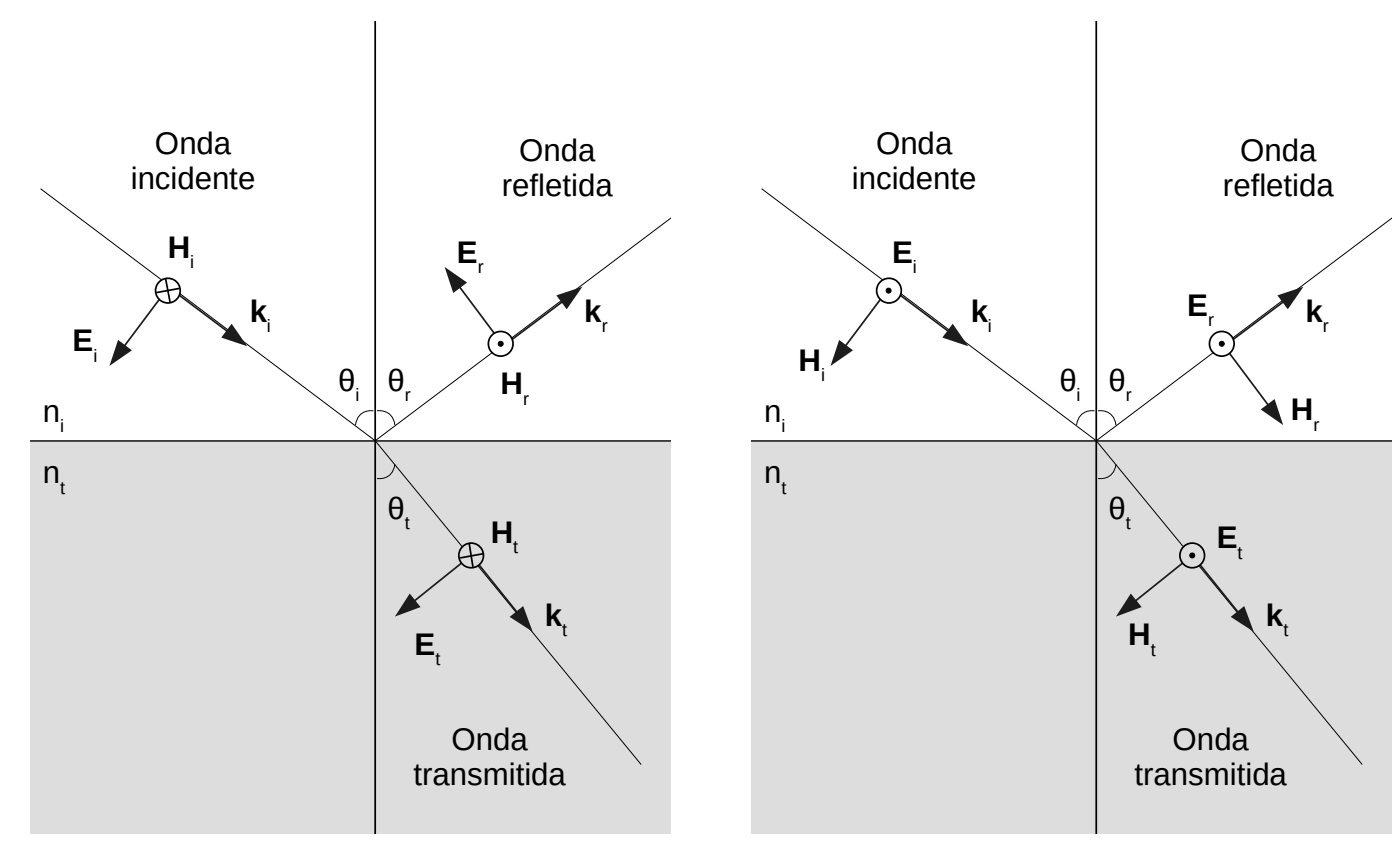

Figura 72 - Campos elétricos e magnéticos das ondas incidentes, refletidas e transmitidas com polarização P (esquerda) e polarização S (direita).

Fonte: Adaptada de LVOVSKY (46).

Aplicando a Eq. A.4

$$
\frac{n_{i}\left(E_{i}-E_{r}\right)}{\mu_{i}}=\frac{n_{t} E_{t}}{\mu_{t}}
$$

e combinando as equações A.3 e A.6, temos os coeficientes de reflexão $r_{P}$ e transmissão $t_{P}$

$$
\begin{aligned}
& r_{P}=\frac{E_{t}}{E_{i}}=\frac{\left(n_{i} / \mu_{i}\right) \cos \theta_{t}-\left(n_{t} / \mu_{t}\right) \cos \theta_{i}}{\left(n_{i} / \mu_{i}\right) \cos \theta_{t}+\left(n_{t} / \mu_{t}\right) \cos \theta_{i}} \\
& t_{P}=\frac{E_{t}}{E_{i}}=\frac{2\left(n_{i} / \mu_{i}\right) \cos \theta_{i}}{\left(n_{i} / \mu_{i}\right) \cos \theta_{t}+\left(n_{t} / \mu_{t}\right) \cos \theta_{i}} .
\end{aligned}
$$

No caso da polarização S, as condições de contorno são dadas por

$$
\begin{gathered}
E_{i}+E_{r}=E_{t} \\
-H_{i} \cos \theta_{i}+H_{r} \cos \theta_{i}=-H_{t} \cos \theta_{t}
\end{gathered}
$$

e, de modo análogo, temos os coeficientes

$$
r_{S}=\frac{E_{r}}{E_{i}}=\frac{\left(n_{i} / \mu_{i}\right) \cos \theta_{i}-\left(n_{t} / \mu_{t}\right) \cos \theta_{t}}{\left(n_{i} / \mu_{i}\right) \cos \theta_{i}+\left(n_{t} / \mu_{t}\right) \cos \theta_{t}}
$$




$$
t_{S}=\frac{E_{t}}{E_{i}}=\frac{2\left(n_{i} / \mu_{i}\right) \cos \theta_{i}}{\left(n_{i} / \mu_{i}\right) \cos \theta_{i}+\left(n_{t} / \mu_{t}\right) \cos \theta_{t}} .
$$

Para materiais não magnéticos podemos aproximar $\mu_{i}=\mu_{t}=\mu_{0}$ e escrever os coeficientes de reflexão de intensidade $R$, sabendo que $I \propto|E|^{2}$ para campos no mesmo meio:

$$
\begin{aligned}
& R_{P}=\left|r_{P}\right|^{2}=\left|\frac{n_{i} \cos \theta_{t}-n_{t} \cos \theta_{i}}{n_{i} \cos \theta_{t}+n_{t} \cos \theta_{i}}\right|^{2} \\
& R_{S}=\left|r_{S}\right|^{2}=\left|\frac{n_{i} \cos \theta_{i}-n_{t} \cos \theta_{t}}{n_{i} \cos \theta_{i}+n_{t} \cos \theta_{t}}\right|^{2}
\end{aligned}
$$

e os coeficientes de transmissão de intensidade $T$, por conservação de energia,

$$
\begin{aligned}
& T_{P}=1-R_{P} \\
& T_{S}=1-R_{S} .
\end{aligned}
$$

Para ondas com polarização circular, os coeficientes $R$ e $T$ são dados por

$$
\begin{aligned}
& R=\frac{R_{S}+R_{P}}{2} \\
& T=\frac{T_{S}+T_{P}}{2} .
\end{aligned}
$$





\section{APÊNDICE B - CÁLCULO DO ÂNGULO DE ROTAÇÃO DOS EIXOS DA CÂMERA EM RELAÇÃO AOS EIXOS DE REFERÊNCIA}

Considerando os eixos do nanoposicionador como referência, o vetor deslocamento, capturado pela câmera no plano $x y$, nas condições apresentadas na Seção 5.2, apresentou um ângulo em relação à direção vertical diferente de zero.

A Fig. 73 mostra o deslocamento do centro de massa no plano para um deslocamento vertical do piezoelétrico (10 médias). A partir do coeficiente angular do gráfico, $m=\tan (\theta)$, é possível calcular o desalinhamento do eixo vertical da câmera em relação ao eixo do nanoposicionador. $\mathrm{O}$ valor obtido foi de $\theta=14.7317^{\circ} \pm 0.0004^{\circ} *$.

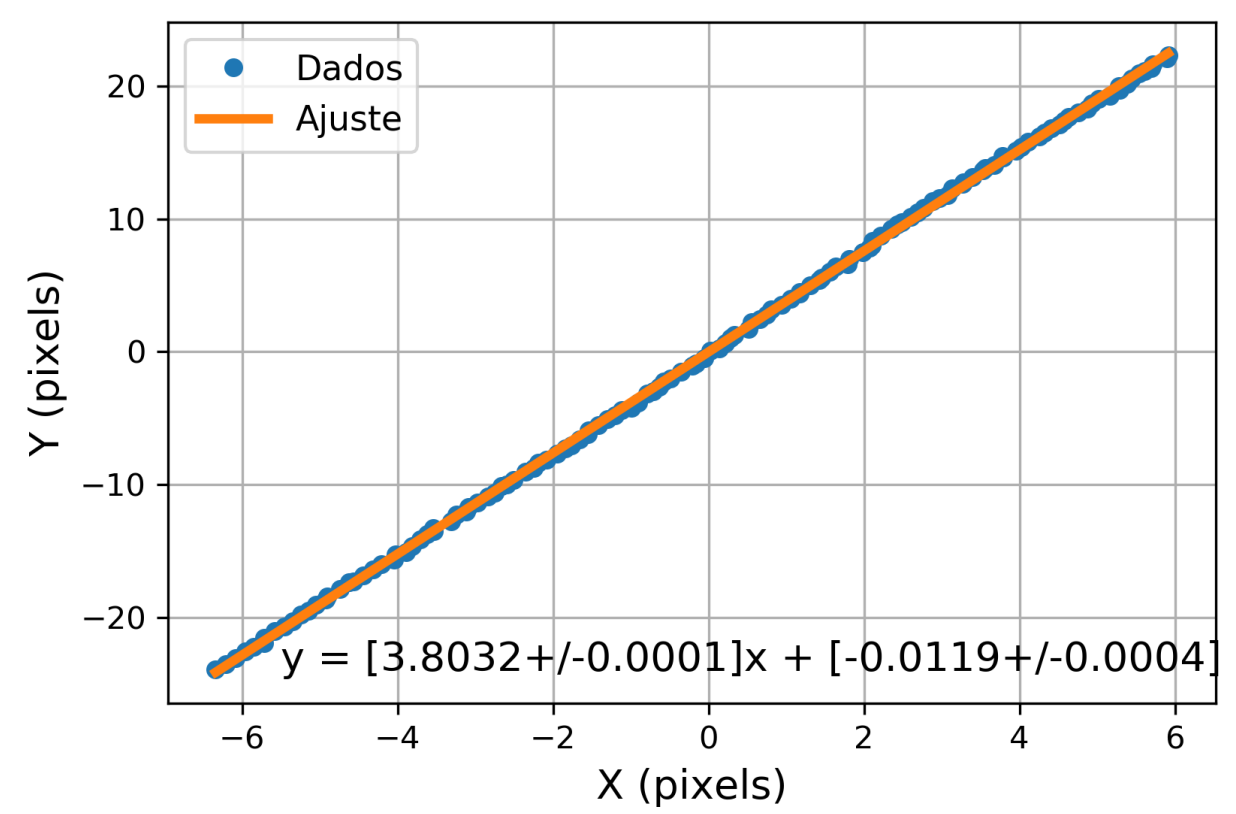

Figura 73 - Deslocamento do centro de massa da partícula no plano $x y$ ao aplicar uma rampa de tensão de $-10 \mathrm{~V}$ a $10 \mathrm{~V}$.

Fonte: Elaborada pela autora.

Calculando o módulo do vetor posição $r_{i}=\sqrt{x_{i}^{2}+y_{i}^{2}}$ e o ângulo deste em relação à horizontal $\theta_{i}=\arctan \left(\frac{y_{i}}{x_{i}}\right)$ para cada frame, sendo $\left(x_{i}, y_{i}\right)$ as coordenadas do centro de massa da partícula, é possível fazer uma rotação por um ângulo $\theta_{r}=14.73^{\circ}$, de modo que

* Enquanto o sistema tem a distribuição do feixe de laser gaussiano aproximadamente simétrica, não é necessário alinhar os eixos da imagem da câmera com o eixo de referência. No entanto, ao adicionar o AOM, além do feixe não ser mais simétrico, a modulação é feita em um eixo bem definido do espaço, e este, coincide com o eixo de referência escolhido 
o novo ângulo do vetor posição é dado por $\theta=\theta_{i}+\theta_{r}$ e, consequentemente, as coordenadas são dadas por

$$
\begin{aligned}
& x=r_{i} \cos \theta \\
& y=r_{i} \sin \theta
\end{aligned}
$$




\section{APÊNDICE C - CALIBRAÇÃO DO FOTODETECTOR}

O laboratório conta com um perfilador de feixe óptico de varredura de fenda capaz de medir a potência do feixe com alta precisão. Com o auxílio deste equipamento, foi feita uma calibração relacionando a tensão de resposta do fotodetector, que coleta parte do feixe infravermelho (Fig. 27), e a potência obtida com o perfilador na saída da objetiva.

Como o sistema foi alinhado sem o uso do AOM (Fig. 74) e com o uso do AOM (Fig. 75), duas curvas de calibração foram obtidas.

Para o sistema sem o AOM, a potência que chega na amostra $P$, em miliwatts, em função da resposta do fotodetector $T$, em volts, é dada por:

$$
P=(0.4430 \pm 0.0002) T+(0.000 \pm 0.001)
$$

e, para o sistema com o AOM, a função de calibração é dada por:

$$
P=(4.47 \pm 0.07) T+(0.08 \pm 0.08)
$$

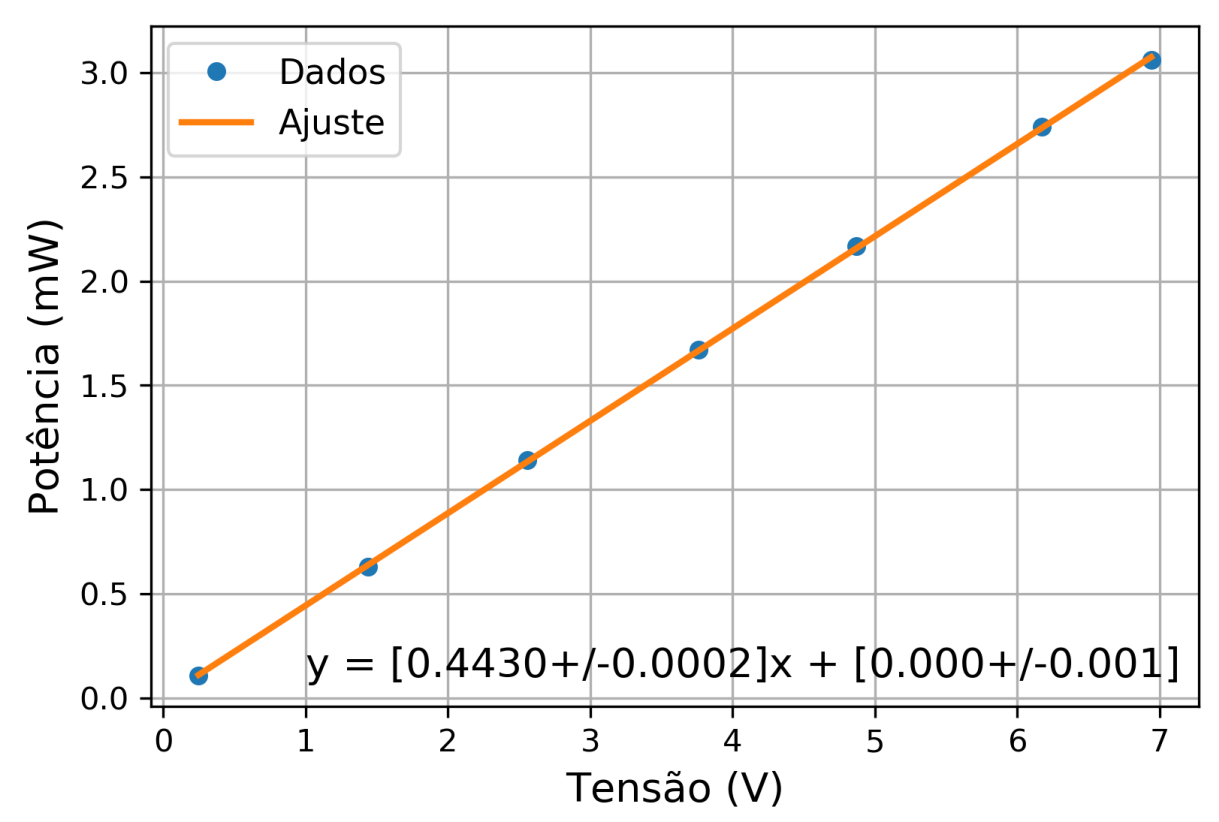

Figura 74 - Curva de calibração da potência na amostra em função do sinal de tensão no fotodetector para o sistema sem o AOM.

Fonte: Elaborada pela autora. 


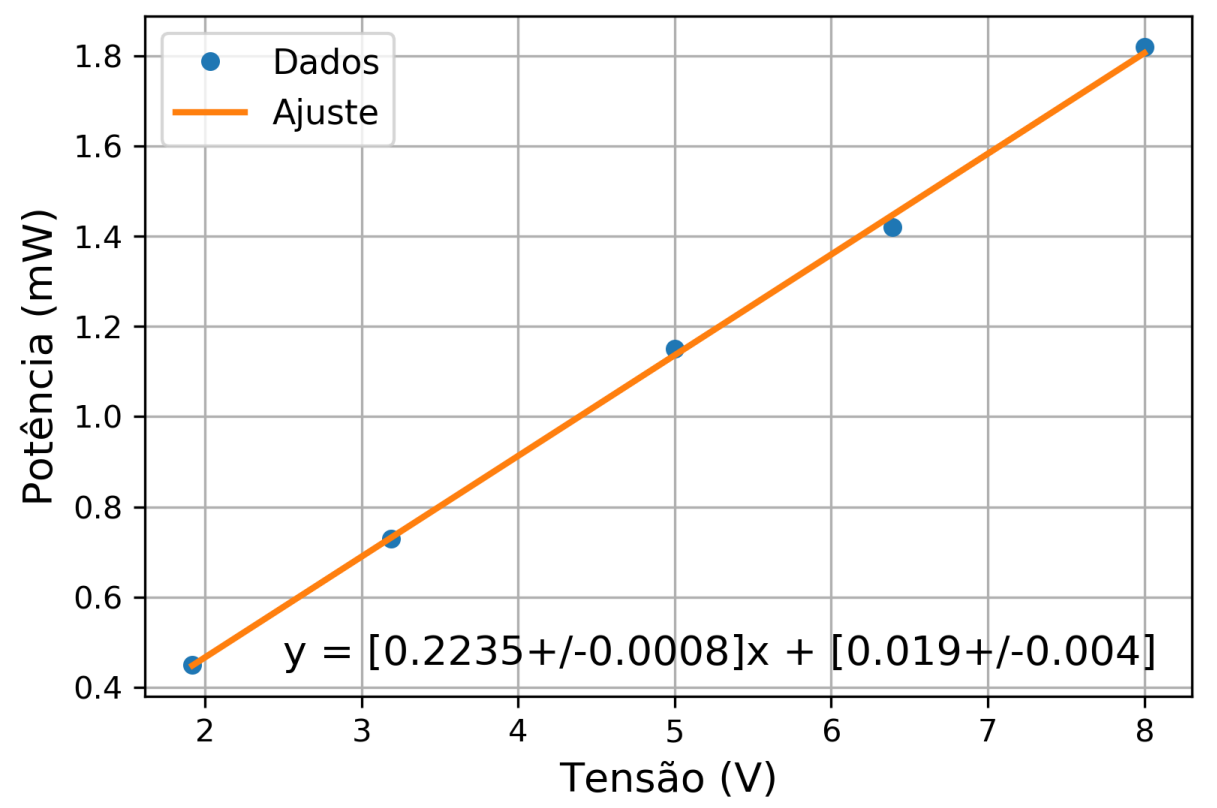

Figura 75 - Curva de calibração da potência na amostra em função do sinal de tensão no fotodetector para o sistema com o AOM.

Fonte: Elaborada pela autora. 


\section{APÊNDICE D - SIMULAÇÃO DO MOVIMENTO BROWNIANO}

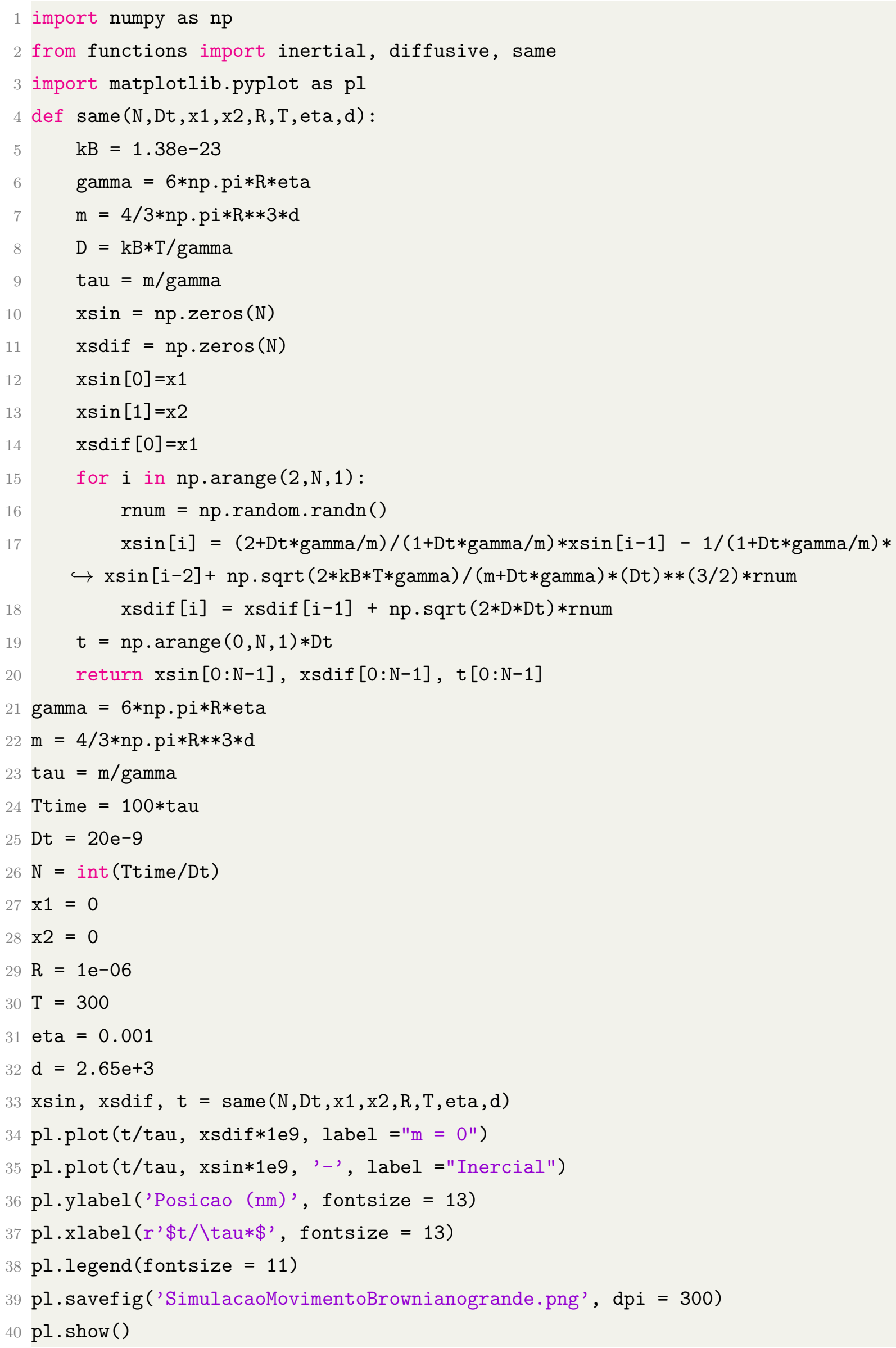





\section{APÊNDICE E - SIMULAÇÃO DO POTENCIAL HARMÔNICO}

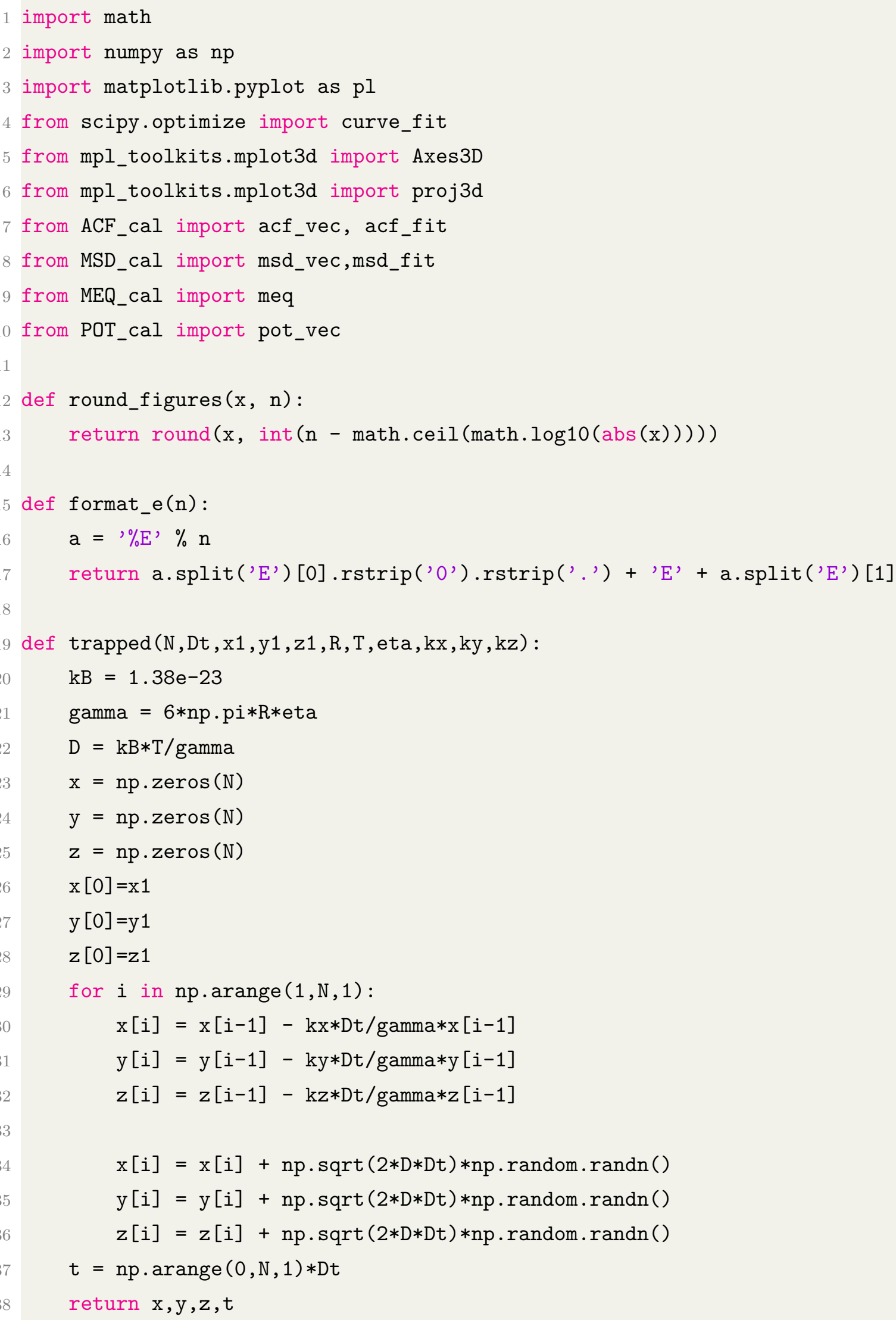


40 \# Parametros

41 Ttime $=10$

$42 \mathrm{Dt}=1 \mathrm{e}-03$

$43 \mathrm{~N}=\operatorname{int}($ Ttime/Dt)

$44 \mathrm{x} 1=0$

$45 \mathrm{y} 1=0$

$46 \mathbf{z} 1=0$

$47 \mathrm{R}=1 \mathrm{e}-06$

48 Temp $=300$

49 eta $=0.001$

$50 \mathrm{~d}=2.65 \mathrm{e}+3$

$51 \mathrm{kx}=3 * 1 \mathrm{e}-6$

$52 \mathrm{ky}=3 * 1 \mathrm{e}-6$

$53 \mathrm{kz}=3 * 0.2 \mathrm{e}-6$

54 gamma $=6 * \mathrm{np} \cdot \mathrm{pi} * \mathrm{R} *$ eta

$55 \mathrm{~m}=4 / 3 * \mathrm{np} \cdot \mathrm{pi} * \mathrm{R} * * 3 * \mathrm{~d}$

56 tau $=$ gamma $/ \mathrm{kx}$

57

58 \# Simulacoes

$59 \mathrm{x}, \mathrm{y}, \mathrm{z}, \mathrm{t}=\operatorname{trapped}(\mathrm{N}, \mathrm{Dt}, \mathrm{x} 1, \mathrm{y} 1, \mathrm{z} 1, \mathrm{R}, \mathrm{Temp}, \mathrm{eta}, \mathrm{kx}, \mathrm{ky}, \mathrm{kz})$

$60 \mathrm{pl} \cdot \operatorname{plot}(t, \mathrm{x} * 1 \mathrm{e} 9$, label $=" \mathrm{X} ")$

$61 \mathrm{pl} \cdot \mathrm{plot}(\mathrm{t}, \mathrm{y} * 1 \mathrm{e} 9$, label $=$ "Y")

$62 \mathrm{pl} \cdot \mathrm{plot}(\mathrm{t}, \mathrm{z} * 1 \mathrm{e} 9$, label $=" \mathrm{Z} ")$

$63 \mathrm{pl} . \mathrm{ylabel}$ ('Posicao ( $\mathrm{nm})^{\prime}$ )'

$64 \mathrm{pl} . x \mathrm{xlabel}$ ('Tempo (s)')

$65 \mathrm{pl}$. legend()

$66 \mathrm{pl}$.savefig('Particula_aprisionada.png', dpi = 300)

$67 \mathrm{pl}$.show()

68

69 scale_y $=5.0$

70 scale_z $=10.0$

71 max_scale $=\max \left(s c a l e_{-} x\right.$, scale_y, scale_z

72 scale_x $=$ scale_x/max_scale

73 scale_y=scale_y/max_scale

74 scale_z=scale_z/max_scale

75 scale $=n p \cdot \operatorname{array}([$ scale_x $, 0,0,0]$,

$76 \quad[0$, scale_y, 0,0$]$,

$77 \quad\left[0,0\right.$, scale_z $\left._{-}, 0\right]$,

$78 \quad[0,0,0,1]])$

79

80 def get_proj_scale(self): 


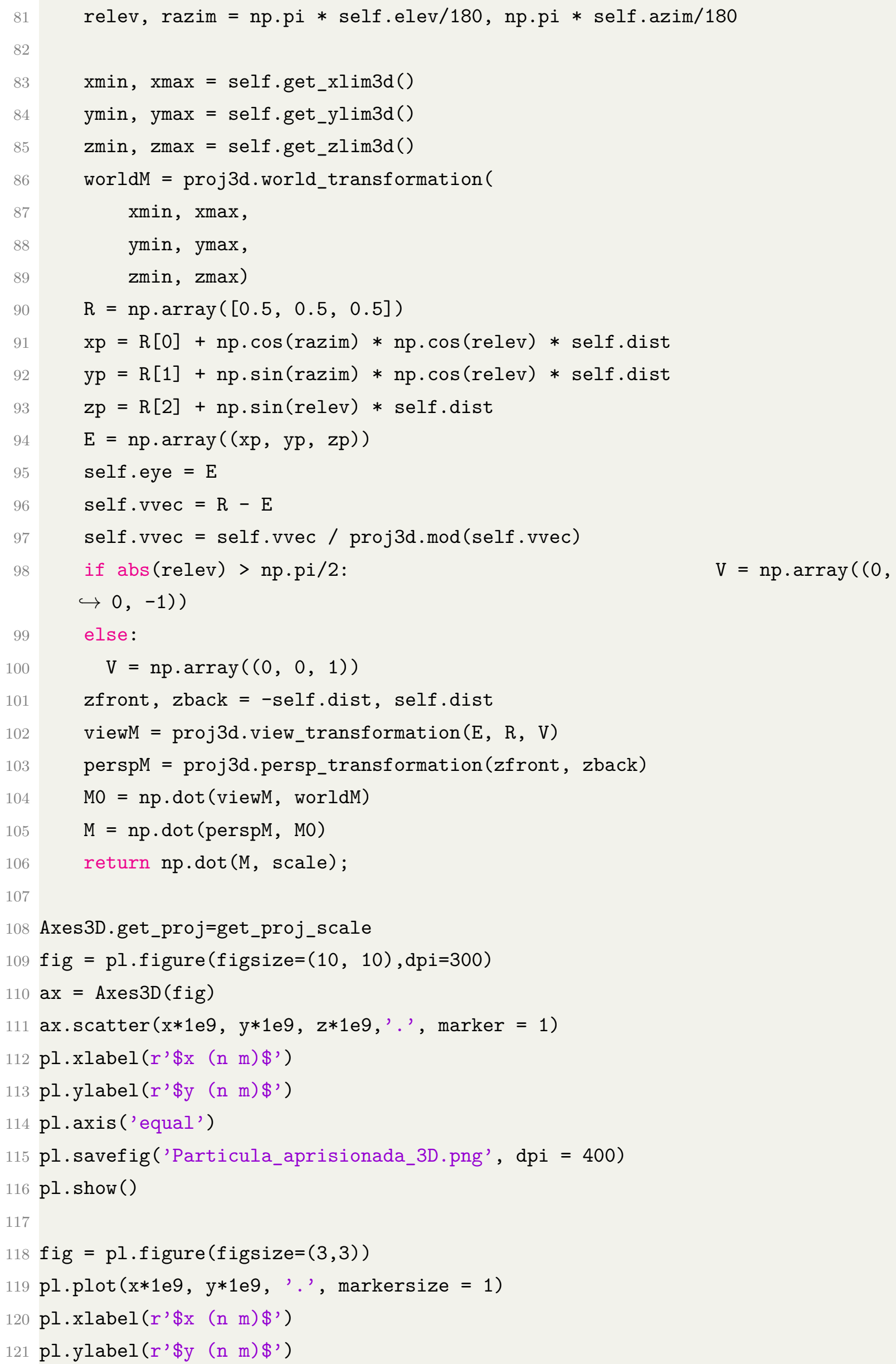


22 pl.savefig('Particula_aprisionada_xy.png', dpi = 300)

23 pl.show ()

124

$25 \mathrm{fig}=\mathrm{pl}$. figure $(\mathrm{figsize}=(3,6), \mathrm{dpi}=300)$

26 pl.plot (x*1e9, z*1e9, '.', markersize = 1)

$\mathrm{pl} . \mathrm{xlabel}\left(\mathrm{r}^{\prime} \$ \mathrm{x}\right.$ (n m) \$')

$\mathrm{pl} \cdot \mathrm{ylabel}\left(\mathrm{r}^{\prime} \$ \mathrm{z}\right.$ ( $\left.\left.\mathrm{n} \mathrm{m}\right) \$^{\prime}\right)$

pl.savefig('Particula_aprisionada_xz.png', dpi = 300)

pl.show ()

131

132 \# Estudo da dinamica

$133 r=\mathrm{R}$

$134 \mathrm{dt}=\mathrm{Dt}$

$135 \mathrm{nu}=$ eta

$136 \mathrm{~T}=600$

$137 \mathrm{kBT}=1.38 * 1 \mathrm{e}-23 * 300 \# \mathrm{SI}$

138 nbins $=200$ \#

$139 \mathrm{xe}=\mathrm{x}$

140

141 \#Analise do potencial

$142 \mathbf{s x}=\mathrm{np} \cdot \operatorname{std}(\mathrm{xe})$

143 fitx, $x x, U x$, counts $=$ pot_vec (xe, nbins)

144 print('Potential Analysis: Done')

$145 \mathrm{k}$ _pot $=$ round_figures $(2 * f i t x[0], 3)$

146 a_pot $=$ round_figures $(f i t x[0], 3)$

147 b_pot $=$ round_figures $(f i t x[1], 3)$

148 c_pot $=$ round_figures $(f i t x[2], 3)$

149

150 \# Ajuste gaussiano

$151 \mathrm{xf}=\mathrm{xx}$

$152 \mathrm{yf}=$ counts

$153 \mathrm{n}=\operatorname{sum}(\mathrm{yf})$

154 mean $=\operatorname{sum}(x f * y f) / \mathrm{n}$

155 sigma=math. $\operatorname{sqrt}(\operatorname{sum}(\mathrm{yf} *(\mathrm{xf}-$ mean $) * * 2) / \mathrm{n})$

156

157 def gaus(x,a,x0, sigma, offset):

158 return $a * n p \cdot \exp (-(\mathrm{x}-\mathrm{x} 0) * * 2 /(2 * \operatorname{sigma} * * 2))+$ offset

159

160 poptf,pcovf = curve_fit (gaus, $x f, y f, p 0=[1$, mean, sigma, 0.0$]$ )

161

162 \# Metodo de equipaticao

$163 \mathrm{k}_{\text {_meq }}=\operatorname{meq}(\mathrm{xe})$ 
164 print('Equipartition Method: Done')

165

166 \# DQM

167 MSD $=$ msd_vec $(x e, T)$

168 gamma $=6 * n p \cdot p i * r * n u$

169 poptmsd, xmsd, ymsd = msd_fit(MSD [1:],dt,kBT, gamma,k_meq)

170 a_msd = round_figures (poptmsd [0] ,3)

171 b_msd = round_figures (poptmsd [1],3)

172

173 tauc $=$ b_msd

174 k_msd_a $=$ round_figures $\left(2 * k B T / a \_m s d, 3\right)$

175 gamma_msd $=$ round_figures $($ tauc*k_msd_a, 3)

176 print('Mean Squared Displacement: Done')

177

178 \# Correlacao

$179 \mathrm{ACF}=$ acf_vec $(\mathrm{xe}, \mathrm{T})$

180 poptacf, xacf, yacf $=$ acf_fit $(A C F, d t, k B T$, gamma, $k$ meq $)$

181 a_acf $=$ round_figures $($ poptacf $[0], 3)$

182 b_acf $=$ round_figures $($ poptacf $[1], 3)$

183 tauc $=$ b_acf

184 k_acf_a $=$ round_figures $\left(\mathrm{kBT} / \mathrm{a}_{-} \mathrm{acf}, 3\right)$

185 gamma_acf = round_figures (tauc*k_acf_a,3)

186 print('Autocorrelation Function Method: Done')

187

188 \# Distribuicao de probabilidade

189 norm1t $=[$ float $(i) / \operatorname{sum}(n p \cdot \exp (-k x * n p .1$ inspace $(-300 * 1 e-09,300 * 1 e-09$, len (norm1t)

$\hookrightarrow) * * 2 /(2 * \mathrm{kBT})))$ for $\mathrm{i}$ in $\mathrm{np} \cdot \exp (-\mathrm{kx} * \mathrm{np} .1 \mathrm{inspace}(-300 * 1 \mathrm{e}-09,300 * 1 \mathrm{e}-09$, len

$\hookrightarrow($ norm 1$)) * * 2 /(2 * \mathrm{kBT}))]$

190 norm2t $=$ [float (i)/sum (np. exp $(-2 * k x * n p .1$ inspace $(-300 * 1 e-09,300 * 1 e-09$, len (norm2

$\hookrightarrow)) * * 2 /(2 * \mathrm{kBT}))$ ) for $i$ in $\mathrm{np} \cdot \exp (-\mathrm{kx} * \mathrm{np}$. Iinspace $(-300 * 1 \mathrm{e}-09,300 * 1 \mathrm{e}-09$,

$\hookrightarrow \operatorname{len}(\operatorname{norm} 1)) * * 2 /(2 * \mathrm{kBT}))]$

191 norm3t $=[\mathrm{float}(\mathrm{i}) / \operatorname{sum}(\mathrm{np} \cdot \exp (-3 * \mathrm{kx} * \mathrm{np} .1 \mathrm{inspace}(-300 * 1 \mathrm{e}-09,300 * 1 \mathrm{e}-09$, len (norm3

$\hookrightarrow)) * * 2 /(2 * \mathrm{kBT}))$ ) for $\mathrm{i}$ in $\mathrm{np} \cdot \exp (-\mathrm{kx} * \mathrm{np} .1$ inspace $(-300 * 1 \mathrm{e}-09,300 * 1 \mathrm{e}-09$,

$\hookrightarrow \operatorname{len}(\operatorname{norm} 1)) * * 2 /(2 * \mathrm{kBT}))]$

192

$193 \operatorname{norm} 1=[\mathrm{float}(\mathrm{i}) / \operatorname{sum}(\mathrm{np} \cdot \exp (-\mathrm{kx} * \mathrm{xf} * * 2 /(2 * \mathrm{kBT})))$ for i in $\mathrm{np} \cdot \exp (-\mathrm{kx} * \mathrm{xf} * * 2 /(2 *$ $\hookrightarrow \mathrm{kBT}))]$

194 norm2 $=[f l o a t(i) / \operatorname{sum}(n p \cdot \exp (-2 * k x * x f * * 2 /(2 * k B T)))$ for $i$ in $n p \cdot \exp (-k x * x f$ $\hookrightarrow * * 2 /(2 * \mathrm{kBT}))]$

195 norm3 $=[f l o a t(i) / \operatorname{sum}(n p \cdot \exp (-3 * k x * x f * * 2 /(2 * k B T)))$ for $i$ in $n p \cdot \exp (-k x * x f$ $\hookrightarrow * * 2 /(2 * \mathrm{kBT}))]$ 
197

$198 \mathrm{pl} . \mathrm{plot}(\mathrm{xf} * 1 \mathrm{e} 9, \mathrm{yf}$, 'o', markersize=3)

$199 \mathrm{pl} \cdot \mathrm{plot}(\mathrm{xf} * 1 \mathrm{e} 9$, norm1, $1 \mathrm{w}=2)$

200 pl.xlabel ('Posicao $(\mathrm{nm})$ ', fontsize = 13)

201 pl.ylabel ('Probabilidade', fontsize = 13)

202 pl.savefig('sim_Histogramadaposicao_kx1.png', dpi = 300)

203 pl.show ()

204

$205 \mathrm{pl} . \mathrm{plot}(\mathrm{np} .1 \mathrm{inspace}(-300 * 1 \mathrm{e}-09,300 * 1 \mathrm{e}-09$, len (norm1t)) $* 1 \mathrm{e} 9$, norm $1 \mathrm{t}, 1 \mathrm{w}=2$, label = $\hookrightarrow \quad$ r'\$ $\left.\backslash \mathrm{kappa}=1 \mathrm{pN} / \mathrm{mu} \mathrm{m} \${ }^{\prime}\right)$

$206 \mathrm{pl}$.plot (np.linspace $(-300 * 1 \mathrm{e}-09,300 * 1 \mathrm{e}-09$, len (norm2t)) $* 1 \mathrm{e} 9$, norm $2 \mathrm{t}, 1 \mathrm{w}=2,1 \mathrm{abel}=$ $\left.\hookrightarrow \quad r^{\prime} \$ \backslash \mathrm{kappa}=2 \mathrm{pN} / \mathrm{mu} \mathrm{m} \${ }^{\prime}\right)$

$207 \mathrm{pl}$.plot (np.linspace $(-300 * 1 \mathrm{e}-09,300 * 1 \mathrm{e}-09$, len (norm3t)) $* 1 \mathrm{e} 9$, norm3t, $1 \mathrm{w}=2$, label = $\left.\hookrightarrow \quad r^{\prime} \$ \backslash \mathrm{kappa}=3 \mathrm{pN} / \mathrm{mu} \mathrm{m} \$^{\prime}\right)$

$208 \mathrm{pl} . x \mathrm{abel}$ ('Posicao $(\mathrm{nm})$ ', fontsize $=13$ )

209 pl.ylabel ('Probabilidade', fontsize = 13)

$210 \mathrm{pl}$.legend (fontsize $=11$ )

211 pl.savefig('sim_Histogramadaposicao.png', dpi = 300)

212 pl.show()

213

214 \# Analise do potencial

$215 \mathrm{pl} . \mathrm{plot}(\mathrm{xx} * 1 \mathrm{e} 9, \mathrm{Ux}-\mathrm{fitx}[2]$, 'o', markersize=3)

$216 \mathrm{pl} \cdot \mathrm{plot}\left(\mathrm{xx} * 1 \mathrm{e} 9, \mathrm{kx} *(\mathrm{xx} * * 2) / 2,{ }^{\prime}-{ }^{\prime}, 1 \mathrm{w}=2\right)$

$217 \mathrm{pl} . \mathrm{xlabel}(' \mathrm{X}(\mathrm{nm})$ ', fontsize $=13$ )

$218 \mathrm{pl} \cdot \mathrm{ylabel}$ ('Ux $(\mathrm{J})$ ', fontsize $=13$ )

219 pl.savefig('sim_analisepotencial_kx1.png', dpi = 300)

220 pl.show()

221

$222 \mathrm{pl} . p l o t(n p . l i n s p a c e(-300 * 1 \mathrm{e}-09,300 * 1 \mathrm{e}-09$, len(norm1t))*1e9, kx*(np.linspace

$\hookrightarrow(-300 * 1 \mathrm{e}-09,300 * 1 \mathrm{e}-09, \operatorname{len}($ norm $1 \mathrm{t})) * * 2) / 2,1 \mathrm{w}=2, \mathrm{label}=r^{\prime} \$ \backslash \mathrm{kappa}=1 \mathrm{pN}$ $\left.\hookrightarrow / \mathrm{mu} \mathrm{m} \$^{\prime}\right)$

223 pl.plot (np.linspace $(-300 * 1 e-09,300 * 1 e-09$, len (norm1t))*1e9, 2*kx* (np.linspace

$\hookrightarrow(-300 * 1 \mathrm{e}-09,300 * 1 \mathrm{e}-09, \operatorname{len}($ norm $2 \mathrm{t})) * * 2) / 2,1 \mathrm{w}=2, \mathrm{label}=r^{\prime} \$ \backslash \mathrm{kappa}=2 \mathrm{pN}$

$\left.\hookrightarrow / \mathrm{mu} \mathrm{m} \$^{\prime}\right)$

224 pl.plot (np.linspace (-300*1e-09,300*1e-09, len(norm1t))*1e9, 3*kx*(np.linspace

$\hookrightarrow(-300 * 1 \mathrm{e}-09,300 * 1 \mathrm{e}-09, \operatorname{len}($ norm3t) $) * * 2) / 2,1 \mathrm{w}=2, \mathrm{label}=r^{\prime} \$ \backslash \mathrm{kappa}=3 \mathrm{pN}$ $\left.\hookrightarrow / \mathrm{mu} \mathrm{m}^{\prime}{ }^{\prime}\right)$

$225 \mathrm{pl} . x \mathrm{label}(' \mathrm{X}(\mathrm{nm})$ ', fontsize $=13$ )

$226 \mathrm{pl} \cdot \mathrm{ylabel}$ ('Ux $(\mathrm{J})$ ', fontsize $=13$ )

$227 \mathrm{pl}$.legend (fontsize $=11$ )

228 pl.savefig('sim_analisepotencial.png', dpi = 300)

229 pl.show() 
231 \# DQM

$232 \mathrm{pl} . p l o t(\mathrm{np} .1 \mathrm{inspace}(0, \operatorname{len}(\mathrm{MSD}), \mathrm{T} / 10) * \mathrm{dt} * 1 \mathrm{e} 3, \operatorname{MSD}[0: \mathrm{T}: 10] * 1 \mathrm{e} 18$, 'o', markersize $\hookrightarrow=3)$

$233 \mathrm{pl} \cdot \mathrm{plot}(\mathrm{xmsd} * 1 \mathrm{e},(2 / \mathrm{kx} * \mathrm{kBT} *(1-\mathrm{np} \cdot \exp (-\mathrm{xmsd} /(\mathrm{gamma} / \mathrm{kx})))) * 1 \mathrm{e} 18,1 \mathrm{w}=2)$

$234 \mathrm{pl} . x \mathrm{xlabel}$ ('Tempo (ms)', fontsize $=13$ )

$235 \mathrm{pl}$.ylabel ( $r^{\prime}$ \$DQM_x $\left(\mathrm{nm}^{\wedge} 2\right)$ \$', fontsize $\left.=13\right)$

$236 \mathrm{pl}$. savefig('sim_desvioqm_kx1.png', dpi $=300$ )

$237 \mathrm{pl}$.show()

238

$239 \mathrm{pl} \cdot \mathrm{plot}\left(\mathrm{xmsd} * 1 \mathrm{e} 3,(2 * \mathrm{kBT} *(1-\mathrm{np} \cdot \exp (-\mathrm{xmsd} /(\mathrm{gamma} /(\mathrm{kx})))) / \mathrm{kx}) * 1 \mathrm{e} 18, \quad \mathrm{lw}_{\mathrm{w}}=2,1 \mathrm{abel}=\right.$ $\left.\hookrightarrow r^{\prime} \$ \backslash \mathrm{kappa}=1 \mathrm{pN} / \mathrm{mu} \mathrm{m}^{\prime}\right)$

$240 \mathrm{pl} \cdot \mathrm{plot}(\mathrm{xmsd} * 1 \mathrm{e} 3,(2 * \mathrm{kBT} *(1-\mathrm{np} \cdot \exp (-\mathrm{xmsd} /(\mathrm{gamma} /(2 * \mathrm{kx})))) /(2 * \mathrm{kx})) * 1 \mathrm{e} 18, \quad \mathrm{lw}=2$, $\hookrightarrow$ label $=r^{\prime} \$ \backslash$ kappa $\left.=2 \mathrm{pN} / \mathrm{mu} \mathrm{m}^{\prime}{ }^{\prime}\right)$

$241 \mathrm{pl} . \mathrm{plot}(\mathrm{xmsd} * 1 \mathrm{e},(2 * \mathrm{kBT} *(1-\mathrm{np} \cdot \exp (-\mathrm{xmsd} /(\mathrm{gamma} /(3 * \mathrm{kx})))) /(3 * \mathrm{kx})) * 1 \mathrm{e} 18,1 \mathrm{w}=2$, $\hookrightarrow$ label $\left.=r^{\prime} \$ \backslash \mathrm{kappa}=3 \mathrm{pN} / \mathrm{mu} \mathrm{m} \${ }^{\prime}\right)$

$242 \mathrm{pl} . x \mathrm{xlabel}$ ('Tempo (ms)', fontsize = 13)

$243 \mathrm{pl} \cdot \mathrm{ylabel}\left(\mathrm{r}^{\prime}\right.$ \$DQM_x $\left(\mathrm{nm}^{\wedge} 2\right)$ \$', fontsize $=13$ )

$244 \mathrm{pl}$.legend (fontsize $=11$ )

245 pl.savefig('sim_desvioqm.png', dpi $=300$ )

$246 \mathrm{pl}$. show()

247

248 \# Correlacao

$249 \mathrm{pl} . \mathrm{plot}(\mathrm{np} .1 \mathrm{inspace}(0, \operatorname{len}(\mathrm{ACF}), \mathrm{T} / 10) * \mathrm{dt} * 1 \mathrm{e}, \mathrm{ACF}[0: \mathrm{T}: 10] * 1 \mathrm{e} 18$, 'o', markersize $\hookrightarrow=3)$

$250 \mathrm{pl} \cdot \mathrm{plot}(\mathrm{xacf} * 1 \mathrm{e} 3, \mathrm{kBT} *(\mathrm{np} \cdot \exp (-\mathrm{xacf} /(\mathrm{gamma} / \mathrm{kx}))) * 1 \mathrm{e} 18 /(\mathrm{kx}), \mathrm{lw}=2)$

$251 \mathrm{pl} . x \mathrm{label}$ ('Tempo (ms)', fontsize $=13$ )

$252 \mathrm{pl} \cdot \mathrm{ylabel}\left(\mathrm{r}^{\prime} \$ \mathrm{C}_{-} \mathrm{x}\left(\mathrm{nm}^{\wedge} 2\right){ }^{\prime}\right.$, fontsize $\left.=13\right)$

$253 \mathrm{pl}$.savefig('sim_autocorrelacao_kx1.png', dpi $=300$ )

$254 \mathrm{pl}$.show()

255

$256 \mathrm{pl} . p l o t(n p . l i n s p a c e(-40,40,1000), \mathrm{kBT} *(\mathrm{np} \cdot \exp (-\mathrm{np}$. absolute (np.linspace (-0.04, $\hookrightarrow 0.04,1000)) /($ gamma $/ \mathrm{kx}))) * 1 \mathrm{e} 18 /(\mathrm{kx}), l_{\mathrm{w}}=2$, label $=\mathrm{r}^{\prime} \$ \backslash \mathrm{kappa}=1 \mathrm{pN} / \mathrm{mu}$ $\left.\hookrightarrow \mathrm{m} \${ }^{\prime}\right)$

$257 \mathrm{pl} . p l o t(n p . l i n s p a c e(-40,40,1000), k B T *(n p \cdot \exp (-n p \cdot a b s o l u t e(n p \cdot l i n s p a c e(-0.04$, $\hookrightarrow 0.04,1000)) /(\operatorname{gamma} /(2 * \mathrm{kx})))) * 1 \mathrm{e} 18 /(2 * \mathrm{kx})$, label $=\mathrm{r}^{\prime} \$ \backslash \mathrm{kappa}=2 \mathrm{pN} / \mathrm{mu}$ $\left.\hookrightarrow \mathrm{m} \${ }^{\prime}\right)$

258 pl.plot (np.linspace (-40, 40, 1000), kBT*(np.exp(-np.absolute (np.linspace (-0.04, $\hookrightarrow 0.04,1000)) /($ gamma $/(3 * \mathrm{kx})))) * 1 \mathrm{e} 18 /(3 * \mathrm{kx})$, label $=\mathrm{r}^{\prime} \$ \backslash \mathrm{kappa}=3 \mathrm{pN} / \mathrm{mu}$ $\left.\hookrightarrow \mathrm{m} \${ }^{\prime}\right)$

$259 \mathrm{pl} . x \mathrm{xlabel}\left(\mathrm{r}^{\prime} \$\right.$ Tempo \(ms)\$', fontsize $=13$ )

$260 \mathrm{pl} \cdot \mathrm{ylabel}\left(\mathrm{r}^{\prime} \$ \mathrm{C}_{-} \mathrm{x} \backslash\left(\mathrm{nm}^{\wedge} 2\right)\left(\mathrm{m}^{\wedge} 2\right)\right.$ \$', fontsize $\left.=13\right)$ 
$261 \mathrm{pl}$. legend (fontsize $=11$ )

262 pl.savefig('sim_autocorrelacao.png', dpi $=300$ )

$263 \mathrm{pl}$.show() 


\section{APÊNDICE F - FUNÇÕES DE UM POTENCIAL HARMÔNICO}

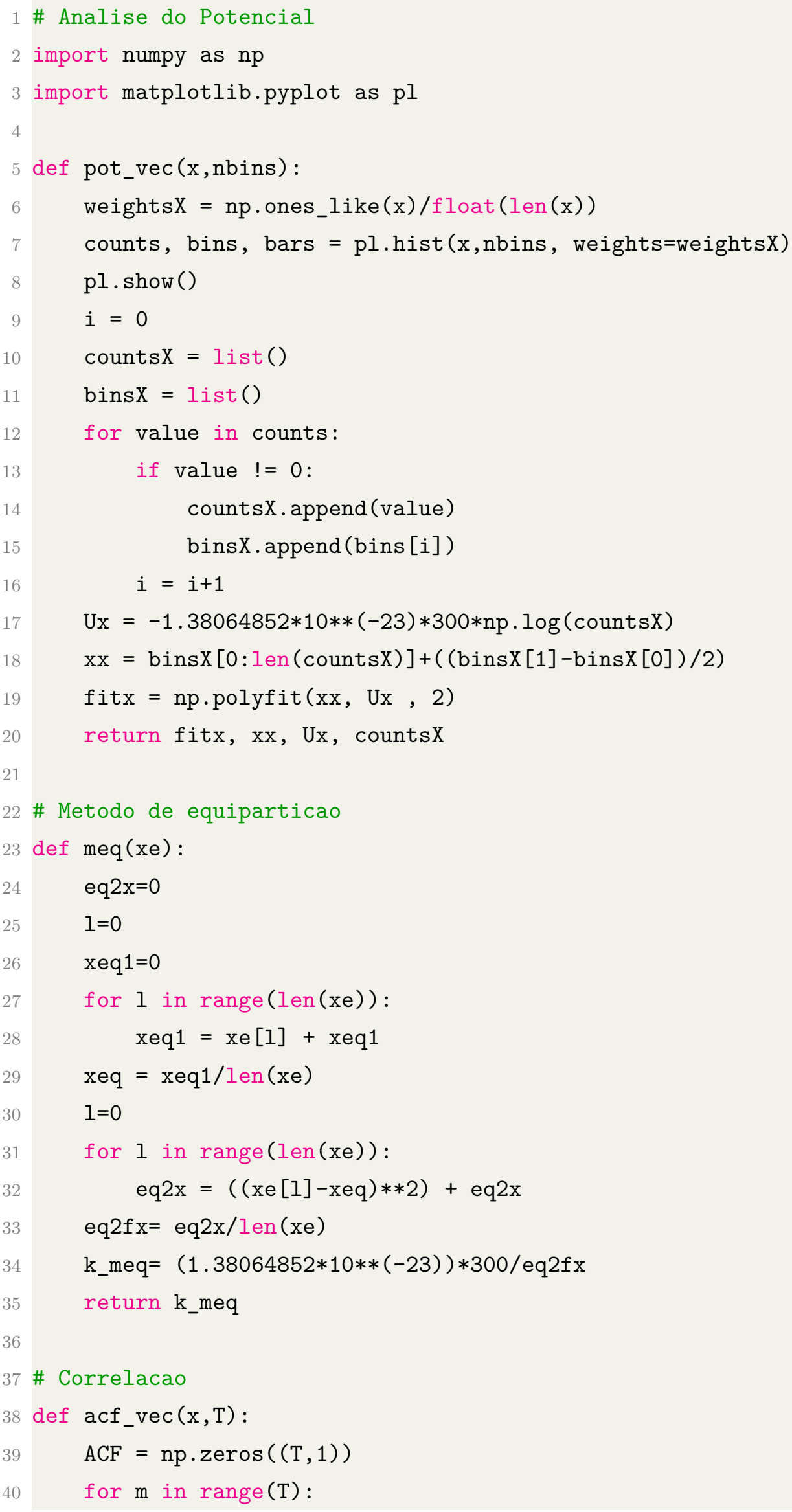


44 def acf_fit(ACF,dt,kBT, gamma,k_meq):

56 \# DQM

57 def msd_vec $(x, T)$ :

63 def msd_fit(MSD, dt,kBT, gamma,k_meq) :

$\mathrm{a}_{-} 0=\mathrm{kBT} / \mathrm{k}$-meq

b_0 = gamma $/ k_{-}$meq

$\mathrm{x}=\mathrm{np}$. arange $(\operatorname{len}(\mathrm{ACF})) * d t$

$\mathrm{y}=\mathrm{np}$. squeeze $(\mathrm{ACF})$

def exponenial_func(x, a, b):

return $a * n p \cdot \exp (-x / b)$

return popt, xacf, yacf

$$
\text { MSD }=n p \cdot z \operatorname{zeros}((T, 1))
$$

for $\mathrm{m}$ in range $(\mathrm{T})$ :

return MSD [1:]

$\mathrm{a}_{-} \mathrm{O}=\mathrm{kBT} / \mathrm{k}_{-}$meq

b_0 = gamma $/ k_{-}$meq

$\mathrm{x}=\mathrm{np} \cdot \operatorname{arange}($ len $($ MSD $)) * \mathrm{dt}$

$\mathrm{y}=\mathrm{np}$.squeeze(MSD)

def exponenial_func2 $(x, a, b)$ :

return $a *(1-n p \cdot \exp (-x / b))$

return popt, xmsd, ymsd
$\operatorname{ACF}[\mathrm{m}]=\mathrm{np} \cdot \operatorname{mean}(\mathrm{np} \cdot \operatorname{multiply}(\mathrm{x}[\mathrm{m}+1:: 1], \mathrm{x}[1: \operatorname{len}(\mathrm{x})-\mathrm{m}: 1]))$ return ACF $[1:]$

popt, pcov $=$ curve_fit (exponenial_func, $x, y)$

xacf $=$ np.linspace $(0, \operatorname{len}(x) * d t, 100)$

yacf $=$ exponenial_func (xacf, $*$ popt $)$

$\operatorname{MSD}[\mathrm{m}]=\mathrm{np} \cdot \operatorname{mean}((\mathrm{x}[\mathrm{m}+1:: 1]-\mathrm{x}[1: \operatorname{len}(\mathrm{x})-\mathrm{m}: 1]) * * 2)$

popt, pcov $=$ curve_fit (exponenial_func2, $x, y)$

xmsd $=$ np.linspace $(0, \operatorname{len}(x) * d t, 100)$

ymsd $=$ exponenial_func2 $(x m s d, *$ popt $)$ 


\section{APÊNDICE G - SIMULAÇÃO DE POTENCIAIS DINÂMICOS}

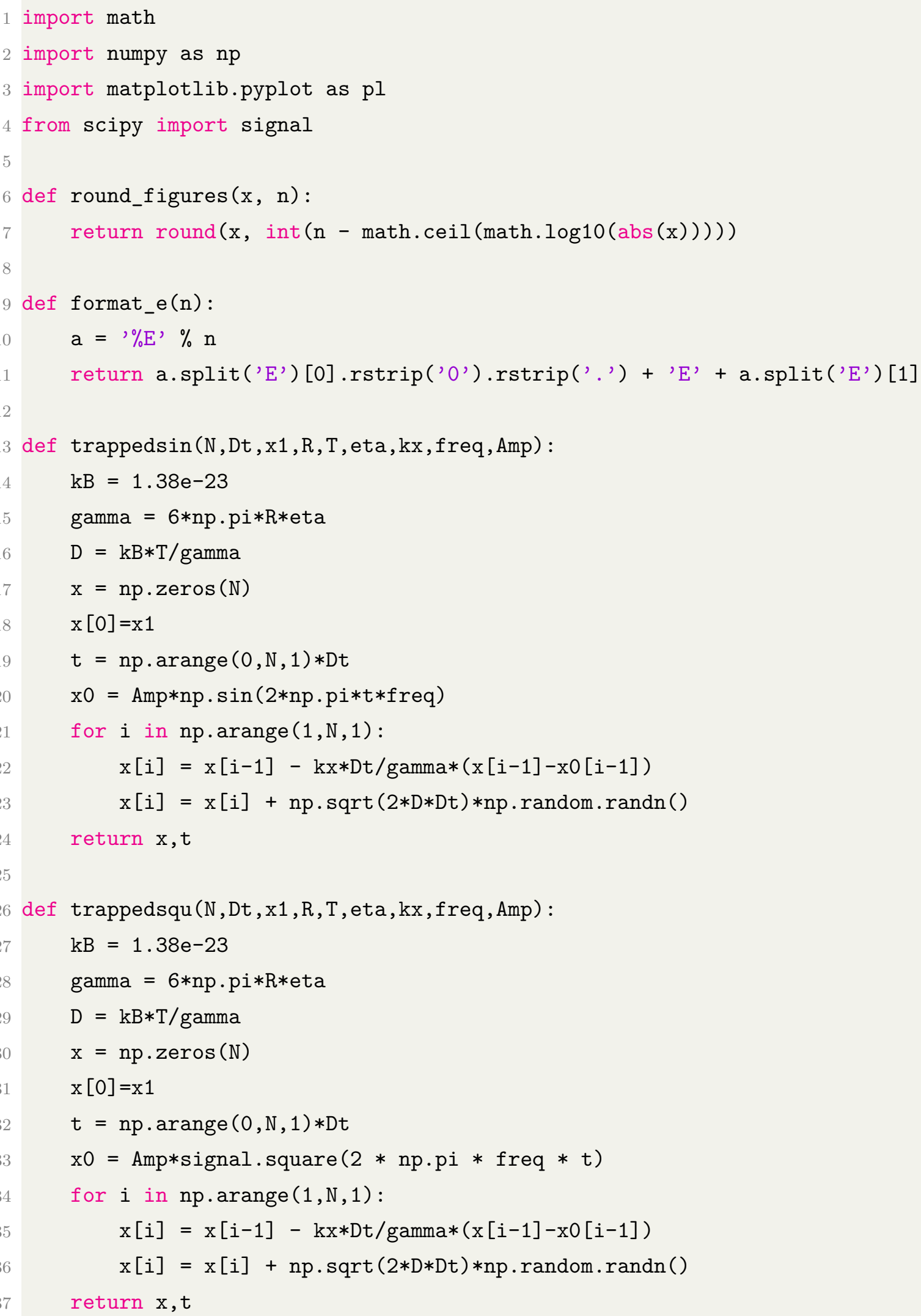


39 def trappedtri(N,Dt, $\mathrm{x} 1, \mathrm{R}, \mathrm{T}$, eta, $\mathrm{kx}$, freq, Amp) :

$40 \mathrm{kB}=1.38 \mathrm{e}-23$ 


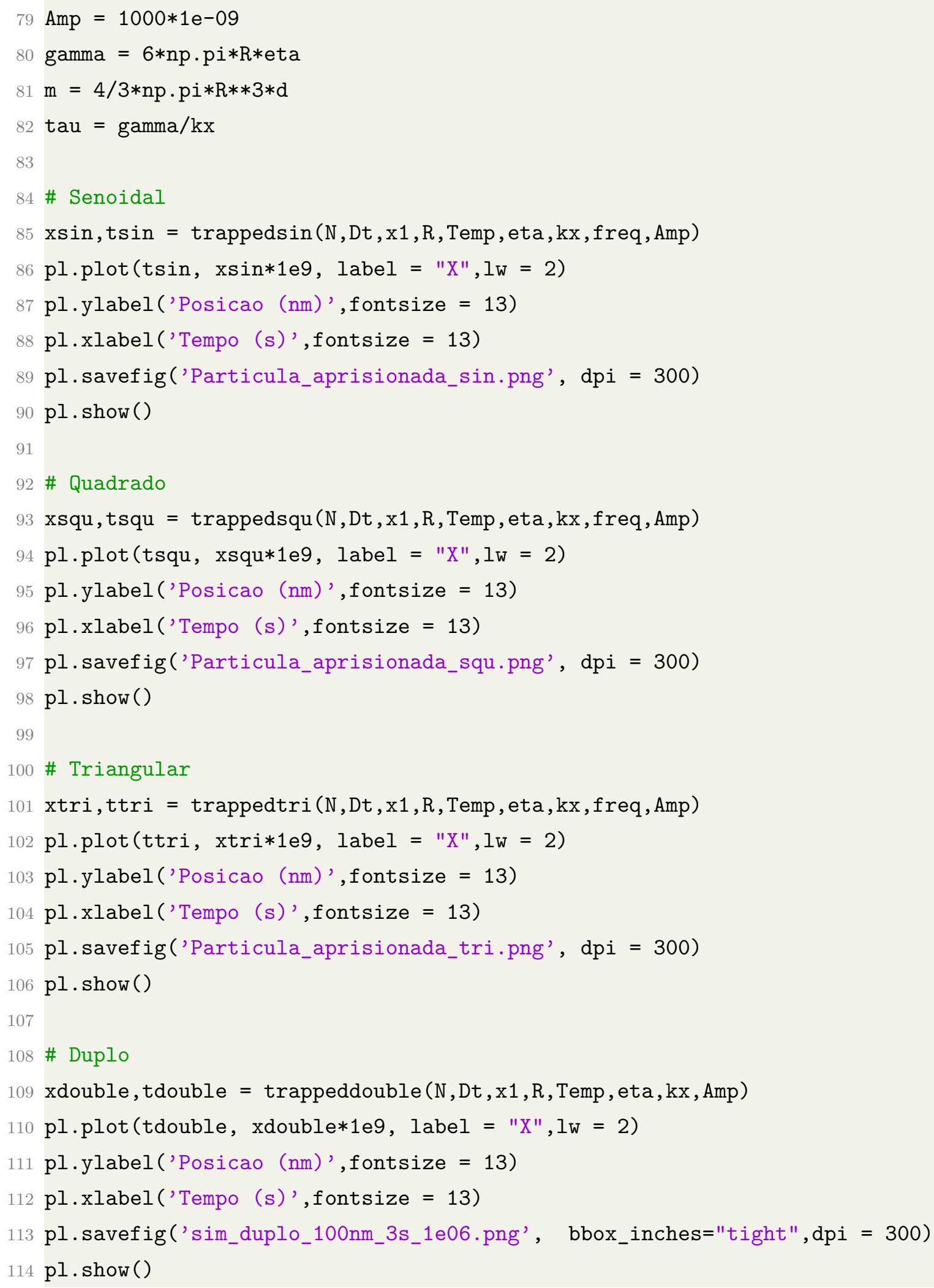





\section{APÊNDICE H - CONTAGEM DO NÚMERO DE TRANSIÇÕES DA PARTÍCULA NO POÇO DUPLO}

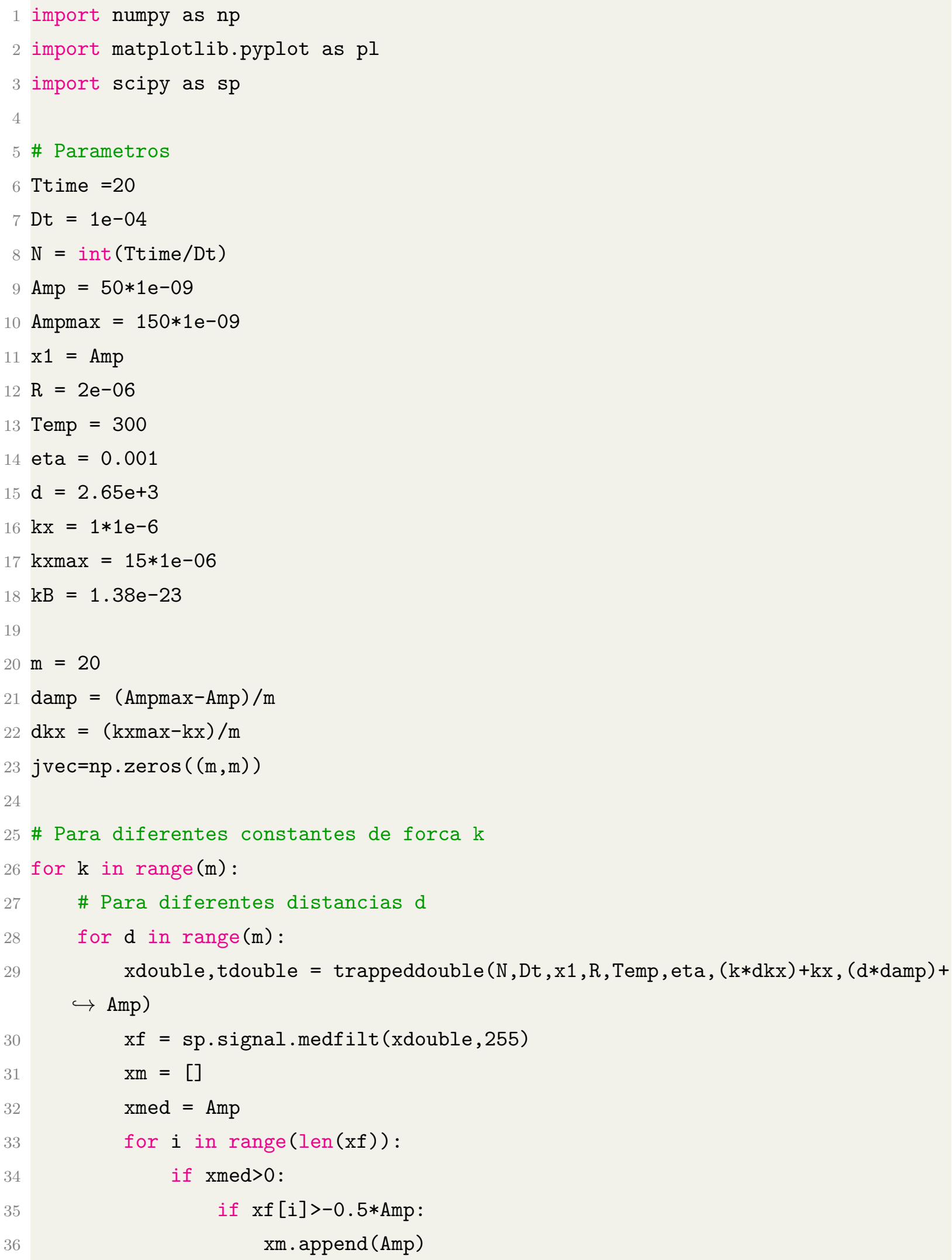


56 fig1, ax2 = pl.subplots ()

$57 \mathrm{CS}=\operatorname{ax} 2 \cdot \operatorname{contourf}(($ Amp + damp $* \mathrm{np} \cdot \operatorname{linspace}(0, \mathrm{~m}, \mathrm{~m})) * 2 * 1 \mathrm{e} 09, \quad(\mathrm{kx}+\mathrm{dkx} * \mathrm{np} \cdot \operatorname{linspace}(0, \mathrm{~m}$ $\hookrightarrow, \mathrm{m})) * 1 \mathrm{e} 06$, jvec)

58 ax2.set_xlabel ( $r^{\prime}$ Distancia entre pocos $(\$ \backslash \operatorname{mathrm}\{n m\} \$)^{\prime}$, fontsize = 13)

59 ax2.set_ylabel ( $r$ 'Constante de forca ( $\$ \backslash \operatorname{mathrm}\{\mathrm{pN} / \mathrm{mu} \mathrm{m}\} \$$ )', fontsize = 13)

60 cbar = fig1. colorbar $(\mathrm{CS})$

61 cbar.ax.set_ylabel ('Numero de transicoes', fontsize $=13$ )

62 pl.savefig('sim_contorno_duplo_20s_kxd.png', bbox_inches="tight", dpi $=300$ )

$63 \mathrm{pl} . \operatorname{show}()$ 


\section{APÊNDICE I - CÓDIGOS PARA CALIBRAÇÃO DO NANOPOSICIONADOR}

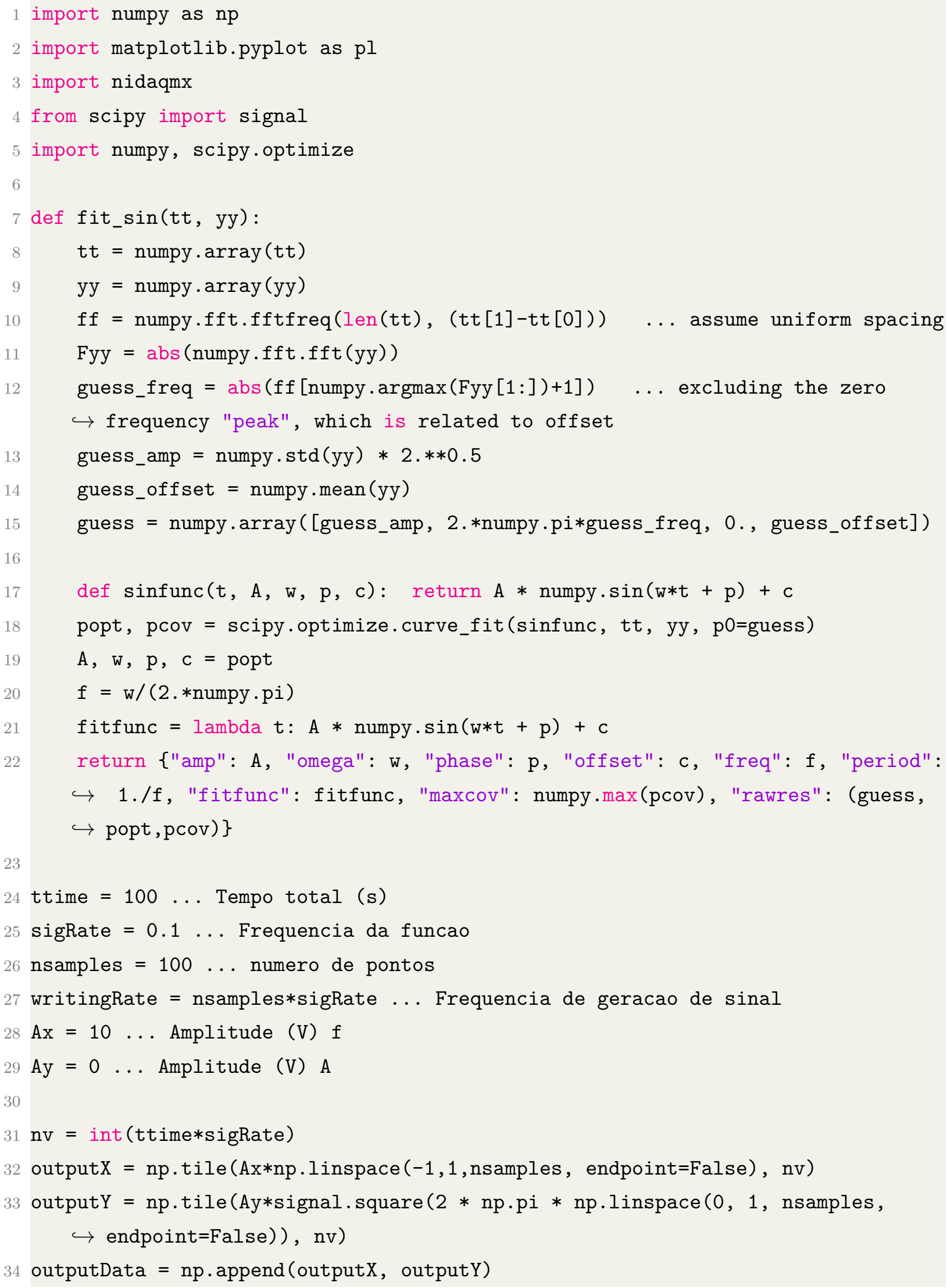


35 outputData $=$ outputData.reshape $((2$, outputX.size $))$

print (outputData.shape)

with nidaqmx.Task() as writeTask, nidaqmx.Task() as readTask:

writeTask.ao_channels.add_ao_voltage_chan ("Dev3/ao0:1")

readTask.ai_channels.add_ai_voltage_chan("Dev3/ai2",terminal_config =

$\hookrightarrow$ TerminalConfiguration.RSE, min_val=-10, max_val=10, units=VoltageUnits.

$\hookrightarrow$ VOLTS)

writeTask.timing.cfg_samp_clk_timing(rate = writingRate, sample_mode $=$ nidaqmx . constants.

$\hookrightarrow$ AcquisitionType.FINITE, samps_per_chan $=\operatorname{len}($ outputX) $)$ readTask.timing.cfg_samp_clk_timing(rate = writingRate, sample_mode $=$ nidaqmx. constants.

$\hookrightarrow$ AcquisitionType.FINITE,

$$
\text { samps_per_chan = len }(\text { outputX)) }
$$

writer = AnalogMultiChannelWriter(writeTask.out_stream)

reader $=$ AnalogMultiChannelReader (readTask.in_stream)

print("The channels linked to WriteTask are: ")

for $i$ in writeTask.ao_channels:

print (i)

print("Starting writing and reading using", outputX.size) estT $=$ outputX.size/writingRate

print ("Estimated time: ", ttime)

writer.write_many_sample (outputData,timeout=ttime)

readTask.start()

writeTask.start()

number_of_channels $=1$

number_of_samples = len (outputX)

values_read $=\mathrm{np}$.zeros (

(number_of_channels, number_of_samples), dtype=np.float64)

reader.read_many_sample(

values_read, number_of_samples_per_channel=number_of_samples, timeout=ttime)

print("Start writing")

writeTask.wait_until_done(timeout = estT+5)

print("Done with data") 
73 for $i$ in range(int(len(values_read.transpose())/nsamples)) :

74 vf $=-$ values_read.transpose () [nsamples*i:nsamples*(i+1)]

75 $s=(s+v f)$

$77 \mathrm{~S}=\mathrm{s} /($ len (values_read.transpose ())/nsamples)

$78 \mathrm{x}=$ outputX

$79 \mathrm{pl} . p l o t(x[20: 100], \mathrm{S}[20: 100]$, label='Dados')

$80 \mathrm{pl} \cdot \operatorname{plot}(\mathrm{np} \cdot \operatorname{array}(x[20: 100]), \operatorname{res}[" f i t f u n c "](n p \cdot \operatorname{array}(x[20: 100]))$, label="Ajuste $\hookrightarrow ")$

$81 \mathrm{pl} . x \mathrm{xlabel}$ ('Tensao (V)')

$82 \mathrm{pl} . \mathrm{ylabel}$ ('Irradiancia (u.a.)')

$83 \mathrm{pl}$. legend (loc="best") 



\section{APÊNDICE J - CÓDIGOS PARA CALIBRAC̣ÃO DA CÂMERA}

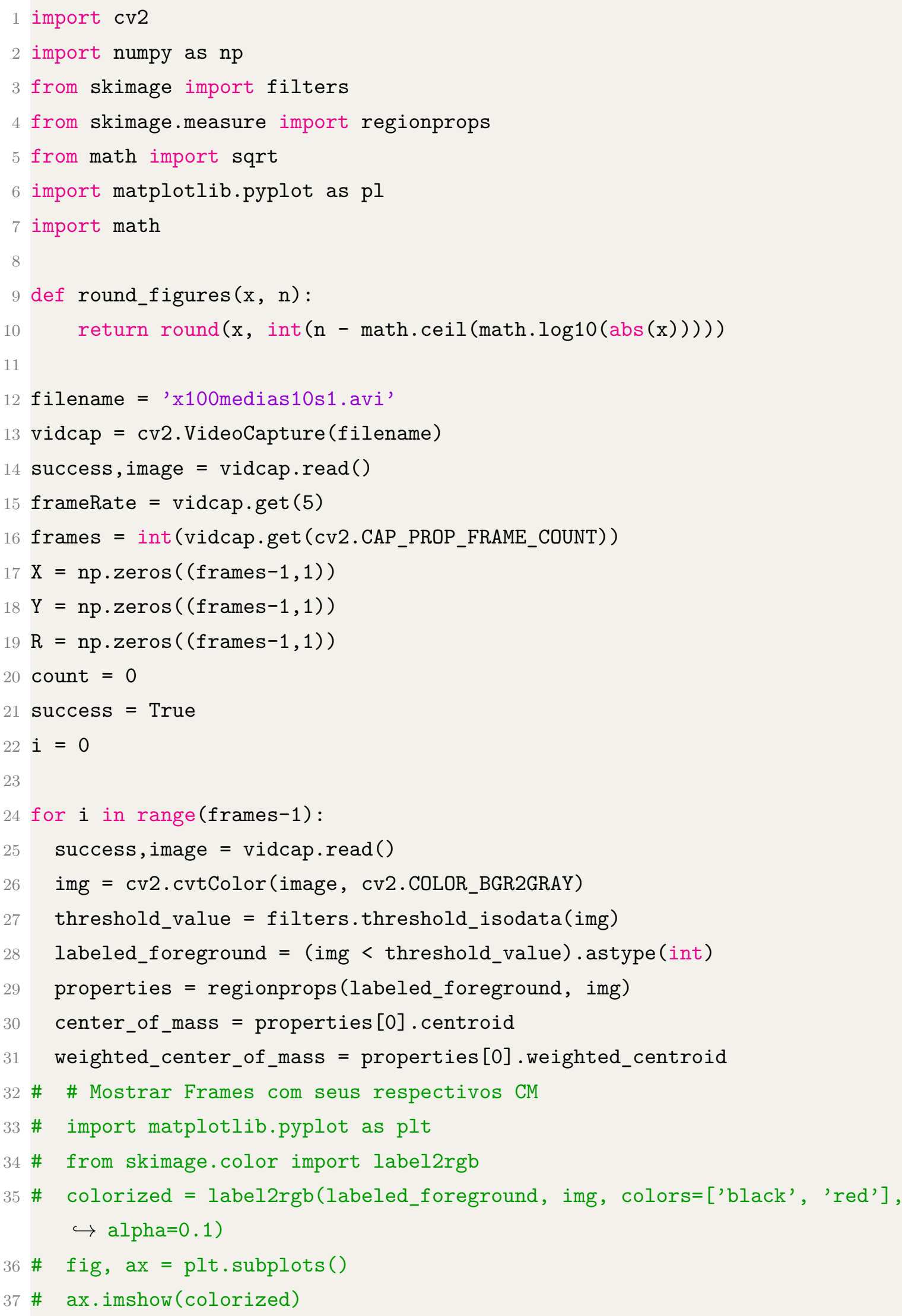


38 \# \# Note the inverted coordinates because plt uses ( $x, y$ ) while NumPy uses ( $\hookrightarrow$ row, column)

39 \# ax.scatter (center_of_mass [1], center_of_mass [0], s=160, c=' C0', marker='+')

40 \# plt.show()

$41 \mathrm{X}[$ count, 0$]=$ center_of_mass [1]

$42 \mathrm{Y}[$ count, 0$]=$ center_of_mass $[0]$

$43 \mathrm{R}[$ count, 0$]=\operatorname{sqrt}(($ center_of_mass $[1] *$ center_of_mass $[1])+$ (center_of_mass $[0] *$ $\hookrightarrow$ center_of_mass $[0])$ )

44 count $+=1$

45

$46 \mathrm{xe}=\mathrm{X}$

47 ye $=Y$

$18 \mathrm{re}=\mathrm{R}$

49 xer $=n p \cdot \operatorname{zeros}(\operatorname{len}(\mathrm{xe}))$

yer $=n p \cdot z e r o s(l e n(x e))$

rer $=n p \cdot z e r o s(l e n(x e))$

thetarad $=\mathrm{np} \cdot \mathrm{pi} / 2-\mathrm{np} \cdot \arctan (3.8032)$

53

54 for $k$ in range(len(xe)):

$55 \mathrm{re}[\mathrm{k}]=\operatorname{math} \cdot \operatorname{sqrt}((\mathrm{xe}[\mathrm{k}] * \mathrm{xe}[\mathrm{k}])+(\mathrm{ye}[\mathrm{k}] * \mathrm{ye}[\mathrm{k}]))$

56 thetai $=\operatorname{math} \cdot \operatorname{atan}(\mathrm{ye}[\mathrm{k}] / \mathrm{xe}[\mathrm{k}])$

57 thetaf $=$ thetai + thetarad

$58 \quad \operatorname{xer}[\mathrm{k}]=\mathrm{re}[\mathrm{k}] *$ math.cos $($ thetaf $)$

59

yer $[\mathrm{k}]=\operatorname{re}[\mathrm{k}] *$ math.sin (thetaf)

$60 \operatorname{rer}[\mathrm{k}]=\operatorname{math} \cdot \operatorname{sqrt}((\operatorname{xer}[\mathrm{k}] * \operatorname{xer}[\mathrm{k}])+\operatorname{yer}[\mathrm{k}] * \operatorname{yer}[\mathrm{k}])$

61 xem $=$ xer $-\mathrm{np} \cdot \operatorname{mean}(\mathrm{xer})$

62 yem $=$ yer - np.mean (yer)

63 rem $=$ rer $-\mathrm{np} \cdot \operatorname{mean}(\mathrm{rer})$

34 nsamples $=\operatorname{int}(15.21 * 10)$

65

66 \# Sinal de tensao e deslocamento em pixels

67 ttime $=10$

68 sigRate $=1$

69 nsampless $=100$

70 writingRate $=$ nsampless $*$ sigRate

$71 \mathrm{nv}=2$

72 output $=\mathrm{np} \cdot \mathrm{tile}(\mathrm{np} \cdot \mathrm{linspace}(-10,10, \mathrm{nsamples}$, endpoint=False $), \mathrm{nv})$

73 tempo $=$ np. arange $($ len (output) $)$

$74 \mathrm{pl} . \operatorname{subplot}(2,1,1)$

$75 \mathrm{pl} \cdot \mathrm{plot}(\mathrm{np} \cdot 1$ inspace $(0, \mathrm{nv}$, len (output)), output, ' $\mathrm{C1}$ ', $1 \mathrm{w}=2)$

$76 \mathrm{pl}$.ylabel ('Tensao ( $\mathrm{V}$ )', fontsize $=13$ )

$77 \mathrm{pl} . \operatorname{subplot}(2,1,2)$ 
$78 \mathrm{pl}$.plot (np.linspace (0,nv, len (ye [0:nsamples*nv-1])), -yem [0:nsamples*nv-1], ' CO', $\hookrightarrow 1 \mathrm{w}=2)$

$79 \mathrm{pl} . \mathrm{ylabel}$ ('Deslocamento (pixels)', fontsize $=13$ )

$80 \mathrm{pl} \cdot \mathrm{xlabel}$ ('Tempo ( $\mathrm{s}$ )', fontsize $=13$ )

$81 \mathrm{pl}$.subplots_adjust (hspace $=0.5$ )

82 pl.savefig('figrampa10_modificado.png', dpi = 300)

$83 \mathrm{pl}$.show()

84

85 \# Calibracao da imagem

86 xem1 $=0$

87 yem1 $=0$

88 rem1 $=0$

$89 \mathrm{sx}=0$

90 sy $=0$

$91 \mathrm{sr}=0$

92 for $i$ in range(int(len(xem)/nsamples)):

$93 x \operatorname{xem1}=\operatorname{xem}[n s a m p l e s * i: n s a m p l e s *(i+1)]$

$94 \operatorname{yem} 1=$ yem [nsamples*i:nsamples* $(i+1)]$

$95 \quad$ rem1 $=$ rem[nsamples $* i: n s a m p l e s *(i+1)]$

$96 \quad \mathbf{s x}=(\mathbf{s x}+\mathrm{xem} 1)$

$97 \quad$ sy $=($ sy + yem1 $)$

$98 \mathrm{sr}=(\mathrm{sr}+\mathrm{rem} 1)$

$99 \mathrm{Sx}=\mathrm{sx} /($ len $(\mathrm{xem}) / \mathrm{nsamples})$

$100 \mathrm{Sy}=\mathrm{sy} /($ len $(\mathrm{xem}) / \mathrm{nsamples})$

$101 \mathrm{Sr}=\mathrm{sr} /($ len $(\mathrm{xem}) / \mathrm{nsamples})$

102 ten $=\mathrm{np} \cdot \operatorname{arange}(\operatorname{len}(\mathrm{Sx})) * 20 * 0.19447 / \mathrm{nsamples}$

103

104 from scipy import stats

$105 \mathrm{x}=\mathrm{np} \cdot \operatorname{array}(\operatorname{ten}[10:$ nsamples -10$])$

$106 \mathrm{y}=\mathrm{np} \cdot \operatorname{array}(-\mathrm{Sy}[10: \mathrm{nsamples}-10]) \cdot \operatorname{reshape}(132)$

107 slope, intercept, r_value, p_value, see = stats.linregress $(x, y)$

$108 \mathrm{mx}=\mathrm{x} \cdot \operatorname{mean}()$

$109 \mathrm{sx} 2=((\mathrm{x}-\mathrm{mx}) * * 2) \cdot \operatorname{sum}()$

110 sd_intercept $=\operatorname{see} * \operatorname{sqrt}(1 . / \operatorname{len}(\mathrm{x})+\mathrm{mx} * \mathrm{mx} / \mathrm{sx} 2)$

111 sd_slope $=$ see $* \operatorname{sqrt}(1 . / \mathrm{sx} 2)$

$112 \mathrm{pl} \cdot \mathrm{plot}(\operatorname{ten}[10: \mathrm{nsamples}-10],-\mathrm{Sy}[10: \mathrm{nsamples}-10]$, 'o', markersize=5, label = " $\hookrightarrow$ Dados")

$113 \mathrm{pl} \cdot \mathrm{plot}(\operatorname{ten}[10: \mathrm{nsamples}-10]$, ten [10:nsamples-10]*slope+intercept, $1 \mathrm{w}=3$, label $=$ $\hookrightarrow$ "Ajuste")

114 pl.xlabel('Deslocamento (um)', fontsize = 13)

$115 \mathrm{pl} . y l a b e l$ ('Deslocamento (pixels)', fontsize $=13$ )

$116 \mathrm{pl}$.legend (fontsize $=11$ ) 
$17 \mathrm{pl} \cdot \operatorname{grid}()$

$18 \mathrm{pl} \cdot \operatorname{text}\left(0.6,-24,{ }^{\prime} \mathrm{y}=[14.300+/-0.003] \mathrm{x}+[-27.771+/-0.006]\right.$ ', fontsize $\left.=13\right)$

119 pl.savefig('Calibracaocamerapixelum_modificado_grid.png', dpi $=300$ )

$20 \mathrm{pl}$. show ()

121

22 \# Essa parte e feita logo apos a aquisicao do CM, sem a rotacao aplicada

23 \#Angulo entre os eixos X e Y da imagem

$124 \mathrm{x}=\mathrm{np} \cdot \operatorname{array}(\mathrm{Sx}[10: \mathrm{nsamples}-10]) \cdot \operatorname{reshape}(132)$

$25 \mathrm{y}=\mathrm{np} \cdot \operatorname{array}(\mathrm{Sy}[10:$ nsamples-10]) $\cdot$ reshape (132)

126 slope, intercept, $r_{-}$value, p_value, see = stats.linregress $(\mathrm{x}, \mathrm{y})$

$\mathrm{mx}=\mathrm{x} \cdot \operatorname{mean}()$

$\mathrm{sx} 2=((\mathrm{x}-\mathrm{mx}) * * 2) \cdot \operatorname{sum}()$

sd_intercept $=\operatorname{see} * \operatorname{sqrt}(1 . / \operatorname{len}(\mathrm{x})+\mathrm{mx} * \mathrm{mx} / \mathrm{sx} 2)$

sd_slope $=$ see $* \operatorname{sqrt}(1 . / \mathrm{s} \times 2)$

thetagrau $=90-\mathrm{np} \cdot \arctan ($ slope $) * 180 / \mathrm{np} \cdot \mathrm{pi}$

thetarad $=n p \cdot p i / 2-n p \cdot \arctan ($ slope $)$

133

$134 \mathrm{pl} \cdot \mathrm{plot}(\mathrm{Sx}[10: \mathrm{nsamples}-10], \mathrm{Sy}[10: \mathrm{nsamples}-10]$, 'O', markersize=5, label = "

$\hookrightarrow$ Dados")

$135 \mathrm{pl} \cdot \mathrm{plot}(\mathrm{Sx}[10: \mathrm{nsamples}-10], \mathrm{Sx}[10: \mathrm{nsamples}-10] * \mathrm{~s} l o p e+i n t e r c e p t, 1 \mathrm{w}=3$, label = " $\hookrightarrow$ Ajuste")

$36 \mathrm{pl} . \mathrm{xlabel}(' \mathrm{X}$ (pixels)', fontsize $=13$ )

$137 \mathrm{pl}$.ylabel('Y (pixels)', fontsize $=13$ )

$138 \mathrm{pl}$.legend (fontsize $=11$ )

$139 \mathrm{pl}$.savefig('CentrodemassaXY_modificado.png', dpi $=300$ )

$140 \mathrm{pl} . \operatorname{show}()$ 


\section{APÊNDICE K - CÓDIGOS PARA A CALIBRAÇÃO DA PINÇA ÓPTICA}

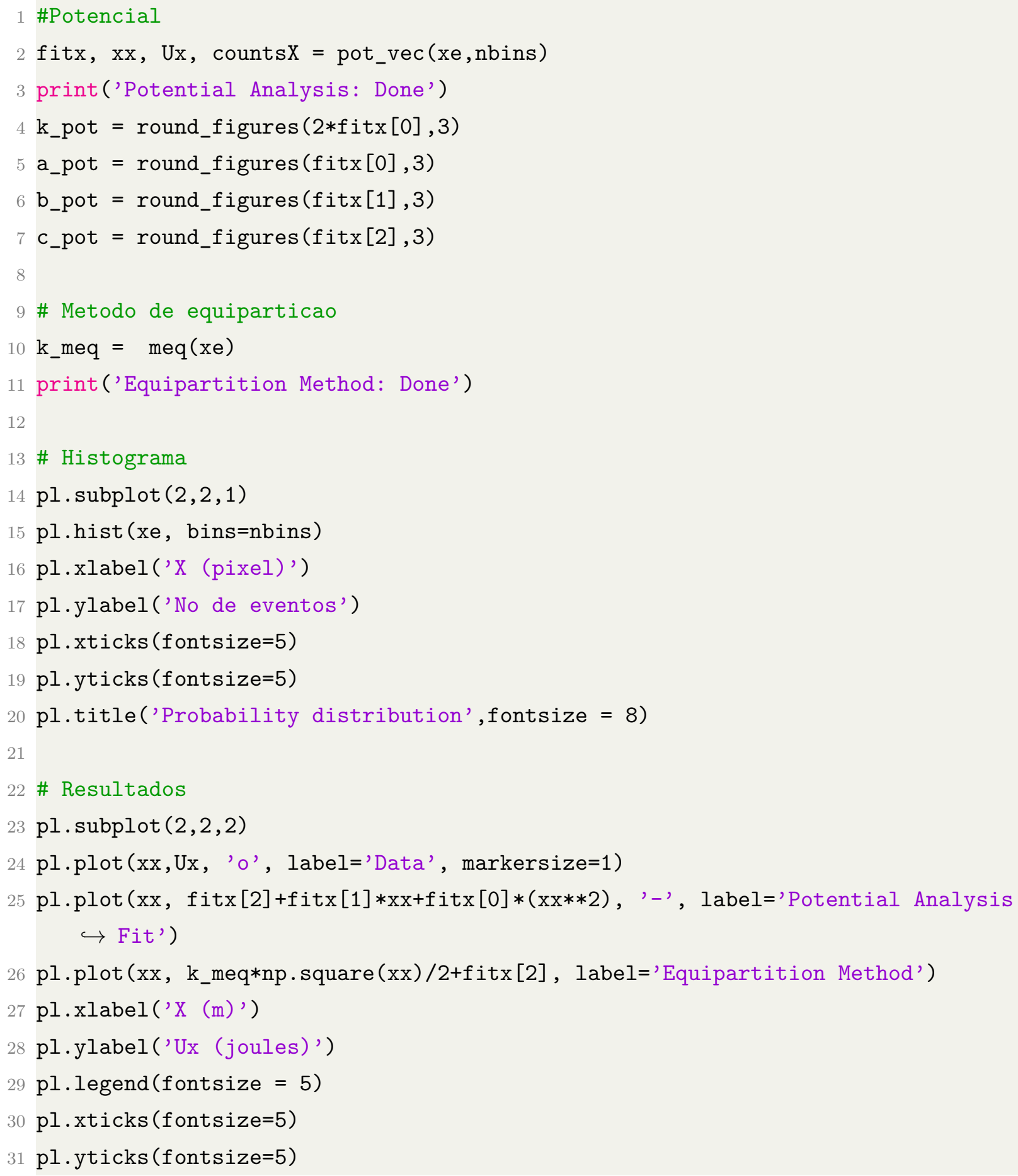





\section{APÊNDICE L - CÓDIGOS PARA A CALIBRAÇÃO DO AOM}

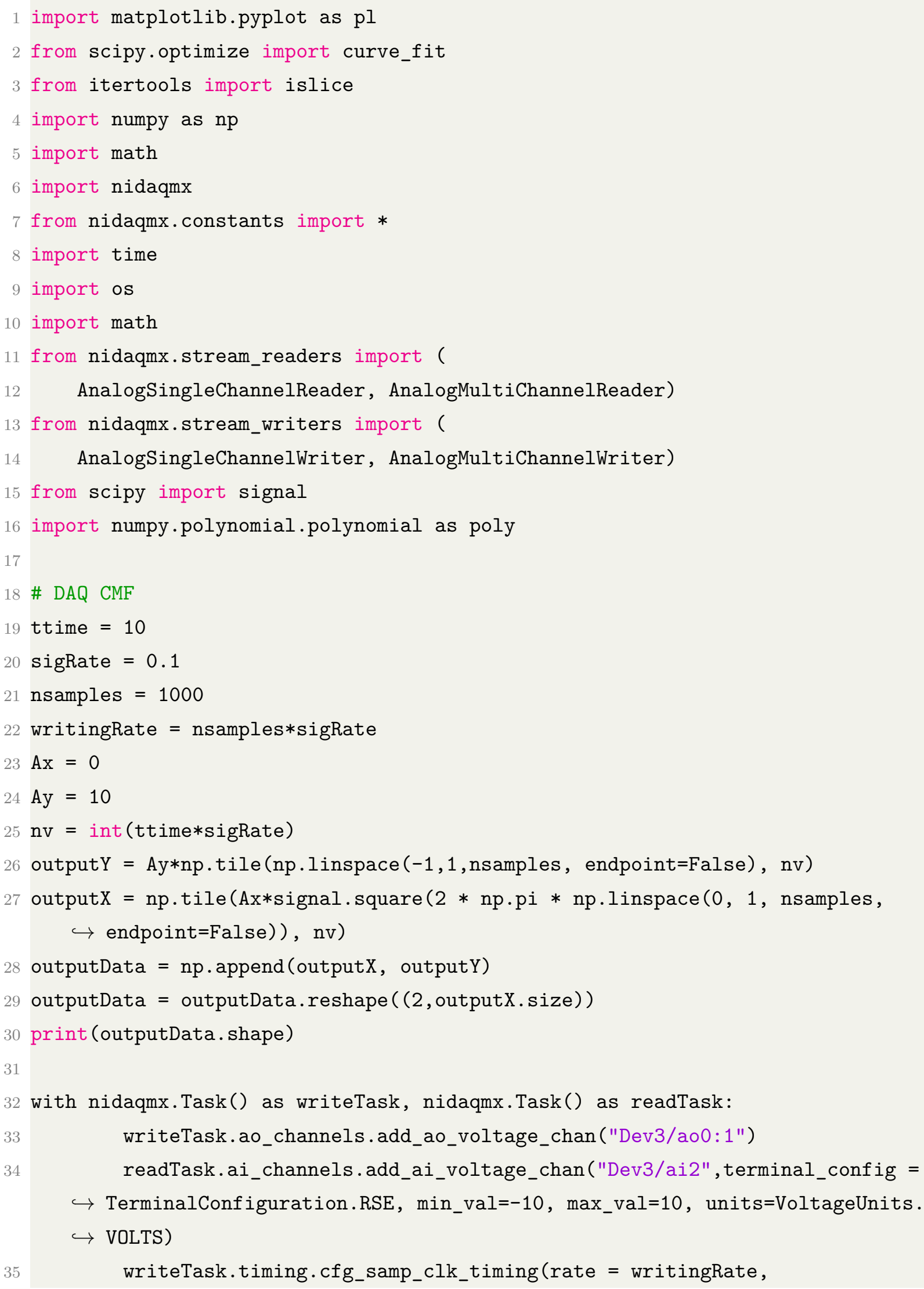


69

$70 \mathrm{n}$

72 \# DAQ CMA

73 ttime $=10$

74 sigRate $=0.1$ 


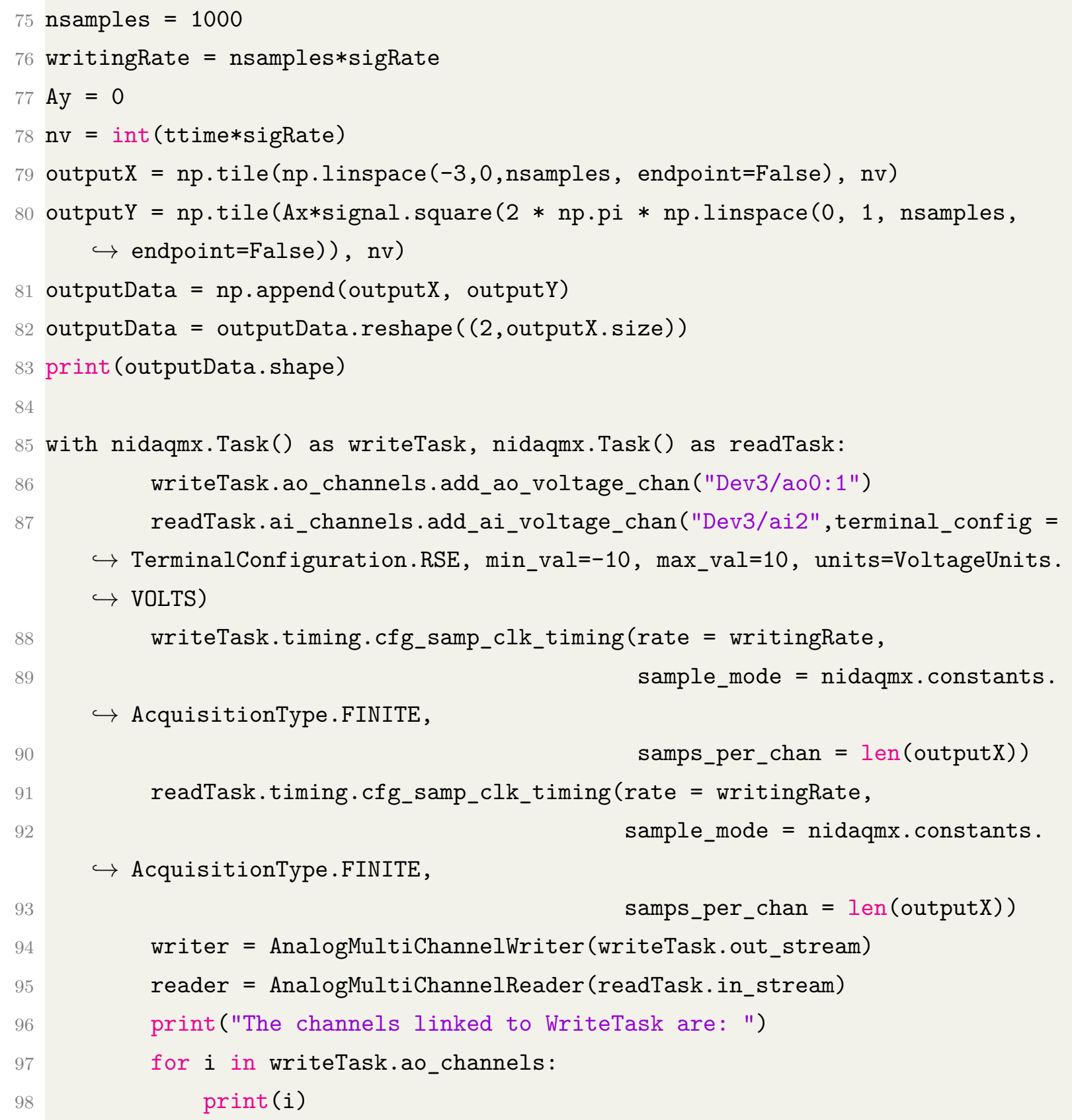

print("Starting writing and reading using", outputX.size) estT = outputX.size/writingRate print("Estimated time: ", estT) writer.write_many_sample (outputData, timeout=ttime) readTask.start() writeTask.start() number_of_channels $=1$ number_of_samples = len (outputX) values_reada $=\mathrm{np} \cdot$ zeros ( (number_of_channels, number_of_samples), dtype=np.float64) reader.read_many_sample( values_reada, number_of_samples_per_channel=number_of_samples, 


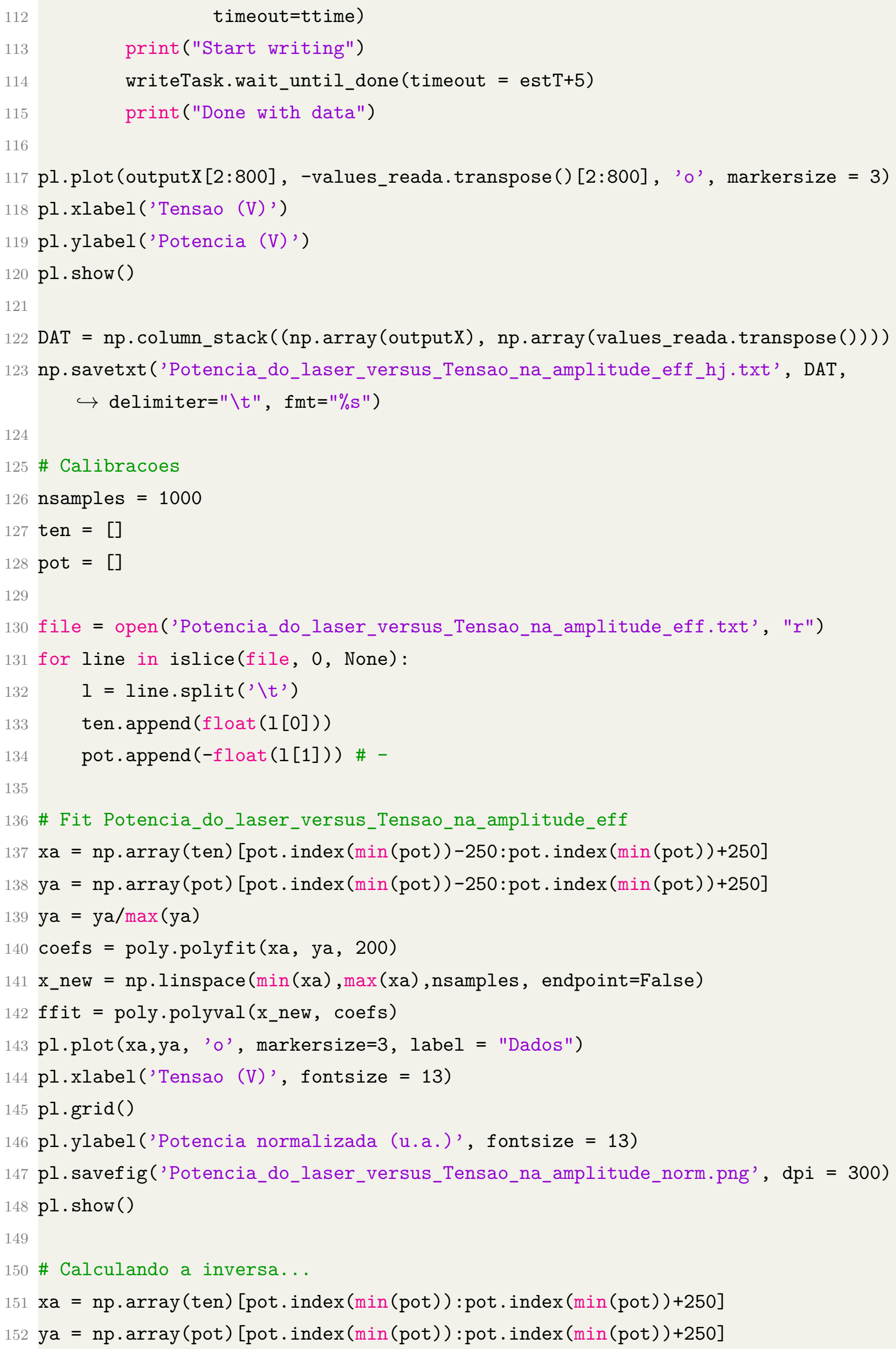




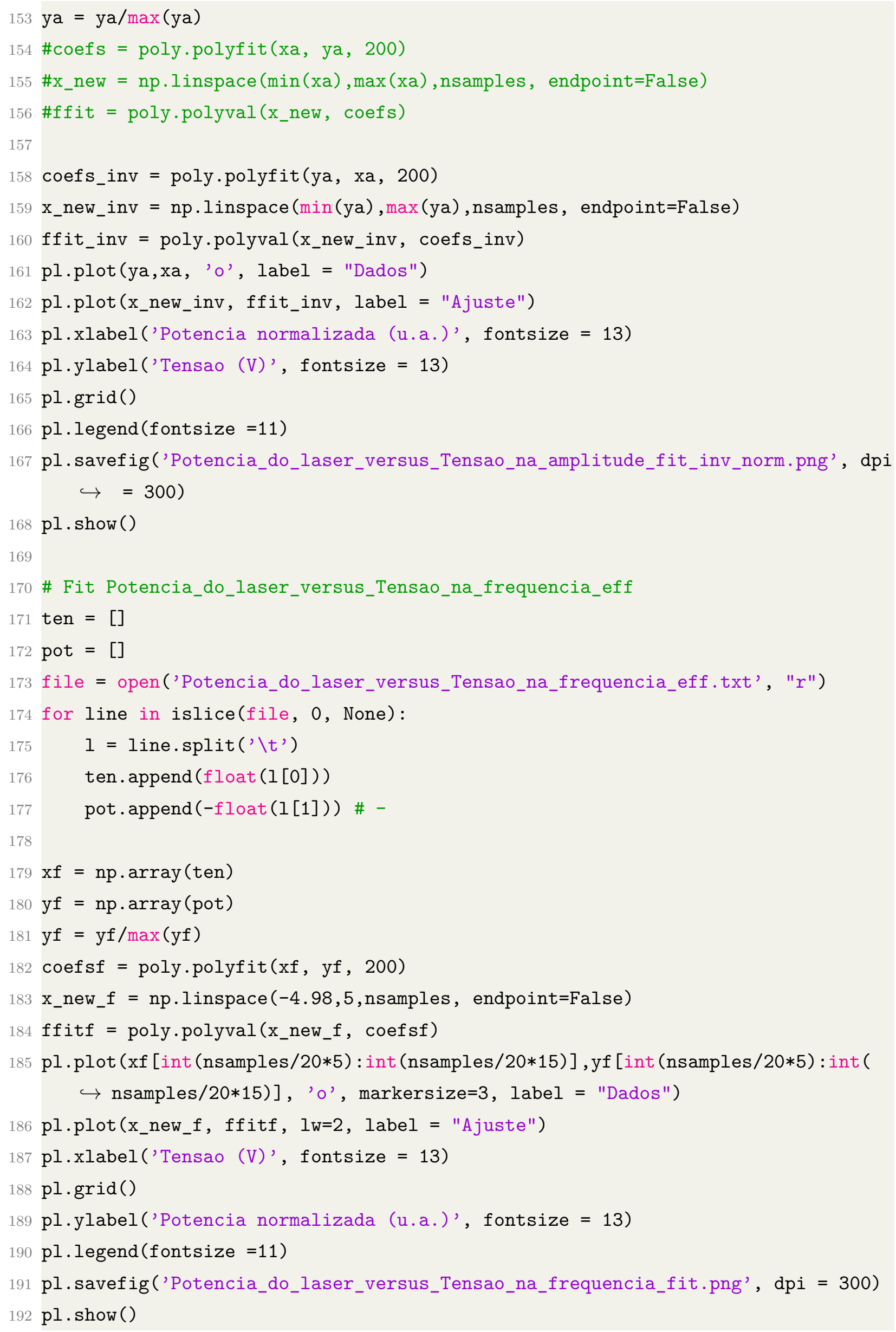




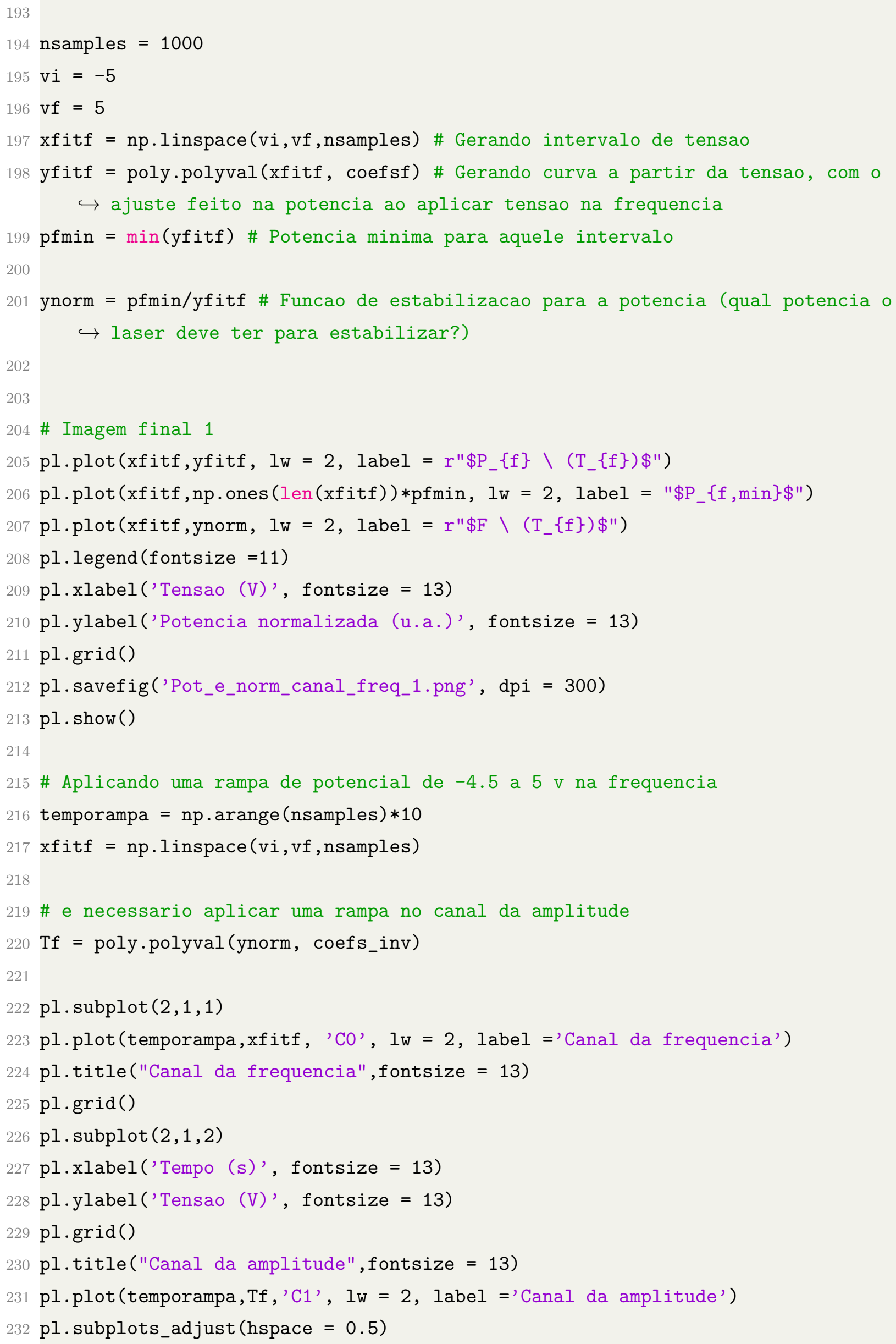


233 pl.savefig('Rampa_amp_e_freq_1.png', dpi $=300$ )

$234 \mathrm{pl}$.show()

235

236 \# Salvando ajuste

237 DAT $=$ np.column_stack $((n p \cdot \operatorname{array}(\operatorname{coefsf})$, np.array $($ coefs_inv $)))$

238 np.savetxt ('CalibracaoAOM_Ajustes_hj.txt', DAT, delimiter="\t", fmt="\%s") 



\section{APÊNDICE M - CÓDIGOS PARA A GERAÇÃO DE POTENCIAIS DINÂMICOS}

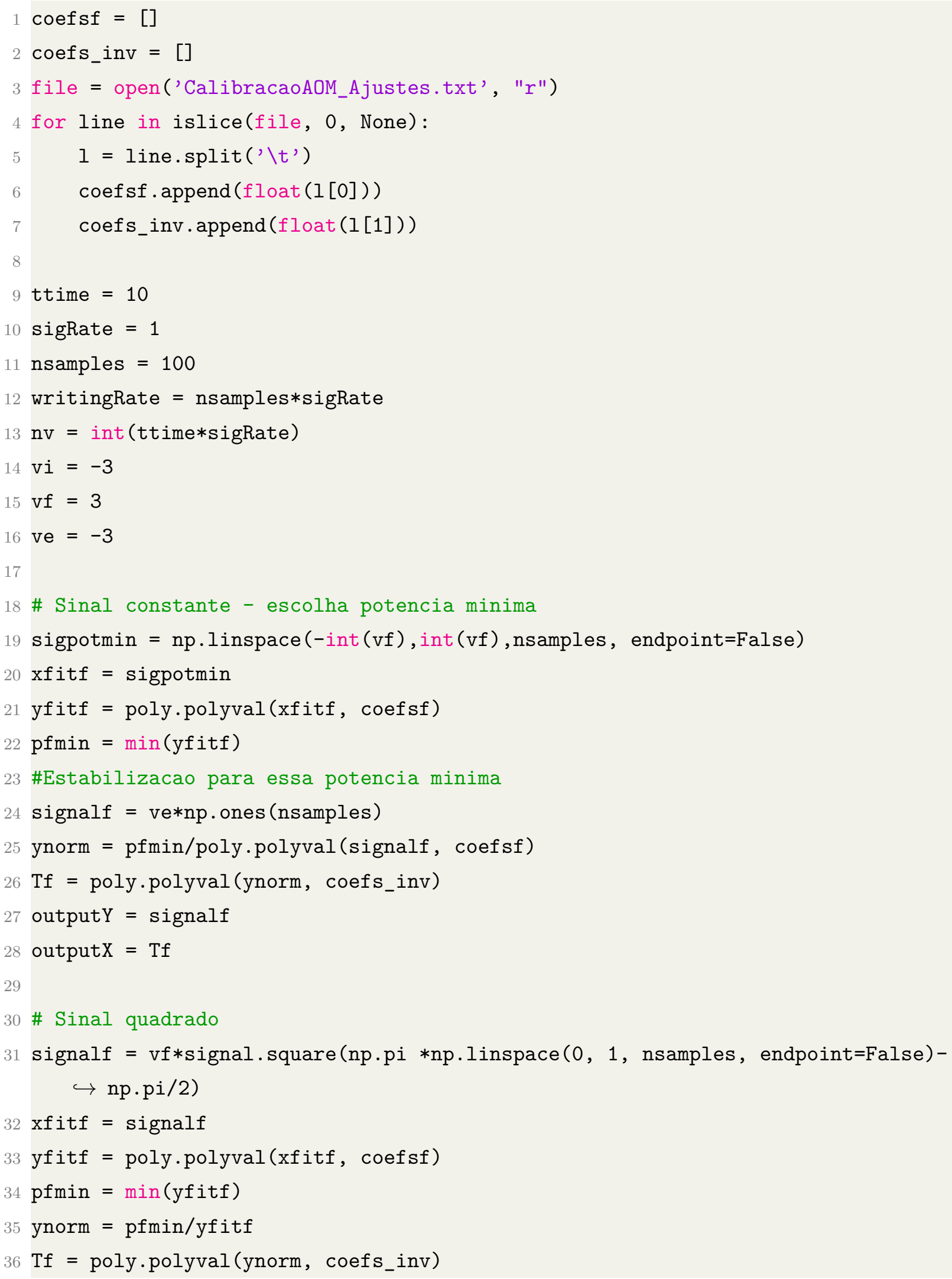




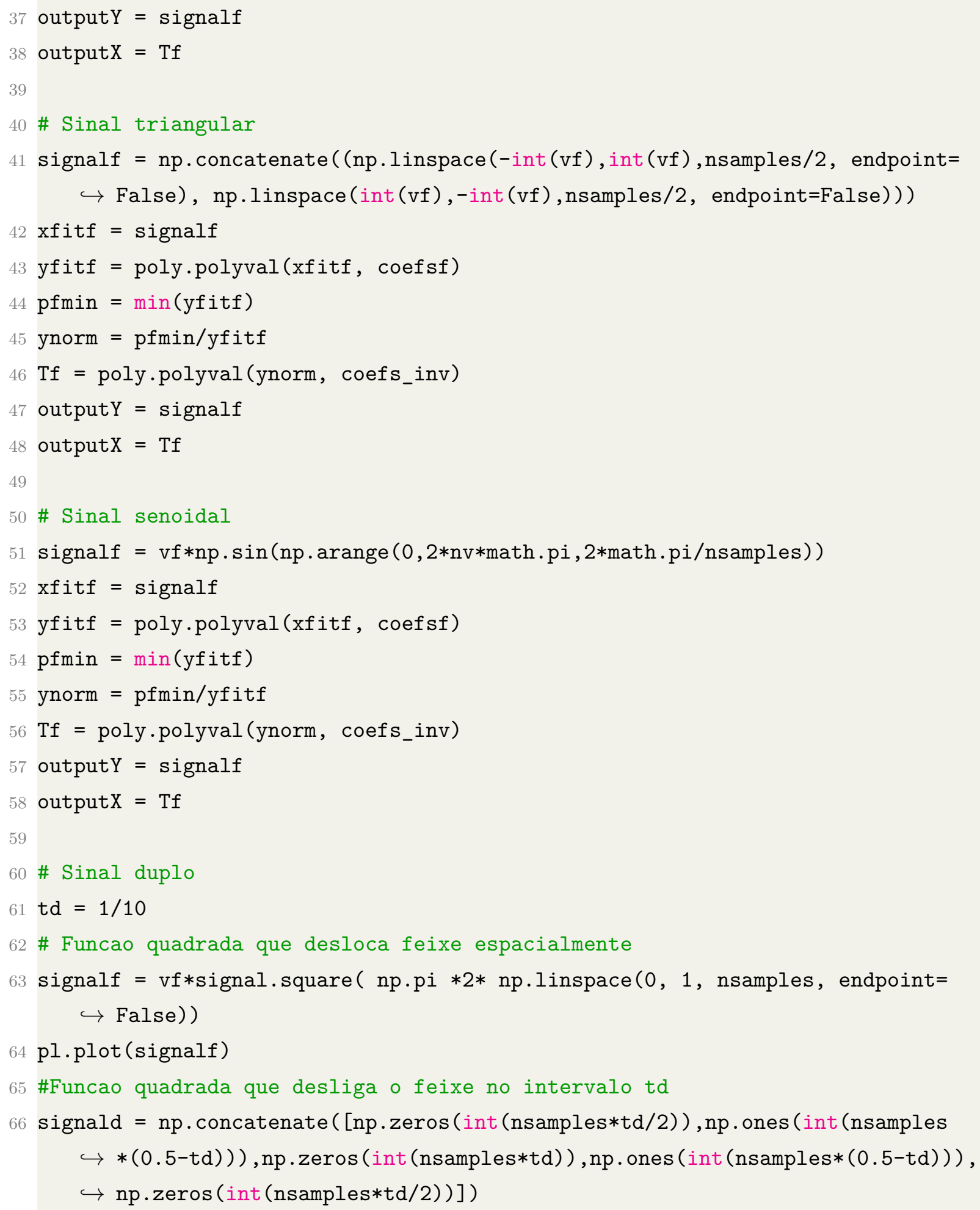

67 \# Calculo da potencia minima

68 xfitf $=$ signalf

69 yfitf = poly.polyval (xfitf, coefsf)

$70 \operatorname{pfmin}=\min (y f i t f)$

71 \# Funcao de estabilizacao sem desligar

72 ynorm $=$ pfmin/yfitf

73 \# Multiplicacao entre funcao de estabilizacao e funcao que desliga o laser

74 normdes $=$ ynorm $*$ signald 
75 \# Criando valores de tensao para aplicar no canal da amplitude

$76 \mathrm{Tf}=$ poly.polyval(normdes, coefs_inv)

$77 \mathrm{pl} \cdot \mathrm{plot}(\mathrm{Tf})$

78 outputY $=$ signalf

79 outputX $=$ Tf 